Zsófia Papp

Legislators' constituency orientation under party-centred electoral rules.

Evidence from Hungary 


\section{Institute of Political Science}

Supervisor:

Prof. Dr. Gabriella Ilonszki, DSc

(C) Zsófia Papp 
Corvinus University of Budapest

Political Science Doctoral Program

Legislators' constituency orientation under party-centred electoral rules.

Evidence from Hungary

Doctoral Dissertation

Papp Zsófia

Budapest, 2013 


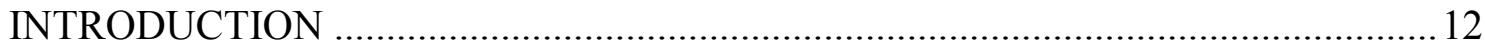

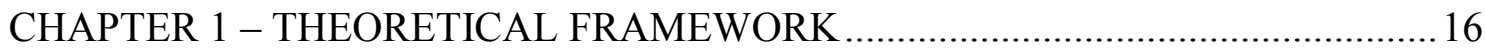

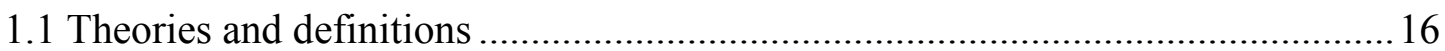

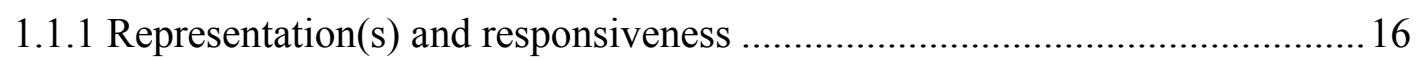

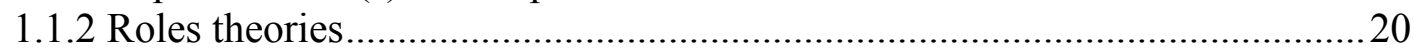

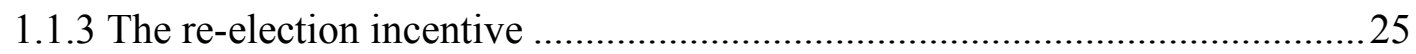

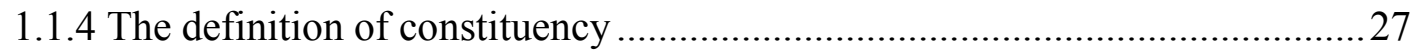

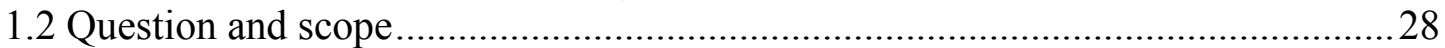

CHAPTER 2 - ELECTORAL RULES AND METHODOLOGICAL

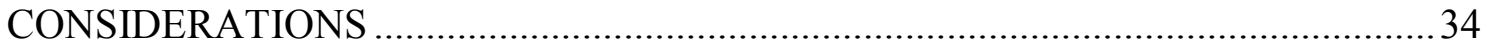

2.1 An overview of the effect of electoral rules on personal representation.................36

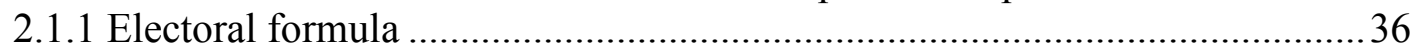

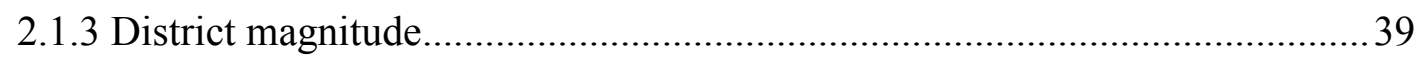

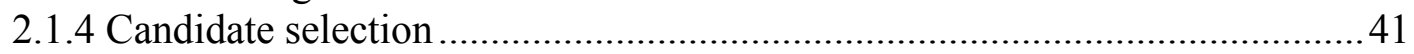

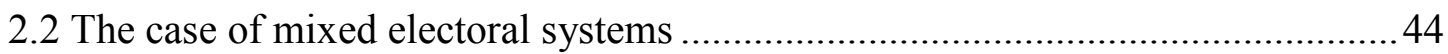

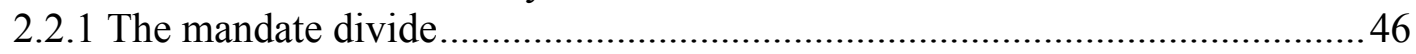

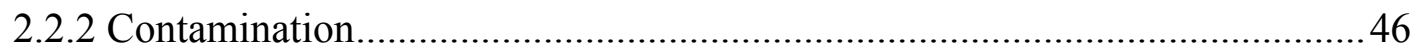

2.3 Case selection: the Hungarian electoral system and its political implications ......50

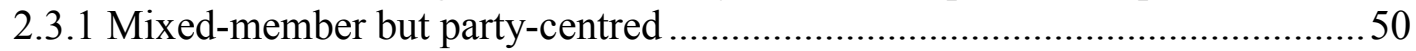

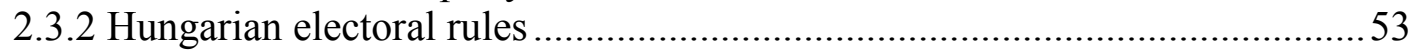

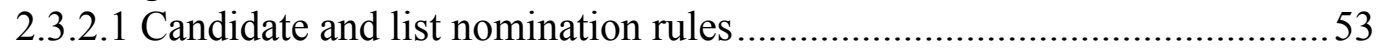

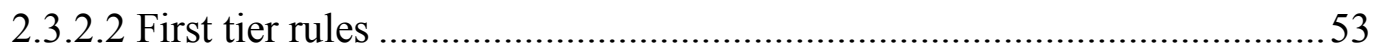

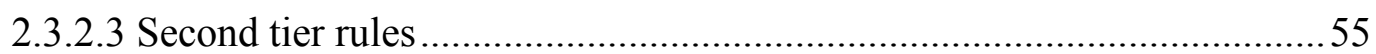

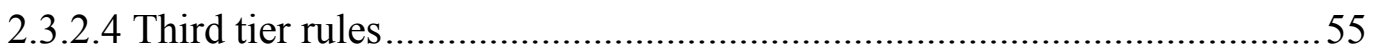

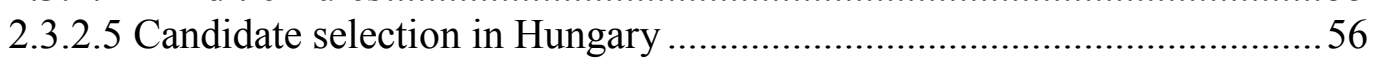

2.3.3 Political implications of the Hungarian electoral system ..............................58

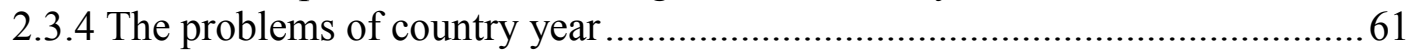

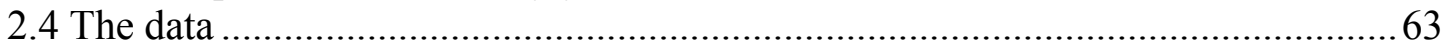

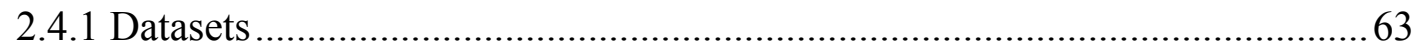

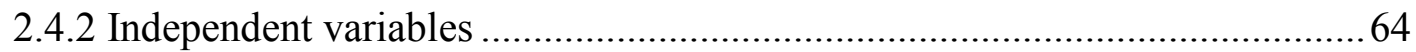

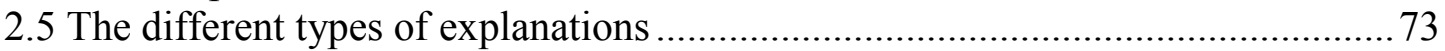

CHAPTER 3 - THE HUNGARIAN REPRESENTATIVES' ROLE PERCEPTIONS. 77

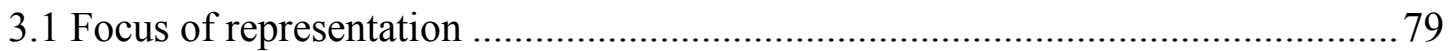

3.1.1 Focus of representation and independent variables - bivariate relationships. 82

3.1.2 The determinants of representational focus ............................................. 90

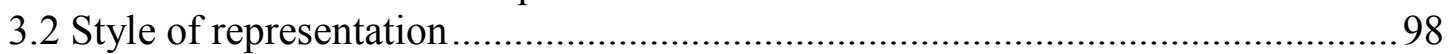

3.2.1 Style of representation and independent variables - bivariate relationships 100

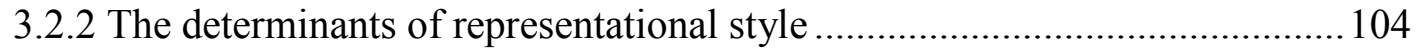

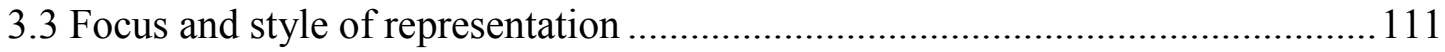

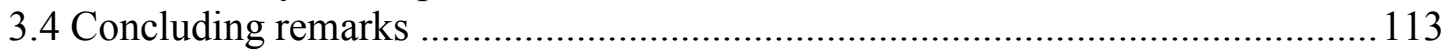

CHAPTER 4 - MEMBER PERSONALIZATION AND CONSTITUENCY

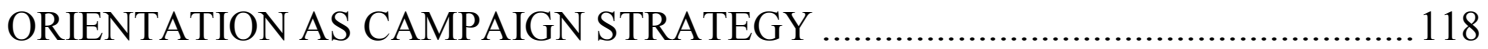

4.1 The four dimensions of personal campaigning .............................................. 119

4.2 Personal campaigning and independent variables - bivariate relationships ....... 124

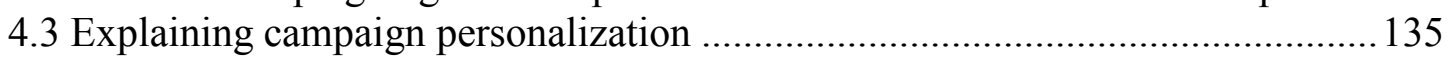

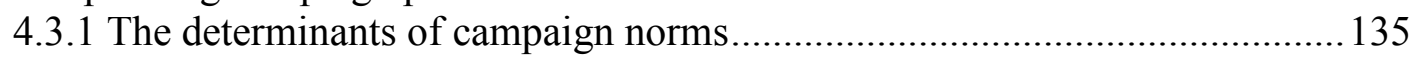

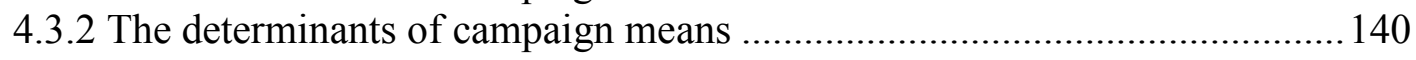


4.3.3 The determinants of campaign organization................................................. 145

4.3.4 The determinants of campaign agenda ................................................ 150

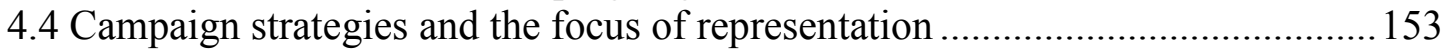

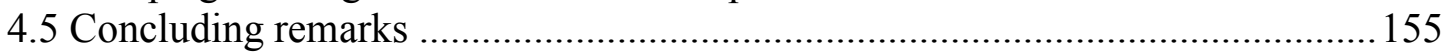

CHAPTER 5 - LOCAL ORIENTATION IN THE HUNGARIAN PARLIAMENT .. 159

5.1. Rules of questioning in the Hungarian Parliament.......................................... 161

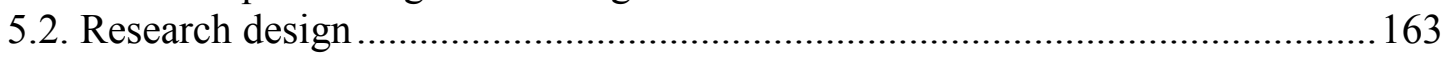

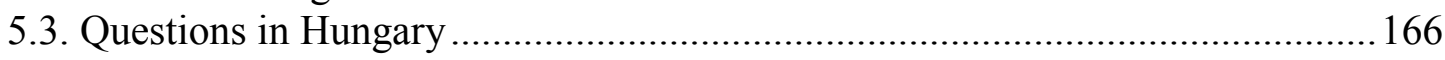

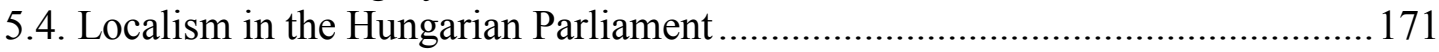

5.4.1. Local orientation of the questions in general.......................................... 171

5.4.2. Local orientation of the questions with respect to the place of election...... 174

5.4.3. Local orientation of the questions with respect to the place of candidacy .. 175

5.4.4. Parliamentary questioning and independent variables - bivariate relationships

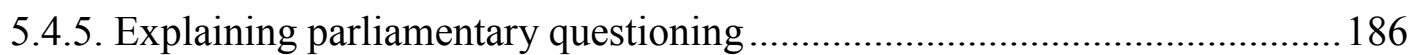

5.4.5.1. Estimating the number of questions .................................................. 186

5.4.5.2. Estimating the relative number of local questions .............................. 194

5.5. The relation of parliamentary questioning to the focus of representation and

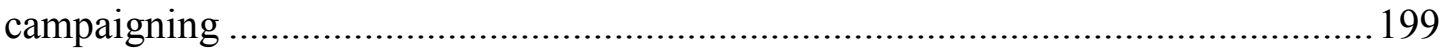

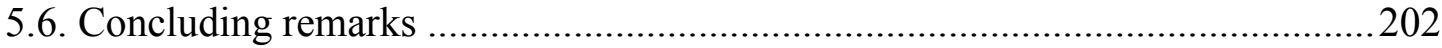

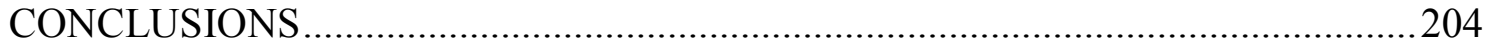

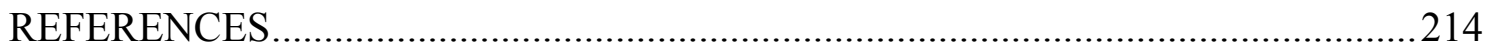

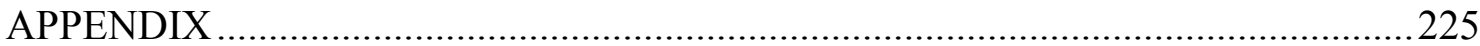

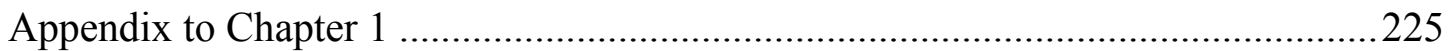

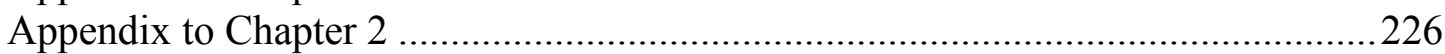

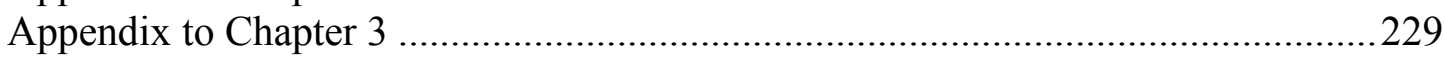

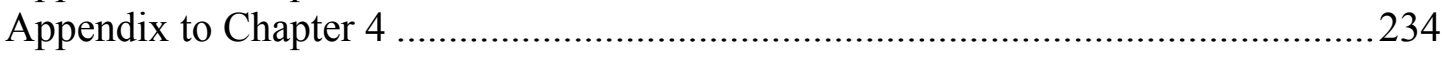

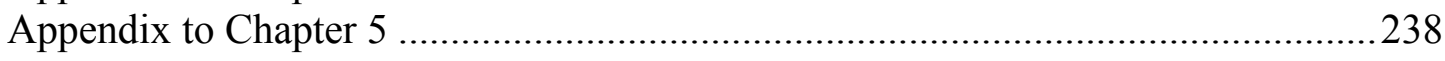




\section{LIST OF TABLES}

TABLE 2.1. A typology of mixed-member systems with PR list tiers

TABLE 2.2. The selectorates of the different parties prior to the 2010 national elections

TABLE 2.3. The level of decision-making with regards to the candidate selection procedure prior to the 2010 national elections

TABLE 2.4. The proportion of SMD representatives who are nominated on party lists 59

TABLE 2.5. PPG membership and mandate type after the 2010 general elections .......61

TABLE 2.6. The proportion of list members running in SMDs ..................................65

TABLE 2.7. The proportion of MPs with previous local political background .............67

TABLE 2.8. The percentage of MPs holding multiple offices .....................................6 68

TABLE 2.9. The proportion of members holding SMD positions during the previous terms.

TABLE 2.10. The proportion of newcomers in the Hungarian Parliament .....................70

TABLE 2.11. The proportion of party leaders ......................................................... 71

TABLE 2.12. The average values of the absolute difference between the placement of the members and the party on a left-right scale under different mandate types and parties

TABLE 2.13. The different types of explanations associated with the independent variables

TABLE 3.1. Changes in the focus of representation in the past twenty years in Hungary

TABLE 3.2. Focus of representation and mandate type …......................................... 82

TABLE 3.3. Focus of representation and candidacy on the nominal level in 2010 .......84

TABLE 3.4. Focus of representation and local political background.............................86

TABLE 3.5. Focus of representation and MPs' careers in single member districts .......87

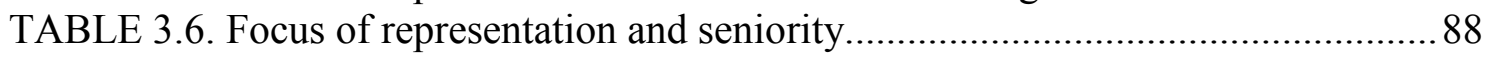

TABLE 3.7. Focus of representation and party leadership ...........................................8 89

TABLE 3.8. Results of the multinomial logistic regressions estimating the log-odds of not being constituency oriented

TABLE 3.9. Results of the binary logistic regressions estimating the log-odds of being

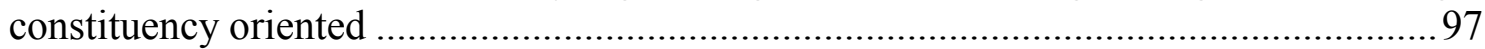

TABLE 3.10. MPs' attitudes with regards to voting in parliament in the case of

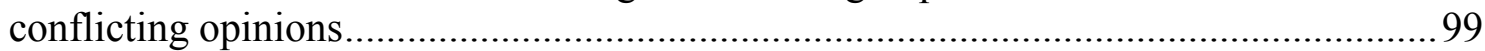

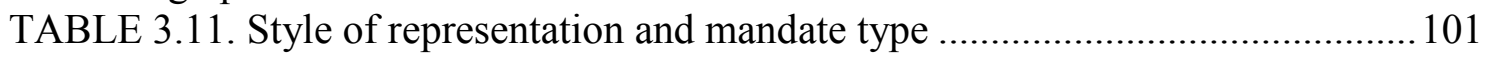

TABLE 3.12. Style of representation and candidacy.............................................. 101

TABLE 3.13. Style of representation and local political background .......................... 103

TABLE 3.14. Style of representation and MPs' careers in single member districts .... 104

TABLE 3.15. Results of the binary logistic regressions estimating the log-odds of voting according to the voters' views in a voters vs. party conflict................................105

TABLE 3.16. The distribution of the various types of representational style ............... 107 TABLE 3.17. Results of the binary logistic regressions estimating the log-odds of being a delegate of the constituents, a party delegate and a trustee....................................... 109

TABLE 3.18. The relationship between the focus and style of representation.............. 112

TABLE 4.1. Personalized campaign tools: usage and origins ................................... 121

TABLE 4.2. The relation of campaign norms, means and organization to the type of candidacy..... 
TABLE 4.3. The relation of campaign norms, means and organization to local political positions

TABLE 4.4. The relation of campaign norms, means and organization to MPs' careers in single member districts ....

TABLE 4.5. The relation of campaign norms, means and organization to seniority ... 133

TABLE 4.6. The relation of campaign norms, means and organization to national and regional party leadership positions.

TABLE 4.7. Results of OLS estimation of campaign norms...................................... 136

TABLE 4.8. The results of Poisson models estimating the number of personalized campaign tools used during the 2010 campaign ....

TABLE 4.9. Results of the binary logistic regression estimating the log-odds of using various personalized campaign tools

TABLE 4.10. Results of the zero-inflated beta regression estimating the proportion of staff members hired personally by the MPs

TABLE 4.11. Results of the binary logistic regression estimating the logit of touching upon local issues

TABLE 4.12. The relationship between the focus of representation and campaign norms, means and organization

TABLE 4.13. The relationship between the focus of representation and campaign organization and organization

TABLE 5.1. The interrelations between the three localism variables

TABLE 5.2. Variables describing the nature of the county-related questions.

TABLE 5.3. Constituency related questions of single member district representatives

TABLE 5.4. Questions, question type and type of mandate ...................................... 178

TABLE 5.5. Questions, question type and candidacy .............................................. 178

TABLE 5.6a. Questions, question type and local political background (before the local elections in October 2010)

TABLE 5.6b. Questions, question type and local political background (after the local elections in October 2010)

TABLE 5.7. Questions, question type and careers in single member districts ............. 182

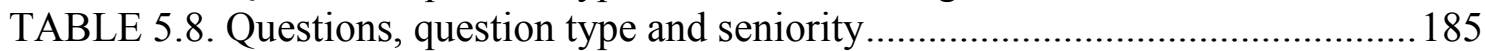

TABLE 5.9. Questions, question type and party leadership ....................................... 185

TABLE 5.10a. The results of the negative binomial models estimating the number of questions submitted between May 2010 and January 2013 ....................................... 188

TABLE 5.10b. The results of the negative binomial models estimating the number of questions submitted between May 2010 and January 2013 ...................................... 189

TABLE 5.11. Results of the zero-inflated beta regressions estimating the proportion of locally relevant questions...

TABLE 5.12. The relationships between questioning behaviour, campaign norms, means and organization.

TABLE 5.13. The relationship between questioning behaviour and campaign agenda201 TABLE 6.1. The role of the various independent factors in explaining the different aspects of constituency orientation 


\section{LIST OF FIGURES}

FIGURE 1.1 The relationships between the different components of the electoral connection

FIGURE 1.2 Attitudes perceived as a dependent and independent variable in the connection between the explanatory factors, member attitudes and behaviour.

FIGURE 2.1 Expected relations between district magnitude and the politicians' incentive to cultivate personal vote under open and closed lists (Shugart, Valdini, and Suominen 2005, 439, figure 1).

FIGURE 2.2 The interaction of selection rules and ballot structures (Norris, 2004, p. 233, figure 10.1)

FIGURE 2.3. Hungarian electoral rules at the $1^{\text {st }}$ and $2^{\text {nd }}$ tiers ....................................5

FIGURE 3.1. The effect of the natural log of district magnitude on the probabilities of an MP focusing on different subjects (regional list MPs only).

FIGURE 3.2. MCA coordinate plot disentangling the relationship between focus and style of representation

FIGURE 4.1. The distribution of campaign norms (\%).....

FIGURE 4.2. Aggregated usage of the different personalized campaign tools (count variable, \%)

FIGURE 4.3. The distribution of the proportion of staff members hired by the MPs themselves (zeros include not having personal teams at all)

FIGURE 5.1. The number of oral and written questions submitted (Source: www.partlament.hu).

FIGURE 5.2. The distribution of local-oriented questions submitted to different departments and offices.

FIGURE 5.3. The proportion of members of the different parties to submit questions 169

FIGURE 5.4. The (approximate) distribution of questions with regards to party affiliation.....

FIGURE 5.5. The number of county specific questions

FIGURE 5.6. The predictive margins of the interaction between local political background before and after the local elections.

FIGURE 5.7. The distribution of zeros in the case of the relative number of questions with local concern 


\section{LIST OF APPENDIXES}

APPENDIX 1.1. The hierarchy of the different measures of member personalization in terms of abstraction 225

APPENDIX 2.1 Questions from the questionnaire of the Hungarian Election Study MP

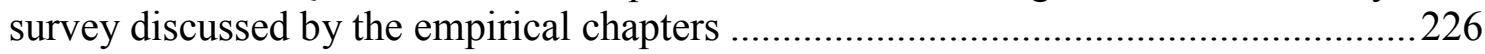

APPENDIX 2.2. The coding of the independent variables of the dissertation .............228

APPENDIX 3.1. The continuity of candidacy on the nominal level, 1990-2006........229

APPENDIX 3.2. Focus of representation and candidacy on the nominal level in 2010

(list members only)

APPENDIX 3.3 The effect of the log of district magnitude on the probabilities of an MP focusing of different alternatives

APPENDIX 3.4. Style of representation and seniority

APPENDIX 3.5. Style of representation and party leadership

APPENDIX 3.6. Results of the binary logistic regressions estimating the log-odds of voting according to the voters' views in a voters vs. MP conflict

APPENDIX 3.7. Results of the binary logistic regressions estimating the log-odds of voting according to the MP's views in an MP vs. party conflict.

APPENDIX 3.8. The effect of the log of district magnitude on the probabilities of an MP being a party delegate, a delegate of the constituents or a trustee (regional list members only).

APPENDIX 4.1. The proportion of personalized means and agendas of campaigning within the different groups of candidacy

APPENDIX 4.2. The relationship between campaign means, agendas, and multiple office holding

APPENDIX 4.3. The relationship between campaign means, agendas, and MPs' careers in single member districts

APPENDIX 4.4. The relationship between campaign means, agendas, and seniority 235 APPENDIX 4.5. The relationship between campaign norms, means, agendas, organization and MPs' ideological distance from their parties

APPENDIX 4.6. The relationship between campaign means, agendas, and national and regional party leadership positions.

APPENDIX 5.1. The codebook on oral and written questions

APPENDIX 5.2. The distribution of questions submitted to different departments and offices

APPENDIX 5.3. The distribution of questioning MPs in terms of PPG membership .240 APPENDIX 5.4. The result of the negative binomial model estimating the number of questions with a local focus submitted between May 2010 and January 2013. APPENDIX 5.5. Results of the zero-inflated beta regressions estimating the proportion of locally relevant questions. 


\section{LIST OF ABBREVIATIONS}

\begin{tabular}{|c|c|}
\hline DM & District Magnitude \\
\hline DV & Dependent Variable \\
\hline \multirow[t]{2}{*}{ Fidesz } & Fidesz - Magyar Polgári Szövetség \\
\hline & Fidesz - Hungarian Civic Union \\
\hline IV & Independent Variable \\
\hline \multirow[t]{2}{*}{ Jobbik } & Jobbik Magyarországért Mozgalom \\
\hline & Jobbik - The Movement for a Better Hungary \\
\hline \multirow[t]{2}{*}{ KDNP } & Kereszténydemokrata Néppárt \\
\hline & Christian Democratic People's Party \\
\hline \multirow[t]{2}{*}{ LMP } & Lehet Más a Politika! \\
\hline & Politics Can be Different! \\
\hline MMD & Multi-Member District \\
\hline MMM & Mixed-Member Majority \\
\hline MMP & Mixed-Member Proportional \\
\hline MP & Member of Parliament \\
\hline \multirow[t]{2}{*}{ MSZP } & Magyar Szocialista Párt \\
\hline & Hungarian Socialist Party \\
\hline PPG & Parliamentary Party Group \\
\hline PR & Proportional Representation \\
\hline \multirow[t]{2}{*}{ PVEA } & Personal Vote Earning Activities \\
\hline & Also known as Personal Vote Earning Attributes \\
\hline SMD & Single Member District \\
\hline STV & Single Transferable Vote \\
\hline
\end{tabular}




\section{ACKNOWLEDGEMENTS}

First and foremost, I would like to thank Gabriella Ilonszki for being much more than a supervisor in a traditional sense. Her invaluable professional advice and personal encouragement defined my attitudes fundamentally. Any shortcomings of this dissertation are solely my responsibility, but everything valuable I wrote down is the product of her rigorous but caring guidance.

I would also like to thank Gergely Karácsony, who taught me the basics of research. His passion of deepening our knowledge about politics and society inspired me greatly.

I am grateful to my parents, without whom this dissertation would have not come into being. Thank you for never questioning my decisions about profession and life, and for making all this possible. My success is yours.

I thank my sister, Eszter and brother, Bálint for the support and patience during my doctoral studies, and for teaching me to be a better person. Thank you for loving me despite my flaws.

I thank my friends Emese, Évi, Gábor, Kriszti, Vici for their patience especially in the last six months of the writing process, and that they never complained about me neglecting them. You are the best!

Last, but not least at all, I would like to take the opportunity to express how grateful I am to Gergö, for his unlimited support and for his tireless effort to make life easier for me during these busy months.

Regardless of the reception of this dissertation, I am happy to have it started. 


\section{INTRODUCTION}

During the past ten years, the research on representational roles seems to regain its position among the most studied political phenomena within the international scholarly literature. This new wave of political science literature revolves around the connection between electoral rules and personal representation. The re-emergence of the idea that the individual plays an important role in establishing the link between citizens and politics builds on the worldwide weakening of political parties. Opinion polls suggest that there is a growing amount of voters who are indecisive about their preferences, and cannot identify themselves with either of the parties. This, and the declining turnout, the rise of volatility in party preferences and shrinking party membership are the signs that the parties failed "in their capacity to engage ordinary citizens" (Mair, 2005, p. 7). As a result of the disillusionment with parties, personal representation and constituency orientation are likely to receive an increased attention both by voters and representatives. The measurably greater emphasis on individual politicians challenges the responsible party model, which considers parties as the vehicles of representation.

Oddly, however, voting behaviour in parliament does not seem to support the decline of the party as such. On the "normal course" of legislation, party discipline prevails: Members of Parliament still vote in line with the Parliamentary Party Group (PPG) in the majority of the instances. According to Dalton, Farrell and McAllister, "the evidence of decline is too selective, emphasizes changes in the mass public rather than in party performance, and is arguably too focused on the mass party ideal" (Dalton, Farrell, and McAllister, 2011, p. 14), therefore it is too early to bury the political party for good. Parties have the capacity to renew by adopting new strategies to re-earn the voters' trust. Adapting to their decreasing popularity within the electorate, parties engage in behaviour that seems irrational at first sight and which usually distinguishes personal and party representation. Parties put a greater emphasis on the person than it is expected in the party representation framework.

The parties' appearance through their politicians and the selection of reliable candidates who are able to fulfil promises and respond to voters' demands is called personal representation. In this sense, personal representation enhances the quality of representation, and improves "legislative and policy performance" (Colomer, 2011a, p. 
7). To achieve this, candidates have to make themselves visible to voters, and make the connection between citizens and parliament. The best way to do this is to obtain a certain level of constituency orientation, to demonstrate sensitivity to issues of direct concern to their voters. This way constituency focus becomes an inseparable part of personal representation.

Constituency focus, however, leads to "pursuing the interests of particular groups and individuals in society" (Norton, 2002, p. 3). This particularism serves the basis of the debate surrounding constituency representation, and its effect on the quality of democracy. Representation of one particular district might disadvantage citizens living in other constituencies. If, for instance, the MP of constituency A has greater bargaining power against the government than the representative of constituency $\mathrm{B}$, then constituency A gets a larger amount of pork, might even at the expense of constituency B. Thus, a conflict will appear between districts A and B, what never would have surfaced without the particularistic behaviours of their MPs. Depending of the positions of their representatives, the quality and efficiency of representation will not be the same throughout the constituencies. The districts of opposition MPs will always be disadvantaged against the ones of government MPs. The uneven representation corrodes the foundations of democracy: its legitimacy. Furthermore, constituency service and work in parliament cannot be improved unless at the expense of the other. Thus, a heightened level of constituency orientation easily leads to a declining quality of legislation. Last but not least, district focus defies the idea of general representation, with leads us back to the first point.

However, there are a couple of reasons why constituency orientation is desirable to maintain people's trust in democracy. Norton summarizes the possible reasons as follows (Norton, 2002). First, it enables interests closest to the people appear in national politics. Second, it legitimizes the political system in the eyes of the voters. Norton and Wood claim that neglecting district interests would undermine the legitimacy of the legislature (Norton and Wood, 1990). This argument is weakened by the fact that Europe-wide - only a fraction of the voters are able to name their representatives ${ }^{1}$. Third, constituency orientation brings parliament closer to the voters. Fourth, it makes the MPs more visible in their constituencies. Fifth, parties can obtain information that would be costly to collect otherwise. Sixth, as a consequence to that, constituency

\footnotetext{
${ }^{1}$ See the Comparative Study of Electoral Systems (CSES), http://www.cses.org/
} 
orientation provides the party with an advantage at the polls. Seventh, it increases the members' satisfaction with their jobs. And eighth, information associated with constituency focus might reveal problems the government needs to address, before they become acute (Norton, 2002).

There is an increasing interest in how personal representation relates to the trust in legislative institutions (Leston-Bandeira, 2012). If a tighter electoral connection between the representative and represented leads to a greater level of trust in the institutions of representation, then it is also possible to enhance the evaluation of democracy. As the input can easily be controlled by decision makers, the quality of democracy might eventually be positively adjusted.

This dissertation aims to contribute to our knowledge about the circumstances under which personal representation prevails. Previous research on electoral systems established the relationship: candidate- (or person-) centred electoral rules encourage personal-, whereas party-centred systems lead to the dominance of party representation. In this sense, representation is perceived as a one-dimensional scale where personal and party representations indicate the two ends of the continuum. The argument I wish to make in this study is that even in a party-centred electoral system in which voters can vote for candidates, personal representation will appear. In this view, party and personal representations are not mutually exclusive ideas (Colomer, 2011b), but personal representation might be considered a form of party representation. In partycentred mixed member systems, the existence of the nominal tier leads parties to pursue more person-oriented party strategies. Thus, the oft-cited causal effect between mixed electoral rules and personalization can be confirmed. However, to unravel the causal mechanism, we have to perceive the link between electoral rules and personal representation as being mediated by central party strategies.

The structure of the dissertation is as follows. First, in Chapter 1, I build the theoretical framework discussing representation and responsiveness, representational roles, and the re-election incentive. Later in the chapter, I expose my research question and hypothesis, which is followed by a more detailed review of the structure of the study. In Chapter 2 I make the connection between electoral rules and constituency focus. Based on this, I defend my case selection, and briefly review a list of independent variables and the explanations attached to them. Chapter 3 presents the first part of the analysis. Attitudes toward representation will be explained by the pre-selected independent factors. Chapter 4 proceeds with explaining campaign strategies at the 2010 
general elections, with special emphasis on candidate- and constituency-centred behaviour. Chapter 5 concludes the analysis with the investigation of the factors determining constituency-oriented non-legislative behaviour in parliament. 


\section{CHAPTER 1 - THEORETICAL FRAMEWORK ${ }^{2}$}

\subsection{Theories and definitions}

\subsubsection{Representation(s) and responsiveness}

"... representing (...) means acting in the interest of the represented, in a manner responsive to them" (Pitkin, 1967, p. 209). This is the definition used by Hannah Pitkin in her work The Concept of Representation in 1967, the year Eulau and Karps calls the "watershed year" (Eulau and Karps, 1977, p. 238), what changed research of representation for good. Pitkin argued that the traditional mandate-independence controversy does not help us understand the essence of representation, as we will not find the superiority of either, since these only serve as the two extremes of a continuum. "[T] he represented must be both present and not present", in order to be re-presented, which means that the represented "must be in some sense acting though" the representative, while the representative "must really act", which requires a certain degree of independence (Pitkin, 1967, p. 154). Pitkin also characterized representation as a "social relationship rather than (...) an attribute of the individual person" (Eulau and Karps, 1977, p. 237). The mandate and the independency theory resonate with the sanction and the selection model of representation rather well. The sanction model needs a strict issue congruence between the representative and the represented, while the selection model requires the representatives to follow district interests as perceived by them (Mansbridge, 2009). The sanction model fits the traditional principal-agent model, where the agent acts according to the directions of the principals (fulfils a mandate), namely the voters of a district. The main problem with this model is that it makes assumptions that does not resemble reality (Eulau and Karps, 1977). Eulau and Karps cited Wahlke's paper (Wahlke, 1971), where he concluded that citizens are not informed enough to give any directions in terms of policy positions (Eulau and Karps, 1977). Policy congruence, therefore, cannot be the basis of election, which was the requirement against representation for a long period after the paper of Miller and Stokes from 1963 (Eulau and Karps, 1977, pp. 234-235). Rather than expecting the voters to

\footnotetext{
${ }^{2}$ Here I acknowledge the generous support of TÁMOP-4.2.2/B-10/1-2010-0023 at the Corvinus University of Budapest.
} 
have firm policy preferences as well as the time and resources to control representative behaviour, the selection model theorizes that voters tend to select "good" representatives, who would "act on their behalf independent of re-election incentives" (Fearon, 1999). In her synthesizing work, Jane Mansbridge traces back the history of the selection model to Miller and Stokes (Mansbridge, 2009). In their article in 1963, they showed that both models appeared in contemporary US Congress, each predominating certain types of policy issues (Miller and Stokes, 1963). Despite the resonance with the trustee-delegate tradition (in the Burkean sense), the main difference between the sanction and selection models lies not in the better understanding of the general good (as in the case of the Burkean trustee), but the efficiency of the usage of the principal's resources relative to the time of the election: in the sanction model, ex post investment of resources is more efficient, while in the selection model, resources are used ex ante (Mansbridge, 2009). The first one entails constantly evaluating the representatives' work throughout the whole term, and see whether they have met the promises (that where in congruence with the voters' policy preferences), whereas the latter sees the merit in assessing whether the candidate can represent the interests of the voters (without defining those interests) in advance.

In her article in 2003, Mansbridge defines four types of representation (Mansbridge, 2003). Despite the fact that the major relevance of her work is to the American legislators, for the sake of the theoretical overview, it is worth taking a look at the ideas. Promissory representation fits to the traditional principal-agent and the sanction models of representation: agents are accountable to voters in a sense that either they did what they were mandated to (the "mandate" conception of representation), or they did what served the best interest of the voters or the country (the "trustee" conception of representation) (Mansbridge, 2003, p. 516). Voters sanction "deserters" by not voting for them at the next elections. In the case of anticipatory representation "the representative tries to please future voters" (Mansbridge, 2003, p. 517), which entails that voters are expected to make decisions retrospectively. They evaluate the past behaviour of their representatives, and go through a process of deliberation, where the representatives explain their actions to create positive perceptions. This "education" of the future voters makes representation a flowing communication process between voters and their representatives. Contrary to the promissory type of representation, this model is more about interests than preferences: as recognized, preferences can be changed between two elections through mutual education of the represented and the 
representative. Thus, the quality of representation is not evaluated through accountability, but deliberation (Mansbridge, 2003, pp. 516-520). Third, gyroscopic representation is characterized by the lack of external incentives of the representatives. Legislators are expected to act on the basis of their own conscience, and voters try to select members whose internal motivations result in behaviour most likely favourable to the district. This type of representation resonates with the selection model, as voter's goal is to select "good" representatives in both. However, Mansbridge focuses only to the American case of gyroscopic representation. She points out that in the European context, the role of the party is essential to "foresee" representative behaviour. Internal motivations become external, as the party might sanction deserting legislators. At the same time, these motivations are only party external, because commitment to the values represented by the party might come from internal motivations. Therefore, even in the gyroscopic framework of representation, the party cannot be overlooked as the estimator of future MP behaviour in Europe. Mansbridge also stresses the difference between the gyroscopic type of representation and the concept of the Burkean trustee: representatives are selected because they are expected to act similar to how voters would act in parliament, which entails that voters also have an agenda when selecting their representatives. In this framework, deliberation takes place before and at the time of the authorizing election, and the voter "exits" the system between two elections (Mansbridge, 2003, pp. 520-522). The fourth type of representation Mansbridge calls surrogate, referring to the idea of representing the interests of someone or something who or what is not a part of the representative's district. This idea greatly resembles the theory of "shadowing", namely representing those who temporarily "lack representation" in the given districts (Mansbridge, 2003, p. 522). These types of representation, however, do not replace issue congruence between the representative and the represented, they only complement it (Mansbridge, 2003, p. 526). As Fearon points out, voters choose the "good" type of representative also because they have matching policy preferences (Fearon, 1999). Furthermore, Pitkin stresses that the representatives cannot violate voters' wishes for an unreasonably long time without explaining why voters' wishes conflict with voters' interests (Pitkin, 1967, p. 210). Therefore, a minimal degree of issue congruence is expected in the relationship of the voters and the legislators, even if we move beyond the principal-agent framework.

Issue congruence, however, does not necessarily mean responsiveness. Perfect congruence is fairly rare; still, MPs stay in office through multiple legislative terms. 
Matching preferences, therefore, are only one aspect of the relationship between the representatives and the represented: being responsive does not indicate perfect policy match. To solve this problem, Eulau and Karps built the concept of responsiveness from four independent components (Eulau and Karps, 1977). First, policy responsiveness fits the definition of issue congruence. The main problem with this concept is that legislators might act according to the issue preferences of their voters, "yet not act in what is in the best interest of the constituency as [they] might wish to define that interest, thereby being in fact unresponsive" (Eulau and Karps, 1977, p. 242). Policy responsiveness, again, highlights the problem of the mandate-independence controversy: can responsiveness be defined on the basis of the voters' competence in policy matters? Being responsive with regards to policy preferences might not serve the interest of the voters; therefore, representation cannot be solely based upon those preferences. Second, service responsiveness relates to "non-legislative services" (Eulau and Karps, 1977, p. 243), and ombudsman-like activities that aim to solve particular problems of the constituents. These types of activities offer particularistic benefits to a few citizens only, which serves as the basis of criticism toward casework (Eulau and Karps, 1977, p. 244). Nevertheless, Cain et al. argue that the supply of casework affects the demand as well - through spreading reputation and visibility -, enlarging the group of recipients of such services, and educating them to bring their problems to their representatives (Cain, Ferejohn, and Fiorina, 1987; Fiorina, 1977). Third, allocation responsiveness extends benefits to a larger group of people: usually the constituency itself. "[P]ork-barrel politics in legislative allocation of public projects involves advantages and benefits presumably accruing to a representative's district as a whole" (Eulau and Karps, 1977, p. 245). In their volume The Personal Vote: Constituency Service and Electoral Independence, Cain and his colleagues call service and allocation responsiveness constituency service altogether (Cain et al., 1987). Last, but not least, symbolic responsiveness points behind concrete transactions, and describes how the representatives make symbolic gestures toward the represented. Initiating legislation, for instance, can bear symbolic importance apart from the obvious policy increments (Eulau and Karps, 1977, p. 247), which signals the voters that the representatives care about problems directly affecting their districts.

The first models of representation described it as some kind of agreement between citizens and the representatives. The main goal of elections was to choose the "best individuals to defend the interests or values of the community or group" (Colomer, 
2011a, p. 2). The emergence of political parties shifted this relationship toward an interaction between citizens and parties, instead of citizens and the individual legislators representing their districts. This was further enhanced by the extensive usage of multimember PR-list electoral systems, where voters were offered to choose between parties instead of individual candidates. This made party representation more stressful against personal representation. The shift from single member majoritarian systems toward PR (especially in Europe) also made it difficult to apply theories of representation that were based on the logic of one member representing one constituency, further diminishing the linkage between representatives and represented. The main principle of party representation is the representation of policy preferences: "party representation is necessary in order to select the most relevant issues in the public agenda and to design public policy" (Colomer, 2011a, p. 7). Personal representation on the other hand aims to ensure the good quality of representation, by appointing individuals who are reliable and responsive to "voters" demands" (Colomer, 2011a, p. 7). In modern democracies, the two aspects of representation appear in a special mixture in which the composition is heavily influenced by the given setup of the electoral system. This fits the conclusion of Eulau and Karps as well as Mansbridge on the presence of the different types of responsiveness and models within the same system (Eulau and Karps, 1977; Mansbridge, 2003, 2009). This indicates that even in systems, where electoral rules support party representation, some forms of personal representation should be detectable.

\subsubsection{Roles theories}

The study of representational and legislative roles has been revived recently after its backdrop in the 1980-1990s. Unlike approaches in the golden era where sociological theory was the main starting point of theorizing political roles, this new renaissance of role theories follows the footsteps of the neo-institutionalist traditions (Searing, 2011). Just like in other fields of research, the definition of roles is one of the major concerns of the discussion. There is no agreement on what roles are, whether they even exist, or whether roles are merely different forms of strategic behaviour. A recently published volume of Blomgren and Rozenberg picks up where Searing and Strøm left off, synthesizes the existing literature and presents a wide range of the possible applications and interpretations (Blomgren and Rozenberg, 2011a). Instead of beginning with the definitions of the referred authors, and the discussion whether these interpretations fit 
the criteria what we expect roles to fit, it is best to start with the classics of the 1960$70 \mathrm{~s}$, as the whole discussion of the topic originates in their work.

Legislator and social scientist Edmund Burke held his famous speech to the electors of Bristol in 1774, where he argued:

"...it ought to be the happiness and glory of a representative to live in the strictest union, the closest correspondence, and the most unreserved communication with his constituents. Their wishes ought to have great weight with him; their opinion, high respect; their business, unremitted attention. It is his duty to sacrifice his repose, his pleasures, his satisfactions, to theirs; and above all, ever, and in all cases, to prefer their interest to his own. But his unbiased opinion, his mature judgment, his enlightened conscience, he ought not to sacrifice to you, to any man, or to any set of men living. These he does not derive from your pleasure; no, nor from the law and the constitution. They are a trust from Providence, for the abuse of which he is deeply answerable. Your representative owes you, not his industry only, but his judgment; and he betrays, instead of serving you, if he sacrifices it to your opinion."

(Burke, 1854, p. 446)

From here on we give account to the notion of the trustee (Burkean trustee). He argued that there is no place for the representatives to pursue particularistic goals; it is the whole country they ought to represent and views parliament as a "deliberative assembly". Members of Parliament should not follow their constituents' directions, but they should act as they see fit to reach the goals they consider to serve the interests of the country best. ${ }^{3}$

The concept of trustee and delegate was further operationalized by Wahlke et al. in their famous book The Legislative System: Explorations in Legislative Behavior (Wahlke, Eulau, Buchanan, and Ferguson, 1962). They define role orientations as "differences in legislators' conceptions of a particular component of the role of legislator" (Wahlke et al., 1962, p. 7). Their definition of trustee matches Burke's idea

${ }^{3}$ „... Parliament is a deliberative assembly of one nation, with one interest..” (Burke, 1854, p. 446) 
of representation: MPs should rely on their own judgements instead of voter directions, even if it conflicts the perceived short- term interests of the constituents. Delegates, on the other hand, are bound by instructions from the voters. This means, that they do not have the autonomy to act as they see fit in order to represent the best interests of the district. In fulfilling the mandate that voters gave them, the role of the delegate also involves the possibility of acting against the representatives' conscience. The roles of the trustee and the delegate are obviously two ends of a continuum. It is a very realistic assumption that an MP identifies with the two roles under different circumstances: in a certain type of issues they follow the lead of their constituents while in other cases they rely on their own judgements (Blomgren and Rozenberg, 2011b, p. 12). Therefore in the case of the politico, roles are mixed in different degrees that depend on the issue in question.

Nevertheless, Wahlke and his colleagues also criticized Burke on the grounds that he “... combined two notions which, for analytical purposes, should be kept distinct" (Eulau, Wahlke, Buchanan, and Ferguson, 1959, p. 744). The two notions they identified are focus and style of representation. Focus captures the different groups whose interests MPs represent (e.g. their voters, the constituency, the party, all the people in the country etc.), while style describes the manner with which these focal groups are represented (whether MPs follow their own lead or rely rather on the instructions by their constituents). In his speech, Burke linked the country focus to the trustee style of representation, which describes only one possible combination of the two ideas. Own convictions as guideline might also result in representing the particularistic interests of the constituency, while following the voters' will does not exclude the pursuance of the general good either (Eulau et al., 1959, p. 745). The concept advocated by Wahlke et al. (Wahlke et al., 1962) represents style: who do the MPs listen to when they make their legislative decisions?

The conception of trustees and delegates are heavily criticized because they are thought to be over-simplified and too abstract. The famous volume of Donald Searing Westminster's World. Understanding Political Roles in 1994 started a new wave of debate on what representational roles are and how they can be conceptualized. Searing conducted a series of interviews with the members of the British House of Commons, where he identified several types of roles that he categorized into two major groups: position and preference roles. The main achievement of this approach is that it is based on real-life interviews, and not forced upon MPs by scholars (Searing, 1994, p. 13), 
which practice is argued to result in a gap between roles and behaviour (Saalfeld and Müller, 1997, p. 9). Searing promotes the usage of the motivational approach to study roles, which is a mixture of "the sociological (structural and interactional) and the economic traditions" (Searing, 1994, p. 15). Within the motivational framework rules both "constrain and enable" (Searing, 1994, p. 15): while they define the range of roles played by the representative, they also give room for individual preferences and emotional incentives. The two effects play different parts in the shaping of the two major role types. Position roles are "closely defined and highly constrained" (Searing, 1994, p. 15) by the rules and institutions, and describe MPs in leadership positions. Preferences roles, on the other hand, are easier to fashion by personal preferences, because they do have less institutional constraints. Despite the possibility of the wide range of roles backbenchers might play, there does not seem to be as large of a variance in their roles as one could expect. Policy advocates' main goal is to influence government policy, and differ in terms of specialization: (i) ideologues are the promoters of abstract ideas, (ii) generalists focus on concrete issues without specializing, while (iii) specialists are experts of one particular policy field. Ministerial aspirants give the second group of members with preference roles. They see parliament as the springboard to higher, government positions: present activities serve prospective appointments. Constituency members prioritize representing "their constituents' personal cases and collective problems" (Searing, 1994, p. 121). Representatives pursuing ombudsman-like activities are called welfare officers: they often engage in casework aiming to solve individual problems. On the other hand, local promoters' concerns lie with promoting the interests of the constituency as a whole: they work to solve problems that affect the district collectively (e.g. unemployment). Last but not least, parliament men focus on conducting the parliament's business and pursue multiple goals. Some are just watching "the political drama unfold" (Searing, 1994, p. 163), some are enjoying the atmosphere of collegiality, and some seek to enhance their status. None of them ambition higher office or representing special interests of the society including the promotion of the interests of any particular district.

The other very influential piece schematizing the discussion on political roles comes from Kaare Strøm, who promotes the strategic behaviour framework. In his seminal work Rules, reason and routines: Legislative roles in parliamentary democracy (Strøm, 1997), he argues that roles can be understood within the neo-institutional rational choice tradition. He defines roles as "routines, regular patterns of behaviour" (Strøm, 1997, p. 
158) in order to reach certain pre-defined goals. These "game plans" are fuelled by preferences, but depend heavily on current institutional settings. Unlike in the motivational approach, where emotional motivations are partly endogenous, in the neoinstitutional rational choice principle "preferences are exogenously given 'tastes"” (Strøm, 1997, p. 158). In case of the former, it means that at the beginning of their service, representatives have more or less steady preferences of the positions they wish to seek. These preferences initially define the roles played. However, changes in motivations might occur on the course of playing the role and adapting to new situations (Searing, 2011, p. xxv.). In case of the latter, the initial goals or favoured outcomes (preferences) do not change during the "play". Strategies, however, are endogenous in terms of their dependence on institutional factors. Choices between strategies mainly depend on the availability of scarce resources like time or money as well as on decisions relating to their allocations (Strøm, 1997, p. 158). In his work, Strøm identifies four distinct outcomes, which follow a more or less hierarchical logic: (i) re-selection, (ii) reelection, (iii) party office and (iv) legislative office. The pursuit of re-selection naturally precedes re-election incentives especially under SMD and closed-list PR, where MPs can secure re-election just by persuading the party to have them run in safe SMDs or place them on the top of the party lists. Under these conditions, the representatives' fight for re-election shifts to the candidate-nomination stage. The degree to which MPs are motivated to build a lively electoral connection with their constituencies depends on the level they are selected. If the national party leadership has the final word in nominating the candidates, MPs are more likely to be party-oriented; whereas in the case of parties, where candidates are selected locally, a greater level of constituencyorientation is expected. As to the goals of party and legislative offices, in most countries they are either easier to attain by Members of Parliament for political reasons, or this connection might be even required by law.

The strategic behaviour approach has been useful to find the connection between rules and behaviour. Still, there is a great variance left unexplained, indicating that there is more to representative behaviour than what institutions give away. The main problem is that there is a thin line between habits and "repeated patterns of particular types of strategic behaviour", and habits can rarely be considered strategic (Searing, 2011, p. xxv.). Furthermore, with habits, MPs might not behave rationally to reach their goals, and actors may not even recognize the tension between their behaviour and final purposes (Searing, 2011, p. xxiv). Therefore, institutions might not explain behaviour as 
hoped by the followers of the strategic behaviour framework; however it gives account to a very important set of factors that have inspired many scholars: electoral rules. As Strøm argues:

"Electoral systems have several critical implications for the political lives of parliamentarians. They control access to the election ballot and place that power in the hands of local activists, central party leaders or the voters themselves. Electoral systems also determine the effects of ballot placement on electoral prospects, and they have implications for the incentives for competition or co-ordination between parliamentary candidates."

(Strøm, 1997, p. 163)

Accordingly, the understanding in the literature seems to be that electoral rules shape the forms of representation as well as legislative roles in a given political system. Their effect however is not country-specific, in a sense that there are certain general principles along which electoral systems fashion the relationship between citizens and their representatives. These effects will be laid down in Chapter 2.

\subsubsection{The re-election incentive}

The term "electoral connection" originates from Mayhew and his seminal work Congress. The Electoral Connection (Mayhew, 1974). He put his research on the American Congress into the framework of rational choice theory. The basic assumption is that congressmen are "single-minded seekers of re-election" (Mayhew, 1974, p. 16). It can be argued whether this presumption tackles the true motivations of the representatives; nevertheless professionalization of politics makes re-election an important career factor. In practice, this means that the representatives' living is dependent upon the choices they make as Members of Parliament (or Congress in Mayhew's work). Therefore, it may be viable to assume that re-election is a proximate goal (Mayhew, 1974, p. 16) for professional politicians. To reach this goal, they make choices of time and resource allocation. Whether they can influence their re-election is a subject to dispute, especially in political systems with a notable tradition of party representation. It might also be of little importance with regards to the behaviour of the 
MPs, as the real question is not whether they can influence re-election, but whether they think they can (Mayhew, 1974, p. 33).

The different models and approaches of representation accept the re-election incentive to different degrees. The selection model of representation, for instance, assumes that the main goal of the legislators is to pursue good public policy, and voters choose representatives to act in their best interests independently of the desire to be reelected (Fearon, 1999; Mansbridge, 2009). The sanction model on the other hand presumes that the representatives' main goal is re-election, and voters punish deserters by not voting for them at the next elections. As reviewed in the previous section, Strøm also emphasizes the importance of the re-election incentive; however, the motivation of being re-selected precedes it, by the simple reason of their chronological order (Strøm, 1997). Atmor, Hazan and Rahat also argue that under PR-list rules and in systems where the nomination of SMD-candidates is under party control, selection of candidates equals election (Atmor, Hazan, and Rahat, 2011). There is, however, little to gain from simple re-selection: members who want to be re-selected do this because of the further goal of re-election. Therefore, re-selection is to be seen as a tool of getting re-elected, and whether there is a difference between the two motivations is dependent on the parties' candidate selection strategies. To collect additional votes, it is very rational for the party to select members who focus on their constituencies, as long as these MPs do not defy party will in parliament.

Re-selection and re-election tend to be negative political incentives, meaning that parties and voters define the role of the representatives, which they have to adjust their behaviour to in order to be able to stay in position. The cost of not meeting the expectations is bad reputation, and ultimately, failing at the next elections. There are considerable additional motivations - of ambiguous importance - for members to act on behalf of their districts.

Non-electoral incentives represent a "higher" level of motivation. A considerable part of these motivations come from the representatives' role perceptions. The key point is whom the MPs perceive they represent. In the case of those who think they particularly stand for the constituencies where they were elected, we can rightly expect a higher level of intensity in constituency service. In contrast, those who consider themselves as party representatives, a lower level of constituency service is expected. Analogically, a representative of the delegate type maintains more intensive relations with his voters/constituents than a trustee would. The task perception is also strongly 
related to the level of the work in the constituency. It goes without saying that if the constituency service is considered to be part of the job, its level will increase. MPs, who think that their work in parliament is more important than the work in the district, are expected to spend less time in their constituencies. The feeling of responsibility for the voters is also part of the job perception, just as the satisfaction with a well-done job. As Cain et al. argue, MPs enjoy working in the constituency more than they enjoy parliamentary work because they get an instant response about the quality of their work (Cain et al., 1987).

Despite the acceptance of these additional motivations, the main assumption of this dissertation is that Members of Parliament want to be re-elected. The reasoning behind is that, firstly, another goals, like pursuing good public policy, reaching higher (ministerial) positions or serving the interests of the constituency are easier to reach as an elected Member of Parliament. Secondly, the professionalization of politics reached the level, where it is reasonable to assume that re-election is a matter of livelihood: representatives have no other choice but trying to get elected repeatedly.

\subsubsection{The definition of constituency}

When using the word "constituency", it is far from obvious what it is meant by it. The most common association is related to the constituency as a geographical unit, which might not collide with the electoral district. MPs can represent, for instance, districts, regions or the whole country (Eulau and Karps, 1977, p. 248). The types of electoral districts might also differ in terms of latitude even within the same country. Under mixed-member electoral rules, regions or the whole country can very well be perceived as constituencies (as electoral districts), just like single member districts at the $1^{\text {st }}$ tier. This involves, that even in the geographical sense of the expression and within the same system, the heterogeneity of "constituency" is presumed.

The conception of constituency, however, might not only be understood as a geographically defined area. Functional groups, like religious, ethnic or economic groupings, also form a certain kind of constituency in a sense that their interests can also be represented in the legislature (Eulau and Karps, 1977, p. 248). Representation can be obtained by guaranteeing a given amount of seats to the different functional groups, e.g. minorities or occupational groups. Under these conditions, Members of Parliament are elected or delegated by these groupings. Additionally, by obtaining 
corresponding attitudes, these layers of society can very well be represented by members who were not formally elected by these groups.

Thirdly, legislators might represent individual citizens, who turn to their representatives with special problems, regarding their dealings with the state bureaucracy. MPs, therefore, often carry out ombudsman-like activities, and advocate the interests of the citizens regarding concrete issues (Eulau and Karps, 1977, p. 244). Citizens can come from within and outside of the geographical constituency.

After the introduction of general suffrage, representation takes place between citizens and parties. In the responsible party model, parties are regarded as unitary organizations, where MPs work to represent the party directly, and the voters - through the party - rather indirectly. Accordingly, since it can be the focus of representation, the party should also be regarded as constituency (Esaiasson, 2000).

Despite the multitude of possible interpretations, in this dissertation, the word "constituency" has two meanings. First, it refers to the constituency of the geographical kind (electoral districts), second, it relates to the individuals living in those constituencies. In this sense, the definition of constituency representation incorporates geographical and individual representations as well as allocation and service responsiveness.

\subsection{Question and scope}

This dissertation studies constituency orientation under party centred electoral rules. The main question is whether it appears in a country where electoral rules encourage party representation. Previous research has established that electoral systems and member personalization are closely connected: candidate-centred electoral rules enhance personal-, while party-centred systems support party representation. In this sense, representation is perceived as a one-dimensional scale where personal and party representations indicate the two ends of the continuum. My main hypothesis is that in $a$ mixed-member majority system with particularly strong incentives to party representation, personal representation will appear. However, due to the partycenteredness of the system, the decisions are presumed to come from the party rather than being the result of individual discretion. In this view, party and personal representations are not mutually exclusive ideas (Colomer, 2011b), but personal representation might be considered a form of party representation. In party-centred mixed member systems, the existence of the nominal tier leads parties to pursue more 
person-oriented party strategies. Thus, the oft-cited causal effect between mixed electoral rules and personalization can be confirmed. However, to unravel the causal mechanism, we have to perceive the link between electoral rules and personal representation as being mediated by central party strategies.

In the quest to test the above hypothesis I collect evidence from Hungary in a case study fashion. Hungary will serve as a least likely case (Rohlfing, 2012), where member personalization is not likely to appear. Nevertheless, if motivations can be identified that promote personalization, the idea of a direct relationship between electoral rules and personal representation has to be adjusted accordingly. Party strategies will not be investigated directly, but I presume that studying individual member behaviour, these strategies will surface nevertheless. My main assumption is that under such partycentred electoral rules with practically no space for individual action, constituency orientation prevails with the party's blessing.

The dissertation follows the neo-institutionalist approach, and establishes the link between electoral rules, member attitudes and behaviour in contemporary Hungary. It recognizes that even under party-centred electoral rules, there are serious motivations to pursue particularistic goals. These motivations can be proxied by different sets of career factors that relate to the past experience as well as the currently held positions of the legislators. The nature of the independent variables will point to three different types of motivations: (i) electoral, (ii) positions related, and (iii) habitual explanations. The limited importance of habitual motivations (see Chapter 2) in explaining member personalization, hint that personal motivations are second to electoral and position related explanations. This finding will underpin the argument that members do not personalize out of internal reasons, but because they are expected to. Attitudes and behaviour are adjusted to match actual positions leaving endogenous personal motivations little space. 


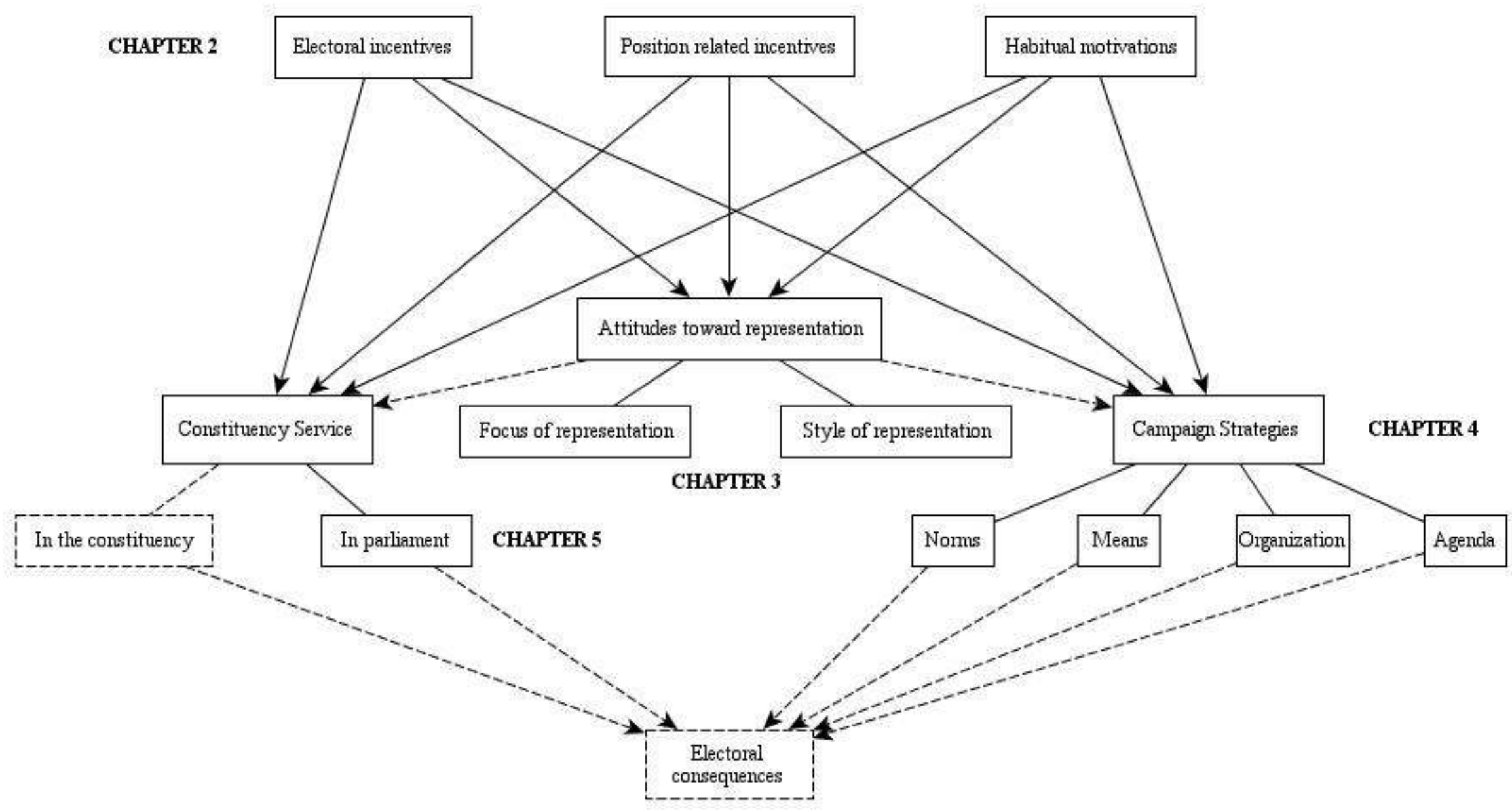

FIGURE 1.1 The relationships between the different components of the electoral connection 
As member personalization can be perceived in various ways, conclusions may change depending on which type of measurement we apply. Thus, I define personalization and constituency orientation in three different ways, in order to get a more complete picture: (i) attitudes toward representation, (ii) campaign strategies at the 2010 general elections, and (iii) non-legislative behaviour in parliament. Figure 1.1 introduces the structure of the dissertation. In the first part of the analysis I establish the link between the independent variables introduced in Chapter 2 and member attitudes perceived as the focus and style of representation. Empirically separating roles into attitudes and behaviour makes attitudes both independent and dependent variables (Blomgren and Rozenberg, 2011c). In the first case, the effect of electoral rules and other factors on attitudes are investigated, whereas in the second, attitudes structure behaviour - which are also affected by the initial independent variables. As Blomgren and Rozenberg put it, "considering roles as independent variables runs the risk of missing the complex relation between roles and the institutional position of the agent" as well as creating a serious problem of multicollinearity (Blomgren and Rozenberg, 2011c, pp. 3-4). Figure 1.2 shows the relationship between the explanatory factors, attitudes and behaviour, where attitudes are perceived both independent and dependent.

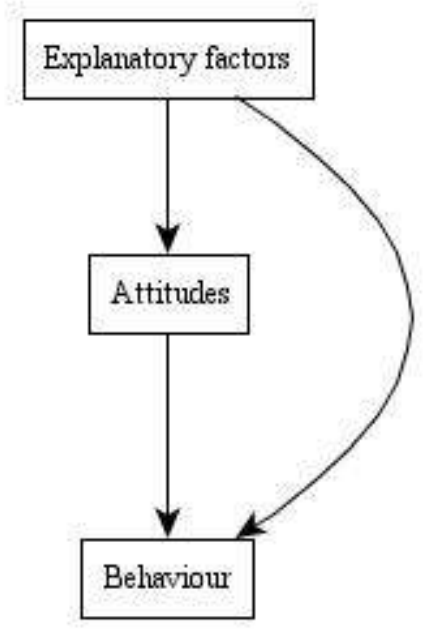

FIGURE 1.2 Attitudes perceived as a dependent and independent variable in the connection between the explanatory factors, member attitudes and behaviour

Although, both approaches are well justified, namely handling roles (that are measured by attitudes in this context) as both independent and dependent, this dissertation exploits the potential of what lies in the latter. Dashed lines on Figure 1.1 
represent the relationships that remain unattended: constituency service in parliament and campaign strategies will not be explained by member attitudes.

In the second part of the analysis, the effects of the independents on campaign strategies will be investigated. As it will be laid down in detail in Chapter 4, personalization is measured by four different dimensions of campaigning: norms, means, organization and agenda. The four components will capture both attitudes and self-reported behaviour. The third part will be focusing directly on constituency service. It examines how explanatory factors influence MPs' non-legislative work in parliament in terms of addressing issues of their electors' concerns. The sequence of the empirical chapters is defined by the level of abstraction the different measures represent. Representational roles in attitudes and partly campaign strategies (norms) operate with abstract ideas of representation and campaigning, while campaign means, organization, agenda and constituency service in parliament capture actual behaviour. This behaviour, however, is approached differently by the two groups of dependent variables. Whereas campaign strategies provide us with indirect measures of behaviour, questioning data directly reflects MPs' actions. In the former case, the indirectness is the consequence of responding members having to report on their own behaviour. The order of the various aspects with regards to their relative abstraction is showed by Appendix 1.1.

A great bulk of literature examines whether personal traits and actions contribute to electoral success. There are several reasons why students of voting behaviour started to explain voters' choices with factors beyond party preferences: the worldwide weakening of party affiliations, the increase in volatility of votes and the changes in the nature of the campaigns (Cain et al., 1987, p. 12). The international literature provides an answer with the concept of the personal vote. In the 1970s research on personal vote was motivated by the increasing proportion of re-elections among representatives in the USA and the UK although the mentioned trends would have implied the opposite. Students of personal vote (Cain et al., 1987; Canache, Mondak, and Cabrera, 2000; Carey and Shugart, 1995; Gaines, 1998; Herrera and Yawn, 1999; Marsh, 2007; Mondak and Huckfeldt, 2006; Mondak, 1995; Morgenstern and Swindle, 2005; Norris, Vallance, and Lovenduski, 1992; Norton and Wood, 1990; Shugart, Valdini, and Suominen, 2005; Swindle, 2002; Tavits, 2010) assume that a certain proportion of votes cast for the candidates can be explained with variables beyond party affiliation, fixed characteristics of the voters and the trends in economics as well. These factors are derived from the qualifications, abilities, personal characteristics and the record of the 
candidate (Cain et al., 1987, p. 9), which can be enhanced by active constituencyoriented behaviour.

Recognizing that constituency-oriented behaviour does not only depend on the institutional and career factors, but on the demand of favouring the districts, the electoral connection is to view as a cycle of constituents' wishes and representatives' behaviour. It is difficult to establish a one-directional link between the two: the question is whether citizens react to the supply, or the supply broadens as the demand is enhanced by external factors? The answer is probably: both. This dissertation begins the research of this cycle by taking a closer look at the representatives' point of view, excluding - both external and internal - demand from the equation. It is probably more exact to say that real demand is unexploited, perceived demand is taken into account at some point of the research, as it is assumed that representatives step up for their constituencies because they aim for re-election. This entails that Members of Parliament and their parties think that there is a certain kind of demand to an active constituency representation. Meeting the "real" demand in the voters' eyes serves the basis of personal vote. Making it simple, if voters think that the MP has done his or her job well they will vote for him or her, but if they think he or she has not worked hard enough, they will vote for whom they expect to do so. Hence, "Electoral consequences" on Figure 1.1 refers to the effects of constituency-oriented behaviour (personal voteseeking), which is most likely to show in votes. Uncovering the whole complexity of this electoral connection is a two-pillar project: one has to examine member perceptions and behaviour as well as their translation into votes (voting behaviour). To cover both cannot be the ambition of this dissertation; it will only investigate the first. 


\section{CHAPTER 2 - ELECTORAL RULES AND METHODOLOGICAL CONSIDERATIONS}

The effects of electoral rules on MPs' attitudes toward representation and their behaviour in their constituencies and parliament have been thoroughly discussed in the scholarly literature. Electoral rules have four main aspects that bear great importance in shaping the electoral connection. Firstly, electoral formula captures the effect of majoritarian and proportional electoral rules. Researchers try to give a scientific explanation to what seems obvious: MPs elected under SMD majority rules are more district-oriented than those elected in party-list proportional (PR) systems. The second aspect is the effect of district magnitude which cannot entirely be separated from the electoral formula, or more elaborately mandate type. District magnitude larger than 1 quantifies the list tier in a sense, that it brings variation into that category. Therefore the two may be interpreted as covering the same question. By this reason I do not intend to rigorously separate the two when discussing the results of previous research. Thirdly, ballot structure covers the number and type of votes the electors cast. Fourthly, the nominating procedure measures the candidates' ability to access the party label. In other words, it describes the influence of party leadership over the rank of candidates on the party lists.

One of the most influential and comprehensive theoretical papers is the work of Carey and Shugart (Carey and Shugart, 1995), in which they ranked the different electoral systems on the basis of the incentives they offer to cultivate personal vote. They classify the different electoral systems along four factors. (i) Ballot control $(B A L L O T)^{4}$ refers to the candidates' ability to access the party label. In other words, it describes the parties' influence on the final list of candidates. The more control a party poses over nomination and the rank order of candidates on the party lists, the less the incentive to cultivate a personal vote. (ii) Vote pooling (POOL) measures the degree

\footnotetext{
${ }^{4}$ Ballot from the perspective of Carey and Shugart refers to candidate selection strategies. In this sense, their usage of expressions is not consistent with the rest of the literature. When I use the term ballot I refer to ballot structure: the number and type of votes the electors cast. The expression uppercase BALLOT relates to the meaning Carey and Shugart attach to it.
} 
with which votes cast to one particular candidate help other candidates to be elected. In the case of no pool, votes will be transferred to neither the party nor other candidates of the party. The smaller the extent of pooling, the greater the incentive to build a solid personal reputation. (iii) Vote types (VOTES) "measure the number and types of votes cast; single partisan vote, multiple votes, or a single vote below the party level" (Carey and Shugart, 1995, p. 418) $)^{5}$. The rule of thumb in this case is that the more personalized the vote gets, the greater the value of "personal vote earning activities" (PVEA). The two extremes of this continuum are the cases in which the voter casts one single vote to one party, and where the voter chooses one candidate from a party list. (iv) The fourth variable is district magnitude $(D M)$ that affects incentives to personal vote in two different ways depending on the ballot structure (BALLOT), which will further discussed further in the following sections.

The greatest virtue of Carey and Shugart's model is that it is general and flexible enough to offer a guideline to classifying every single electoral system in the world regardless of their complexities. The model is easy to apply since the effect of the first three variables always point in the same direction. This means that "ceteris paribus, an increase $^{6}$ in BALLOT, POOL, or VOTES always increases the value of personal reputation" (Carey and Shugart, 1995, p. 420). Only the effect of district magnitude interacts with the value of another variable, namely BALLOT.

In this chapter, first I give an overview of the literature on the effects of electoral rules on member personalization. I discuss the electoral formulae, the ballot structure, district magnitude and candidate selection strategies. Then I review the peculiarities of mixed-member electoral systems, paying special attention to the mandate divide and the interaction effect (contamination). Third, case selection is justified by introducing the Hungarian electoral rules and its political consequences. Fourth, the data and independent variables are presented, which is followed by a classification of the IVs into three categories: electoral, position related and habitual motivations.

\footnotetext{
${ }^{5}$ VOTES refer to the structure of the ballot.

${ }^{6}$ The values of the three variables range between 0 and 2 . The higher the value of these variables the more incentive they exert on pursuing personal reputation.
} 


\subsection{An overview of the effect of electoral rules on personal representation}

\subsubsection{Electoral formula}

The dispute on the choice between adversarial and consensual political systems from the aspect of the consequences on the electoral connection unravels around the effects of majoritarian and proportional electoral formulas. The differences between the two major types of electoral systems come from the distinct philosophical roots and the application of single member versus multi-member constituencies.

One of the most frequently cited characteristics of the single member majority systems is that it creates a strong accountability linkage (Lancaster, 1986; Norris, 2000, 2004; Scholl, 1986). Since one district has one single representative, the voters will be able to determine who to reward or punish for the positive or negative outcomes (Lancaster and Patterson, 1990; Lancaster, 1986; Norris, 2004). Moreover, SMD systems make direct sanctioning possible, which leads to an effective system of accountability (Mitchell, 2000). In multi-member constituencies, where a geographical overlap among legislators exists (Heitshusen, Young, and Wood, 2005), the accountability link becomes confused, and the incentive to free-ride increases. The reason for this is that voters have difficulties identifying the representative responsible for the benefits, leaving little room for recognition and reward (Cain et al., 1987; Lancaster, 1986; Scholl, 1986). In MMD-system, members are more accountable to the party leadership than to the electorate (Norris, 2004), which makes the contest for reelection a fight for higher positions on the party list (Curtice and Shively, 2000). Single member district MPs on the other hand are more dependent on local support, since their electoral fortunes depend only on the votes cast for them, and these votes cannot be enhanced or diminished by the electoral performance of the fellow party members (Curtice and Shively, 2000; Mitchell, 2000). One MP is responsible for the whole constituency, and cannot delegate problem-solving to other representatives (Gallagher and Holliday, 2003; Norris, 2004). In other words, (s)he needs to represent the district electorate at large, and cannot concentrate on co-called sub-constituencies (Curtice and Shively, 2000), unlike MMD members who do not have to fight for the median voter's 
support or stick to the centre of the distribution of the ideological scale ${ }^{7}$ (Loewenberg and Kim, 1978).

As voters in SMDs can easily identify who to approach with their problems (Scholl, 1986), and members are usually better known by the electorate (Cooper and Richardson, 2006), single member districts tend to generate larger demand for constituency service, than MMDs (Scholl, 1986). And since SMD MPs are more dependent on their local support, they are more vulnerable to the pressure from the electorate as well (Cooper and Richardson, 2006). This implies that their best interest is to meet the demand, which is partly created by the representatives themselves by advertising their own services (spiral effect).

To sum up the differences between SMD and MMD systems, there is a greater incentive to provide constituency service and stay in touch with the electorate in the former. Majority rules indirectly lead to a higher level of satisfaction with the elected representatives, through the feeling that the voters have someone willing to act on their behalf. Greater satisfaction with the elected fosters the satisfaction with the political system as a whole, strengthening the legitimacy of the democratic institutional settings (Curtice and Shively, 2000). In accordance with this, Norris (Norris, 2000) also points out that due to the clear and decisive outcome an SMD system generates, the overall voter satisfaction with SMD is higher compared to MMD.

\subsubsection{Ballot structure}

As noted earlier, the critiques of the consensual model entail that it reduces the accountability of the elected representatives toward their local parties and constituents (Norris, 2004, p. 76), hence weakening the link between the representative and represented. This, however, is a somewhat oversimplified view of how electoral rules affect the electoral connection. Students of electoral systems agree that the electoral formula is just one factor among many, and is far from being the most important. In fact, the electoral competition in systems using multi-member constituencies might be more candidate-oriented than under SMD. The key aspect here is ballot structure that creates very distinctive subgroups among systems with MMD. Norris (Norris, 2004)

\footnotetext{
${ }^{7}$ This theory, however, was challenged by Scholl (Scholl, 1986) who concluded that SMD members are slightly more group-focused, meaning that they represent a clearly defined group of citizens within their constituencies.
} 
distinguishes upon four types of ballots. (i) Candidate ballot is used in SMD majority systems, where voters pick candidates and choose parties at the same time. Since parties are represented by persons, candidates have considerably strong incentives to build a personal reputation, instead of leaning only on the party label. (ii) Preference ballots are used in open-list PR systems. Voters are usually offered an opportunity to express their candidate preferences as well as party preferences. The effect of these types of ballots depends on the proportion of voters who actually choose to select candidates instead of parties. If citizens cast mostly party votes, the case of preference ballots will not differ from closed-list PR (Norris, 2004) ${ }^{8}$. (iii) Dual ballots are used in mixed electoral systems, where citizens vote for closed party lists as well as for candidates in single member districts. In the case of combined independent dual ballots the result is determined independently on both tiers. Combined proportional ballots, on the other hand, let the share of party list votes determine the final allocation of mandates (Norris, 2004). The effects of mixed electoral rules will be discussed further in more details later. Finally, (iv) party ballots are used in closed-list PR systems, in which the voters cannot change the rank of the candidates which is, therefore, pre-defined by the parties.

The reason why we cannot consider the group of MMD-systems homogeneous in terms of how they affect the electoral connection lies with the different incentives open(preference ballot) and closed-list (party ballot) rules offer. The key factor is intra-party competition. Carey and Shugart's (Carey and Shugart, 1995) main point is that electoral rules are important not because they distribute mandates between parties, but because they allocate "seats to specific candidates within parties" as well (Carey and Shugart, 1995, p. 417). Incumbent candidates in open list systems face a "double incentive" just because they have to defend their seats not only against the candidates of other parties but of their own as well (Curtice and Shively, 2000; Gallagher and Holliday, 2003; Heitshusen et al., 2005; Morgenstern and Swindle, 2005). Cain et al. (Cain et al., 1987) point out that the free rider problem a multi-member system generates is not that big of a concern in PR systems using preference ballots. Closed lists, on the other hand do not give the opportunity for the candidates to get higher on the list based on their personal

\footnotetext{
${ }^{8}$ It has been shown that a very high proportion of voters in countries offering the opportunity to choose between party and candidate votes go with the party vote (Karvonen, 2004). However, Massicotte argues that in mixed member systems wherever citizens have the opportunity, they express personal preferences (Massicotte, 2011).
} 
reputation, making parties the centre of candidate attention instead of constituencies. Curtice and Shively (Curtice and Shively, 2000) show that SMD offers greater incentives to cultivate personal vote than closed list systems, but there is no measurable difference between SMD and MMD with preference ballot. Putting it short, there is an agreement in the literature that - theoretically - open list MMD supports personal voteseeking to a greater extent than $\mathrm{SMD}^{9}$.

Based on the above, one would think that closed list MMD does not support personal vote seeking at all. This might not necessarily be the case however, as there are additional factors and incentives that have to be taken into consideration. One is district magnitude, the other is candidate selection strategies.

\subsubsection{District magnitude}

Regardless of ballot structure the incentive to free-ride, the voters' confusion with who to approach with their problems and who to blame or reward increases with district magnitude (Cain et al., 1987; Norris, 2004; Scholl, 1986). Seddon et al. show that small constituencies "increase the needs for legislators to internalize the consequences of redistributive policies" (Seddon, Gaviria, Panizza, and Stein, 2002, p. 14), which makes them more willing to represent the direct interests of the district in the legislature. According to Lancaster the problems with credit claiming is the main reason of pork barrel politics being a less successful vote-attractor in larger constituencies (Lancaster, 1986).

Apart from its main effect, magnitude is often claimed to have interaction effects with ballot structure - more elaborately with the openness of party lists. Figure 2.1 shows the logic of this interaction.

\footnotetext{
${ }^{9}$ Norris (Norris, 2000) however points out that it is more difficult for voters to evaluate all the candidates on an open list than just one in a single member district.
} 


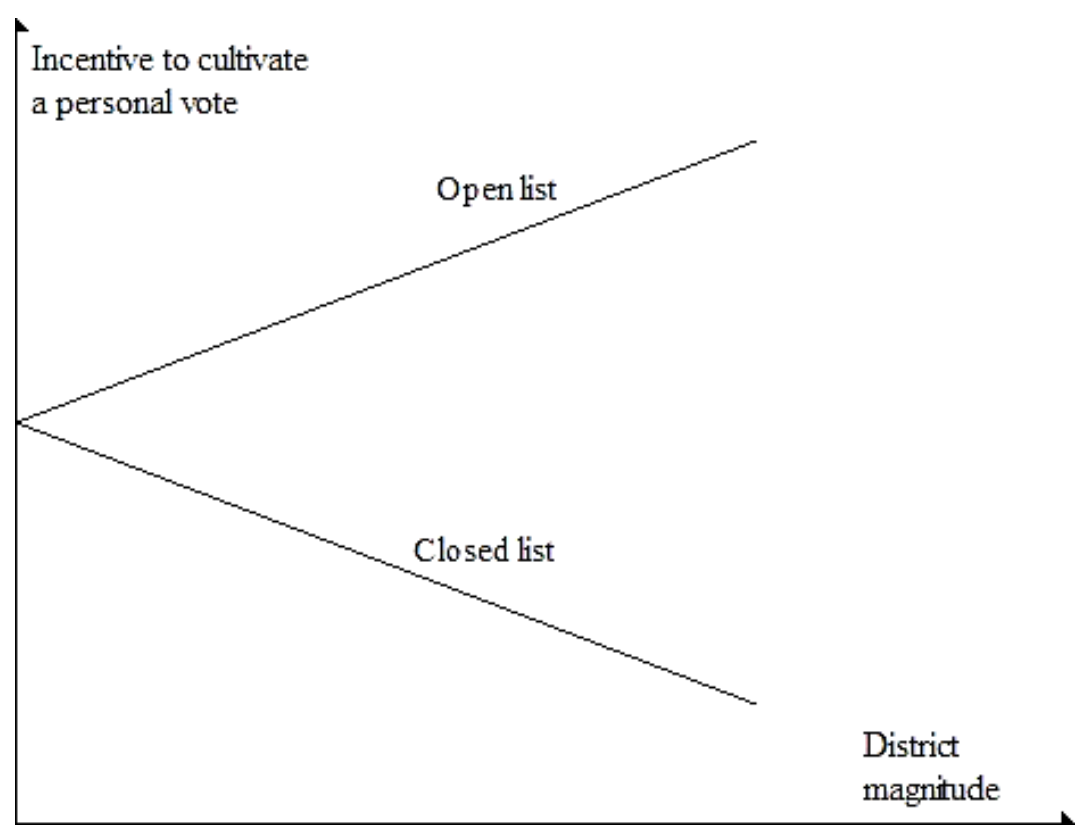

FIGURE 2.1 Expected relations between district magnitude and the politicians' incentive to cultivate personal vote under open and closed lists (Shugart, Valdini, and Suominen 2005, 439, figure 1)

The more candidates appear on the same list, the smaller is one's relative importance. Therefore, in closed list systems the incentive to personal vote-seeking increases with district magnitude. In this case, as the order of candidates depends on the decision of the party leaders, the scenery of earning personal credit is not the constituency but the party itself. In contrast, when district magnitude decreases, candidates ranked on the top will have the incentive to actively collect personal vote so that their positions become secured. To refer to the example of Shugart et al., if a party list has a realistic chance to win three mandates, then the first three candidates on the list are likely to make some extra effort to win those seats (Shugart, Valdini, and Suominen 2005, 440). These actions are less profitable under larger magnitude, as candidates in the first ranks are likely to win seats relying on the party label either way (Shugart et al., 2005).

In the case of open and flexible lists, candidates of the same parties compete for seats in parliament. This means that the rank does not determine the political fate of the candidates. Nevertheless, in practice, only a small proportion of voters use the opportunity to express preferences beyond party sympathies (Karvonen, 2004). According to Shugart and his colleagues, the incentives to gain personal reputation get stronger on such lists, and the cost of neglecting PVEA increases in line with district magnitude (Carey and Shugart, 1995; Shugart et al., 2005). The mechanism of this effect is related to the information demand voters make in order to be able to decide 
between candidates (Shugart et al., 2005). As a general rule, ceteris paribus, the information demand is larger in an open list system than in the case of closed lists. Increasing magnitude in open list systems increases the probability of a candidate to get elected. At the same time, intra-party competition becomes fiercer; voters need extra information to be able to decide which candidate to vote for. To meet this demand, candidates will advertise their attributes and services more actively. Contrarily, in the case of closed lists, where the rank of candidates is pre-determined by the party, the benefit from smaller efforts to ensure one candidate's own election is getting larger with increasing magnitude ${ }^{10}$.

Oddly, although Carey and Shugart examined list systems particularly, their train of thought is in sync with Cain et al.'s approach on the relationship between the voting system and personal vote. Cain, Ferejohn and Fiorina claim in their classic work, The Personal Vote (Cain et al., 1987), that single member districts provide the greatest incentives for gaining personal vote. The final conclusion of Carey and Shugart, however, is not the same relating the degree with which SMD raises the incentives to cultivate personal vote, by the reason of its dependence on other factors like access to the party label, and inner-party competition. Even so, the two findings are not contradicting either. In case we regard single member candidates as closed lists, the decrease of the district magnitude should increase the incentives to gain personal vote. While the magnitude in SMDs is one, the incentive reaches its maximum in closed list systems.

\subsubsection{Candidate selection}

District magnitude is not the only factor creating incentives to cultivate personal reputation in closed list MMD, but certain features of candidate selection strategies might also encourage candidates to seek personal vote. As Atmor et al. put it “... while electoral systems determine the distribution of power at the inter-party level, party and personal representation cannot be wholly explained by them if one does not take into consideration the intra-party arena as well” (Atmor et al., 2011, p. 32).

\footnotetext{
${ }^{10}$ Although Figure 2.1 indicates a linear relationship between district magnitude and the incentives to cultivate a personal vote, Mitchell argues that there is no proof that the relationship described by Carey and Shugart (Carey and Shugart, 1995) is in fact linear (Mitchell, 2000, p. 347).
} 
The major difficulty that party leaders face at the time of candidate selection is the problem of collective action (Carey and Shugart, 1995, p. 419; Shugart et al., 2005, p. 437). Those who control the access to the party label have a substantial interest in the quality of party reputation. This also means that career-wise they are at the mercy of their parties' electoral fate (Carey and Shugart, 1995, p. 419), which leads to tension between personal and party reputation, individual politicians and district level party leaders. Morgenstern argues that both parties and candidates are "agents of representation", and their relative importance is determined by the electoral rules (Morgenstern, 2004). However, they use two separate channels of communication: parties send their messages though policy goals, whereas candidates advertise differentiating attributes (Shugart et al., 2005). The two goals, namely enhancing party reputation by the party leaders and seeking personal vote by the individual candidates are not necessarily contradicting. Especially in SMD systems, where the votes of the person are also votes for the party. Therefore, it is the party's best interest that their candidates collect extra votes, without disrupting party unity within the given district.

A direct link between citizens and MPs can be provided by decentralized selection of candidates (Mitchell, 2000). Norris (Norris, 2004) describes the interaction between selection rules and ballot structure as shown in Figure 2.2. Local party selection encourages local accountability and creates greater incentives to personal vote seeking and representing the local interests. Centralized party selection on the other hand supports party voting and eventually leads to more cohesive and disciplined parliamentary parties. 


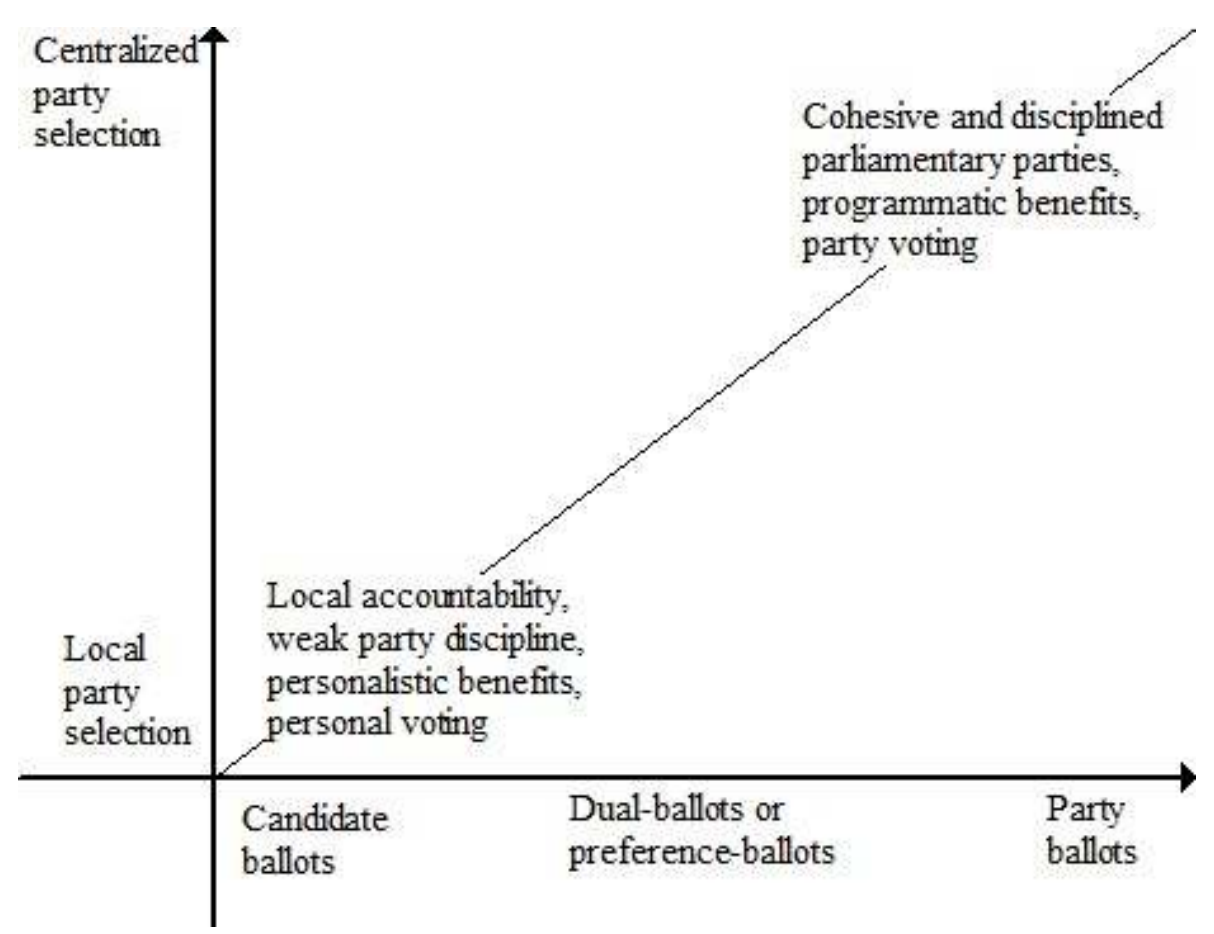

FIGURE 2.2 The interaction of selection rules and ballot structures (Norris, 2004, p. 233, figure 10.1)

Atmor, Hazan and Rahat define four dimensions that have to be taken into account when evaluating selection rules in terms of their effects on personal representation (Atmor et al., 2011). First, the inclusiveness of candidacy encourages personal representation, while exclusive candidacy motivates party representation. Second, in the case of an exclusive selectorate, MPs are exposed to smaller pressure to deviate from the party lines, while an inclusive selectorate provides more incentive to pursue personal representation. Oddly, in the most exclusive end of the continuum, where only the single leader decides who gets selected, personal representation will emerge, since the leader might not adhere to the party programme. Third, selection though appointment might enhance personal representation, as selectors are from rivalling blocks from within the party, which makes compromise in candidate selection more likely. Fourth, the decentralization of the process enhances personal representation, pork-barrel politics and the high responsiveness to local and regional level interest.

But is there any place for personal vote seeking in a party with centralized candidate selection procedures? Oddly, the answer is yes. Even when there is no place for the voters to choose between candidates of the same party, the party's right to nominate a candidate of its own choosing plays a crucial role in forming the incentives to personal vote cultivation (Carey and Shugart, 1995, p. 417). Cain el al. (Cain et al., 1987) point 
out that there are possible party strategies that encourage the nomination of locally wellknown candidates to the party lists to attract votes. Curtice and Shively (Curtice and Shively, 2000) and Gallagher and Holliday (Gallagher and Holliday, 2003) also agree that if voters value MPs who engage themselves actively into constituency service, district representation and ombudsman-like activities, then the parties have an incentive to give priority to voter appeal. Based on this assumption, MPs have a good reason to believe that focusing on the constituency will increase their chances of re-selection as well as re-election (Gallagher and Holliday, 2003). Riera has shown that in the case of Spain, the vote shares of the two main parties are higher in those districts where the candidates on the top are high-quality politicians (Riera, 2011) ${ }^{11}$.

\subsection{The case of mixed electoral systems}

The case of mixed electoral systems is particularly interesting for students of the electoral connection. We have a fair knowledge of how the different electoral rules affect the relationship between the representative and the represented all other things being equal, but mixed member electoral systems open up new dimensions of the phenomena. The reason for this is simple: the way certain parts of the electoral systems effect personal vote seeking does not determine the effect of the whole system (Shugart, 2001, p. 41), since the different tiers interact with each other in different ways. Therefore, in order to be able to determine the effect an electoral system poses on the electoral connection, we have to examine each polity individually.

As Shugart and Wattenberg put it, mixed-member electoral systems "offer voters a direct role in choosing an elected representative for their localities, but also provide for some element of proportional representation" (Shugart and Wattenberg, 2001, p. 1). In their edited volume, Shugart and Wattenberg (2001) define mixed-member electoral systems as one subset of multiple-tier systems, where two types of votes are cast: a nominal vote ${ }^{12}$ to one or more candidates, and a list vote for a party $\operatorname{list}^{13}$. Table 2.1

\footnotetext{
${ }^{11}$ This finding however, should be evaluated knowing that Spanish voters have a particularly low level of party identification (Riera, 2011).

${ }^{12}$ The nominal vote does not necessarily follow the plurality principle. Single Transferable Vote (STV) is considered using nominal voting as well as SMD (Shugart and Wattenberg 2001).

${ }^{13}$ Party lists - apart from a few exceptions - are most commonly closed lists (Shugart and Wattenberg, 2001).
} 
shows their classification in which they divide electoral systems on the basis of seat and vote linkage.

TABLE 2.1. A typology of mixed-member systems with PR list tiers

\begin{tabular}{cccc}
\hline & & \multicolumn{2}{c}{ Vote linkage } \\
\cline { 3 - 4 } Seat & No (parallel) & No & Yes \\
linkage & Yes (compensatory) & MMM & MMM with partial \\
compensation \\
Source: (Shugart and Wattenber
\end{tabular}

Source: (Shugart and Wattenberg, 2001, p. 15, Table 1.1)

*Although it is theoretically possible, there are no electoral systems with seat and vote linkage.

Seat linkage means whether there is a link between the different tiers in terms of the allocation of mandates. In parallel mixed-member systems list seats are not adjusted on the basis of seats won on the nominal tier (Shugart and Wattenberg, 2001, p. 14). In the case of linked tiers, the number of mandates won from party lists is determined by the number of seats received from the nominal tier. The application of seat linkage defines the type of mixed systems: mixed-member majority (MMM) systems are characterized by parallel distribution, while systems with seat linkage are considered mixed-member proportional (MMP). Vote linkage on the other hand, entails whether votes are transferred between the nominal and list tiers. In Hungary, for example, votes not yielding any seats will be transferred to the third tier of the system, which gives a compensatory element to the mixed-member majority rule. The trade-off mixedmember systems aim to balance - in terms of the electoral connection - is between strong candidates and strong parties. The most important feature of mixed-member systems is that they are able to realize nominal representation with substantial constituent ties and, at the same time, relatively strong and cohesive parties in parliament (Shugart, 2001).

A substantial part of the literature on the effects of mixed electoral rules tries to map the degree of the mandate divide on the one hand, and contamination on the other. In fact these two phenomena are perceived over against each other. Mandate divide refers to the fact that SMD and list members have differing attitudes and behaviour in terms of their relationship with the constituents, due to the different incentives the electoral rules offer. The advocates of contamination on the other hand argue that bringing SMD and list members together in one system results in interaction effects that make them less distinct compared to representatives elected under pure majority and PR rules. 


\subsubsection{The mandate divide}

The mandate divide is caused by the fact that there are at least two types of MPs elected under different electoral rules that present the representatives with different incentives. A recurring reason is accountability: SMD members are accountable to the geographical area they were elected in, while the electoral fate of list members depends on the party's goodwill, therefore they can be held accountable by the party for their actions as Members of Parliament. On these grounds, students of electoral rules find it plausible to say that SMD and list members differ significantly in terms of their job perceptions and their attitudes toward party discipline (Montgomery, 1999). It has been shown that mandate type affects MPs' perceptions of pork barrel allocations (Lancaster and Patterson, 1990), and it makes a difference in how representatives perceive their roles (Klingemann and Wessels, 2001). Even in Japan, Pekkanen, Nyblade and Krauss show that mandate type matters in the allocation of offices (Pekkanen, Nyblade, and Krauss, 2006). Ward reports that in New-Zealand the media refers to list members as second class representatives (Ward, 1998). Bowler and Farrel (Bowler and Farrell, 1993) theorize that by the reason of the lower demand to constituency service, and the fact that list representatives are able to "shirk" this demand results in them working less in their constituencies.

\subsubsection{Contamination}

Contamination refers to the decreasing heterogeneity among representatives elected under different electoral rules, but within the same electoral system. This means that MPs elected in SMDs and party lists are more alike, than it would be suggested based on the attitudes and behaviour of MPs elected under pure majority or PR rules. Contamination is thought to be the reason of mixed-member systems being different than solely the sum of their parts. According to previous research, contamination has two sources (Crisp, 2007; Sieberer, 2010), one of which is related to the parties' strategies of nomination, and the other to individual candidate strategies. The literature discussing the first aspect investigates the question of mixed-member electoral systems producing a higher number of competing parties on the SMD tier than the experience from a pure SMD system would suggest. In other words, the existence of the PR tier creates a multiparty competition on the majority tier as well, overwriting Duverger's law of the relationship between electoral rules and the number of parties (Cox and 
Schoppa, 2002; Herron and Nishikawa, 2001). As Herron and Nishikawa put it, the mechanical effect of the mixed systems ${ }^{14}$ seems to be less punishing than that of a pure SMD system, which creates the incentives to multiparty competition (Herron and Nishikawa, 2001, p. 65). The reason for this is that the performance of parties on the list tier is influenced by the fact that they also nominated an SMD-candidate in a constituency of the same area (Cox and Schoppa, 2002; Ferrara and Herron, 2005; Herron and Nishikawa, 2001; Sieberer, 2010). Parties are even encouraged to nominate candidates in districts with no chance of winning (Herron and Nishikawa, 2001), just to make the party more visible (Cox and Schoppa, 2002) and thereby boost list votes. Cox and Schoppa (Cox and Schoppa, 2002) argue that candidates who run in constituencies, where they otherwise would have not, campaign in a more party-centred way. Additionally, parties will have the incentive to resist electoral coordination and run candidates in as many SMDs as possible (Cox and Schoppa, 2002).

The other source of contamination is related to candidate strategies. Candidate and member behaviour on the two tiers will be more alike compared to pure SMD and pure lists systems, where one tier does not influence the behaviour on the other. As Crisp puts it, "contamination refers broadly to the idea that the existence of one tier prevents legislators from the other tier from behaving as they were elected in a 'pure' systems made up of their tier alone" (Crisp, 2007, p. 1462). Mixed electoral rules have moderating effects in terms of party- as well as candidate-centeredness: list MPs will most likely be more candidate- or less party-centred than MPs in a pure list system. Analogically, district MPs tend to be less candidate- or more party-centred compared to a pure majority system. While, the two tiers offer different incentives, there are also factors that are the same, e.g. if parties dominate candidate selection, candidates have the same motivations on both tiers. Additionally, the institutional incentives, for example, parliamentary rules apply equally to all members (Sieberer, 2010), enforcing similar behavioural patterns. Nevertheless, one of the major reasons of converging candidate strategies are centralized nomination strategies and the institution of dual candidacy. Thames (Thames, 2005) points out that in the case of parties with centralized candidate nomination strategies, SMD representatives will show the same behavioural and attitudinal patterns than list members, because they need the party's support for re-

\footnotetext{
${ }^{14}$ They investigated a special type of the mixed electoral rules, namely mixed-superposition electoral systems.
} 
election. He argues that in order to be able to map the attitudes and behaviour of the SMD MPs, "one must concentrate on the relationship between single-member district deputies and political parties" (Thames, 2005, p. 285). In this view, the extent of contamination depends on the degree with which individual members' re-election depends on the party's support (Thames, 2005, p. 285) ${ }^{15}$. Herron comes to the same conclusion, namely that member behaviour is mostly dependent upon "the party's ability to control access to parliamentary seats" (Herron, 2002, p. 366). Bawn and Thies also claim that the parties' candidate nomination strategies is the main factor in determining where the electoral incentives will fall between a pure majority and a pure PR electoral system (Bawn and Thies, 2003, p. 26).

Contamination - or the interaction effect - is the reason why the mandate divide does not always prevail. Morlang (Morlang, 1999) and Ishiyama (Ishiyama, 2000) have found no evidence of the existence of the divide in Hungary. Lundberg (Lundberg, 2006) also claims that voters in Germany do not distinguish between the two types of MPs. ${ }^{16}$

Candidate strategies are also influenced by whether dual candidacy is allowed or not. Dual candidacy refers to the candidates' ability to run on multiple tiers at the same time. A candidate who runs on more than one tier has to balance between his or her party's

${ }^{15}$ Thames connects centralized nomination strategies to highly institutionalized party systems and concludes that in such systems the mandate divide is less likely to prevail than in systems on the earlier stages of party system institutionalization (Thames, 2005).

${ }^{16}$ The availability of dual listing leads to a notion, what Krauss, Nemoto and Pekkanen call "reverse contamination" (Krauss, Nemoto, and Pekkanen, 2011). Reverse contamination refers to the possibility that votes might perceive list ranking as information on the nominal tier candidate (Krauss et al., 2011, p. 748). They distinguish between two possible candidate strategies which are applied depending on the type of the mixed-member systems. In MMP, nominal tier candidates try to climb as high on the party lists as possible, while in MMM absence or low ranking stand in the best interests of the candidates. In the first case, high ranking signals that the candidate is favoured by the party, therefore (s)he might have considerable influence within the party after elected. On the other hand, the message of high ranking is that the candidate will be elected anyhow, so the vote cast for him or her might go to waste on the nominal tier. Low ranking or absence from the party list signals that the candidate has to be elected on the nominal level, because (s)he is running without "insurance" of dual candidacy. 
will and the wants of the constituents in his or her SMD, and shape strategies accordingly. As Herron puts it "because of dual candidacy, a legislator might then need to satisfy both a national party and a local constituency, to varying degrees" (Herron, 2002, p. 367). He even suggests that instead of mandate type one shall rather focus on the type of candidacy ${ }^{17}$. According to Lundberg (Lundberg, 2006) dual candidacy is the reason for German voters not being able to distinguish between SMD and list representatives.

As a consequence of multiple candidacies, SMD losers very often win mandates as list members in the same geographical area. This fact is particularly important as it gives the basis of the notion of shadowing which is a very popular subject of studies deriving contamination from candidate strategies. The shadowing hypothesis theorizes that despite their electoral defeat list MPs can be highly interested in working for the SMD they ran in. In marginal constituencies for instance, the second candidate might also feel the need to act like the winner only because (s)he wants to stay in the competition for the next elections (Ingall and Crisp, 2001; Kumbhat and Marcian, 1976; Norris et al., 1992; Norris, 2004; Soroka, Penner, and Blidook, 2009; Zittel, 2012). Data shows that even in non-marginal districts, list MPs often appear as the "shadows" of the SMD members, and - despite their status - set up local office (Carman and Shephard, 2007) and engage in constituency service just like their SMD counterparts. In this sense, past and future candidacy is more important than the type of mandate (Lundberg, 2006). Pekkanen, Nyblade and Krauss also argue that these "zombie"18 politicians - apart from being more constituency-oriented - pursue more personalistic campaigns (Pekkanen et al., 2006). The utmost importance of shadowing is explained by Lundberg (2006), who argues that voters with strong partisan affiliations might never turn to their representatives if they come from other parties. The availability of the vanquished party can be crucial with regards to the level of trust in the political system. This is extremely important in constituencies where - out of historical reasons - the candidates of the

\footnotetext{
${ }^{17}$ Herron also claims that apart from dual candidacy, the safety of positions is the most important factor that has to be taken into account when explaining member behaviour (Herron, 2002).

18 “... there are 'zombie' MPs, who are losing SMD candidates elected on their party's PR list (and thereby 'risen from the dead')" (Pekkanen, Nyblade, and Krauss, 2006, p. 185).
} 
same party win election after election; which means - in the most extreme case disenfranchisement ${ }^{19}$ for the voters of the opposition in the constituency ${ }^{20}$.

\subsection{Case selection: the Hungarian electoral system and its political implications}

The most common criticism of cross-country research is that it is difficult to identify the casual effects independently from other cross-country factors (Jun and Hix, 2010). Hence, it might be more gainful to focus the attention exclusively to a single country, and thereby hold cultural and historical aspects constant. This dissertation sticks to the latter, and tests whether traces of personal representation appear under party centred electoral rules. In this section I give an outline of the Hungarian electoral rules in 2010 and argue that despite of its being mixed-member, it is more proper to consider it as party centred. Since my concerns lie with the 2010-2014 electoral term, I only take the rules prior to the electoral reform in $2011^{21}$ into account. The reason for this is simple: at the time of the data collection, MPs were not aware of the details of the new electoral system; therefore they did not have the opportunity to adjust to the new rules, and incorporate this knowledge into their attitudes. It is probably right to assume that member attitudes were formed by the rules MPs were elected under in 2010. This analysis, however, is not entirely without any practical benefits. Mapping the effects of the former electoral rules certainly gives us some ideas of how the new system is likely to form the attitudes, behaviour and strategies of the representatives, by revealing which factors are relevant and which have no effects at all. This however is not subject to investigation at this point.

\subsubsection{Mixed-member but party-centred}

There is no doubt with regards to whether the Hungarian electoral system is to be classified as mixed-member. Using the classification of Shugart and Wattenberg (Shugart and Wattenberg, 2001), the Hungarian electoral system falls into the category of mixed-member majoritarian with partial compensation (see Table 2.1). A country

\footnotetext{
${ }^{19}$ Lundberg call this "historical disenfranchisement" (Lundberg, 2006, p. 74).

${ }^{20}$ This might also be the reason why trust in SMD systems can be improved by applying multimember list tier as well (Lundberg, 2006, p. 74).

${ }^{21}$ The Hungarian Parliament passed the bill on the new election law on 23rd December, 2011.
} 
having a mixed electoral system often leaves scholars with the conclusion that the country is half-way between being candidate- and party-centred. Although, the SMD tier brings a certain degree of candidate-centeredness into the system, its effect is far from being mechanical. In this section I will argue that the Hungarian electoral system has to be considered party-centred, therefore it is a critical case to test whether partycentred electoral systems truly suppress personal representation. Mechanical effects leave limited space for members to act on behalf of their constituencies; still, a certain degree of personal representation appears. This aspect, however, must be the construct of the parties, as the existence of the nominal level enables party strategies that encourage candidate-centeredness. Mixed-electoral rules, therefore, indeed push politics to a more person oriented way, but not due to individual initiative, but to the manifestation of central party strategies. Hence, in order to be able to fully understand how mixed systems work, a more detailed classification of such systems is in order. This task, however, is way beyond the scope of this dissertation. My goal is to show that party-centeredness does not necessarily involve minimum personal representation. Furthermore, it is a shortcut to classify Hungary as half-way between party and personal representation on the basis of the mechanical effect of the rules. The causal effect is certainly there, however, the causal mechanism remains unexploited.

In a 2011 edited volume by Josep Colomer, electoral systems were classified in a two-dimensional space (Colomer, 2011b). Electoral formula was made the proxy for party representation, while ballot structure accounts for personal representation. The idea of visualizing personal and party representation in a two- (or more) dimensional space inspired this dissertation greatly. Namely, this means that personal and party representations are no longer considered as two end-points of a one-dimensional continuum (Colomer, 2011a, p. 10., Table 1.1), but electoral systems are perceived as a combination of the two. A similar approach is followed by Carey and Shugart, who assign numbers to the different components of the electoral systems, but still end up translating it into a one-dimensional scale (Carey and Shugart, 1995). A demand side approach is followed by Colomer and his colleagues (Colomer, 2011b), in which ballot structure describes the opportunities of the voters to choose between parties or candidates. In other words, it refers to the degree with which citizens are able to participate in the selection of representatives. With their ability to do so, voters eventually control the quality of Members of Parliament. 
The Hungarian electoral system was classified semi-open on the personal representation dimension, by the reason of its application of double vote. This means that Hungarian voters can express their preferences in terms of both parties and candidates. This, however, does not involve ability to select representatives who fit the job the most. The key factor here is candidate selection, which is also incorporated in Colomer's (2011) volume. Atmor and his colleagues argue that it is "necessary to move beyond the inter-party arena if one truly wants to assess the difference between personal and party representation and its political consequences" (Atmor et al., 2011, p. 32). They further claim that in countries, where SMDs are applied, and a large amount of these seats is safe, candidate selection plays a more crucial role than the election itself (Atmor et al., 2011, p. 31). Also the degree of centralization of candidate selection pushes SMD tiers toward party representation, as members' first goal is likely to be reselected. Thus, it is clear that ballot structure itself does not capture personal representation, as the incentives are influenced by factors like candidate selection. In this view, Colomer's classification appears too simplifying. However, it is correct to say, that candidate selection procedures are too volatile to form the basis of classification, as they would make the distinction between country years instead of countries. Furthermore, selection procedures within one country might also not be identical, therefore, the unit of grouping becomes the party year. These considerations would make electoral system classifications too complex, and would leave tables with small-N cells, making the very sense of labelling pointless. Even so, scholars should be more careful when classifying electoral systems, as this naturally changes the conclusions we draw from the behaviour of the different systems. Too technical approaches do not take system peculiarities into account, leaving us to conclude based on rough differentiations. Thus, large scale models can serve only as starting points to a more elaborate investigation of how personal representation is shaped under the specific combinations of electoral rules.

As mentioned earlier, in this section I intend to show that taking the institutional mechanisms into account, the Hungarian electoral system is rather party-centred. Therefore, the incentives to personal representation or personal vote-seeking that the electoral system creates with the nominal tier cannot be exploited against party representation, but should be understood as a subtype of it. 


\subsubsection{Hungarian electoral rules}

Hungary has a three tier electoral system ${ }^{22}: 176$ representatives are elected in single member districts, a maximum of 152 seats are distributed among 20 fixed regional party lists, and a minimum of 58 mandates are available on the national level tier. Voters, however, do not vote for the $3^{\text {rd }}$ tier party lists.

\subsubsection{Candidate and list nomination rules}

Prospective single member district candidates need the signatures of 750 eligible citizens to make it to the ballots. To nominate a regional party list, each party has to successfully nominate SMD candidates in $1 / 4$ of the corresponding constituencies, but at least in two of them. For a national party list, a party needs to have seven regional lists.

\subsubsection{First tier rules}

Figure 2.3 shows the election process on the nominal tier of the Hungarian electoral system. First, the validity of the election round is determined on the basis of the electoral turnout. In the first round the threshold is $50 \%$, which means that the round in which the turnout is less than or equal to $50 \%$ of the eligible will be considered invalid. In this case, a run-off is held with all the candidates that ran in the $1^{\text {st }}$ round. In the case of a valid $1^{\text {st }}$ round, the candidate with the absolute majority of the total district vote wins the race. If no candidate reaches the sufficient amount of votes, a $2^{\text {nd }}$ round is held. In this round, the first three candidates from the $1^{\text {st }}$ one and everyone else with more than $15 \%$ of the votes will compete for the mandate. The rules of the run-off are the same both in the cases of invalid and inconclusive $1^{\text {st }}$ rounds.

In the $2^{\text {nd }}$ round the minimum of valid votes is $25 \%$ of all the citizens eligible to vote. If the turnout does not exceed this minimum, by-election is held with identical rules $^{23}$. If the turnout is higher than $25 \%$, the run-off automatically leads to a result, since only simple majority is required.

\footnotetext{
${ }^{22}$ Throughout the dissertation I will use present tense to address issues of the Hungarian electoral system; however, at the time of submission, new electoral rules are in place.

${ }^{23}$ In the case of an inconclusive $2^{\text {nd }}$ round, the remaining seats being distributed through byelections, the new parliament will step into power with a reduced amount of representatives.
} 


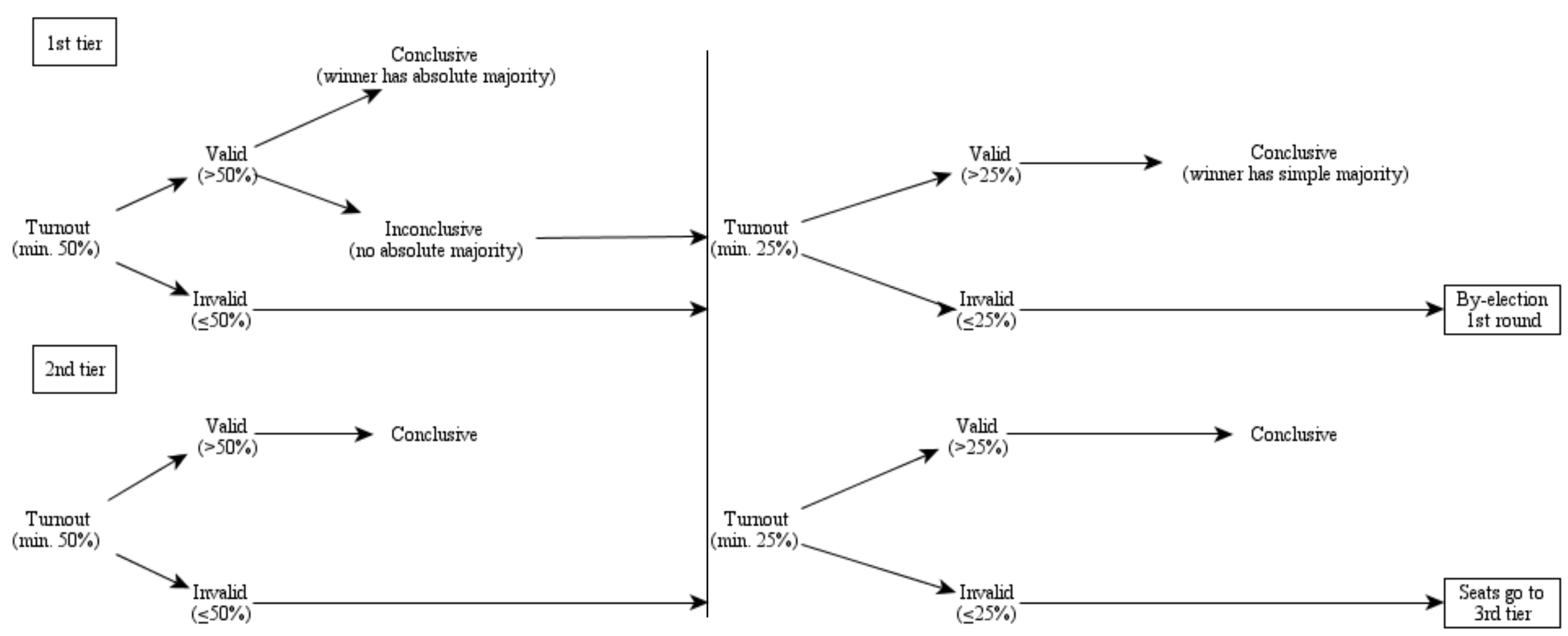

FIGURE 2.3. Hungarian electoral rules at the $1^{\text {st }}$ and $2^{\text {nd }}$ tiers 


\subsubsection{Second tier rules}

On the $2^{\text {nd }}$ tier of the electoral system, the rules of validity are identical to the SMD rules: $50 \%$ turnout is needed in the $1^{\text {st }}, 25 \%$ in the $2^{\text {nd }}$ round. The difference lies with the conclusiveness of the election: on the regional list level if a round is valid, it is conclusive as well. Another difference is the lack of by-elections when the $2^{\text {nd }}$ round was not valid. In this case, the mandates will not be distributed on the $2^{\text {nd }}$, but on the $3^{\text {rd }}$ level of the systems. With other words, these seats increase the amount of mandates available to candidates on the national party lists. The election process is also shown by Figure 2.3.

The allocation of mandates on the regional list level follows the rule of the highest remainder. The quota is calculated district wise according to the Hagenbach-Bischoff formula ${ }^{24}$. After the division by the quota, the remaining mandates will be distributed among the parties whose remaining votes (votes that did not yield any mandates) reach $2 / 3$ of the quota (this is called the $2 / 3$ rule). Mandates not allocated after this procedure will augment the number of seats available at the national list level. District magnitude varies between 4 and $28 .^{25}$

The national aggregate of the regional party votes of a party has to exceed $5 \%$ of all the votes cast to regional party lists to enable the party to get any mandates on either the regional list or the national list level. Parties under $5 \%$ of the national vote total get their $1^{\text {st }}$ tier mandates only.

\subsubsection{Third tier rules}

As noted earlier, voters do not cast any votes to the $3^{\text {rd }}$ tier of the electoral system. The sum of all non-utilized votes from the $1^{\text {st }}$ valid rounds - both $1^{\text {st }}$ and $2^{\text {nd }}$ tier - forms the basis of mandate allocation on the national level. Non-utilized votes from the nominal tier are votes that were cast to the losing candidates. From the $2^{\text {nd }}$ tier, votes

${ }^{24} H B=\frac{\sum v}{m+1}$, where $\sum v$ is the total number of votes, and $\mathrm{m}$ is the district magnitude.

${ }^{25}$ District magnitudes of the different counties are as follows. Budapest 28, Baranya 6, BácsKiskun 8, Békés 6, Borsod-Abaúj-Zemplén 11, Csongrád 6, Fejér 6, Győr-Moson-Sopron 6, Hajdú-Bihar 8, Heves 5, Jász-Nagykun-Szolnok 6, Komárom-Esztergom 5, Nógrád 4, Pest 14, Somogy 5, Szabolcs 9, Tolna 4, Vas 4, Veszprém 6, Zala 5. 
that were not needed to win any mandates will add to the national level votes ${ }^{26}$. In the case of $2^{\text {nd }}$ tier mandates that were allocated using the $2 / 3$ rule, the difference between the quota and its $2 / 3$ will be subtracted from the national votes. After determining the final count of votes, d'Hondt' $\mathrm{s}^{27}$ method is used to distribute the mandates.

\subsubsection{Candidate selection in Hungary}

As the rules of candidate selection are not the subject of this dissertation, I base my argument on the previous research of the few who tried to uncover the formal and informal rules of the selection processes of the contemporary Hungarian parties. I consider the argument and conclusions of Marjai valid, who based her results on a series of face-to-face interviews with competent party officials of four Hungarian parliamentary parties - Fidesz, Jobbik, LMP and MSZP (Marjai, 2012).

Although she admits that the local level has strong powers in nominating candidates in the case of the four parties, national level decision-makers can overwrite local decisions in most of the cases. In the case of Fidesz, the party centre selects, interviews and approves candidates, while Jobbik's and LMP's leadership confines to interviewing and approving potential candidates (Marjai, 2012, p. 48). In three out of four cases, the national party centre has veto power over the local level nominations. The only exception is the case of MSZP, where " $[\mathrm{u}]$ ntil the last candidate selection period (where candidates running at the 2014 general elections were selected) local branches had the right to decide who will run for office and higher organizational levels had almost no way to correct their choice" (Marjai, 2012, p. 45).

Marjai identifies the selectorates of Fidesz, Jobbik and LMP as the group of national level leaders, whereas in the period under investigation, the regional level assembly of delegates seems to control candidate nomination in MSZP (Marjai, 2012, p. 49). The degree of decentralization is the highest in the case of the Socialists, where the larger importance of the local levels is demonstrated, with the controls of the national level (Marjai, 2012, p. 49).

\footnotetext{
${ }^{26}$ This means that even the votes of the parties who won several seats on the regional list level will pool to the $3^{\text {rd }}$ tier, but evidently with lower amounts than in the case of parties unsuccessful in the regional competition.

${ }^{27}$ D'Hondt's method is a highest average method, where the total votes cast for each party is divided first by 1 , then by 2 , then by 3 etc. until the total number of seats is allocated.
} 
A somewhat different picture is presented by Szabó et al. (Szabó, Mihályffy, and Kiss, 2011), especially in the cases of MSZP and LMP. The candidate selection procedure of Fidesz seems to be the most centralized, as only a handful of people had a say in who gets to be running in one of the SMDs (Mihályffy, 2011, p. 26). Regarding MSZP there is no evidence that the selection procedure was locally organized, however, party centre named the most important criteria in selecting locally well-known and respected persons (Ughy, 2011). With regards to LMP, the findings of Takács (2011) add new layers to the results of Marjai (2012). Although national party leadership plays an important role in selecting SMD candidates, it did not exercise its right to put a veto on the decisions of the local organizations in about 2/3 of the cases (Takács, 2011, p. 89).

TABLE 2.2. The selectorates of the different parties prior to the 2010 national elections

\begin{tabular}{cccccc}
\hline & Fidesz & Jobbik & KDNP & LMP & MSZP \\
\hline Party members & $25.6(32)$ & $37(10)$ & $9.5(2)$ & $70(7)$ & $27.8(10)$ \\
Delegates & $15.2(19)$ & $3.7(1)$ & $14.3(3)$ & $0(0)$ & $55.6(20)$ \\
Party leadership & $24(30)$ & $40.7(11)$ & $23.8(5)$ & $30(3)$ & $5.6(2)$ \\
Other $^{\mathrm{a}}$ & $3.2(4)$ & $0(0)$ & $14.3(3)$ & $0(0)$ & $0(0)$ \\
More of the above & $32(40)$ & $18.5(5)$ & $38.1(8)$ & $0(0)$ & $11.1(4)$ \\
\hline$\chi^{2}$ & & $68.807^{* * *}$ & & \\
Cramer's V & & .28 &
\end{tabular}

Source of the data: Hungarian Election Study 2010

Entries are percentages, case numbers in parentheses.

${ }^{a}$ Other selectorates were not specified by the questionnaire.

$* \mathrm{p}<.1, * * \mathrm{p}<.05, * * * \mathrm{p}<.01$

Table 2.2 presents the selectorates of the various parties as their MPs reported it in 2010. Although Fidesz and KDNP ran joint candidates and lists, their results are reported separately to see whether there was any difference between the processes of candidate selection within the party alliance with regards to the two partners. Selection of candidates appears to be the most exclusive in the cases of these parties and Jobbik: party leadership decides the fate of candidates in a relatively high percentage of cases. The role of party membership is the most prominent within Fidesz, Jobbik and LMP. Furthermore, more than a half of MSZP members (55.6 \%) were selected by delegates, whereas this body was underrepresented within the other four parties. 
TABLE 2.3. The level of decision-making with regards to the candidate selection procedure prior to the 2010 national elections

\begin{tabular}{cccccc}
\hline & Fidesz & Jobbik & KDNP & LMP & MSZP \\
\hline Constituency & $23.8(30)$ & $3.6(1)$ & $17.4(49$ & $70(7)$ & $63.9(23)$ \\
County & $1.6(2)$ & $0(0)$ & $8.7(2)$ & $0(0)$ & $8.3(3)$ \\
National & $42.9(54)$ & $60.7(17)$ & $43.5(10)$ & $30(3)$ & $13.9(5)$ \\
More of the above & $31.7(54)$ & $35.7(10)$ & $30.4(7)$ & $0(0)$ & $13.9(5)$ \\
\hline$\chi^{2}$ Cramer's V & & $53.172^{* * *}$ & \\
\hline
\end{tabular}

Source of the data: Hungarian Election Study 2010

Entries are percentages, case numbers in parentheses.

$* \mathrm{p}<.1, * * \mathrm{p}<.05, * * * \mathrm{p}<.01$

Representatives were also asked about the level where the decision of their candidacy was made. Answers presented in Table 2.3 support previous conclusions regarding the centralization of the selection process. LMP and MSZP members were mostly selected in their constituencies, while the national level dominated FideszKDNP and Jobbik. Decentralization of candidate selection within MSZP is probably the consequence of the campaign strategy the party was following. By the time of the 2010 elections, party label was too "worn out" to build a campaign around. Therefore, traces of personalization appeared in order to increase the distance between the candidates and the party. However, as Ughy reported, not only the expected electoral results were taken into account, but the former roll-call behaviour of senior MPs as well (Ughy, 2011, p. 52). Hence, party loyalty played an important role in candidate selection in the case of the Socialists as well. In sum, the majority of the Hungarian parliamentary parties control candidate selection from its centre. Even the less centralized ones ensure veto rights to the party leadership, and enforce aspects that strengthen the party as an organization.

\subsubsection{Political implications of the Hungarian electoral system}

As noted earlier, Hungary has a mixed-member majority (MMM) system, which enables vote but not seat linkage. This means that seat shares are determined on each tier individually, but votes cast on one tier can help candidates get elected on another. In the context of the Hungarian system, unutilized votes on the first two tiers automatically pool to the national level, so that smaller parties are compensated for their poor performance in the SMDs. In this section I make my argument on why the Hungarian electoral system should lead to party-centred outcomes. 
Electoral rules are particularly party-centred in Hungary in terms of the incentives they offer to individual action. The appeal of the single member tier is potentially diminished by the fact that candidates of the parties that stand any chance of winning in the constituencies - with the exception of the Socialists - are selected by the national party leadership. This entails that any action that serves the interest of the constituency is weighted upon its standing against the interests of the national party. As their political fate might depend on it, it is safe to assume that in any conflict of interest, members shall act according to the national party's will instead of pleasing the constituency.

The next factor weakening the potential positive effect of the SMD tier on a lively electoral connection is oddly, dual candidacy. Most of the single member candidates appear on the regional party lists (possibly on the top), which decreases the importance of the $1^{\text {st }}$ tier in getting elected. Table 2.4 shows the proportion of SMD representatives who were also running on other tiers of the electoral system.

TABLE 2.4. The proportion of SMD representatives who are nominated on party lists

\begin{tabular}{ccccc}
\hline $\begin{array}{c}\text { Election } \\
\text { year }\end{array}$ & $\begin{array}{c}\text { Regional list } \\
\text { candidate }\end{array}$ & $\begin{array}{c}\text { National list } \\
\text { candidate }\end{array}$ & $\begin{array}{c}\text { Both regional and national list } \\
\text { candidate }\end{array}$ & Total \\
\hline 1990 & $42.2(76)$ & $6.1(11)$ & $19.4(35)$ & $67.4(122)$ \\
1994 & $38.6(68)$ & $6.8(12)$ & $48.9(86)$ & $94.3(166)$ \\
1998 & $15.6(28)$ & $4.5(8)$ & $76(136)$ & $95.6(172)$ \\
2002 & $44.9(80)$ & $1.7(3)$ & $48.3(86)$ & $95.5(170)$ \\
2006 & $58(102)$ & $4(7)$ & $35.2(62)$ & $96.1(171)$ \\
2010 & $46.9(84)$ & $0(0)$ & $50.8(91)$ & $97.7(175)$ \\
\hline Average & 41 & 3.8 & 46.4 & 91.1
\end{tabular}

Source: Hungarian Representatives Dataset (Centre for Elite Research, CUB)

Entries are percentages, case numbers in parentheses. Single member district MPs represent $100 \%$.

According to the last column, the proportion of list candidates (regardless of the type of the list) among SMD members stagnates at a very high percentage (95-98\%) in the last four terms. This percentage peaked in 2010, where almost $98 \%$ of SMD members pursued multiple goals. Constituency representatives had a very wide "safety net" in case they would have lost the SMD-race ${ }^{28}$. This suggests two things. First, dual candidacy became a widespread practice among parliamentary parties. Second, there are only a few candidates who specialise in either running campaigns on the nominal level, or focusing the efforts to the party campaign. Concentrating on both reveals that

${ }^{28}$ This contradicts the findings of Krauss et al., who claim that candidates in MMM systems have a strong incentive to be absent from the party lists (Krauss et al., 2011). 
candidate and party focus is not something that is easily separable in the behaviour of Hungarian Members of Parliament.

Up to the 2010 general elections, the proportion of $1^{\text {st }}$ tier MPs running on all tiers shows a declining tendency, while those running on only two tiers (in this context in both SMD and regional list, or SMD and national list) are increasing in numbers. This indicates that the "safety net", that ensures the candidates getting elected by all means is narrowing: it was enough to have only one back-up option. The choice of the "type of insurance" is remarkable however. The fact that nominal tier candidates were running on the regional list level rather than the national one, gives away the increasing importance of the local/regional level. SMD candidates seemed to specialize in the lower levels of the electoral system, potentially leading to a more locally centred form of representation. The year 2010 put a break into this trend with a jump in the proportion of members who were candidates on all of the tiers of the electoral system. ${ }^{29}$ Note, however, that this is only the data associated with Members of Parliament and not the population of candidates. Therefore, the results might not properly reflect the candidate selection strategies of the parties.

Regarding the party lists, the voters' inability to change the rank of the candidates, gives the party leadership more power in determining member behaviour. The above characteristics match Crisp's (Crisp, 2007) criteria of a system being party-centred on the intraparty dimension ${ }^{30}$. In this aspect I debate Colomer's new classification of electoral systems (Colomer, 2011a, p. 10), especially that Hungary scores unusually high on the personal representation dimension. Although voters are offered the opportunity to choose between candidates, this choice is not intrinsic, as they cannot influence who parties nominate. The nomination procedure being centralized leaves the SMD tier identical to a closed list tier in terms of the access to the party label. To get nominated in the SMDs, prospective candidates have to act in favour of the party, hence

${ }^{29}$ One suitable explanation for this is the fact that only Fidesz-KDNP candidates had a living chance to win in the SMDs. Therefore, having no "safe seats", the remaining parties had to ensure the election of their candidates in different ways than earlier. This is particularly true in the case of the Socialists. As election on regional party lists was also not ensured, candidates had to be nominated on the national lists as well.

${ }^{30}$ An additional factor is the length of the party lists. According to Crisp (2007) long lists makes each candidate relatively anonymous. Lists in Hungary are three times as long as there are mandates to allocate in any given region. 
the SMD leaves less room for real personal representation. Despite the existence of the nominal tier, the overall characteristics of the electoral rules pushed the system to a more party-centred sphere. Thus, based on ballot structure and candidate selection, it is well justified to regard the Hungarian electoral system as a critical case in testing whether personal representation is present under party centred electoral rules. Being a least likely case (Rohlfing, 2012), it is expected that personal representation as a form of the electoral connection is not likely to prevail. Incentives to the individual candidates encourage them to pursue party-oriented goals. Thus the reasons why personal representation still appears are to be found in party strategies. In the next section I outline possible incentives for the party to encourage personal representation.

\subsubsection{The problems of country year}

It is common knowledge that Fidesz-KDNP won a majority that post-transition Hungary has rarely ${ }^{31}$ seen before. With an overall $52.7 \%$ of the votes they secured $2 / 3$ $(68.1 \%)$ of the seats in the Hungarian Parliament. Table 2.5 shows the distribution of party affiliations cross-tabulated with type of mandate on the first day of the term 2010$2014^{32}$.

TABLE 2.5. PPG membership and mandate type after the 2010 general elections

\begin{tabular}{|c|c|c|c|c|c|}
\hline & SMD members & Regional list members & National list members & & Total N \\
\hline \multirow[t]{2}{*}{ Fidesz } & 66.9 & 31.7 & 1.4 & $100 \%$ & 227 \\
\hline & 86.3 & 49.3 & 4.7 & & \\
\hline \multirow[t]{2}{*}{ Jobbik } & 0 & 55.3 & 44.7 & $100 \%$ & 47 \\
\hline & $\mathbf{0}$ & 17.8 & 32.8 & & \\
\hline \multirow[t]{2}{*}{ KDNP } & 58.3 & 41.7 & 0 & $100 \%$ & 36 \\
\hline & 11.9 & 10.2 & $\mathbf{0}$ & & \\
\hline \multirow[t]{2}{*}{ LMP } & 0 & 31.2 & 68.8 & $100 \%$ & 16 \\
\hline & $\mathbf{0}$ & 3.4 & 17.2 & & \\
\hline \multirow[t]{2}{*}{ MSZP } & 3.4 & 47.4 & 49.2 & $100 \%$ & 59 \\
\hline & 1.1 & 19.3 & 45.3 & & \\
\hline \multirow[t]{3}{*}{ Independent } & 100 & 0 & 0 & $100 \%$ & 1 \\
\hline & 0.7 & $\mathbf{0}$ & $\mathbf{0}$ & & \\
\hline & $100 \%$ & $100 \%$ & $100 \%$ & & \\
\hline Total N & 176 & 146 & 64 & & \\
\hline
\end{tabular}

Source of the data: www.parlament.hu

Entries are percentages.

\footnotetext{
${ }^{31}$ The winning coalition in 1994 (MSZP and SZDSZ) won $71.77 \%$ of the mandates.

3214 May 2010.
} 
Furthermore, Fidesz and KDNP won $98.2 \%$ of the 176 constituency seats, and $59.5 \%$ of seats available at the regional party lists ${ }^{33}$. One could justifiably argue that selecting the country year as case for this dissertation might distort the results because of the imbalance of parties at the $1^{\text {st }}$ tier of the electoral system. The dominance of Fidesz-KDNP on the first two tiers makes this case too peculiar to make conclusions about the whole system based only on 2010. However, I would argue that this situation oddly gives more power to the findings. Candidate selection in Fidesz-KDNP is regarded as the most centralized with the most exclusive selectorate. Thus, the electoral system must have stronger party-centred effects on member attitudes and behaviour than in the case of a more balanced partisan set-up with the selection strategies being less centralized in general. Therefore, if different forms of personal representation are found under such circumstances, then it is logical to expect that it prevails at less extreme conditions as well. Also, if it appears, then it is very likely that partycenteredness does not rule out other forms of representation.

Chance of winning is another interesting issue that is influenced by the election year in the context of the dissertation. Many (Curtice and Shively, 2000; Heitshusen et al., 2005; Herron, 2002; Jun and Hix, 2010; Lundberg, 2006; Sieberer, 2010) argue that the candidates' chances of winning affects their behaviour. 2010 was a special year from this aspect as well, because based on opinion polls prior to the election (which were supported by the election results), virtually no SMD candidates were expected to defeat nominees of Fidesz and KDNP. They were not expected to finish even close to them. Thus, chance of winning did probably not play a substantial role in 2010, at least not on the most personalized level of the electoral system. Nevertheless, it can be argued that safe seats make the system more party centred, as the decision of who gets elected is now truly in the hands of selectors. Therefore, the choice of 2010 to conduct research results in a more extreme case of party centeredness, which again, is less likely to show signs of personal representation and constituency orientation.

\footnotetext{
${ }^{33}$ The relative ,unsuccessfulness" of Fidesz-KDNP on the national level is the product of the compensatory nature of the $3^{\text {rd }}$ tier.
} 


\subsection{The data}

\subsubsection{Datasets}

The main hypothesis of the dissertation is that despite the institutional disincentives, constituency orientation is a relevant option in the case of Hungary. Furthermore, its appearance is rather systematic, as it shows considerable variation in terms of the independent variables under investigation. The empirical chapters of this dissertation are based on three datasets. First, the MP survey ${ }^{34}$ of the Hungarian Election Study was used to measure representational roles (Chapter 3) and campaign strategies (Chapter 4). The data was collected in June 2010, right after the new parliament was elected. 15 MA- and PhD-students from two universities ${ }^{35}$ carried out 232 face-to-face interviews based on a standard questionnaire among the Hungarian representatives ${ }^{36}$. The questions resemble the research goals of the Comparative Candidates Survey ${ }^{37}$, enabling to put the findings into a comparative perspective on a later stage of the research. This however, is way beyond the scope of this dissertation, which only ambitions to lay down the foundations of future comparative research involving Hungary. Survey questions used in this study are shown in Appendix 2.1 in Hungarian. English translations will be provided throughout the dissertation.

Second, during the spring of 2013, parliamentary questions were coded by the researchers of the Centre for Elite Research at the Corvinus University of Budapest ${ }^{38}$. The dataset contains oral and written questions from May 2010 to January 2013, to map constituency orientation in non-legislative parliamentary behaviour.

34 The core dataset is available for download from this link: http://www.valasztaskutatas.hu/eredmenyek-en/adatbazisok/magyar-adatok. This database, however, does not contain all the information used in this dissertation. Independent variables were collected by the author based on the official websites of the Hungarian Parliament (http://www.parlament.hu/angol/angol.htm ), the National Election Office (http://valasztas.hu/en/onkval2010/index.html ), and party websites.

${ }^{35}$ Corvinus University of Budapest and Eötvös Loránd University.

${ }^{36}$ In this project I served as the supervisor of fieldwork.

${ }^{37} \mathrm{http}: / /$ www.comparativecandidates.org/

${ }^{38}$ I am immensely grateful to Adrienn Tóth and Rudolf Tamás Metz, who worked tirelessly to code individual questions. I am also grateful to Gabriella Ilonszki and Réka Várnagy to give their valuable insights to the initial research design. 
Third, while the above data sources give the dependent variables of this dissertation, some of the independents were provided by the Hungarian Representatives Dataset tended by the Centre for Elite Research ${ }^{39}$. However, the majority of the IVs were coded by the author using official sources like the websites of the Hungarian Parliament ${ }^{40}$ and the National Election Office ${ }^{41}$. The introduction of IVs follows in this chapter whereas DVs are discussed in Chapters 3-5. Additional data was used to support the argument, reference and details - if necessary - are given later in the text.

\subsubsection{Independent variables}

As to the independent variables, the coding of the different factors is summarized in Appendix 2.2. The hypothesized effects of mandate type and district magnitude are not in need of further elaboration. In short, SMD members and MPs from smaller districts are expected to be more constituency-oriented in attitudes and behaviour than list MPs and members from larger constituencies respectively.

The case of candidacy was also mentioned earlier in connection with the shadowing hypothesis. MPs running in single member districts focus on the constituency with greater probability than members who did not ambition nominal level positions. List members might also try to build a solid personal base to retain chances of being elected on the $1^{\text {st }}$ tier at the next elections. The proportion of list members running in SMDs throughout the post-transition period is shown by Table 2.6.

\footnotetext{
${ }^{39}$ It would be impossible to account for all the researchers who helped create the dataset throughout the years. However, I must acknowledge the help of Adrienn Tóth, who made important improvements to the data with regards to the term 2010-2014.

An earlier version of the data is free to download at http://elitkutatas.unicorvinus.hu/index.php?id=adatok .

${ }^{40} \mathrm{http}: / /$ parlament.hu/

${ }^{41} \mathrm{http}: / /$ valasztas.hu/
} 
TABLE 2.6. The proportion of list members running in SMDs

\begin{tabular}{cccc}
\hline Election year & Regional list MPs running in SMD & National list MPs running in SMD & Total $^{1}$ \\
\hline 1990 & $50(68)$ & $41.8(41)$ & $46.6(109)$ \\
1994 & $53.7(72)$ & $61.4(59)$ & $58(131)$ \\
1998 & $72.9(97)$ & $58.3(49)$ & $67.3(146)$ \\
2002 & $56.9(87)$ & $42(34)$ & $51.7(121)$ \\
2006 & $48.7(74)$ & $36.4(24)$ & $45(98)$ \\
2010 & $34.2(53)$ & $70.1(47)$ & $45(100)$ \\
\hline Average & 52.7 & 51.6 & 52.2
\end{tabular}

Source: Hungarian Representatives Dataset (Centre for Elite Research, CUB)

Entries are percentages, case numbers in parentheses.

${ }^{\mathrm{I}}$ List members represent $100 \%$

An average of $52.7 \%$ of regional list members was stepping up as nominal tier candidates, throughout the years. This means that half of the representatives elected on regional lists had at least some motivation to build a solid personal reputation before the elections. Shadowing theory suggests that a considerable percentage of these dual candidates continue to work in the SMDs after the race. The weight of this possibility was the most prominent in 1998, where almost $73 \%$ of the regional list members aspired to be elected on the first tier. On average, national list members were not less interested in building a stable local base. There are, however, considerable differences between elections. The percentage of nominal level candidates among national list members peaked in the term under investigation (2010-2014). The possible reason for this jump is the moderate success of parties other than Fidesz in securing SMD positions. Dual candidacy serves as a safety net to their candidates. As these parties were also rather unsuccessful on the regional level, they mostly got elected on the $3^{\text {rd }}$ tier of the electoral system. On the one hand, these candidates were nominated on the national level with greater proportions, and they were also elected there with a larger probability on the other. The data presented here shows that multiple candidacy and the relatively free pass between the layers of the electoral system creates an encouraging ground for electoral strategies beyond what it seems realistic based on the present type of mandates.

As discussed in the previous section, there are significant incentives for building a steady personal reputation under party-centred electoral rules. Despite the considerable conflict of interest, the party centre might oddly be interested in nominating politicians with strong local ties, just to boost the percentage of votes cast for the party, and ensure election on the nominal level. Strong local ties can take several different forms, one of which being local political experience. One type of political experience at the local level 
is mandate accumulation. "Cumul des mandats" refers to the state in which a Member of Parliament holds elected office(s) on a different level(s) of government at the same time. The dilemma of the party centre is known: local politicians are both assets and threats to the party (Navarro, 2009, p. 7). Cumulants are assets by the reason of their additional staff, network, knowledge of local issues, but most importantly their local supporters. Tavits argues that "voters strive for a balance between national and local representation: voters vote for a party, i.e. for a programmatic promise, but within that party they wish to be represented by somebody who is familiar with local concerns. Thus, local politicians are an asset for a vote - and seat-maximizing party at election times"42 (Tavits, 2010, p. 230). Therefore, strategically, selectors should take candidate attributes into consideration on the nominal as well as the PR list tier. But "what serves parties well at election time may undercut their ability to pursue their programmatic policies and act coherently in parliament" (Tavits, 2010, p. 231). They impose threats because they are more likely to act independently, pursue their own goals, and have their own priorities which do not necessarily match party positions. Additionally, they tend to ask more from the parliament, namely local subsidies and special attention to local issues (Dewogheraele, Berton, and Navarro, 2008).

Additionally, local birthplace is considered a very important factor that voters take into consideration when they choose who to vote for. Local birthplace suggest that the candidate knows the constituency and is familiar with the wants and needs of the people living there ("I know what you want", (Gallagher, 1988; Shugart et al., 2005). Local political experience on the other hand, reflects that the candidate knows the ways and means of the constituency's business, which presumes a certain level of local knowledge irrespectively of the place of birth. Political experience in general could also imply that the candidate knows how the political systems works, therefore the MP is capable of effectively representing the constituency on the national level as well (" $I$ know how to get it”, (Putnam, 1976; Shugart et al., 2005; Tavits, 2010).

Table 2.7 shows the proportion of representatives with local political background in Hungary. The data covers information only on the MPs' local political background before their first terms as national MPs ${ }^{43}$. The percentage of members with previous

\footnotetext{
42 Tavits does not only write about cumulants, but all candidate with PVEA.

${ }^{43}$ Local positions obtained after the first election are not taken into account. However, later in the analysis, actual local positions will be accounted for.
} 
local political experience continuously increases among SMD representatives: while in $199435.7 \%$ of nominal tier representatives served in one of the three local positions ${ }^{44}$, this proportion is $77.1 \%$ in 2010 . In general, the proportion of MPs with local political background shows a steady increase within the Hungarian Parliament. In 2010 almost $63 \%$ of the representatives have held local positions before, that is more than 37 \%points higher than the proportion in 1994, indicating that local political experience has become more important throughout the years.

TABLE 2.7. The proportion of MPs with previous local political background

\begin{tabular}{ccccc}
\hline Election year & SMD & Regional list & National list & Total \\
\hline 1990 & n.a. ${ }^{\text {I }}$ & n.a. ${ }^{\text {I }}$ & n.a. ${ }^{\text {I }}$ & n.a. $^{\text {I }}$ \\
1994 & $35.7(63)$ & $24.6(33)$ & $7.6(7)$ & $25.6(103)$ \\
1998 & $50(90)$ & $51.8(69)$ & $27.3(23)$ & $45.8(182)$ \\
2002 & $57.8(103)$ & $65.3(100)$ & $38.2(32)$ & $56.8(234)$ \\
2006 & $57.4(104)$ & $63.9(101)$ & $36.7(25)$ & $56.5(230)$ \\
2010 & $77.1(138)$ & $56.1(87)$ & $38.8(26)$ & $62.6(251)$ \\
\hline Average & 55.6 & 52.3 & 29.7 & \\
\hline
\end{tabular}

Source: Hungarian Representatives Dataset (Centre for Elite Research, CUB)

Entries are percentages, case numbers in parentheses.

Local political background in this context means that the given MPs held local positions before their first terms as national MPs.

${ }^{\mathrm{I}}$ Not applicable. Data covers information on local political experience only after the transition.

Table 2.8 presents the extent of mandate accumulation between 1994 and $2010^{45}$. In the first term after the transition in 1989, national representatives were not permitted to hold elected local positions simultaneously. The percentage of cumulants among SMD members reached its maximum in 2010, when $65.4 \%$ also served as elected local officials. Naturally, the proportion of local office holders decreases as we move away from the local level. It is interesting, however, how large the drop was in the proportion

\footnotetext{
${ }^{44}$ Mayor, local and regional council members. On the course of the dissertation, the analyses were also carried out with a separation of the different local level positions. As handling mayors, local and regional council members separately did not alter results and conclusions substantially, I decided to merge these categories and concentrate on any local connections overlooking the qualitative differences between these positions.

${ }^{45}$ I am grateful to Réka Várnagy, who generously made available the data she collected for her doctoral dissertation. From her perspective, an MP is a multiple office holder if (s)he wins a mandate at the local elections after (s)he was elected to parliament. There are approximately four months between the two elections, thus the data does not reflect the positions the MPs held after the national and before the local elections. Later, in this dissertation, this approach will be altered, and the definition of multiple office holding be moderately changed.
} 
of locals among regional and national list members. The increasing percentage of local office holders among Members of Parliament suggests that local notability grows more and more important term after term.

TABLE 2.8. The percentage of MPs holding multiple offices

\begin{tabular}{ccccc}
\hline Election year & SMD & Regional list & National list & \multicolumn{1}{c}{ Total } \\
\hline 1990 & n.a. & n.a. ${ }^{1}$ & n.a. & n.a. ${ }^{\text {I }}$ \\
1994 & $17.6(31)$ & $20.1(27)$ & $10.9(10)$ & $16.9(68)$ \\
1998 & $42.8(77)$ & $32.3(43)$ & $14.3(12)$ & $33.2(132)$ \\
2002 & $53.9(96)$ & $60.8(93)$ & $29.6(24)$ & $51.7(213)$ \\
2006 & $54.7(99)$ & $62(98)$ & $27.9(19)$ & $53.1(216)$ \\
2010 & $65.4(117)$ & $32.9(51)$ & $7.5(5)$ & $43.1(173)$ \\
\hline Average & 46.8 & 41.6 & 18 & 39.6 \\
\hline
\end{tabular}

Source: Hungarian Representatives Dataset (Centre for Elite Research, CUB)

Entries are percentages, case numbers in parentheses.

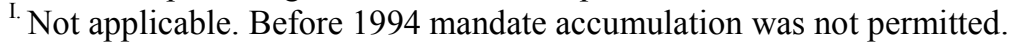

Moving further, not only type of mandate and local positions shape member connections to the local level, but previous legislative experience as well. It can be argued that MPs who have previously held nominal level mandates might focus more on the local level than those who did not hold mandates of that kind. Table 2.9 displays the frequency with which members with different types of seats held SMD mandates before the actual term.

TABLE 2.9. The proportion of members holding SMD positions during the previous terms

\begin{tabular}{ccccc}
\hline Election year & SMD & Regional list & National list & Total \\
\hline 1990 & n.a. & n.a. & n.a. & n.a. \\
1994 & $67.6(119)$ & $26.8(36)$ & $27.2(25)$ & $43.3(180)$ \\
1998 & $91.6(165)$ & $34.6(46)$ & $25(21)$ & $58.4(232)$ \\
2002 & $94.9(169)$ & $41.8(64)$ & $28.4(23)$ & $62.1(256)$ \\
2006 & $83.8(151)$ & $18.4(29)$ & $29.4(20)$ & $49.2(200)$ \\
2010 & $58.1(104)$ & $21.3(33)$ & $17.9(12)$ & $37.1(149)$ \\
\hline Average & 79.2 & 28.6 & 25.6 & 50 \\
\hline
\end{tabular}

Source: Hungarian Representatives Dataset (Centre for Elite Research, CUB)

Entries are percentages, case numbers in parentheses. Data refers to previous SMD experience in any of the preceding terms.

I. Not applicable.

The proportion of former SMD members among current ones is the lowest in 2010, where only $58 \%$ had previous nominal level experience. This suggests a considerable fluctuation among SMD MPs in comparison to the other terms. The overall percentage of former SMD members in 2010 indicates that the aggregated $1^{\text {st }}$ tier experience of the Hungarian representatives is the lowest in the current term.

There is thought to be a connection between the number of terms served and role perception. Norton and Wood explained the considerable growth of constituency service 
in Great Britain (Norton and Wood, 1990). They argue that in the 1960s Members of Parliament started to locate more and more offices into their constituencies, and divided their time more equally between Westminster and their districts. As a result they came up with intra- and inter-generational theories that give a fair explanation of the described trend. The former states that first term MPs are influenced by exactly the same factors as members of the previous generations at their first terms. In the case of the newly elected representatives, the benefits from constituency orientation are the highest in relative terms, whereas its opportunity cost is considered quite low. Consequently the costs of neglecting the service could be fairly high (Norton and Wood, 1990, p. 204).

Similarly, Fenno split incumbency into two periods. During the period of extension, MPs devote a considerable share of their time to the constituency, which gives them the opportunity to consolidate their positions in their districts (Fenno, 1978). In the protectionist phase they just have to mobilize the resources needed to maintain their supporter base. This also means that they can afford to spend less time serving the constituency and focus on national party issues or the parliament's business.

According to the inter-generational explanation, the generation in question proved to be more motivated in increasing the proportion of personal vote than the previous generation in its first term. Additionally, this motivation reached a higher level during the next terms as well (Norton and Wood, 1990, p. 208). Norton and Wood argue that this was the result of changing conditions like the increasing role of the state as well as the growing electoral demand for constituency service. Thus, the MPs who are not sensitive to this demand and do not adjust the amount of their services, find themselves in a disadvantageous situation compared to those who seek to meet the requirements of the citizens (Norton and Wood, 1990) ${ }^{46}$

\footnotetext{
${ }^{46}$ The same was found by Herrera and Yawn in the United States (Herrera and Yawn, 1999).
} 
TABLE 2.10. The proportion of newcomers in the Hungarian Parliament

\begin{tabular}{ccccc}
\hline Election year & SMD & Regional list & National list & Total \\
\hline 1990 & n.a. ${ }^{1}$ & n.a. ${ }^{1}$ & n.a. & n.a. $^{{ }^{l}}$ \\
1994 & $73.9(130)$ & $62.7(84)$ & $39.1(36)$ & $62.2(250)$ \\
1998 & $50(90)$ & $51.1(68)$ & $41.7(35)$ & $48.6(193)$ \\
2002 & $24.2(43)$ & $43.1(66)$ & $38.3(31)$ & $34(140)$ \\
2006 & $16(29)$ & $45.6(72)$ & $29.4(20)$ & $29.7(121)$ \\
2010 & $41.9(75)$ & $47.1(73)$ & $56.7(38)$ & $46.4(186)$ \\
\hline Average & 41.2 & 49.9 & 41 & 44
\end{tabular}

Source: Hungarian Representatives Dataset (Centre for Elite Research, CUB)

Entries are percentages, case numbers in parentheses.

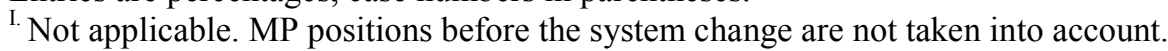

The theory of newcomers being more district-oriented however, builds on countries that have electoral systems that support district focus, namely the US and the UK, where the constituency is the only place they can collect votes. In closed list systems, party members who want to be high on the list, have to compete for the party's goodwill and not the voters' (Heitshusen et al., 2005). Additionally, as argued earlier, the candidate selection process in SMDs is utterly centralized in Hungary, meaning that the national party leadership has a great say in who gets to be running for the seat. Under such circumstances, a more viable strategy for newcomers would be to emphasize their commitment to the party to get as high on the party list as possible. Hence, newcomers are expected to be less oriented toward their constituencies than senior members. As the analysis is conducted on cross-sectional datasets, only the intra-generational aspects are taken into account.

Table 2.10 demonstrates that up until the elections in 2010, candidates with pervious legislative experience were elected with an increasing proportion. Thus, one could argue that professionalization of legislators showed an intensifying tendency (Ilonszki and Kurtán, 2008, 2011; Ilonszki, 2000). In 2010, however, a sudden jump in the percentage of newcomers is detectable. Two explanations seem viable. First, with the emergence of new parties (Jobbik and LMP), who purposefully tried to distance themselves from the ruling political elite, not only in their political messages but their recruitment base, new faces appeared in the legislature. $91.7 \%$ of Jobbik members came from outside the parliament, and $94.4 \%$ of LMP MPs had never served as national representatives before. Second, Fidesz-KDNP won more than the $2 / 3$ of the mandates, which - based on their previous results - is substantially more than they were equipped to fill in with experienced politicians. $42.8 \%$ of Fidesz-KDNP members were newcomers, while this proportion was $11.7 \%$ among the Socialists. 
As to the national level positions, when discussing representational roles we cannot ignore the role of the party. Wahlke and colleagues (Wahlke et al., 1962) argue that the parties play an important socializing role in the process of the development of role perceptions. In the competition for higher party offices MPs - unintentionally - acquire the attitudes of a party delegate. This is the reason why MPs who served in high ranking party positions tend to consider the party as the focus of representation (Zittel, 2012) instead of the constituency. The other reason of the MPS in national positions to be less district-centred is more practical, and is connected to the scarce resources at the MPs' disposal. Time is one of the most important factors in shaping representational roles. Members who fill in higher national positions will have less time to engage in other activities. As they recognize this, their focus of representation will be adjusted accordingly.

TABLE 2.11. The proportion of party leaders

\begin{tabular}{ccccc}
\hline Election year & SMD & Regional list & National list & Total \\
\hline 1990 & $2.8(5)$ & $9.6(13)$ & $6.1(6)$ & $5.8(24)$ \\
1994 & $8(14)$ & $20(27)$ & $35.9(33)$ & $18.4(74)$ \\
1998 & $19.4(35)$ & $22.6(30)$ & $33.3(28)$ & $23.4(93)$ \\
2002 & $29.2(52)$ & $37.9(58)$ & $40.7(33)$ & $34.7(143)$ \\
2006 & $23.2(42)$ & $26.6(42)$ & $41.2(28)$ & $27.5(112)$ \\
2010 & $28.1(50)$ & $39.4(61)$ & $40.9(27)$ & $34.6(138)$ \\
\hline Average & 11.9 & 26 & 33 & 24.1 \\
\hline
\end{tabular}

Source: Hungarian Representatives Dataset (Centre for Elite Research, CUB)

Entries are percentages, case numbers in parentheses. Data contains national and regional party leaders.

Table 2.11 shows the changes in the proportion of party leaders among Members of Parliament holding different kinds of seats. The role of party leaders in parliament reflects a strengthening tendency between 1990 and 2002. From 2002 on it fluctuates at a relatively high percentage which gives away the spoil-like nature of legislative positions.

On the course of the analysis, perceived ideological distance will serve as an independent variable in estimating representational roles, campaign strategies and parliamentary behaviour. The idea comes from Zittel and Gschwend, who explain campaign strategies with the ideological proximity of the individual MPs to their parties (Zittel and Gschwend, 2008). As this indicator relies on attitudinal measures, data covering all terms are not available. In 2010, respondents were asked to place themselves and their parties on a scale from 1 to 11 , where 1 denotes "right" and 11 stands for "left". Ideological distance is defined as the absolute value of the difference between these two. It is expected that larger differences between the perceived positions 
of the legislators and parties produce larger incentives to pursue personalistic goals. Personal representation might be one form of expressing the lack of agreement between the member and the party. In other words, the MPs' goal of putting a certain distance between the person and the party in the eyes of the public might be rooted in the perceived disagreement with the party centre. Table 2.12 shows the mean values of this newly obtained variable under the different types of mandates and within the various parties.

TABLE 2.12. The average values of the absolute difference between the placement of the members and the party on a left-right scale under different mandate types and parties

\begin{tabular}{lccc}
\hline Mandate type & Mean & $\mathrm{N}$ & Std.deviation \\
\hline SMD member & .8393 & 101 & 1.16688 \\
Regional list member & .6101 & 83 & .93784 \\
National list member & 1.0634 & 38 & 1.02603 \\
\hline F & $2.547^{*}$ & & \\
\hline Party & & & \\
\hline Fidesz & .7014 & 133 & .97504 \\
Jobbik & .5349 & 25 & .90376 \\
KDNP & .8751 & 22 & 1.45742 \\
LMP & 1.0000 & 10 & .00000 \\
MSZP & 1.2269 & 33 & 1.30416 \\
\hline F & $2.148^{*}$ & & \\
\hline Total & .7918 & 222 & 1.07013 \\
\hline Source of the & &
\end{tabular}

Source of the data: Hungarian Election Study 2010

$* \mathrm{p}<.1, * * \mathrm{p}<.05, * * * \mathrm{p}<.01$

As to the connection of ideological distance and mandate type, we find no significant differences between SMD, regional and national list members. Regarding the sample, however, it is worth pointing out that the relationship is not "linear" in a sense that the farther away we move from the nominal level, the smaller the distance of MPs from their parties. The logic does not work vice versa either. One could argue that SMD members should naturally be closer to the party, by the reason of the party leaders' reluctance to nominate less loyal members to the most individualized positions. Oddly, however, the average distance from the party is largest in the case of national list members, whereas SMD representative take the middle ground. As for party affiliation, there are no significant differences between members of the different parties either. Jobbik appears to be the most cohesive PPG in the sample, which is hardly a surprise in a case of a radical party. Politicians of such parties must identify to a greater extent, than members of more moderate organizations. The most heterogeneous PPG is the one of the Socialists', probably due to the unprecedented unpopularity of the party. It might 
be a type of cognitive dissonance reduction on the MPs' side to place themselves further on the left-right scale to demonstrate their relative independence from the party centre.

\subsection{The different types of explanations}

The effects of the above independent variables can be differentiated upon with regards to the type of explanation they offer. I distinguish between three types of frameworks: (i) electoral, (ii) position related and (iii) habitual motivations. Often, it becomes difficult to match the IVs and explanations. For instance, the effect of mandate type might very well incorporate the influence that previous legislative experience has on personal representation and constituency focus. This way, by the simple reason of overlapping variables, the distinction between this arguably position related measure (type of mandate) and former positions that indicate the role of habits gets blurred. Therefore, the effects associated with the different independent factors will be perceived in a multivariate setting. Controlling for overlapping factors enable us to account for the net effect of the given explanatory variable. In the following, these net effects are linked to the various types of explanations. Table 2.13 shows the contexts in which the variables will be evaluated. Chapters 3 and 5 apply similar approaches, while slight modifications were necessary in the case of Chapter 4 . The reason for this lies in the different temporality of the various chapters. Whereas Chapters 3 and 5 investigate member attitudes and behaviour during the term 2010-2014, Chapter 4 explains the differences in campaign strategies in 2010. Thus, Chapter 4 describes something that took place prior to the elections, which changes the interpretation of the variables.

First, electoral motivations can directly be connected to electoral goals. These factors resemble the starting point of Mayhew, namely that representatives are "single-minded seekers of re-election" (Mayhew, 1974, p. 16). In this context, members pursue personalistic goals because it serves their interests in being (re-)elected. In the literature, candidacy in SMD appears as a part of the shadowing hypothesis, theorizing that list members work as shadows of SMD representatives in the corresponding constituencies trying to retain their chances at the next elections (Ingall and Crisp, 2001; Kumbhat and Marcian, 1976; Norris et al., 1992; Norris, 2004; Soroka et al., 2009; Zittel, 2012). In this sense, candidacy at the 2010 elections proxies intentions at the next. From another aspect - which also appears in the scholarly debate - the effect of candidacy bears habitual layers as well, as it ensures the representation of those who did not vote for the winning party (Lundberg, 2006). Obviously, Chapter 4 can only incorporate the former 
framework, because representation is not investigated per se, but the appearance of personalization in campaign strategies.

Not only candidacy at the general elections can affect the incentives to local representation, but candidacy at the local elections as well. As in a multivariate setting, local political positions will be controlled for, local candidacy poses pure electoral effects. Working for the constituency, or ensuring ones local visibility might prove beneficial in the competition for the local positions. Thus, electoral explanations might not only cover national electoral goals, but local ones as well.

TABLE 2.13. The different types of explanations associated with the independent variables

\begin{tabular}{|c|c|c|c|c|}
\hline & & Chapter 3 & Chapter 4 & Chapter 5 \\
\hline Mandate type & & position & - & position \\
\hline District magnitude & & position & - & position \\
\hline Candidacy & & electoral/habitual & electoral & electoral/habitual \\
\hline Local political positions & & position & position & position \\
\hline Local candidacy & & electoral & electoral & electoral \\
\hline SMD career & $\begin{array}{l}2006-2010 \\
\text { before } 2006\end{array}$ & $\begin{array}{l}\text { habitual } \\
\text { habitual }\end{array}$ & $\begin{array}{l}\text { position } \\
\text { habitual }\end{array}$ & $\begin{array}{l}\text { habitual } \\
\text { habitual }\end{array}$ \\
\hline Newcomer & & position & position & position \\
\hline Party leader & & position/habitual & position/habitual & position/habitual \\
\hline Ideological distance & & habitual & habitual & habitual \\
\hline Party & & position & position & position \\
\hline
\end{tabular}

Variables are understood as the characteristics of Members of Parliament during the electoral term of 2010-2014. For the sake of simplicity, member characteristics are measured the same way in Chapter 4, only with slight modification in their interpretation.

Position related explanations are based on the role theories of Searing (1994) and Strøm (1997), who both incorporate institutional (Strøm) and position (Searing) effects into their approaches ${ }^{47}$. The main idea here is that representatives are bounded by their positions, and manoeuvre within the institutional frames there were placed into. On these ground, several independent factors are regarded to be position related. However, drawing the line between positions and habitual incentives are problematic on some occasions. Nevertheless, in most cases I take direct positions, while in other instances room is left for alternative explanations.

Mandate type under multivariate settings is clearly positions related, because it defines the job differently in the cases of SMD and list members. Nominal level MPs are "obliged" to engage into a more constituency-oriented work, which is expected of them by the voters and under party-centred electoral rules, by the party centre. In Chapter 4, type of mandate in the 2010-2014 electoral term has no meaning, as it

\footnotetext{
${ }^{47}$ Chapter 3 will elaborate further on these theories.
} 
focuses on a period when type was not yet a characteristic of the individual representatives. Therefore, in that Chapter former SMD experience (between 2006 and 2010) stands for mandate type, differentiating only between nominal level and list members.

Furthermore, local political positions are also classified as a representative of the position related motivations. Multiple office-holders are more inclined to personalize politics and practice a more constituency-oriented type of representation, and these incentives are largely tied to their positions as local office holders. The same applies to newcomers, who are hypothesized to have different incentives to personalize than senior members. As argued in the previous section, newcomers are expected to be less inclined to pursue personal representation, as first their need to demonstrate their loyalty towards the party centre. This connection only holds because of their newcomer status, making the effect of seniority primarily position related.

The case of party leaders is a slightly more complex as the IVs discussed above. First, it can be argued that they act less constituency-oriented because they have limited time to account for both party and constituency business. Furthermore, their most important task is to further the party's interests, define the party's goals and work out strategies. Even if the overall party strategy encourages personal representation, due to their positions, party leaders themselves will not be able to meet both incentives. Second, as Wahlke at al. and Zittel argue (Eulau et al., 1959; Zittel, 2012) climbing up the party ladder has undeniable socializational effects that make politicians more partycentred in their habits. In this sense, the effect of being a party leader might also be more than just a mere alignment to the position. Deeper - and involuntary - motivations can play a role in party leaders being more party-centred than backbench members. Unfortunately, the difference between the two types of explanations cannot be uncovered using the data at hand. Effects will be associated to party leadership as a positional factor in estimating member attitudes, strategies and behaviour.

The effect of party leadership has already brought us to habitual motivations. Among the independent variables listed by Table 2.13, two factors bear incentives that are clearly habitual. First, previous SMD career is connected to neither electoral goals nor to currently held political positions. Experiences of the past influence attitudes and behaviour in the present through mechanisms of socialization. Personal representation might be some kind of routine MPs picked up during their years as nominal level representatives, which newly obtained positions were not able to neutralize. Second, 
perceived ideological distance from the party generates effects that are beyond rational incentives. Greater distance pushes members away from their parties and makes them engage in different kinds of representations. Its effect, again, cannot be the manifestation of electoral goals or positions, but only to less cognitive processes. It is clear that habitual motivations form some kind of residual category within possible explanations. As they come from within, habits cannot be influenced by the party centre as in the case of incentives related to elections or political positions. 


\section{CHAPTER 3 - THE HUNGARIAN REPRESENTATIVES' ROLE PERCEPTIONS}

A considerable part of the representation literature discusses representational roles. These theories rely not only on norms and the formal and informal institutions shaping them but they aim to synthesize the institutionalist and behaviouralist traditions (Zittel, 2012). The main goal is to identify norms and see how they appear in actual behaviour. Role perceptions evolve around two broad ideas: the focus and the style of representation. Focus refers to whose interest legislators represent, while style indicates the manner in which they are represented (Bengtsson and Wass, 2011; Wessels, 2007). According to Eulau et al. these two conceptions should be treated separately, since style does not depend on the different interests representatives pursue (Eulau et al., 1959). Nevertheless, empirically they are hardly separable.

In their seminal work The Legislative System: Explorations in Legislative Behavior, Wahlke et al. define role orientation as "systematic differences in legislators" conception of a particular component of the role of legislator" (Wahlke et al., 1962, p. 16). They also emphasize the importance of the structure in the social demand in developing representational roles (Wahlke et al., 1962). As the representational functions of the parliament and democratic elections directly affect the structure of demand, roles are perceived to be indirect consequences of these. Wahlke and his colleagues distinguish three main role types. While delegates are bound by the instructions of their constituents, Burkean trustees have considerable freedom in deciding what measures serve the interests of the voters. In the case of the politico these two roles are combined in a way that depends on the issue in question. The dominance of one rule or the other depends on the complexity of the demand: the more complex it is, the more likely that MPs indentify with the role of the trustee (Wahlke et al., 1962). Since these roles differ in the manner in which citizens are represented, they grasp the idea of the style of representation.

Searing's main objection to the above categorization is that it is not based on the perceptions and motivations of the MPs, but it is forced upon the representatives by scholars. Consequently, they are abstract ideas that have little to do with reality. In his view, this could be the reason for the lack of correspondence between representational roles and MPs' behaviour in the literature (Searing, 1994). In his work, Westminster's World he stretches the framework of rational choice theory and splits the roles into two 
groups. Position roles - as the name suggests - are strongly tied to the positions of the MPs within the institutional framework. Therefore, institutions unequivocally define roles. Preference roles, on the other hand, are shaped by individual preferences. Institutions in this context connect the ideas and preferences to reality or restrict their realization, but leave the ambitions mainly unchanged. Position roles are often tied to frontbench positions, while preference roles usually relate to backbenchers. In Searing's view, representational roles are the combinations of the institutional framework and individual preferences and the balance of these two changes from role to role. $\mathrm{He}$ distinguishes four basic role types: (i) constituency members, (ii) parliament men, (iii) ministerial aspirants and (iv) policy advocates. The main goal of policy advocates is to influence government policies ${ }^{48}$. Ministerial aspirants consider parliament as merely a springboard to ministerial positions, and structure their behaviour for the sake of future ministerial appointments. Constituency members focus on their constituencies, aught it be defined (either collectively or individually). Finally, parliament men's main priority is to manage the business of the legislature (Saalfeld and Müller, 1997, p. 10).

Whereas Searing emphasises the role of individual motivation, Strøm (1997) turns back to rational choice theory and considers representational roles as strategic decisions (Strøm, 1997). In his approach, roles are routines or strategies to reach predefined goals and are restricted by rules (institutions ${ }^{49}$ ) (Strøm, 1997, pp. 162-163). The aim of choosing strategy is to maximize the probability of reaching the main goal. In the case of representatives, the designated routine (strategy) is the distribution of scarce resources like time, media access and organizational resources. In his definition of MPs' roles, Strøm follows the footsteps of Mayhew (Mayhew, 1974) and Schlesinger (Schlesinger, 1991), who claim that the key to understanding the representatives' behaviour is to research their electoral ambitions. ${ }^{50}$ (i) Re-selection, (ii) re-election,

${ }^{48}$ The group of policy advocates consists of three types of representatives. Ideologues promote abstract ideas, generalists are interested in concrete issues without specializing too much, while specialists focus on very small policy fields (Saalfeld and Müller, 1997).

${ }^{49}$ The institutional features restricting individual action are - among others - legislative rules, the internal rules of the national and local parties as well as electoral rules, shaping political competition (Strøm, 1997, p. 158)

${ }^{50}$ Mayhew considers MPs as ,single minded seekers of re-election” and argues that re-election is a proximate goals for every representative (Mayhew, 1974, p. 16). Schlesinger (Schlesinger, 1991) goes a bit further defining three possible forms of political ambitions. Discrete ambitions 
pursuing (iii) party and (iv) legislative offices can be organized in hierarchical order due to their chronology. In order someone to be re-elected, has to be re-nominated first, thus the pursuit of re-selection precedes the aim of re-election in polities where the access to the party labels are restricted by various actors. In terms of party offices, they are easier to access from inside the parliament than from outside, therefore politicians who wish to become party officials, should pursue re-election as well. There are even party leadership positions that are bound to the parliament, e.g. PPG-leadership. Re-election is a prerequisite of obtaining legislative offices as well. These are positions to which representatives are elected by fellow parliamentarians (for instance the position of the speaker, or committee chair appointments). Strøm's theory involves that since the roles (strategies) are achievable by definition (as they are constructed by the rules), there is a strong correlation between role perceptions and actual behaviour. Therefore, by observing behaviour, we also get information on the perception of the roles. Searing's and Strøm's approach are thought to be interpreted within the idea of the focus of representation.

In this chapter, focus and style of representation are examined as MPs' attitudes toward representation. Based on a survey carried out in June 2010, the variance in the two aspects will be explained by various independent variables, first in a bivariate, then in a multivariate setting.

\subsection{Focus of representation}

Empirically the focus of representation is captured by the question: who is represented? The alternatives aim to cover all the possible types of constituency. Eulau and Karps distinguish between three instances: (i) geographical constituency, (ii) functional groups, and (iii) individuals (Eulau and Karps, 1977). Esaiasson adds a fourth category, namely the political party as constituency (Esaiasson, 2000). As argued earlier, in this study, the term "constituency" refers to the constituency of the geographical kind, and all the citizens within the district, therefore it is a special combination of types (i) and (ii).

relate to one particular office for one single term, in which sense we cannot talk about reelection. Static ambitions are the closest to Mayhew's re-election goal, as they represent "the pursuit of the same office for multiple terms". Progressive ambitions are aspirations to a certain office more important than the current one (Strøm, 1997, p. 159). 
TABLE 3.1. Changes in the focus of representation in the past twenty years in Hungary

\begin{tabular}{lccccc}
\hline & 1992 & 1995 & 1999 & 2007 & 2010 \\
\hline Constituency & $\%(\mathrm{~N})$ & $\%(\mathrm{~N})$ & $\%(\mathrm{~N})$ & $\%(\mathrm{~N})$ & $\%(\mathrm{~N})$ \\
Party/party voters & $34.7(34)$ & $39.8(47)$ & $37.8(28)$ & $42.1(32)$ & $43.5(100)$ \\
A specific group in the society & $24.5(24)$ & $16.1(19)$ & $24.3(18)$ & $14.5(11)$ & $13.1(30)$ \\
All the citizens of the country & $10.2(10)$ & $5.9(7)$ & $5.4(4)$ & $11.8(9)$ & $5.2(12)$ \\
\hline Total & $30.6(30)$ & $38.2(45)$ & $32.5(24)$ & $31.6(24)$ & $38.2(88)$ \\
\hline
\end{tabular}

Source: Centre for Elite Research and DKMKA Elite Research Projects 1992, 1995, 1999, InTune $2007^{51}$, Hungarian Election Study $2010^{52}$

Entries are percentages, case numbers in parentheses. All samples are representative in terms of party affiliation and type of mandate. The 1992, 1995 and 1999 questionnaire was filled in by the representatives themselves. The 2007 and 2010 data relies on face-to-face interviews.

Table 3.1 shows the changes in the focus of representation over the years after the transition. The results are quite conclusive: it seems that the place of the constituency has stabilized in the MPs' perception of their roles. While in $199234.7 \%$ of the respondents said that the focus of their jobs is the constituency, this percentage is 42.5 in 2010. Since there has been no change in the proportion of SMD and list members in the Hungarian Parliament in the past twenty years and all the samples are representative in that matter, the changing proportion of single member district representatives within the samples cannot be the cause of the increasing weight of the constituency. This means that - in their attitudes - Hungarian MPs became more and more open to interactions with the citizens regardless of what type of mandate they hold. The most plausible explanation for this drastic increase is a certain kind of learning process. The level of constituency orientation is shaped through the interactions of the MPs and the citizens. The demand for constituency service might have been bigger than the supply in the beginning, and this demand is very likely to increase in time, as voters also had to adjust to rules of democracy, and learn the possibilities it offers. In other words, constituency orientation is a result of the dynamic relationship between the representatives and the represented, which of course makes it necessary to examine the voters' ideas of representation as well. Unfortunately, as this only has become the focus of investigation very recently ${ }^{53}$, data that follows the changes in voters' preferences in

${ }^{51}$ http://www.intune.it/

${ }^{52}$ http://www.valasztaskutatas.hu/participation-and-representation

${ }^{53}$ Empirical research on the citizens' perceptions of the role of their representatives did not seem relevant in the discipline on an international level either for two reasons (Bengtsson and Wass, 2011, pp. 143-144). First, the group of citizens was considered homogeneous in terms of favouring the mandate conception of representation, making investigation unnecessary. Second, 
terms of representational roles is not available. Data from $2008^{54}$ indicates that the majority of respondents $(57.2 \% ; \mathrm{N}=1724)$ think that the constituency should be the most important for an MP to represent. This group is not homogeneous, however, as 15 $\%(\mathrm{~N}=295)$ of them $(9.8 \%$ of all respondents $)$ "restricted" representation to only those in the constituency who voted for the winning candidate ${ }^{55}$. According to $29.1 \%$ $(\mathrm{N}=877)$ every citizen in the country should be represented by all of the representatives, and only $10.2 \%(\mathrm{~N}=307)$ think that MPs should focus on representing the voters of their own parties ${ }^{56}$. The results show that there is a considerable variation in the ways the represented think about representation in 2008 - which defies the assumption about voters being a homogeneous group in terms of their preferences regarding the focus of representation; still they regard constituency representation as the most important. It is, therefore, reasonable for the MPs to focus on the wants and needs of their constituencies in order to meet the demand that can very well be the basis of voting decisions on the voters' side.

"voters have been assumed to be incapable of forming preferences for the complex process of representation" (Bengtsson and Wass, 2011, p. 144).

${ }^{54}$ Hungarian Election Study (HES) panel from 2008. http://www.valasztaskutatas.hu/eredmenyek-en/adatbazisok/magyar-adatok; TDATA-H27 ${ }^{55}$ This phenomenon does not vary under different party preferences, hence it is not likely that those who voted for the winning candidate do think that he or she should represent only them. But due to the lack of proper data at this time, this possibility cannot be entirely omitted.

${ }^{56}$ The second wave of the HES data collection from 2009 produces very similar results with $51 \%$ of the respondents saying that an MP should represent the constituency, $31.7 \%$ chose all the citizens of the country, while $12.4 \%$ thought it would be the job of the representatives to focus on the party voters. $4.9 \%$ favoured a "certain group in the society". 


\subsubsection{Focus of representation and independent variables - bivariate relationships}

The main question of this section is what factors influence the level of constituency orientation perceived as the focus of representation. The analysis is based on the MP survey dataset of $\mathrm{HES}^{57}$ extended by the data from the Hungarian Representatives Dataset produced by the researchers of the Centre for Elite Research at the Corvinus University of Budapest, and by own collection. The dataset represents the Hungarian Parliament in terms of both type of mandate and party affiliation ${ }^{58}$.

Table 3.2 shows member attitudes toward representing the four types of constituencies under different mandate types.

TABLE 3.2. Focus of representation and mandate type

\begin{tabular}{ccccc}
\hline & Constituency & Party & $\begin{array}{c}\text { A given group in the } \\
\text { society }\end{array}$ & $\begin{array}{c}\text { All the citizens in the } \\
\text { country }\end{array}$ \\
\hline SMD & $67.6(71)$ & $2.9(3)$ & $1.9(2)$ & $27.6(29)$ \\
Regional list & $27.6(24)$ & $14.9(13)$ & $5.7(5)$ & $51.7(45)$ \\
National list & $15.4(6)$ & $35.9(14)$ & $12.8(5)$ & $35.9(14)$ \\
\hline$\chi^{2}$ & & & $64.29 * * *$ & \\
Cramer's V & & & $.373^{* * *}$ & \\
\hline
\end{tabular}

Entries are percentages; case numbers in parentheses.

The original question was formulated as follows: "Who do you represent in your work as a Member of Parliament?"

$* \mathrm{p}<.1, * * \mathrm{p}<.05, * * * \mathrm{p}<.01$

The results are not surprising: $68 \%$ of SMD representatives claimed that they represent the geographical constituency in their work as Members of Parliament, while this proportion is only 28 and $15 \%$ in the cases of regional and national level list members respectively. SMD members were quite dismissive about the party as the focus of representation as well as representing a certain group in the society. The general conception of representation does not stand far from the constituency members either, as $28 \%$ of them said, they work for every citizen of the country. As to regional list MPs, the absolute majority (52\%) represents the whole country, which is quite controversial, since their mandates are tied to the local level, where "local" might be understood as the county. $28 \%$ would work for the constituency, while only $15 \%$ chose the party as focus. The results in the group of national representatives support the intuition: $36-36 \%$ focus on the party and the whole country in their work. The $15 \%$ of

\footnotetext{
${ }^{57} \mathrm{http} / / / \mathrm{www} . v a l a s z t a s k u t a t a s . h u /$ eredmenyek-en/adatbazisok/magyar-adatok; TDATA-H46.

${ }^{58}$ Weights are based on own calculations.
} 
the $3^{\text {rd }}$ level representatives, who said that they work for the constituency defined in a geographical sense, is a surprising result.

In general, the desire to represent the constituency and the country as a whole is widespread among Members of Parliament, which cannot be said about "specific groups" in the society that are way underrepresented within members' responses. Party representation also prevails, especially among list members. Studying the results presented in Table 3.2, two questions arise. First, why is party representation this neglected by district members, especially as party centre is in control of nominal level nominations? Assuming that representatives are rational players, and "single minded seekers of re-election" (Mayhew, 1974, p. 16), their first goal is re-nomination, which is in the hands of the parties. Therefore, the winning strategy would be to act in the party's favour. Generally this would be representing the party's interests. The fact that this is not the case, points to the possibility that something else is expected of them by the party centre or constituency focus does not defy party interests. Constituency representation is the most common tool of personal vote-seeking: members furthering the interests of their constituencies directly are expected to receive votes, which are not attributed to the party label they compete under. These extra votes help them re-elected on the one hand, and if not, they utilize as party votes on the $3^{\text {rd }}$ tier of the electoral system on the other. Therefore, constituency representation becomes party interest as long as it does not endanger party unity in parliament. The second arising question addresses a quite similar issue, namely why is constituency representation this widespread among members who were elected on party lists. Their electoral fate is tied to the party more closely than in the case of nominal level MPs, not only because of renomination is decided by the party centre, but because voters are not able to change their placement on the party lists, making personalization a less effective re-election strategy as it is on the nominal level. This argument applies if the members aim to be elected into the same positions they hold in the current term. However, in case they nurture progressive ambitions (Strøm, 1997), additional strategies might offer better outcomes. In the context of this dissertation, a list member wanting to be elected on the nominal level is considered progressive.

The best way to control for this factor is to take the level of the next candidacy into account. Sadly, at the time of the data collection (June 2010), information on candidacies at the 2014 general elections was not available either for the researcher or for the MPs themselves. A viable proxy may be candidacy at the 2010 elections. 
Evidence from previous terms suggests that - not counting retiring members - a substantial proportion of former SMD candidates are re-nominated at the $1^{\text {st }}$ tier. In each electoral term, more than $80 \%$ of representatives who were running for SMD mandates were re-selected to compete for the same positions at the next elections (see Appendix 3.1). With regards to the relative stability of these values, it is safe to assume that candidacy in 2010 will represent the intentions of members to run, and the parties to reselect MPs at the 2014 general elections rather well. Table 3.3 shows the connection between the focus of representation and nominal level candidacy.

TABLE 3.3. Focus of representation and candidacy on the nominal level in 2010

\begin{tabular}{ccccc}
\hline & Constituency & Party & $\begin{array}{c}\text { A given group in the } \\
\text { society }\end{array}$ & $\begin{array}{c}\text { All the citizens in the } \\
\text { country }\end{array}$ \\
\hline $\begin{array}{c}\text { Not an SMD } \\
\text { candidate }\end{array}$ & $23.4(15)$ & $\begin{array}{c}18.8 \\
(12)\end{array}$ & $7.8(5)$ & $50(32)$ \\
SMD candidate & $51.2(86)$ & $\begin{array}{c}11.3 \\
(19)\end{array}$ & $4.2(7)$ & $33.3(56)$ \\
\hline $\begin{array}{c}\chi^{2} \\
\text { Cramer's V }\end{array}$ & & $14.7^{* * * *}$ & \\
\hline
\end{tabular}

Entries are percentages; case numbers in parentheses.

The original question was formulated as follows: "Who do you represent in your work as a Member of Parliament?"

$* \mathrm{p}<.1, * * \mathrm{p}<.05, * * * \mathrm{p}<.01$

The relationship is straightforward: the absolute majority of constituency level nominees would concentrate on the district, while half of the MPs not selected represent the whole citizenry instead. Interestingly, $23 \%$ of them work for the constituency, although not nominated in any of the 176 SMDs. This result, however, is blurred by the fact that the group of local level nominees include those elected in these constituencies. Appendix 3.2 presents the same relationship, only without SMD representatives, so that the unbiased effect of candidacy can be accounted for. The connection is far from evident in the case of list members: constituency and list candidates hold the representation of the constituency equally important (24 and $23 \%$ ).

Theory suggests that list members are not homogeneous in term of focus of representation. This assumption was already exploited with the preceding analysis, where the tier of candidacy was added to the difference between SMD and list MPs to colour the picture. In the following, district magnitude will be taken into account. As the mandate type and magnitude are more or less the same, its effects have to be analyzed in the proper sentence. Calculated irrespective of mandate type, the relationship 
between district magnitude and constituency focus is significant and firm ${ }^{59}$. However, as we already know that SMD members are more constituency oriented than list ones, the added value of district magnitude is based on its effect among the latter. With respect to party list representatives, the connection between the two variables is weak but significant ${ }^{60}$ : constituency orientation gets more likely when the number of seats available is lower. Nevertheless this difference between the various groups disappears when further narrowing the group of investigation. Taking only regional list members into account, we find no evidence of magnitude having any effect on the focus of representation $^{61}$. This result is considered the most credible, since true variation of the number of available seats appears in the case of $2^{\text {nd }}$ tier representatives. All of the previous steps contained cases, where the effect of mandate type could not be properly isolated. First, the effect of magnitude could be associated with holding nominal level mandates, and second, it captured the difference between regional and national list MPs.

Moving further to career factors, Table 3.4 shows the relationship between multiple office holding and representational focus. I define cumulants as national representatives holding elected local positions precisely at the time of the data collection. This approach is slightly different from what is applied by Várnagy (Várnagy, 2012), who regards MPs who were elected to local positions during the Fall of 2010 as cumulants. The latter definition served the purposes of her work rather well, however, this makes matching local political background to representational attitudes difficult in my case, simply because of the distinct temporal relevance. Mayors, local and county council members are considered local politicians.

\footnotetext{
${ }^{59} \mathrm{~F}=15.8^{* * *}, \mathrm{Eta}^{2}=.174$

${ }^{60} \mathrm{~F}=3.04 * *, \mathrm{Eta}^{2}=.07$

${ }^{61} \mathrm{~F}=1.35, \mathrm{Eta}^{2}=.047$
} 
TABLE 3.4. Focus of representation and local political background

\begin{tabular}{ccccc}
\hline & Constituency & Party & $\begin{array}{c}\text { A given group in the } \\
\text { society }\end{array}$ & $\begin{array}{c}\text { All the citizens in the } \\
\text { country }\end{array}$ \\
\hline $\begin{array}{c}\text { Single office holder } \\
\text { Multiple office } \\
\text { holder }\end{array}$ & $28.7(27)$ & $\begin{array}{c}21.3 \\
(20)\end{array}$ & $9.6(9)$ & $40.4(38)$ \\
$\begin{array}{c}\chi^{2} \\
\text { Cramer's V }\end{array}$ & $54.1(73)$ & $7.4(10)$ & $2.2(3)$ & $36.3(49)$ \\
\hline
\end{tabular}

Entries are percentages; case numbers in parentheses.

The original question was formulated as follows: "Who do you represent in your work as a Member of Parliament?"

$* \mathrm{p}<.1, * * \mathrm{p}<.05, * * * \mathrm{p}<.01$

Results presented in Table 3.4 support intuition: multiple office holders are more constituency-oriented than their colleagues, and additionally, they lag behind the others in terms of representing the other three forms of constituencies. The origin of the hypothesised effect of mandate accumulation is twofold. First, by the reason of their local attachment, they are naturally more concerned by issues related to the local area. Second, as they function in two or more offices within the same working hours, they do not have the opportunity to compartmentalize. Therefore, the politician as Member of Parliament and as local office holder will not be separated: the local politician appears in parliament, and the national representative does on the local level.

After the connection of local political background was established, one could raise the question, whether the effect of local roots can be captured differently. Previous legislative experience on the nominal level might create attachments to the local level that would have not been brought into life otherwise. Additionally, there may be differences in terms of how vivid nominal level experiences are. MPs who have just held SMD mandates are expected to care more about representing the constituency, than either those who filled in the position before, or have never had any experience on the nominal level. Analogically, a significant difference is expected between the latter two: MPs holding SMD mandates sometime in the past will be more district-oriented. 
TABLE 3.5. Focus of representation and MPs' careers in single member districts

\begin{tabular}{ccccc}
\hline & Constituency & Party & $\begin{array}{c}\text { A given group in the } \\
\text { society }\end{array}$ & $\begin{array}{c}\text { All the citizens in the } \\
\text { country }\end{array}$ \\
\hline No SMD career & $40.3(71)$ & $13.6(24)$ & $5.1(9)$ & $40.9(72)$ \\
SMD MP in 2006 & $57.1(24)$ & $9.5(4)$ & $2.4(1)$ & $31(13)$ \\
SMD MP before & $41.7(5)$ & $16.7(2)$ & $16.7(2)$ & $25(3)$ \\
2006 & & 7.9 & \\
\hline$\chi^{2}$ & & .131 & \\
Cramer's V & & &
\end{tabular}

Entries are percentages; case numbers in parentheses.

The original question was formulated as follows: "Who do you represent in your work as a Member of Parliament?"

${ }^{*} \mathrm{p}<.1, * * \mathrm{p}<.05, * * * \mathrm{p}<.01$

Table 3.5 presents the distribution of representational focus under the different categories of constituency experience. Although, the data does not reveal significant differences between the three groups with regards to focus of representation, a few notions have to be highlighted. First, nominal level MPs during the previous term outweigh their colleagues in terms of the importance of representing the constituency: more than $57 \%$ of them claimed the constituency to be the centre of their concern, while this proportion is under $42 \%$ in the other two groups. Second, the opposite tendency prevails in the case of partisan focus. Former incumbents hold furthering the party's interests important to a smaller extent than members whose nominal level experience faded away or never actually existed. Only, these connections do not seem to hold for the whole population of Hungarian MPs.

Moving further, seniority seems to be an important factor in explaining focus of representation. Newcomers are much less willing to represent the interests of the local area: $36 \%$ of them chose constituency, while more than the half of senior members underlined the significance of the district in their work as MPs. This finding might appear counterintuitive within the framework of Norton and Wood's intra-generational approach, but oddly, under party-centred electoral rules it is not. As it is known, Norton and Wood argued that newcomers are more district centred because they lack the level of local embeddedness that could certainly ensure re-election (Norton and Wood, 1990). More experienced members have a more solid base of supporters; hence they have nothing more to do, than maintaining the voting base within their constituencies, whereas new MPs must make a greater effort to widen their local support. In Hungary, where a fairly exclusive group of gate-keepers decide who gets to be nominated, and thus eventually elected, this logic does not explain the connection between seniority and 
constituency focus. New members have to prove their loyalty first under legislative circumstances. Once they had done so, MPs can start to concentrate on furthering local interests. During the first period, newcomers have to stand in line with the party, demonstrate that they will not dissent at roll-calls and will not undermine party authority regarding issues of special importance for the party. Only after this can the party leadership be certain about that members with a strong constituency focus will not endanger party unity. Under such circumstances, district oriented members serve as important resources for the party at Election Day.

TABLE 3.6. Focus of representation and seniority

\begin{tabular}{ccccc}
\hline & Constituency & Party & $\begin{array}{c}\text { A given group in the } \\
\text { society }\end{array}$ & $\begin{array}{c}\text { All the citizens in the } \\
\text { country }\end{array}$ \\
\hline Senior members & $50.4(59)$ & $12.8(15)$ & $6.8(8)$ & $29.9(35)$ \\
Newcomers & $36(41)$ & $14(16)$ & $3.5(4)$ & $46.5(53)$ \\
\hline$\chi^{2}$ & & & $8.25^{* *}$ & \\
Cramer's V & & & $.189^{* *}$ & \\
\hline
\end{tabular}

Entries are percentages; case numbers in parentheses.

The original question was formulated as follows: "Who do you represent in your work as a Member of Parliament?"

$* \mathrm{p}<.1, * * \mathrm{p}<.05, * * * \mathrm{p}<.01$

The results in Table 3.6 partly confirm this argument. As pointed out earlier, constituency representation prevails to be more profound in the case of senior members. On the other hand, it is not party promotion where newcomer MPs put efforts into, but a rather general conception of representation. $46.5 \%$ of them claim to represent all the citizens in the country, while $29.9 \%$ of senior members are concerned about the interests of the citizenry as a whole. The representation of the party is almost equally important in relative terms within the two groups of MPs. These results are most probably not the consequences of the newcomers' characteristics along mandate type and local political background. Taking the interaction of these variables into account, the opposite tendencies should manifest in the attitudes of junior MPs. Although senior members still dominate the nominal level, a considerable part of newcomers was elected in single member districts (41.2\%). Hence, the effect of mandate type should not cause the difference between newcomers and the more experienced. The same reasoning holds to the case of local political background: $61 \%$ of the newcomers serve as local officials, which is a larger part of the group of junior members than the proportion of local politicians among senior MPs (56.8\%). 
Table 3.7 shows the distribution of focus among backbench MPs and party leaders ${ }^{62}$. Constituency representation appears more prominently in the case of "ordinary" Members of Parliament: more than the half of them claims to represent their districts. This aspect is less dominant among party leaders, compared to a more general conception of representation (i.e. representing all the citizens in the country). Data suggests that the difference between these two groups also applies to the whole population.

TABLE 3.7. Focus of representation and party leadership

\begin{tabular}{ccccc}
\hline & Constituency & Party & $\begin{array}{c}\text { A given group in the } \\
\text { society }\end{array}$ & $\begin{array}{c}\text { All the citizens in the } \\
\text { country }\end{array}$ \\
\hline Backbench & $50.3(74)$ & $10.9(16)$ & $4.8(7)$ & $34(50)$ \\
Party leader & $31.3(26)$ & $16.9(14)$ & $6(5)$ & $45.8(38)$ \\
\hline$\chi^{2}$ & & & $7.95^{* *}$ & \\
Cramer's V & & & $.186^{* *}$ & \\
\hline
\end{tabular}

Entries are percentages; case numbers in parentheses.

The original question was formulated as follows: "Who do you represent in your work as a Member of Parliament?"

$* \mathrm{p}<.1, * * \mathrm{p}<.05, * * * \mathrm{p}<.01$

Naturally, party leaders favour party interests to a greater extent (16.9\%) than MPs of the other group (10.9\%). Nevertheless, the main difference does not appear along these lines, but - as pointed out earlier - with regards to constituency representation and furthering the interests of the citizenry as a whole. It has been shown that the same tendencies appear in the cases of these two aspects of representation in terms of seniority, where the offset of constituency representation does not seem to be party representation, but representation in a more general sense. This points to a nexus beyond of what we have thought of representational focus. Constituency and party representations are often presented as two ends of a continuum (see Colomer, 2011b). If it were be true, variables with hypothesised effects on focus should highlight differences in terms of the two extremes. Instead, what we see here is that there are large

${ }^{62}$ Throughout the analysis, the label national party leader is applied to every MP who was listed on their parties' websites as members of the main executive body. The case of LMP is a little different from the other parties by the reason of its unique organizational setting. Since, they could not define the notion of party leaders in the context of their party's organization, - in line with the recommendations of several LMP-representatives - the members of „Választmány” were coded as such. 
differences in the perceived value of district interests on the one hand, and relatively small distance between the two groups in terms of party representation on the other. Thus, from a representational viewpoint, the true contrast of constituency is rather the country as a whole than the party: the real difference is between the general and more particularistic perceptions of representation. If party representation is not that distinct to constituency representation, then it is well justified to expect the latter to prevail under party-centred electoral rules not only in theory, but in practice as well.

As to perceived ideological distance between MPs and their parties, no significant connection to focus of representation was found ${ }^{63}$. By all means, members ideologically farther away from their parties are not more concerned about their constituencies than those whose ideological positions coincides with what they think of the party. In fact, within the sample, party promoters claimed to have a larger distance from the party on the ideological spectrum: while the distance of constituency oriented members from their parties is .76 (s.d.=1.003) units on average, this value amounts to .884 (s.d.=1.039) in the case of party-centred MPs. The closest to the party are MPs promoting the general concept of representation, with an average distance of .7 (s.d.=1.09) units.

\subsubsection{The determinants of representational focus}

To resolve the effects of the different independent factors on the focus of representation, multinomial logistic models ${ }^{64}$ were estimated (see Table 3.8). As to mandate type, the two list tiers seem to differ from the SMD level in terms of the effects they pose on district focus. Regional list members are less likely to focus on the constituency, but this likelihood still remains larger than in the case of national list MPs. This result is in line with the literature and the intuition claiming that constituency members are more district-oriented than their colleagues. It seems logical, that the farther we move from the local level, the smaller the probability of representatives focusing on their constituencies. This finding is hardly unexpected, nevertheless, the design of the dependent variable enables us to differentiate between alternatives not perceived as constituency oriented. Taking a closer look at the results it stands out that

${ }^{63} \mathrm{~F}=1.423$

${ }^{64}$ The Stata procedure mlogit was used to estimate the effects on the dependent variable. Observations are weighted using population weights (pweight) to ensure that data represents the population in terms of mandate type and party affiliation. 
the fact that MPs hold regional list mandates increases the chance of them focusing on the various subjects as an alternative to the constituency. Being a party representative is 16 times $^{65}$ more likely in their case than in the group of single member district representatives. The difference between these two types of mandates is even more pronounced $^{66}$ in the third category (representing a given group in the society). As to representing the country as a whole, the differences seem to fade, but remain notable: regional list MPs are 6 times $^{67}$ more in favour of the general conception of representation than their nominal level counterparts.

Similar tendencies prevail regarding the group of $3^{\text {rd }}$ tier representatives. The largest difference appears in the case of representing the party and a special group in the society. The probabilities of being classified into these categories are enormously ${ }^{68}$ larger considering national list MPs. Regarding the last category (all the citizens in the country), the gap between mandate types narrows: the difference between national list members and nominal level MPs is $10-$ fold $^{69}$, which is a considerably lower value compared to differences measured in the other categories of focus. The effect of mandate type remains strong in the following models; therefore it will not be discussed in detail throughout the analysis.

\footnotetext{
${ }^{65} \mathrm{RRR}$ (relative risk-ratio) $=16.15$ (s.e. $\left.=11.69\right)$

${ }^{66} \mathrm{RRR}=19.5$ (s.e. $=18.8$ )

${ }^{67} \mathrm{RRR}=5.8$ (s.e. $=2.73$ )

${ }^{68} \mathrm{RRR}=90.2$ (s.e. $\left.=83.2\right), \mathrm{RRR}=92.05$ (s.e. $\left.=123.54\right)$

${ }^{69} \mathrm{RRR}=10.24$ (s.e. $\left.=7.67\right)$
} 
TABLE 3.8. Results of the multinomial logistic regressions estimating the log-odds of not being constituency oriented

\begin{tabular}{|c|c|c|c|c|c|c|}
\hline & \multicolumn{3}{|c|}{ B (s.e.) } & \multicolumn{3}{|c|}{ B (s.e.) } \\
\hline & Party & $\begin{array}{l}\text { A given group in the } \\
\text { society }\end{array}$ & $\begin{array}{l}\text { All the citizens in the } \\
\text { country }\end{array}$ & Party & $\begin{array}{l}\text { A given group in the } \\
\text { society }\end{array}$ & $\begin{array}{l}\text { All the citizens in the } \\
\text { country }\end{array}$ \\
\hline Regional list MP & $2.78(.723)^{* * *}$ & $2.971(.964)^{* * *}$ & $1.767(.466)^{* * *}$ & $2.773(.759)^{* * *}$ & $2.679(.873)^{* * *}$ & $1.747(.48)^{* * *}$ \\
\hline National list MP & $4.502(.922)^{* * *}$ & $4.522(1.342)^{* * *}$ & $2.326(.746)^{* * *}$ & $4.382(.96)^{* * *}$ & $4.054(1.247)^{* * *}$ & $2.184(.782)^{* * *}$ \\
\hline Candidacy (only losing) & $-.546(.674)$ & $-.839(.9)$ & $-.561(.571)$ & $-.626(.712)$ & $-.965(.941)$ & $-.637(.602)$ \\
\hline Local political position & $-.688(.543)$ & $-1.061(.845)$ & $-.403(.365)$ & $.088(.591)$ & $.632(.895)$ & $.33(.559)$ \\
\hline Local candidacy & & & & $-1.259(.588)^{* *}$ & $-2.977(.949) * * *$ & $-1.218(.586)^{* *}$ \\
\hline $\begin{array}{l}\text { SMD MP between 2006- } \\
2010\end{array}$ & $.142(.826)$ & $-.262(1.454)$ & $.429(.546)$ & $.176(.83)$ & $-.185(1.421)$ & $.455(.555)$ \\
\hline SMD MP before 2006 & $1.982(1.008)^{* *}$ & $2.484(1.188)^{* *}$ & $.543(.832)$ & $2.414(1.1)^{* *}$ & $3.141(1.296)^{* *}$ & $.919(.93)$ \\
\hline Newcomer & $.48(.603)$ & $-.111(.722)$ & $1.022(.448)^{* *}$ & $.479(.609)$ & $-.045(.746)$ & $1.016(.442)^{* *}$ \\
\hline Ideological distance & $.119(.253)$ & $.412(.298)$ & $.04(.198)$ & $.085(.257)$ & .3590771 .28327 & $.013(.205)$ \\
\hline Party leader & $.992(.591)$ & $.415(.85)$ & $.935(.39)^{* *}$ & $1.051(.593)^{*}$ & $.485(.969)$ & $.981(.395)^{* *}$ \\
\hline Constant & $-3.511(.879)^{* * *}$ & $-4.098(1.082)^{* * *}$ & $-1.634(.536)^{* * *}$ & $-3.185(.926)^{* *}$ & $-3.415(1.221)^{* * *}$ & $-1.289(.564)^{* *}$ \\
\hline $\mathrm{N}$ & & 221 & & & 221 & \\
\hline Wald $\chi^{2}$ & & $82.93 * * *$ & & & $84.2 * * *$ & \\
\hline Pseudo $\mathrm{R}^{2}$ & & .187 & & & .209 & \\
\hline
\end{tabular}

Entries are coefficients; standard errors in parentheses. Standard errors are robust.

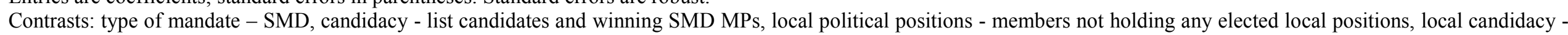

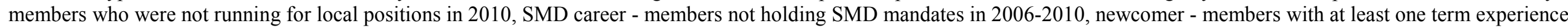
as national representatives, party leader - backbench MPs.

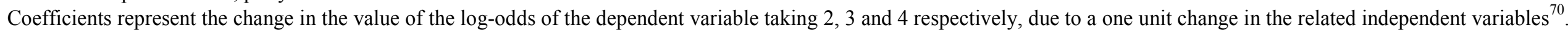
The control category is constituency orientation.

$* \mathrm{p}<.1, * * \mathrm{p}<.05, * * * \mathrm{p}<.01$

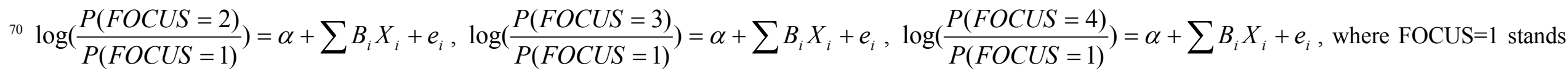
for constituency oriented MPs. 
Moving further, the purpose of candidacy is to grasp the importance of "shadowing", which arises when list members act as if they would have been elected on the nominal level. To avoid serious multicollinearity between candidacy in SMDs and actually filling in district seats ${ }^{71}$, the candidacy variable was recoded in a way that it represents SMD candidates not winning the race in single member districts. This way the close connection between being nominated and winning will be less dominant, enabling the independent variables to measure what they were designed to without too large of a bias. Evidence from Table 3.8 is far from supporting the "shadowing" hypothesis. List members who were nominated on the $1^{\text {st }}$ level of the electoral system do not care more for the district than the members without such interests. After elected, representatives probably adapt to the new situation, and incorporate their new jobs into their perceived roles. In this sense, representational roles in Hungary are not the results of some longterm process - as attitudes usually are -, but the manifestation of an electoral position. These results also indicate that candidacy is either not fit to measure prospective candidacies - as suggested earlier -, or we cannot speak of a permanent campaign appearing in members' perceptions of their roles.

Surprisingly, local political background is not significant under multivariate circumstances either. Local politicians do not seem to be more concerned about their districts, than members with no local ties. To uncover the peculiarity of this result, a few words on the local background variable are in order. MP interviews took place after the 2010 general (April), but before the 2010 local elections (October). To align to the timing of the data collection, local background was coded on the basis of the local positions filled in between the two elections in 2010. Therefore, local politicians were caught at the end of their terms as local office holders, being freshly elected to the national parliament. It is very likely that the newly obtained or fresh defended national position outweighed local responsibilities in a sense that there was no time to incorporate the latter into the former. Furthermore, it is possible that elected MPs held local positions in June 2010, but did not wish to be re-elected. Thus, representational roles might not depend on the currently held positions, but on the intentions to have continued presence on the lower levels. To unravel these possibilities, a new variable is introduced to the models, namely candidacy at the 2010 local elections. $61 \%$ of the

\footnotetext{
${ }^{71}$ SMD members have to be nominated on the nominal level, creating a serious variable overlap between mandate type and candidacy.
} 
sample-MPs were nominated for local office: $31 \%$ ambitioned to be mayors, $35 \%$ ran for local council seats, while roughly $31 \%$ were nominated to regional councils ${ }^{72}$. The usage of this variable however gives space to criticism in a sense that candidacy on the local level was not revealed at the time of the 2010 parliamentary elections. Therefore, it certainly does not give us exact measurement on long(er)-term electoral motivations. Nevertheless, it is fair to assume that at the time of the national campaign, MPs had some established ideas on whether they will be nominated to any lower level political positions. Hence, actual candidacy on the local level is considered an adequate proxy of future plans. The results displayed in Table 3.8 confirm this logic: local candidacy has indeed a significant effect on the focus of representation. The coefficients with regards to all three groups are negative, which means, that the likelihood of being constituency oriented is larger in the case of members running for local office. In terms of probabilities, the chance of being classified into the $2^{\text {nd }}$ and $3^{\text {rd }}$ categories are almost identical in the cases of local candidates and those not interested in the local competition. This means that in choosing the party and a certain social group as focus is not much influenced by the MPs status as a local candidate. However, in both cases, the likelihood of being classified as a party representative or someone who cares for a well defined social group is significantly lower than being district oriented in the case of candidates at the local elections (Table 3.8). In the last category, larger changes in the probability manifests when comparing the two groups of MPs. The slope is still negative, indicating a drop in the probability of representing the country as a whole after switching local candidacy from 0 to 1 , everything else held constant. Therefore, taking this particular independent variable into account, the offset of constituency representation does not seem to be the party, but the generalistic approach.

Moving further, SMD career was operationalized as two variables: holding an SMD position in the previous term and being a nominal level MP some time before that. The assumption behind this distinction is that members who served as SMD representatives between 2006 and 2010 probably still carry the attitudes of nominal level MPs. This however, is less certain in the case of members who have held these positions in the past: new experiences easily overwrite attitudes connected to past positions. Table 3.8 displays quite odd results in this respect. SMD positions in the previous term do not affect the odds of focusing on the different aspects of representation. Constituency

${ }^{72}$ In Hungary, multiple candidacy is permitted on the local level. 
representation is not more prevalent among representatives with fresh SMD experience than in the case of members with no nominal level experience at all. More unexpected is the positive significant effect what past SMD experience poses on the odds of representing the party. The odds of being party centred are more than 7 times $^{73}$ larger than becoming district centred in the case of members with past experience. Note, that this is all compared to MPs with no SMD careers prior to the current term. Although, in the second set of models (see Table 3.9), where the dependent variable distinguishes merely between the constituency oriented and those with different focus, this variable is not significant, its sign indicates that there is something pushing former SMD members away from the nominal level representation. This finding completely undermines habitual explanations: position effects in the past do not transform into customs in the present.

As to newcomers and party leaders, we find similar results. Holding everything else constant, both groups are more likely to consider themselves as the representatives of the whole country rather than pursuing constituency interests. As effects of other variables are also controlled for, both confirm the results of the bivariate analysis, only in a more powerful way. Interestingly, the probabilities of being party and constituency oriented are no different from each other, which adds to the richness of evidence supporting the hypothesis that members do not perceive constituency and party representation as the two ends of a continuum.

Last but not least, the perceived ideological distance is not proven to play any significant role in the way representatives think about their jobs. Members, who fall farther away from their parties in terms of ideology, are not more likely to represent the constituency, than those closer to the party. Therefore, it is safe to say, that district focus is not something that arises in connection with the rejection of the party line. This seems to be the final hit on habitual explanations: factors not connected to current positions do not influence representatives' role perceptions in Hungary.

The effect of district magnitude in a multivariate setting resembles the results of the bivariate analysis. Appendix 3.3 shows the effect of the natural log of district magnitude on the probabilities of an MP focusing on the different categories of the dependent variable. Due to the correspondence between mandate type and magnitude, only the latter was controlled for in the model. However, as pointed out earlier, these results do

${ }^{73} \mathrm{RRR}=7.25$ (s.e. $=7.31$ ) 
not represent the true effect of magnitude on constituency focus. The sharp decline in the probability of being constituency oriented under increasing magnitude is very likely to be the effect of district magnitude taking one. In other words, the effect of magnitude incorporated the effect of mandate type ${ }^{74}$. Taking only regional list members into account $^{75}$, magnitude does not seem to have any substantial influence on the dependent variable. Figure 3.1 shows how steady the probabilities of being classified into the different categories when increasing district magnitude are. Changes in the probabilities in the case of the different alternatives under increasing district magnitude are not significantly different from the changes we observe in the case of constituency orientation $^{76}$.
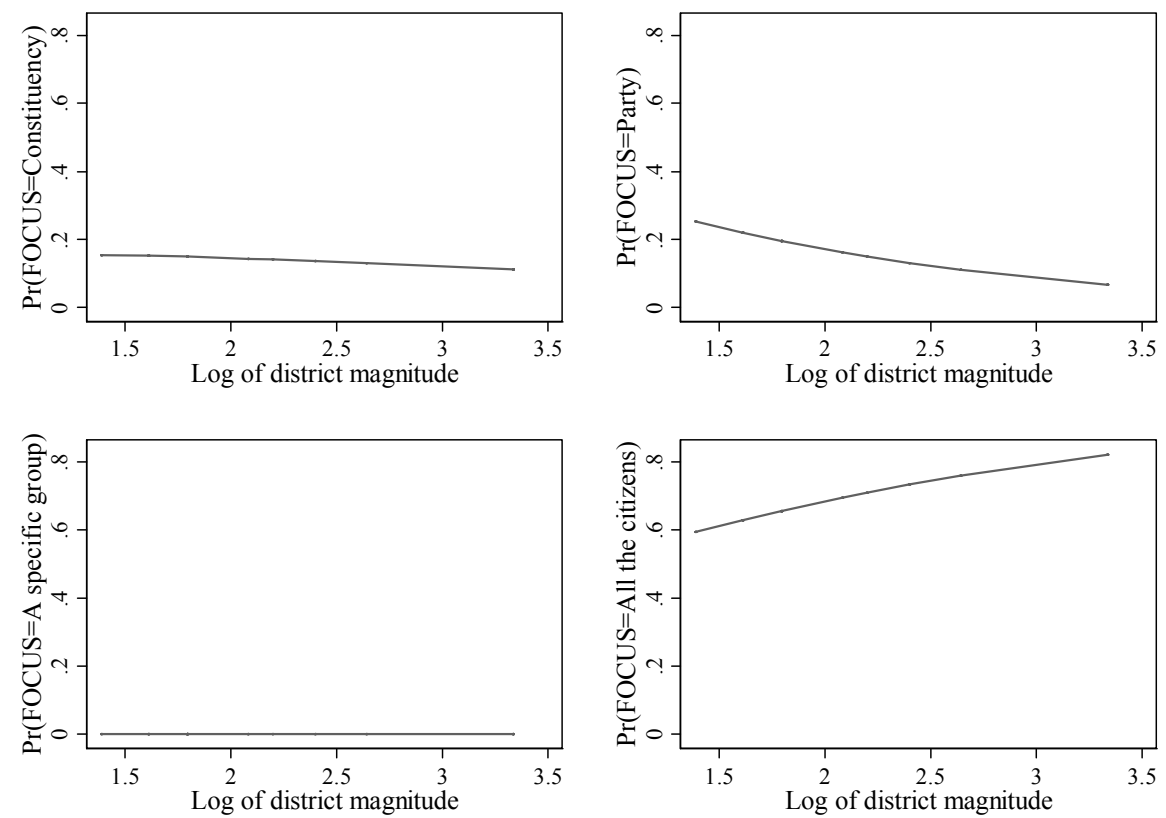

FIGURE 3.1. The effect of the natural log of district magnitude on the probabilities of an MP focusing on different subjects (regional list MPs only)

${ }^{74} \mathrm{~B}_{2}=.92(\text { s.e. }=.207)^{* * *}, \mathrm{~B}_{3}=1.17$ (s.e.=.342)***, $\mathrm{B}_{4}=.627($ s.e. $=.168) * * *$

${ }^{75}$ District magnitude is a constant (58) in the case of national list members. Counting 58 seats for the national list is a shortcut, because the actual number of seats won on the $3^{\text {rd }}$ tier is always bigger than that. Mandates not allocated on the $2^{\text {nd }}$ tier pool to the $3^{\text {rd }}$ level. Thus, 58 is the minimum number of seats distributed on the national level.

${ }^{76} \mathrm{~B}_{2}=-.33$ (s.e.=.56), $\mathrm{B}_{3}=-.86($ s.e. $=.61), \mathrm{B}_{4}=1.27($ s.e. $=1.56)$ 
Due to estimation problems ${ }^{77}$, the effect of the party could not be controlled for in the multinomial logistic models. Thus, the dependent variable was transformed so that is makes a distinction between constituency and not constituency oriented members. Table 3.9 presents the results of the binary logit models ${ }^{78}$. The control category this time is the group of MPs who are not constituency oriented, so coefficients can be interpreted as the effect of different factors on constituency orientation ${ }^{79}$. Hence, positive values indicate that the variable in question enhances the likelihood of being constituency oriented.

TABLE 3.9. Results of the binary logistic regressions estimating the log-odds of being constituency oriented

\begin{tabular}{lll}
\hline & B (s.e.) & B (s.e.) \\
\hline Regional list MP & $-1.937(.455)^{* * *}$ & $-1.906(.454)^{* * *}$ \\
National list MP & $-2.824(.718)^{* * *}$ & $-2.548(.864)^{* * *}$ \\
Candidacy (only losing) & $.647(.551)$ & $1.911(1.121)^{*}$ \\
Local political position & $-.303(.511)$ & $-.652(.529)$ \\
Local candidacy & $1.347(.54)^{* *}$ & $1.304(.544)^{* *}$ \\
SMD MP between 2006-2010 & $-.336(.517)$ & $-.344(.517)$ \\
SMD MP before 2006 & $-1.409(.818)^{*}$ & $-1.245(.819)$ \\
Newcomer & $-.852(.409)^{* *}$ & $-.439(.437)$ \\
Ideological distance & $-.054(.185)$ & $-.041(.185)$ \\
Party leader & $-.984(.382)^{* *}$ & $-.907(.383)^{* *}$ \\
Jobbik & & $-3.258(1.562)^{* *}$ \\
KDNP & & $.088(.735)$ \\
LMP & & $-15.634(1.637)^{* * *}$ \\
MSZP & & $-.819(1.175)$ \\
Constant & $.969(.511)$ & $1.021(.525)$ \\
\hline $\mathrm{N}$ & 221 & 221 \\
Wald $\chi^{2}$ & $46.77 * * *$ & $317.83 * * *$ \\
Pseudo R & .259 & .29 \\
\hline
\end{tabular}

Entries are coefficients; standard errors in parentheses. Standard errors are robust.

Contrasts: type of mandate - SMD, candidacy - list candidates and winning SMD MPs, local political positions - members not holding any elected local positions, local candidacy - members who were not running for local positions in 2010, SMD career - members not holding SMD mandates in 2006-2010, newcomer - members with at least one term experience as national representatives, party leader backbench MPs, party - Fidesz

Coefficients represent the change in the value of the log-odds of being constituency oriented, due to a one unit change in the related independent variables. ${ }^{80}$

$* \mathrm{p}<.1, * * \mathrm{p}<.05, * * * \mathrm{p}<.01$

${ }^{77}$ Crosstabulating focus and party affiliation produced cells with no observations.

${ }^{78}$ The Stata procedure logit was used to estimate the effects on the dependent variable.

Observations are weighted using population weights (pweight) to ensure that data represents the population in terms of mandate type and party affiliation.

${ }^{79}$ Note that in the previous models, the group of the constituency oriented served as control.

${ }^{80} \log \left(\frac{P_{X}}{1-P_{X}}\right)=\alpha+\sum B_{i} X_{i}+e_{i}$ 
The first column in Table 3.9 displays the results of the model estimated using the very same variables as in Table 3.8. Connections established earlier still hold in this setting, therefore it is needless to interpret the results regarding these variables. The question here is, whether there is a difference between parties in terms of district orientation. The answer is yes, ceteris paribus, Jobbik and LMP members are significantly less constituency oriented than Fidesz MPs.

It is hardly a surprise that Fidesz and MSZP MPs proved to be the most constituency oriented. As mandate type was controlled for, this is not the result of the enormous win of Fidesz in the SMDs, nor previous SMD experience. The latter, however, is closer to the solution, although past experience does not count on the level of the individual MPs, but it does in a rather collective way. Being present at the nominal level is a part of these two parties, by the simple reason of their positions and history in the Hungarian political system. Fidesz and MSZP have been a part of Hungarian politics right from the beginning in 1989/90, and short after that became the two strongest parties, forming a quasi-two-party-system ${ }^{81}$ up until 2010. Due to Hungarian electoral rules, only large and strong parties are able to collect seats at the $1^{\text {st }}$ tier. As both parties proved to be successful in harvesting the nominal level at the elections prior to 2010, the value and prestige of SMD mandates defines the essence of being a Member of Parliament in their case. In the case of smaller parties, like Jobbik and LMP the "spirit" of the constituency is not a part of the party culture for two reasons. First, as new parties, they have not had enough stimuli to shape a district-centred way of thinking, and second due to the disadvantaging effect of the electoral system, as small parties they are not motivated to think about the constituency as the centre of their existence as representatives.

\subsection{Style of representation}

As mentioned earlier, while focus refers to whose interest legislators represent, style indicates the manner in which these interests are represented. Empirically, the research on style of representation is not different from investigating roll-call behaviour on the level of attitudes. MPs are asked to choose sides in the case of conflicts of opinion between the party, the constituents, and the representatives themselves.

Actual roll-call behaviour will not be investigated on the grounds of the argument of Thomassen and Andeweg, namely that because of the collectivist approach of

${ }^{81}$ For more details on the Hungarian party system see (Enyedi, 2006, 2007). 
representation - and due to the primary goal of preserving government unity - "there is little left to explain once party membership has been taken into account" (Thomassen and Andeweg, 2004, p. 48). The Hungarian case is not different either: since 1998, the Rice-index measuring the cohesion of the largest Hungarian parties (Fidesz and MSZP) never dropped below $96 \%$ (Ilonszki and Jáger, 2008). Attitudes toward voting and actual voting behaviour in parliament are not expected to collide; still, the former can mirror certain perceptions that surface in different forms than dissent. Additionally, the analysis on representational focus hinted that representing the constituency and the party do not appear on the two opposite ends of the continuum, indicating that these might not be completely conflicting in the MPs' thinking. Style, however, measures a different kind of constituency orientation, where representing the district (voters) is conflicted with the interests of the party. Therefore, MPs are faced with an artificial situation, where they are asked to choose between things, which they normally feel uncomfortable to choose between.

TABLE 3.10. MPs' attitudes with regards to voting in parliament in the case of conflicting opinions

\begin{tabular}{lccc}
\hline $\begin{array}{l}\text { In case of conflicting opinions, the } \\
\text { MP would vote according to the } \\
\text { views of... }\end{array}$ & $\%(\mathrm{~N})$ & $\%(\mathrm{~N})$ & $\%(\mathrm{~N})$ \\
\hline $\begin{array}{c}\text {..the voters } \\
\ldots \text { the party }\end{array}$ & $55(109)$ & $61.5(127)$ & $62.1(124)$ \\
$\ldots$ him/herself & $45(90)$ & $38.5(79)$ & $37.9(76)$ \\
\hline
\end{tabular}

Entries are percentages; case numbers in parentheses.

The original question was formulated as follows: "How should a Member of Parliament vote in parliament if...

(1) the voters in his/her constituency have one opinion and his/her party takes a different position?

(2) his/her own opinion on an issue does not correspond with the opinion of the voters in his/her constituency?

(3) his/her own opinion on an issue does not correspond with the opinion of the voters in his/her party's position?"

Members were asked to mark their preferences with regards to voting according to the opinions of three entities pairwise. This produces three variables: (i) voting in line with opinions of voters versus party, (ii) voters versus the MP himself and (iii) the party versus the MP himself. Table 3.10 displays the frequencies of the three variables. $55 \%$ would desert the party lines when it comes to conflict with the opinions of the voters, but only 37.9 would place his or her own views before party considerations. With regards to the disagreement between the voters and the MPs themselves, $38.5 \%$ prefers a delegate type of representation. It becomes clear that on average, voting according to one' personal opinion is at the bottom, while the positions of the voters are 
cherished. Party representation lies somewhere between these two, which suggests that the delegate type of representation is closer to the Hungarian MPs than taking the role of the trustee. In a way, voting in line with the party position corresponds to the idea of acting as a delegate, only not of the voters but the party.

Additionally, we have to take a closer look at the formulation of the survey question (see Table 3.10). Members were not asked about their behaviour, but about hypothetical instructions; not about the "sein" but the "sollen". Therefore, the results do not entail that members do indeed vote according to the opinion of their voters ${ }^{82}$, only that they think it would be the proper thing to do. In the next sections, the connection between style and the already introduced independent factors will be uncovered both in bivariate and multivariate settings.

\subsubsection{Style of representation and independent variables - bivariate relationships}

Explanatory factors in this section will be identical to the independent variables introduced in explaining focus of representation. Table 3.11 shows the connections between the three style variables and mandate type. In the case of the choice between voters' opinions and party positions, SMD members are largely in favour of voting according to the former. Regional list MPs share the same sympathies to the voters, only to a different magnitude, while national list members recognize the superiority of the party position. The differences between the three types of mandates produce significant results. The closer the MPs are to the nominal level, the larger proportion of them "takes the voters' opinions to the parliament".

With regards to the choice between voters and the MPs' own standings, the same tendencies prevail. Nominal and regional level MPs picked voter positions again, in an even greater proportion than in the case when voters were conflicted with the parties. Although the relationship is not significant in the case of the third style variable (choice between party and himself), the relative importance of the roles of the delegate and the trustee resembles the relation of the two concepts outlines earlier: the role of the delegate (voter and party) still prevails as opposed to the trustee type of representation.

\footnotetext{
${ }^{82}$ In fact, we know that they vote in line with the party position (Ilonszki and Jáger, 2008).
} 
TABLE 3.11. Style of representation and mandate type

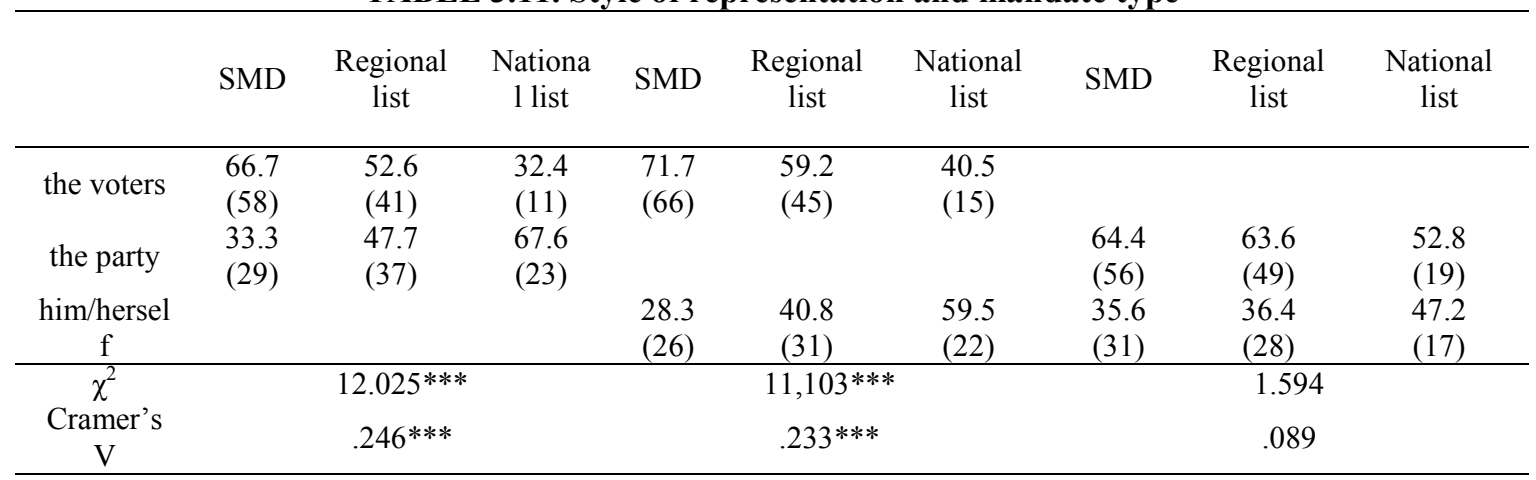

Entries are percentages; case numbers in parentheses.

The original question was formulated as follows: "How should a Member of Parliament vote in parliament if...

(1) the voters in his/her constituency have one opinion and his/her party takes a different position?

(2) his/her own opinion on an issue does not correspond with the opinion of the voters in his/her constituency?

(3) his/her own opinion on an issue does not correspond with the opinion of the voters in his/her party's position?"

$*_{\mathrm{p}}<.1, * * \mathrm{p}<.05, * * * \mathrm{p}<.01$

Moving further, the tier of candidacy only seems to matter in connection with the first style variable. Significantly more SMD candidates claimed voting according to the views of the voters compared to the party's. Although the connection is not significant in the other two cases, we can make careful conclusions regarding the sample. Representing voters' opinions in parliament is more important than voting in line with their own convictions, both in the cases of SMD candidates and those not interested in the nominal level. In the third case, both groups prefer the party, but they differ in terms of the magnitude of rejecting the role of the trustee: SMD candidates tend to vote in line with their own opinion to a greater extent.

TABLE 3.12. Style of representation and candidacy

\begin{tabular}{|c|c|c|c|c|c|c|}
\hline & $\begin{array}{l}\text { Not an SMD } \\
\text { candidate }\end{array}$ & SMD candidate & $\begin{array}{c}\text { Not an SMD } \\
\text { candidate }\end{array}$ & $\begin{array}{c}\text { SMD } \\
\text { candidate }\end{array}$ & $\begin{array}{c}\text { Not an SMD } \\
\text { candidate }\end{array}$ & $\begin{array}{c}\text { SMD } \\
\text { candidate }\end{array}$ \\
\hline the voters & $41.8(23)$ & $60.4(87)$ & $58.2(32)$ & $62.9(95)$ & & \\
\hline the party & $58.2(32)$ & $39.6(57)$ & & & $71.2(37)$ & $59.2(87)$ \\
\hline him/herself & & & $41.8(23)$ & $37.1(56)$ & $28.8(15)$ & $40.8(60)$ \\
\hline$\chi^{2}$ & \multicolumn{2}{|c|}{$5.569 * *$} & \multicolumn{2}{|c|}{.382} & \multicolumn{2}{|c|}{2.344} \\
\hline Cramer's V & \multicolumn{2}{|c|}{$0.167 * *$} & \multicolumn{2}{|c|}{.043} & \multicolumn{2}{|c|}{.109} \\
\hline
\end{tabular}

Entries are percentages; case numbers in parentheses.

The original question was formulated as follows: "How should a Member of Parliament vote in parliament if...

(1) the voters in his/her constituency have one opinion and his/her party takes a different position?

(2) his/her own opinion on an issue does not correspond with the opinion of the voters in his/her constituency?

(3) his/her own opinion on an issue does not correspond with the opinion of the voters in his/her party's position?"

$* \mathrm{p}<.1, * * \mathrm{p}<.05, * * * \mathrm{p}<.01$ 
Taking only regional list members into account, district magnitude again was not found significantly connected to perceptions of representation. Although party promoters came from larger districts on average $(12.02$, s.d. $=9.465)$ than those who would rather vote to meet the positions of their voters $(10.16$, s.d. $=7.44)$, the differences do not hold for the entire population of the Hungarian MPs ${ }^{83}$. Very similar results were found in the second case (voters versus party): a larger average district magnitude is associated with voting in line with the MPs' own views $(12.43$, s.d. $=9.7)$ than with the voters' $(10.06$, s.e. $=7.641)$. This result, again, was not found significant on a $5 \%$ level ${ }^{84}$. Finally, the average magnitude is almost the same among party delegates (11.93, s.d.=9.306) and trustees $\left(11.32\right.$, s.d.=8.429), producing no significant differences ${ }^{85}$.

As to local political background, Table 3.13 summarizes results of its connection to style of representation. Multiple office holders tend to vote rather in favour of their voters than either of the party or themselves. The effect becomes prominent when it comes to the trade-off between being a delegate of the voters or a trustee. Here, the difference between single and multiple office holders appears to be larger than in the first case, where single office holders also tend to vote in line with their voters' opinion. Oddly, in terms of the choice between the party position and the trustee-role, multiple office holders chose representing the party with a greater magnitude than those only holding the parliamentary mandate.

\footnotetext{
${ }^{83} \mathrm{~F}=.936$

${ }^{84} \mathrm{~F}=1.415$

${ }^{85} \mathrm{~F}=.087$
} 
TABLE 3.13. Style of representation and local political background

\begin{tabular}{|c|c|c|c|c|c|c|}
\hline & $\begin{array}{l}\text { Single office } \\
\text { holder }\end{array}$ & Multiple office holder & $\begin{array}{l}\text { Single } \\
\text { office } \\
\text { holder }\end{array}$ & $\begin{array}{c}\text { Multiple } \\
\text { office holder }\end{array}$ & $\begin{array}{c}\text { Single } \\
\text { office } \\
\text { holder }\end{array}$ & $\begin{array}{c}\text { Multiple } \\
\text { office holder }\end{array}$ \\
\hline the voters & $53.6(45)$ & $56.5(65)$ & $50(44)$ & $70.3(83($ & & \\
\hline the party & $46.4(39)$ & $43.5(50)$ & & & $53(44)$ & $68.4(80)$ \\
\hline him/herself & & & $50(44)$ & $29.7(35)$ & 47 (39) & $31.6(37)$ \\
\hline$\chi^{2}$ & & .171 & \multicolumn{2}{|c|}{$8.82 * * *$} & \multicolumn{2}{|c|}{$4.865^{* *}$} \\
\hline
\end{tabular}

Entries are percentages; case numbers in parentheses.

The original question was formulated as follows: "How should a Member of Parliament vote in parliament if...

(1) the voters in his/her constituency have one opinion and his/her party takes a different position?

(2) his/her own opinion on an issue does not correspond with the opinion of the voters in his/her constituency?

(3) his/her own opinion on an issue does not correspond with the opinion of the voters in his/her party's position?"

$*_{\mathrm{p}}<.1, * * \mathrm{p}<.05, * * * \mathrm{p}<.01$

As established earlier in this chapter, member careers in SMDs can effect how members think about representation. As these factors touch upon previous experience, their effects are likely to be habitual. Members with nominal level legislative experience are expected to be more constituency-oriented, which is closest to the conception of voter delegate in this context. Nonetheless, this appears not to be the case. Members, who did not have any nominal level responsibilities on the course of their careers, are more voter-oriented than 2006-2010 SMD incumbents. Habits, however, seem to work within the group of MPs holding the SMD mandates before 2006 (and not between 2006 and 2010). The same tendency prevails with regards to the situation where the opinion of the voters and the MPs are in conflict. 
TABLE 3.14. Style of representation and MPs' careers in single member districts

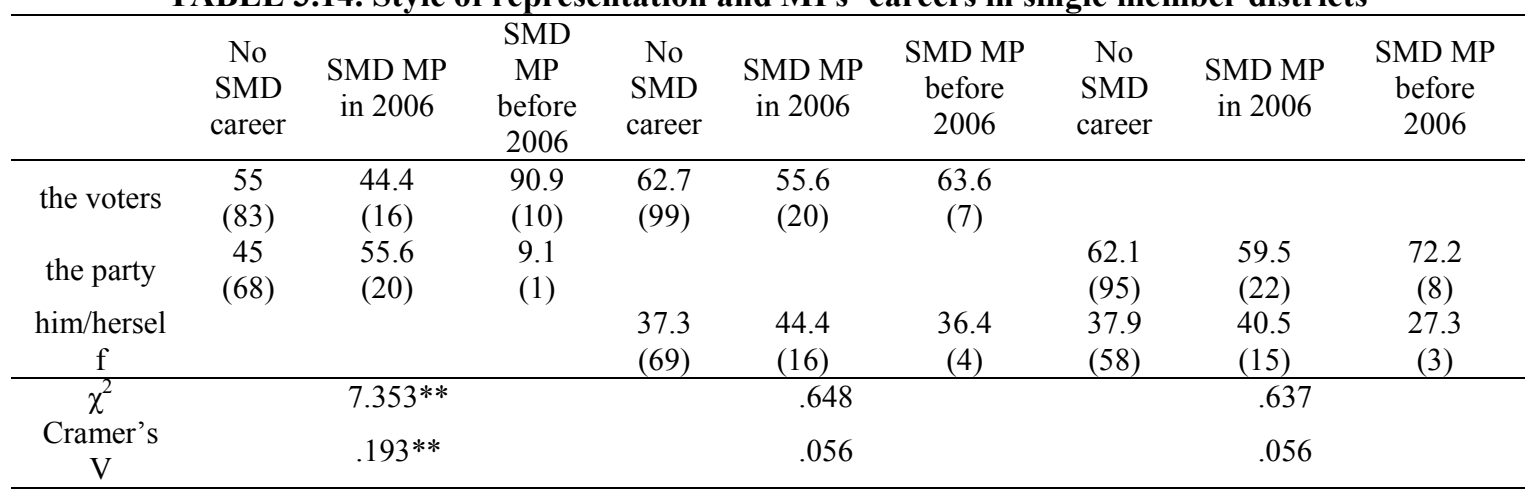

Entries are percentages; case numbers in parentheses.

The original question was formulated as follows: "How should a Member of Parliament vote in parliament if...

(1) the voters in his/her constituency have one opinion and his/her party takes a different position?

(2) his/her own opinion on an issue does not correspond with the opinion of the voters in his/her constituency?

(3) his/her own opinion on an issue does not correspond with the opinion of the voters in his/her party's position?"

${ }^{*} \mathrm{p}<.1,{ }^{* *} \mathrm{p}<.05, * * * \mathrm{p}<.01$

Last but not least, seniority, party leadership and ideological distance from the party does not prove to be significant in a bivariate setting (for deatails see Appendix 3.4 and 3.5). The tendencies outlined earlier still prevail though: members tend to prefer the delegate roles regardless of their characteristics. Nevertheless, senior members do not appear to be more voter oriented, nor do backbench MPs. Furthermore, representatives who place themselves closer to their parties are not less concerned of the opinion of their voters than MPs who positioned themselves rather away.

\subsubsection{The determinants of representational style}

This section introduces multivariate results on the basis of different models estimating various types of dependent variables. First, the core factors will be modeled, then transformed versions are taken a closer look at. Models are built following of the logic of the previous secion. At the first stage, mandate type, candidacy, local background, SMD careers, seniority, party leadership and ideological distance will be controlled for. In the next step local candidacy will be added to the equation to unravel the true effect of local positions. At last, the effect of the party will be taken into account.

Starting with the simplest models, Table 3.15 displays the results of estimating the log-odds of choosing the voters' opinion in case it is conflicted with the position of the 
party $^{86}$. With regards to the effect of the mandate type, the probability of being partycentred increases more sharply in the case of national list members, than their regional counterparts. Obviously, this is true regarding the probability of being constituentcentred, only the other way around: the relative change in the probability of voting according to the voters' opinions is larger in the group of $3^{\text {rd }}$ tier MPs.

TABLE 3.15. Results of the binary logistic regressions estimating the log-odds of voting according to the voters' views in a voters vs. party conflict

\begin{tabular}{|c|c|c|c|}
\hline & B (s.e.) & B (s.e.) & B (s.e.) \\
\hline Regional list MP & $-1.128(.429)^{* * *}$ & $-1.142(.431)^{* * *}$ & $-1.1(.446)^{* *}$ \\
\hline National list MP & $-2.66(.693) * * *$ & $-2.694(.693)^{* * *}$ & $-2.858(.882)^{* * *}$ \\
\hline Candidacy (only losing) & $.989(.5)^{* *}$ & $.989(.5)^{* *}$ & $.439(.905)$ \\
\hline Local political position & $-.27(.404)$ & $-.177(.524)$ & $.133(.583)$ \\
\hline Local candidacy & & $-.148(.496)$ & $-.06(.518)$ \\
\hline SMD MP between 2006-2010 & $-.54(.495)$ & $-.539(.493)$ & $-.35(.522)$ \\
\hline SMD MP before 2006 & $2.169(1.176)^{*}$ & $2.176(1.168)^{*}$ & $2.093(1.166)$ \\
\hline Newcomer & $.722(.398)^{*}$ & $.723(.398)^{*}$ & $.541(.426)$ \\
\hline Ideological distance & $.105(.153)$ & $.099(.153)$ & $.205(.173)$ \\
\hline Party leader & $-.288(.354)$ & $-.286(.354)$ & $-.437(.369)$ \\
\hline Jobbik & & & $2.085(1.26)$ \\
\hline KDNP & & & $.928(.72)$ \\
\hline LMP & & & $.282(1.624)$ \\
\hline MSZP & & & $.15(1.00)$ \\
\hline Constant & $.665(.583)$ & $.71(.566)$ & $.298(.604)$ \\
\hline $\mathrm{N}$ & 192 & 192 & 192 \\
\hline Wald $\chi^{2}$ & $26.62 * * *$ & $26.8 * * *$ & $30.63 * * *$ \\
\hline Pseudo $\mathrm{R}^{2}$ & .116 & .116 & .155 \\
\hline
\end{tabular}

Entries are coefficients; standard errors in parentheses. Standard errors are robust.

Contrasts: type of mandate - SMD, candidacy - list candidates and winning SMD MPs, local political positions - members not holding any elected local positions, local candidacy - members who were not running for local positions in 2010, SMD career - members not holding SMD mandates in 2006-2010, newcomer - members with at least one term experience as national representatives, party leader backbench MPs, party - Fidesz

Coefficients represent the change in the value of the log-odds of choosing the voters' opinion in case it is conflicted with the position of the party, due to a one unit change in the related independent variables. ${ }^{87}$ Control group is voting according to the voters' opinion.

$* \mathrm{p}<.1, * * \mathrm{p}<.05, * * * \mathrm{p}<.01$

The first two models of Table 3.15 appear to prove the shadowing hypothesis. Members who were nominated on the nominal level, but lost the competition and got into parliament as list MPs, are more likely to take the voter-delegate position than the one of the party delegate. However, when the party is controlled for, the significant

${ }^{86}$ The Stata procedure logit was used to estimate the effects on the dependent variable. Observations are weighted using population weights (pweight) to ensure that data represents the population in terms of mandate type and party affiliation.

${ }^{87} \log \left(\frac{P_{X}}{1-P_{X}}\right)=\alpha+\sum B_{i} X_{i}+e_{i}$ 
effect of candidacy diminishes, questioning the overall relevance of this variable in explaining style of representation.

All other variables appear not to have any effect on the dependent variable, which strengthens the explanations of motivations that are connected to electoral rules. Only between MPs holding different types of mandates is considerable difference detectable in terms of how they think they should vote in a situation of conflicting interests. None of the positions tying the members to voters or the local level more closely play a role in shaping how members think about voting in parliament in an ideal world where there are no party constraints on member decisions. The insignificance of these variables, however, points to the conclusion that MPs do not perceive voting as a part of representing particularistic interests. Of course, there is a variation in the trade-off between the voters and the party, as several members chose the voters (see Table 3.10), but it is not structured by the logic of the positions of the MPs. Variation is random in a sense, that independent variables taken into account could not capture the differences between the two types of answers.

The ineffectiveness of the selected variables in explaining the variation in style of representation is even more pronounced under the conflicting opinions of the voters and MPs as well as the party and MPs. Appendix 3.6 and 3.7 show the additional models. With regards to the choice between the opinion of the voters and the party, only party affiliation appears to pose a significant effect on the dependent variable. According to the results, LMP members seem to support voting in line with the opinion of the voters even against their own views more than Fidesz members do. However, this result should be handled with care, as the unweighted sample represents LMP representatives rather insufficiently. The same applies to the results of models estimating the log-odds of voting according to the MP's views in an MP vs. party conflict. Although LMP members seem to be more pro-trustee than Fidesz MPs, which would also support intuition, the statistical significance of this result should not be taken as proof. In the context of this model, however, the effect of mandate type re-appears. National list MPs are significantly more likely to think that representatives should meet the party position against their own deliberation when voting in parliament. SMD and regional list members have a more solid trustee-like attitude when thinking about roll-call behaviour.

Using the above variables separately to measure style of representation one has to face the possibility that the real preferences fade away. Namely, it is a viable scenario that a given member chooses the voters over himself, but supports voting according to 
party positions against voter opinions. Can such a member regarded as a true delegate of his constituents? Choosing the voters once, does not necessarily makes an MP a delegate of the constituents. To solve this issue, three new variables were generated, which combine information of the original three variables pairwise. In case the respondent who thinks that an MP should vote in line with his or her voters' opinion both in the cases where it conflicts with the positions of the party and the MP's views, is considered a true constituent delegate. Analogically, a true party delegate is someone who thinks he should vote according to the party's positions no matter if it does not correspond with the opinions of his constituents or himself. Last but not least, the third variable denotes trustees, who would prefer that roll-call expresses their own judgement. Sample frequencies (with population percentages) are displayed by Table 3.16 .

TABLE 3.16. The distribution of the various types of representational style

\begin{tabular}{llll}
\hline & & N & \% \\
\hline Constituent delegate & No & 122 & 60.4 \\
& Yes & $\mathbf{8 0}$ & $\mathbf{3 9 . 6}$ \\
\hline Party delegate & No & 137 & 70.2 \\
& Yes & $\mathbf{5 8}$ & $\mathbf{2 9 . 8}$ \\
\hline Trustee & No & 165 & 79.5 \\
& Yes & $\mathbf{4 2}$ & $\mathbf{2 0 . 5}$ \\
\hline
\end{tabular}

Although these categories are mutually exclusive, hence they could be collapsed into one single variable to model, roles will be estimated separately in order to get a clearer picture. Thus, constituent delegates will not be compared to one of the other two categories, but to its complementer. Therefore, the essence of being constituent oriented will be captured, rather than its relative occurrence in contrast with the other types. Table 3.17 displays the results of the binary logistic regressions ${ }^{88}$. With regards to being a constituent delegate, electoral system variables seem to be the most powerful estimators. In all of the three settings, regional and national list members are considerably less likely to become delegates of their voters. Instead they turn out to be party delegates, voting in line with their parties' positions opposing the voters and even themselves. For a regional list member, it is 3 times more likely to choose the party or himself in a situation when these opinions are contrasted to the voters'. Regarding

${ }^{88}$ The Stata procedure logit was used to estimate the effects on the dependent variable. Observations are weighted using population weights (pweight) to ensure that data represents the population in terms of mandate type and party affiliation. 
national list representatives, this likelihood is 10 times larger compared to nominal level MPs.

Position variables other than mandate type do not seem to affect the probability of one acting as a true delegate of the constituents. One exception is holding party leadership positions. Within the third model setting, being a party leader affects the likelihood of being a voters' delegate negatively: the likelihood of bringing the voters' will into the roll-call is the half of the chance they vote with under other influence. Taking the results of the second group of models into account, party leadership does not affect the likelihood of being a party delegate. In other words, party leadership defines what MPs are not (constituent delegates), instead of what they are or should be (party delegates). 
TABLE 3.17. Results of the binary logistic regressions estimating the log-odds of being a delegate of the constituents, a party delegate and a trustee

\begin{tabular}{|c|c|c|c|c|c|c|c|c|c|}
\hline & \multicolumn{3}{|c|}{ Constituent delegate } & \multicolumn{3}{|c|}{ Party delegate } & \multicolumn{3}{|c|}{ Trustee } \\
\hline & B (s.e.) & B (s.e.) & B (s.e.) & B (s.e.) & B (s.e.) & B (s.e.) & B (s.e.) & B (s.e.) & B (s.e.) \\
\hline Regional list MP & $-1.152(.429)^{* * *}$ & $-1.143(.437)^{* * *}$ & $-1.055(.451)^{* *}$ & $1.219(.481)^{* *}$ & $1.249(.475)^{* * *}$ & $1.064(.501)^{* *}$ & $.243(.561)$ & $.176(.555)$ & $.147(.58)$ \\
\hline National list MP & $-2.354(.747)^{* * *}$ & $-2.335(.75)^{* * *}$ & $-1.991(.78)^{* *}$ & $1.787(.704)^{* *}$ & $1.864(.703)^{* * *}$ & $1.478(.838)^{*}$ & $.549(.684)$ & $.429(.683)$ & $.251(.948)$ \\
\hline Candidacy (only losing) & $1.051(.559)^{*}$ & $1.051(.559)^{*}$ & $1.044(.862)$ & $-.679(.496)$ & $-.679(.494)$ & $-.95(.733)$ & $-.037(.54)$ & $-.022(.539)$ & $.417(.895)$ \\
\hline Local political position & $.022(.37)$ & $-.025(.472)$ & $.136(.489)$ & $.973(.488)^{* * *}$ & $.772(.654)$ & $.465(.767)$ & $-1.053(.459)^{* *}$ & $-.763(.562)$ & $-.604(.652)$ \\
\hline Local candidacy & & $.081(.458)$ & $.074(.456)$ & & $.322(.611)$ & $.191(.641)$ & & $-.468(.48)$ & $-.357(.537)$ \\
\hline $\begin{array}{l}\text { SMD MP between 2006- } \\
2010\end{array}$ & $-.542(.5)$ & $-.541(.502)$ & $-.365(.515)$ & $.25(.533)$ & $.235(.528)$ & $-.035(.573)$ & $-.153(.637)$ & $-.163(.639)$ & $-.011(.617)$ \\
\hline SMD MP before 2006 & $.286(.664)$ & $.277(.668)$ & $.191(.688)$ & $-1.572(1.143)$ & $-1.584(1.128)$ & $-1.431(1.112)$ & $.066(.944)$ & $107(.947)$ & $.112(.876)$ \\
\hline Newcomer & $.049(.391)$ & $.05(.393)$ & $-.052(.432)$ & $-1.009(.417)^{* *}$ & $-1.023(.42)^{* *}$ & $-.69(.44)$ & $.453(.494)$ & $.451(.494)$ & $.226(.611)$ \\
\hline Ideological distance & $.089(.157)$ & $.092(.159)$ & $.162(.159)$ & $-.154(.177)$ & $-.143(.176)$ & $-.214(.183)$ & $.024(.187)$ & $.012(.183)$ & $-.011(.198)$ \\
\hline Party leader & $-.643(.344)^{*}$ & $-.644(.345)^{*}$ & $-.716(.35)^{* *}$ & $.486(.381)$ & $.479(.378)$ & $.484(.431)$ & $.071(.433)$ & $.091(.433)$ & $.069(.436)$ \\
\hline Jobbik & & & $.732(1.054)$ & & & $-.444(1.022)$ & & & $-.474(1.082)$ \\
\hline KDNP & & & $.225(.724)$ & & & $-1.454(1.246)$ & & & $1.424(.718)^{* *}$ \\
\hline LMP & & & $-16.388(1.323)^{* * *}$ & & & $-15.093(.994)^{* * *}$ & & & $17.968(1.082)^{* * *}$ \\
\hline MSZP & & & $-.576(.957)$ & & & $.793(.917)$ & & & $-.371(1.186)$ \\
\hline Constant & $.271(.556)$ & $.243(.579)$ & $.089(.598)$ & $-1.679(.777)^{* *}$ & $-1.772(.727)^{* *}$ & $-1.28(.741)^{*}$ & $-1.249(.605)^{* *}$ & $-1.109(.603)^{*}$ & $-1.422(.664)^{* * *}$ \\
\hline $\mathrm{N}$ & 195 & 195 & 195 & 189 & 189 & 189 & 200 & 200 & 200 \\
\hline Wald $\chi^{2}$ & $18.09 * *$ & 18.09 & $404.19^{* * *}$ & $20.82 * *$ & $21.16^{* *}$ & $472.34 * * *$ & 8.7 & 9.08 & $641.5^{* * * *}$ \\
\hline Pseudo $R^{2}$ & .07 & .07 & .118 & .104 & .105 & 0.152 & .07 & 0.07 & 0.203 \\
\hline
\end{tabular}

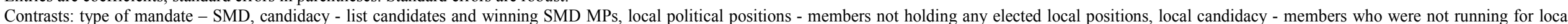
positions in 2010, SMD career - members not holding SMD mandates in 2006-2010, newcomer - members with at least one term experience as national representatives, party leader - backbench MPs, party - Fidesz

Coefficients represent the change in the value of the log-odds of being a delegate of the constituents, a party delegate and a trustee, due to a one unit change in the related independent variables. ${ }^{89}$

${ }^{*} \mathrm{p}<.1,{ }^{* * \mathrm{p}}<.05, * * * \mathrm{p}<.01$

${ }^{89} \log \left(\frac{P_{X}}{1-P_{X}}\right)=\alpha+\sum B_{i} X_{i}+e_{i}$ 
Back to the first set of models (Table 3.17), in the final equation, party affiliation seems to have a significant effect on members' voter-orientation. LMP MPs differ from Fidesz representatives with a great deal: they are less prone to representing the voters' opinion at roll-call than the members of the biggest party. However, the concerns worded earlier with regards to the sample size considerations in the group of LMP members affect the validity of these results as well. The same applies to the second the third group of models. LMP members are less likely to be party delegates, and are with a greater probability identifying with the role of the trustee. The findings related to the parties lead us to conclude that the various political formations do not substantially differ in terms of style of representation. LMP serves as an exception, where members tend to prefer trustee roles instead of voting according to voter and party wishes.

As to being a party delegate, mandate type again is the strongest variable to explain the likelihood of an MP to vote according to the party line no matter if it conflicts with the opinions of the voters or the member himself. Interestingly, mandate accumulation appears to positively affect being a party delegate. This relationship, however, is diminished when local candidacy was brought into the analysis. We also know that local politicians are less likely to identify themselves with the role of the trustee; however, this connection also disappears when local candidacy is controlled for ${ }^{90}$. This leaves us with cumulants being either the party's or the voters' delegate. Data confirms the former but does not reject the latter either, which is unexpected in a sense, that local politicians were hypothesized to take the voters' side in a conflict of opinions. This finding indicates that voting in parliament is not necessarily regarded as a way to represent the interests of the constituency, let this be a territorial area or the people living in it.

The effect of seniority provides another peculiar result. Newcomers are less likely to become delegates of the party, at least they think, MPs should vote according to the opinion of the voters or their own conscience. Studying focus of representation, it became clear that newcomers tend to focus on the interests of all the citizens in the country. However, in parliament, they appear agreeing to follow party orders. Thus, it seems that the generalistic approach of representation manifests in sticking to the party

\footnotetext{
${ }^{90}$ Although this phenomenon suggests multicollinearity problems, Variance Inflation Factors (VIF) fluctuate around 2 in the cases of local political background (2.04) and local candidacy (2.02). Therefore, the issue of multicollinearity is not addressed any further.
} 
line at roll-call in the case of inexperienced MPs. This raises the question of how focus and style are related, which is addressed in the next section.

Taking only regional list members into account, district magnitude does not appear to have any effect on how MPs think they should vote in parliament. Appendix 3.8 shows the sample effect ${ }^{91}$, however, these cannot be generalized to the whole population of $2^{\text {nd }}$ tier members. Nevertheless, it is clear that the larger the district magnitude, the higher the probability of an MP being a party delegate. Analogically, the lower the magnitude, the higher the chance of one identifying himself with the role of the constituents' delegate. Thus, data supports the hypothesis connected to district magnitude on the level of the sample. Members in a smaller district feel the need to represent the voters rather than the parties in parliament.

\subsection{Focus and style of representation}

In this section, the relationship between focus and style of representation will be examined. Focus is operationalized as a four-fold variable, already introduced in the previous sections. As to style, the transformed variables measuring "true" roles are used. Data reveals that there is no statistical connection to be found between the two notions under investigation. Nevertheless there are some tendencies worth mentioning. First, more than the half of constituent delegates claimed to represent the constituency in their work as Members of Parliament. At the same time, $49.4 \%$ of constituency oriented MPs are also constituent delegates, which percentage is higher than the proportion of constituent delegates in the other three groups of focus.

\footnotetext{
${ }^{91}$ The log of district magnitude was controlled for in binary logit regressions estimating the log odds of being a party delegate, a delegate of the constituents and a trustee. Candidacy, local political background, SMD career, seniority, party leadership and ideological distance were controlled for as well. Only regional list members were used on the course of the estimation.
} 
TABLE 3.18. The relationship between the focus and style of representation

\begin{tabular}{|c|c|c|c|c|c|c|c|}
\hline & \multicolumn{2}{|c|}{ Constituent delegate } & \multicolumn{2}{|c|}{ Party delegate } & \multicolumn{2}{|c|}{ Trustee } & \\
\hline & No & Yes & No & Yes & No & Yes & \\
\hline \multirow{2}{*}{ Constituency } & 50.6 & 49.4 & 69.9 & 30.1 & 85.2 & 14.8 & $100 \%$ \\
\hline & 34.7 & 51.3 & 42.6 & 42.4 & 45.7 & 30.2 & \\
\hline \multirow{2}{*}{ Party } & 72.4 & 27.6 & 58.6 & 41.4 & 70 & 30 & $100 \%$ \\
\hline & 17.4 & 10 & 12.5 & 20.3 & 12.8 & 20.9 & \\
\hline \multirow{5}{*}{$\begin{array}{l}\text { A specific } \\
\text { group in the } \\
\text { society } \\
\text { All the } \\
\text { citizens of the } \\
\text { country }\end{array}$} & 66.7 & 33.3 & 54.5 & 45.5 & 83.3 & 16.7 & $100 \%$ \\
\hline & 6.6 & 5 & 4.4 & 8.5 & 6.1 & 4.7 & \\
\hline & 64.9 & 35.1 & 76.4 & 23.6 & 75.3 & 24.7 & $100 \%$ \\
\hline & 41.3 & 33.8 & 40.4 & 28.8 & 35.4 & 44.2 & \\
\hline & $100 \%$ & $100 \%$ & $100 \%$ & $100 \%$ & $100 \%$ & $100 \%$ & \\
\hline$\chi^{2}$ & \multicolumn{2}{|c|}{5.927} & \multicolumn{2}{|c|}{4.412} & \multicolumn{2}{|c|}{4.312} & \\
\hline Cramer's V & \multicolumn{2}{|c|}{.172} & \multicolumn{2}{|c|}{.15} & \multicolumn{2}{|c|}{.144} & \\
\hline
\end{tabular}

Entries are percentages.

${ }^{*} \mathrm{p}<.1, * * \mathrm{p}<.05, * * * \mathrm{p}<.01$

Second, the role of the trustee is connected to party focus and the most generic conception of representation (i.e. representing all the citizens in the country.). The proportion of trustees is the largest within the group of MPs representing their parties (30\%), while members representing all citizens form the largest group within the cluster of trustees $(44.2 \%)$. To visualize the connections between focus and style multiple correspondence analysis (MCA) was carried out. Figure 3.2 presents the MCA coordinate plot, where three things stand out. First, the trustee is indeed closest to the most generic perception of an MP's job. Otherwise it is defined negatively: members who are neither party nor constituent delegates will most probably identify with the role of the trustee. Second, party delegates are close to those who focus on party interests and who represent a specific group in the society. Third, constituent delegates and constituency oriented members are also not far from each other. Additionally, not being a trustee is also a strong indication of someone representing the constituency. 


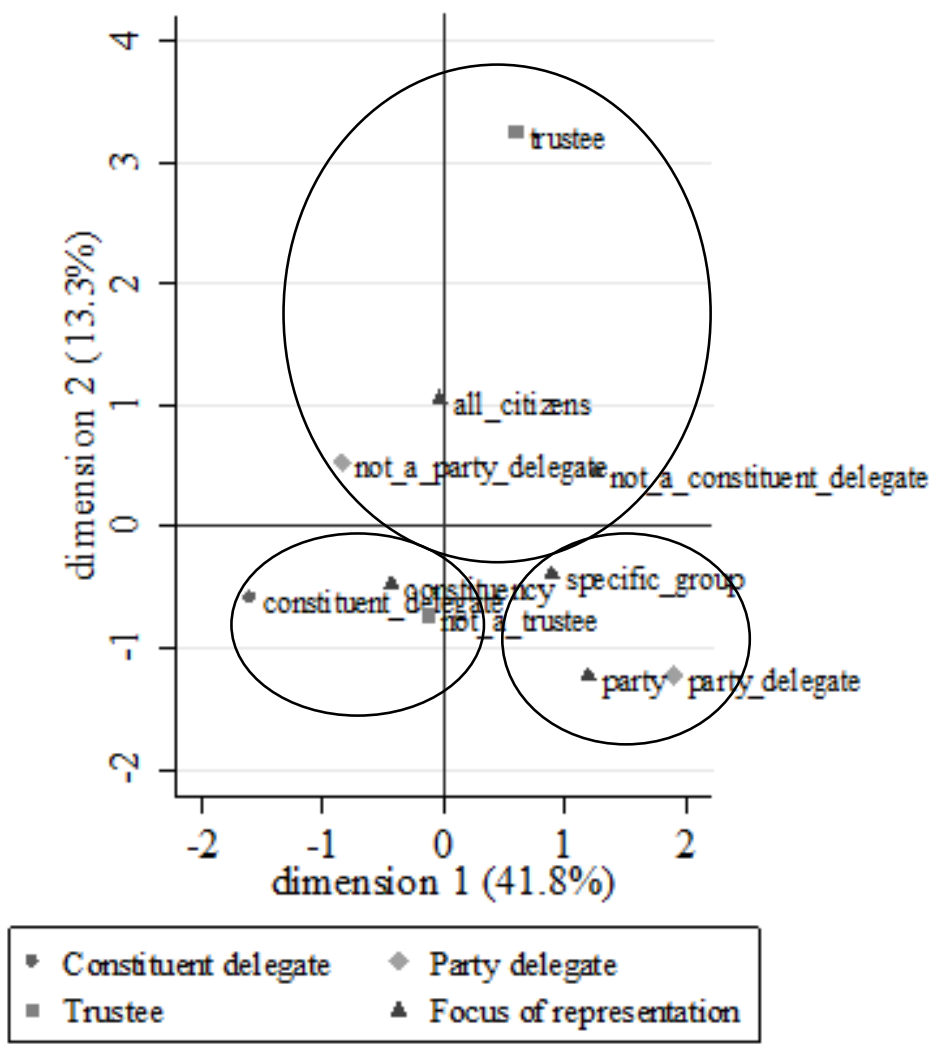

Total intertia $=.116$

FIGURE 3.2. MCA coordinate plot disentangling the relationship between focus and style of representation

As pointed out earlier, the connections shown by Figure 3.2 do not apply to the whole population of Hungarian MPs. However, if focus of representation is dichotomized in a way that it differentiates between constituency-oriented MPs and those focusing on different entities, there is a significant connection between focus and becoming a constituent delegate ${ }^{92}$. Nevertheless, the relationships are not persuasive with regards to the empirical connectedness of the two conceptions. What MPs represent does not affect how they represent it.

\subsection{Concluding remarks}

In this chapter, as the first step of the analysis, focus and style of representation was discussed with regards to Hungarian Members of Parliament. The two conceptions were operationalized in line with the international scholarly literature, focus being perceived who members think they represent, while style stood for the way they are represented. Separation of the two phenomena is necessary, as it is not self-evident, that constituency

${ }^{92} \chi^{2}=5.434^{* *}, \mathrm{~V}=.164$ 
oriented members will vote based on the opinion of the constituents. There are other ways to represent the districts and the voters than just transmitting voter opinions to roll-call. The most important lesson of the weak connections between focus and style is that voting in parliament is not a part of representing the interest of whoever the MPs represent the interests of. It also follows that focus and style of representation are structured by different factors.

To take these results as what they are, a few comments on the measures of style are in order. Members had problems answering these particular questions. First and foremost, most of them claimed that they could have identified with the role of the politico, but that alternative was intentionally not offered. The second problem is related to a more practical issue, namely that the information shortage they face when voting in parliament. As they claimed, there is no way of knowing how voters think about issues; there is absolutely no reality in interviewing them before every vote. Therefore, MPs who really think that one should vote according to the voters opinions are probably underrepresented in the sample, because of non-sampling bias. Moreover, some of the MPs had trouble with identifying with the abstract ideas the questions represented.

Furthermore, there was a tendency of choosing the voter against their own opinion, even in cases in which it was clear from comments that members think they should vote based on their own convictions. In this context, the difference between voters' opinions and interests manifested. Members claimed that they should vote according to constituent interests, and not opinions, as citizens do not have enough information to decide what serves their interests best. Hence, as respondents claimed, voters' opinion often contradicts with their interests. The scholarly literature knows this as the tension between the trustee and the delegate roles. Still, MPs tended to choose the voters, although, it was clear that they would prefer a more trustee-like type of representation. Thus, it is uncertain how suitable these questions are in investigating representational style. Not just empirically, but conceptually as well. The exceptionally high levels of party cohesion "forced upon" MPs by the party centre does not leave space for individual initiative at roll-calls. Very often, government unity is at stake; therefore, the PPG regularly brings members to book for dissent ${ }^{93}$. This rigorousness then appears in attitudes, taking representation through vote out of the list of possibilities.

\footnotetext{
${ }^{93}$ PPGs have a substantial power to discipline their MPs. Mostly, they apply oral warning, but member often have to pay fines in cases of dissent or absence from voting. As these practices
} 
As pointed out earlier, the two notions measure different aspects; therefore they are shaped by different factors. The variety of significant independent factors is larger in the case of representational focus. All types of explanations appear. Electoral motivations were operationalized as future electoral goals, namely candidacy at the local elections in 2010. It had a significant positive effect on being constituency-oriented. Nevertheless, it did not affect style of representation indicating that individual electoral goals are not approached through roll-call either. As to position roles, not unexpectedly, mandate type proved to be the most powerful estimator of both focus and style. Single member district MPs are more constituency oriented than their colleagues elected on party lists on the one hand, and tend to support voting in line with voter opinions on the other. This result underlines the importance of electoral rules in structuring member attitudes. Despite the party centeredness, the various electoral tiers bring variation into member orientations in the hypothesized way. It could be argued that position roles in general bear habitual relevance as well. Filling in a given position also creates the basis of motivations not directly connected to holding that particular position. It becomes rather a part of what an MP thinks is right to think or do. In the case of mandate type these effects are supposed to be minimal, as fieldwork took place short after the 2010 elections. Thus, members did not have time to adjust in terms of habits that root deeper than just their actual jobs. In the case of other position variables, it is possible that position and habitual motivations mingle. Further research could separate the two effects by controlling for the length of time an MP has spent in that particular position. In the case of members serving longer, the significance of habits will increase.

With regards to focus of representation, seniority and party leadership appeared to have significant effects on constituency orientation. Both decreased the probability of becoming constituency oriented. In the case of newcomers, the party-centeredness of the candidate selection procedure is to blame. New members have yet to build their are related to preserving government unity in parliament, governing parties apply forfeit more often. For instance, in December 2012 József Ángyán received a 250000 HUF (about 833 EUR) fine due to dissent, whereas László L. Simon had to pay 150000 HUF (500 EUR) for absence from an important vote. During the 2006-2010 electoral term, MSZP had also strict rules settling MP responsibilities. In March 2008, József Karsai paid 100000 HUF (333 EUR) for dissent. The absence of Imre Farkas at the very same vote cost him 80000 HUF (266 EUR). In October 2008 five MSZP members were punished for not being present during interpellation votes. 
bases in their constituencies; therefore they are less of an asset to the party, making its power stronger in deciding ones political fate. Once they had proven their loyalties and had managed to gain some visibility -, they will have a bigger bargaining power, enabling them to focus their efforts to matters different from convincing the party centre that they are all in for the party. Party leadership is the only position factor - apart from mandate type - that affects both focus and style. The habitual aspect of this variable is strong as well. In order to become a party leader one has to climb the "corporate ladder", which has an undeniable socializational effect (Zittel, 2012). Thus members in these positions probably acquired practices on the way that make them habitual representatives of the party.

Not only explanatory factors with significant effects on the dependent variables provide challenging cases, but also those that were not proven relevant. The hypothesized effects of district magnitude, candidacy, local positions, SMD career and ideological distance were not supported. Most interestingly, - as opposed to previous research findings (Papp, 2011) - the hypothesis of shadowing was rejected. MPs who were interested in the electoral competition on the nominal level, but got elected on party lists are not more constituency oriented than those who did not have $1^{\text {st }}$ tier electoral ambitions. This suggests two things. First, the representation of constituents who voted for the side that lost is not fully realized, if representation is understood in a territorial dimension. Second, nominal level candidacy does not proxy future candidacy, which would be one of the reasons behind list members acting as $1^{\text {st }}$ tier MPs. Losing candidates do not take their list seats preparing to the "next round". This is either because Hungarian MPs lack that level of electoral consciousness or because of the uncertainty of candidacy at the next elections. Furthermore, if a member has a safe position on the party list, without habitual motivations, constituency work is just an inconvenience. Nevertheless, local candidacy affects the choice between the voters' opinions and the party position, which indicates that this factor might hold relevance in further research after all. On the level of attitudes, however, its importance is limited.

The insignificance of local political positions is another peculiar issue. The fact that holding elected local office does not affect constituency orientation indicates that MPs are able to compartmentalize their jobs as national legislators and local office holders. As the former, they do not feel the need to bring in the interests of the local area. Putting it this way, it is not necessarily true, as mandate type explained all the variance that local positions might have explained. A more correct interpretation would argue 
that the effect of local positions does not add anything to the influence mandate type has on representational attitudes. 


\section{CHAPTER 4 - MEMBER PERSONALIZATION AND CONSTITUENCY ORIENTATION AS CAMPAIGN STRATEGY ${ }^{94}$}

Moving down with the level of abstraction - after explaining the variance in the focus and the style of representation -, the next step of the analysis aims to grasp personal vote-seeking in relation to campaign strategies. In this chapter, I base my argument on the idea of Zittel and Gschwend, who perceive personal vote-seeking as individualized campaign strategies (Zittel and Gschwend, 2008). Compared to constituency-oriented attitudes, campaign personalization is a more practical measure of the relative importance of personal reputation to the party label. Thoughts about the value of personalization are manifested in actual behaviour. However, the strength of these measures is diminished by the fact that actual behaviour is often restrained not only by the institutional factors but by the party as well. Campaign strategies are influenced by the party centre more easily than attitudes are, oddly making this arguably more practical measure of member personalization less suited to measure the representatives' true preferences, as they do not only rely on the MPs' hearts but party pressure as well. Obviously, party strategies will play a greater role in shaping member personalization in this chapter. Hence, one should be careful when comparing the results of the different chapters, although - as shown later in this chapter - measures correlate to a substantial extent.

This chapter will examine the relationship of electoral motivations and career backgrounds to the ways Members of Parliament organized their campaigns in 2010. Results, therefore, may only be generalized to the very population of representatives, and establishing whether the revealed connections hold to candidates who did not get elected is beyond the scope of this dissertation. Hence, it is important to emphasize that this chapter does not introduce findings on campaign strategies and their background per se, but uses these measures to proxy the way MPs (and parties) think of the value of personalization, which later on, appears in their acts of representation (see Chapter 5).

The structure of the chapter is as follows. First, I introduce the dependent factors, which measure four different aspects of personal campaigning. Second, the independent

\footnotetext{
${ }^{94}$ I am grateful for the general comments of András A. Gergely, Attila Bartha, Ervin Csizmadia, Balázs Kiss, Péter Róbert, Andrea Szabó and Gabriella Szabó. I am also thankful to Dániel Róna, who prepared very detailed comments to this chapter.
} 
variables are re-introduced, and put into a new context. Bivariate analysis will unfold the possible interrelatedness of the variables. Third, multivariate models will examine the effects of the selected independents on the four dimensions of personalization as campaign strategy.

\subsection{The four dimensions of personal campaigning}

Zittel and Gschwend define four different components of personalization: campaign norms, means, agenda and organization (Zittel and Gschwend, 2008). In this section, I briefly describe these, and review the measurement considerations with regards to the data at hand. The chapter will present results based on the MP survey of the Hungarian Election Study carried out in 2010.

Campaign norms are captured by asking the respondents to place the main goal of their campaigns on a one-dimensional scale of attracting as much attention to their personal candidacy as possible versus furthering their parties' reputation ${ }^{95}$. In the 2010 MP survey we offered an 11-point scale: the respondents were given the opportunity not to commit themselves to one or the other alternative, but to assess the two goals as equally important. $32.2 \%(\mathrm{~N}=69)$ of the responding MPs would distribute their resources evenly between personal and party campaigns. Furthermore, the dominance of party campaign prevails: $15.6 \%$ (33) of the members favour pure party ${ }^{96}$ campaigns, while only $4.2 \%$ (9) prefer personal vote-seeking exclusively ${ }^{97}$ (see Figure 4.1). However, if merging the categories below and above the mode, a more balanced picture stands out. Only a slightly larger group of representatives claimed the partisan focus of their campaigns to be more important than the personal aspects: $34.6 \%$ (74) favour party campaigns, whereas $33.2 \%$ (71) prefer personalization.

\footnotetext{
${ }^{95}$ „What was the primary aim of your campaign? Where would you place yourself on a scale from 1 to 11 , where 1 means 'to attract as much attention as possible for me as a candidate' and 11 means 'to attract as much as possible attention for my party'?"

${ }^{96}$ Took the scale value 1 .

${ }^{97}$ Took the scale value 11.
} 


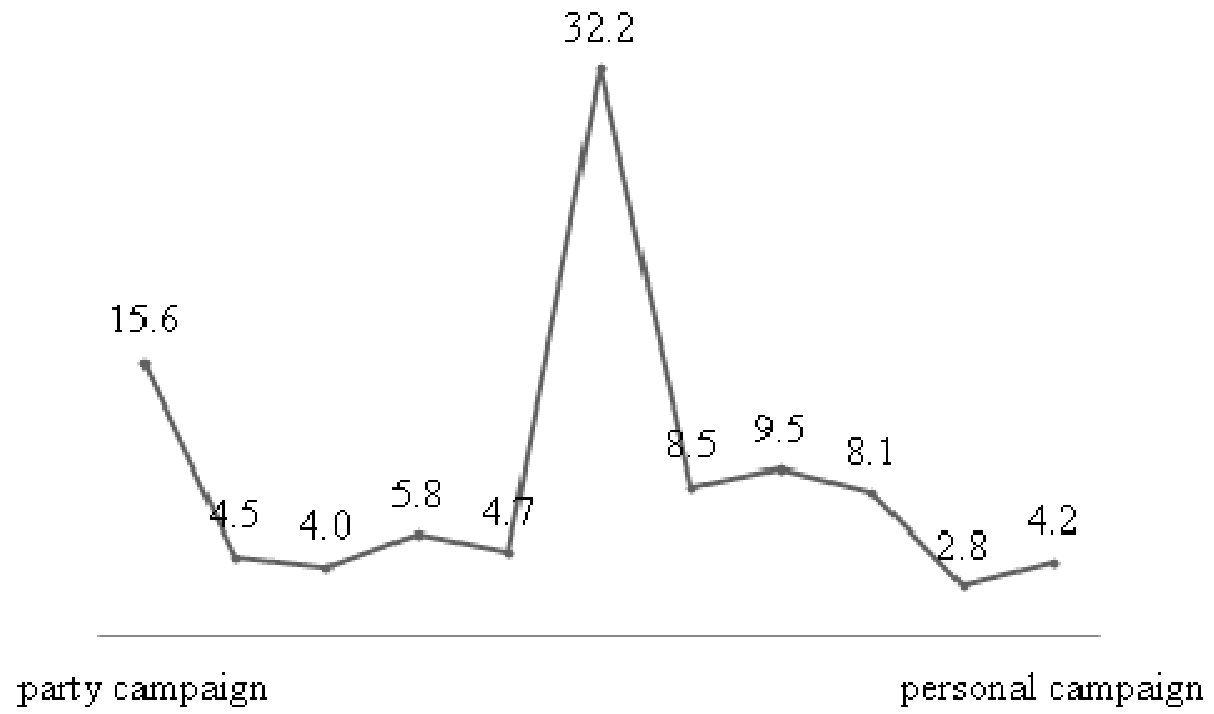

FIGURE 4.1. The distribution of campaign norms (\%)

Campaign means refer to the modes of separating "candidate and party image in the public eye" (Zittel and Gschwend, 2008, p. 989). Table 4.1 shows the frequency of the usage of seven different tools of personal campaign and their origins in terms of whether the MP's personal team is responsible or rather the party centre. The majority of the Hungarian national representatives reported to have used at least one of the personalized campaign tools. The usage of the listed tools is in synch with their perceived importance by the MPs $^{98}$ : the larger the utility of the given tool ${ }^{99}$, the greater the chance of an MP engaging him- or herself in the related activity. However, not only the application of the tools depends on their perceived usefulness, but whether the MP's personal staff is involved or not. Important campaign methods are very likely to be placed into the hands of a smaller group overseen personally by the MP him- or herself $^{100}$. The proportion of tasks carried out by the personal team is unexpectedly high considering the distribution of campaign norms shown by Figure 4.1. This suggests that even MPs who allocated their resources to a partisan campaign have felt the need to practice more personalized ways of campaigning. This indicates that personal and party

${ }^{98}$ Organizing social gatherings is the only exception, where - due to minimal variance - no statistical connection is observable between attending these events and their perceived utility.

${ }^{99}$ Members were asked to assess the importance of the listed campaign tools in their campaigns on a four-point scale ( 1 - not at all important, 2 - not very important, 3 - fairly important, 4 very important).

${ }^{100}$ Again, social gatherings serve as exceptions along with using personalized posters during the campaign, where the support of the party appears to be the most prominent. 
campaign does not necessarily are the two ends of the continuum, but it can very well be integrated into the same strategy: party campaign is able to incorporate substantial effort to personalization.

TABLE 4.1. Personalized campaign tools: usage and origins

\begin{tabular}{ccccc}
\hline & $\begin{array}{c}\text { The usage of the personalized } \\
\text { campaign tools }\end{array}$ & $\begin{array}{c}\text { Personalized campaign tools created by } \\
\text { the MP's personal team }\end{array}$ \\
\hline $\begin{array}{c}\text { II } \\
\text { Personalized campaign } \\
\text { tools }\end{array}$ & $\mathrm{N}$ & $\%$ & $\mathrm{~N}$ & $\%$ \\
\hline Posters & 164 & 77.2 & 57 & 34.6 \\
Ads in local printed media & 149 & 71 & 127 & 81.7 \\
Office hours & 157 & 74 & 134 & 83.3 \\
Social gatherings & 206 & 96.7 & 153 & 75.1 \\
Flyers & 174 & 82.4 & 123 & 70.6 \\
Spots in local radio/TV & 135 & 63.7 & 108 & 76.2 \\
Website & 161 & 76.1 & 122 & \\
\hline
\end{tabular}

${ }^{\mathrm{T}}$ The whole sample represent $100 \%$.

${ }^{\text {II }}$ MPs using the given tool represent $100 \%$.

Figure 4.2 presents the distribution of the aggregated usage of the different personalized campaign tools. Percentages indicate the number of personalized means MPs used during their campaign in $2010.44 .1 \%(\mathrm{~N}=102)$ claimed to use all methods listed, while $10.2 \%$ (24) applied none of them. Oddly, this newly obtained count variable is not monotonous: starting from zero and increasing the number of tools, the proportion of MPs decreases monotonously; however, from four onwards, the number of representatives begins to increase sharply. Evidently, the relationship between this aggregated variable and the norms of campaign is prominent ${ }^{101}$ : members ready to run more personalized campaigns choose to use more personalized campaign tools indeed.

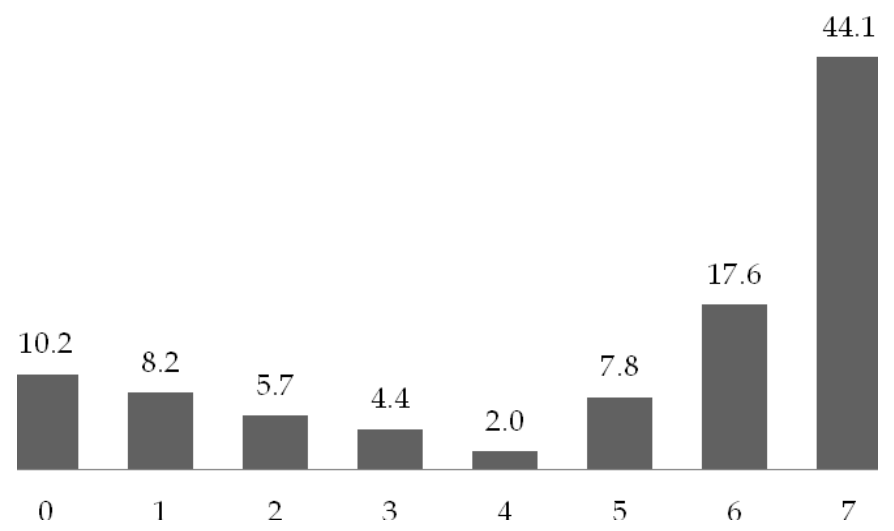

FIGURE 4.2. Aggregated usage of the different personalized campaign tools (count variable, \%)

${ }^{101}$ Pearson correlation $=.567 * * *$ 
With regards to campaign agenda, Zittel and Gschwend (2008) argue that they "should highlight issues that are relevant for the particular constituencies" (Zittel and Gschwend, 2008, p. 989). Raising district-specific issues communicates not only that the candidate cares about the constituency concerned but that (s)he is familiar with the specialities of the given local area as well. As to constituency-related topics brought up during campaign, $69.2 \%(\mathrm{~N}=144)$ of the respondents claimed that they included problems specifically related to their districts and which were left unattended by the party. Not surprisingly, MPs who preferred more personalized campaigns tend to have covered district-specific topics significantly more often than promoters of the party ${ }^{102}$.

Regarding the topics raised, issues are either moderately specific or very much so. Moderately specific issues grasp general problems with a slight local concern, like corruption, public safety, infrastructure, unemployment, health care issues etc. More specific campaign topics also relate to these rather general fields of interest, but mention something very concrete about their relation to the district, what makes these campaign agendas connected to the districts to a greater extent $(61.6 \%$ of the MPs touching upon locally relevant issues mentioned moderately district-specific problems). Very specific issues often concern local products (for example chocolate, grain and fruit), issues of environment protection and a very concrete mention of diverse infrastructural projects ( $38.4 \%$ addressed very specific issues in their campaigns) ${ }^{103}$.

In Zittel and Gschwend's work (2008) the notion of campaign organization relates to the distribution of financial resources within the campaign budgets of the members. A growing proportion of party resources indicates a more party-oriented campaign, while a smaller party contribution enables a certain independence from the party lines, and presents the opportunity to pursue more personalistic goals in campaigning (Zittel and Gschwend, 2008, p. 989). However, this being very sensitive information - and subject of fierce political debates -, Hungarian MPs are usually not asked about their budgets directly in MP surveys. Instead, the structure of the budget is proxied from a human resource angle: the proportion of staff-members who work for the MP on behalf of the party $^{104} \cdot 71.2 \%(\mathrm{~N}=165)$ of the respondents had personal campaign staff at their

\footnotetext{
${ }^{102} \mathrm{~F}=31.19 * * * ; \mathrm{Eta}=.363$

${ }^{103}$ Concrete issues are not mentioned in order to preserve respondent anonymity.

104 „How large was your campaign team and how many of these people were provided by the party?"
} 
disposal, where on average, $84 \%$ of the staff-members were personally recruited by the candidates.

The nature of the dependent variables and the fact that campaign strategies are highly centralized in Hungary makes it difficult to perfectly separate the intentions of the party and the MPs. However, these are the very characteristics that make it possible to account for personalization as the campaign strategy of the party centre. With other words, the drawback of using these variables to measure member personalization serves us with an indirect measure of how parties trade-off between focusing on the party aspect of the campaign and on personalization. The four measures of campaigning incorporate member attitudes with different intensity. The most "honest" measure of member perceptions are campaign norms and agenda. The former represents a perception rather the true state of the campaigns. It measures how representatives felt they manoeuvred between pursuing partisan and personalistic goals. It is fair to assume that members who attach a greater value to personalization see their campaigns as having been structured according to this ideal. As shown later in this chapter (see Table 4.12), members performing more personalized campaigns are very likely to be the ones who claim to represent the constituency after they were elected. Hence, differences in the values of campaign norms reflect the differences of how MPs perceive the importance of personalization and constituency representation. Along campaign norms, agenda is the most suited measure to capture the MPs' endeavour to seek interests beyond party goals. Mentioning constituency-specific issues during the campaign is the easiest way to separate one's image from the party's without doing too much harm to the latter. District related topics do not defy party interests in either case, as they mostly touch upon problems independent of issues on the national political agenda. Contrarily, campaign means and organization are more of a subject to party influence. The range of applied tools is usually assigned by the party centre to the individual candidates. As to organization, the percentage of team members hired by the MPs themselves, often depend on the distribution of various party resources. This means that additional resources pulled to employ extra team members have to have the party's blessing one way or another. In this sense, the existence of the personal campaign staff and the proportion of personally hired team members are largely dependent on the party's preference regarding personalization with respect to the very candidate in question. On the other hand, a reverse reasoning might also appear viable, namely that increased 
party support - in cases where it should decrease ${ }^{105}$ - indicates that member personalization is a central campaign strategy. Therefore the party is willing to invest human resources ${ }^{106}$ into the personal campaigns of its candidates. The main difference between the two approaches is that while in the first case members play an active role in "calling in" the staff members, regardless of whether the financing is related to the party or not, in the second, allocating extra resources to the candidate is an utmost party decision. By this reason, besides the fact that the party has control over campaign organization either way, the first case proxies strong personal motivation, whereas the second points to overall party strategy. ${ }^{107}$

\subsection{Personal campaigning and independent variables - bivariate relationships}

Regarding the four dimensions of campaigning, the selection of explanatory factors must differ from what is presented in the preceding empirical chapter (Chapter 3). Unlike attitudes toward representation, these measures represent what was and not what is. Explanatory factors, therefore, should be selected so that they match the time frame of the dependent variables, and describe MP status at the time of the elections in 2010 and not during the current term of 2010-2014, when the data was collected. However, the logic of the causal relationships remains the same, leaving the hypotheses regarding their effects unchanged. Consequently, incumbency in 2006 entails the type of mandate the MP held during the 2010 campaign. It goes without saying that local political background does not represent multiple office-holding any more, since in Spring 2010 members coming from outside the parliament held local positions only. In terms of

\footnotetext{
${ }^{105}$ For example theory would suggest that in the case of single member district candidates, the proportion of personal staff hired by the candidates increases.

${ }^{106}$ Besides paid employees, activists are taken into account as well. The cost attached to volunteers being allocated to the individual candidates is the opportunity cost of them not working on the central party campaign.

${ }^{107}$ Short before closing this manuscript, Karlsen and Skogerbø (Karlsen and Skogerbø, 2013) came out with their idea to set up two dimensions of campaigning which incorporates the aspects applied in this chapter. In their view, campaign organizations add to the organizational and strategic dimension, while norms and agenda embody the communicative focus of campaigning. By separating localization and party centeredness, they show that "a campaign might be localized in both organizational and communicative terms, but still be party-centred on both dimensions" (Karlsen and Skogerbø, 2013, p. 3) using Norway as a case study.
} 
candidacy, the meaning of the variable changes in a sense that as present (2010) type of mandate will not be a part of the equation, candidacy does not have to be restricted only to members who were running in SMDs but lost to their competitors. Candidacy will be measured as it is: members running in SMDs will be contrasted to MPs who were not. Consequently, based on this analysis, it would not make much sense to conclude on the relevance of the "shadowing hypothesis", which only gains significance after the MPs are elected. On the other hand, factors like party leadership, seniority and ideological distance are not altered. In the case of ideological distance, however, it is assumed that the difference between the placement of the party and the MP on the left-right scale did not substantially change during the period between the campaign and June 2010, when the data collection took place. Therefore, present ideological distance is expected to proxy past ideological distance rather well.

As suggested above, the logic of explanations does not differ from the approach introduced in Chapter 3. Candidacy in single member districts stand for direct electoral motivations. Members do shape their behaviour to reach particularistic goals, in this case to get (re-) elected. In this sense, the Mayhewean approach that perceive representatives as "single minded seekers of re-election" (Mayhew, 1974, p. 16) will structure member attitudes and behaviour. MPs who wish to be elected in SMDs will adjust their campaigning strategies to be more person-oriented and put a greater emphasis on issues that concern the local area compared to members with different electoral motivations. Incumbency, party leadership and seniority concern the current positions of the MPs, therefore, they resemble what Searing defined as position roles (Searing, 1994). Motivations to pursue personalization arrive from the MPs' actual positions, what settle the boundaries within which the members have room to manoeuvre. Party leaders may be less focused on leading candidate-centred campaigns by the reason of their duties of furthering the party's interests. To prove themselves worthy of the party's trust, newcomers are supposedly more reclined upon the party will than senior members. Incumbents prefer constituency orientation because this is what is required of them as representatives of a given territorial area. Motivations arising from the current positions of the MPs are to consider incentives created by their jobs. Finally, previously held nominal level mandates and ideological distance from the party involve serious motivational or habitual aspects. The effects of these variables stem neither from direct electoral motivations, nor from currently held positions. Therefore, they can be viewed as a residual category that is not defined by institutions or rules. Previous 
experience in single member districts captures the residual effect of serving as a representative of the nominal level, which makes MPs more sensitive to local issues and personalization. Ideological difference from the party is the main driving force of "true" personalization (Zittel and Gschwend, 2008), in a sense it is defined by scholars who portray personal representation and personalization as opposed to furthering party interests. Members, who do not fit into the party line, may distance themselves by pursuing more individualistic goals, either in attitudes, campaigning or behaviour in parliament. The major goal of this chapter, again, is to establish the predominance of one explanation to the other by comparing the effects that the listed factors have on member attitudes and behaviour. Motivations, of course, cannot be clearly separated, which means that every above factor may have its position incentive as well as a habitual one. This is especially true in the case of party leaders. As Wahlke and his colleagues argue (Wahlke et al., 1962) that the parties play an important socialization role in the process of MPs developing role perceptions. In the competition for higher party offices MPs unintentionally acquire the attitudes of a party delegate. This is the reason why MPs who serve in high ranking party positions tend to consider the party as the focus of representation (Zittel, 2012). At this point, there is no reason to think that this is not true regarding personalized campaign strategies. However, campaigning being an utterly rational activity, party interests are being pushed to the front, especially as party leaders are held accountable for electoral defeat. With this end in view, leaders might efface the habitual aspects of their behaviour. This might also involve party leaders pursuing personalized campaign strategies, as in some constellations it serves the interests of the party. Therefore, party leadership will be considered more of a position role within the context of campaigning.

It is evident from the data presented in the previous section regarding the four dimensions of campaigning, that personal vote-seeking among the Hungarian parliamentarians is more widespread than one would expect based on the few incentives that the electoral system offers. With regards to the tier of candidacy, direct electoral goals support the initial hypothesis in three out of four aspects of campaigning (see Table 4.2). Representatives running in single member districts tend to favour a more personalized type of campaign, than those who had no interests in gaining any popularity in the smallest units of the electoral system. Nominal level candidates also appear to choose personalized campaign means from a broader range of tools: in average, they applied 6.2 of the listed methods, whereas list candidates only used 1.5. 
TABLE 4.2. The relation of campaign norms, means and organization to the type of candidacy

\begin{tabular}{cccc}
\hline Type of candidacy & Campaign norms $^{\mathrm{a}}$ & Campaign means $^{\mathrm{b}}$ & Campaign organization $^{\mathrm{c}}$ \\
\hline Party list only & $2.92(2.313)$ & $1.52(1.763)$ & $.908(.298)$ \\
SMD & $6.35(2.449)$ & $6.23(1.316)$ & $.73(.337)$ \\
\hline Total & $5.6(2.8)$ & $4.94(2.558)$ & $.759(.336)$ \\
F & $72.7^{* * *}$ & $487.55^{* * *}$ & 2.44 \\
Eta & .506 & .824 & .198 \\
\hline
\end{tabular}

Entries are mean values; standard deviation in parentheses

${ }^{a}$ Campaign norms are measured by an 11 point scale ( 1 - party campaign, 11 - personal campaign)

${ }^{\mathrm{b}}$ The number of personalized campaign tools.

${ }^{c}$ The proportion of personally recruited staff members.

$* \mathrm{p}<.1, * * \mathrm{p}<.05, * * * \mathrm{p}<.01$

As to the campaign tools applied by the members, the same tendency prevails (see Appendix 4.1). SMD candidates used personalized campaign tools more often of necessity. However, the listed means are not homogeneous in terms of how relatively inviting they are to the different types of members. The least characteristic differences between SMD and list candidates can be observed in the case of holding office hours and attending social gatherings. This indicates that these two were the ones that are the least associated with the tier of candidacy, shifting the emphasis to the fact of the nomination - or to being a politician - as it is, regardless of its level. Even politicians, who are not interested in entering the competition for the $1^{\text {st }}$ tier seats are motivated to ensure that the voters have the opportunity to seek out an appointment; and making public appearances is also a must. These occasions are also personalized in a sense that the candidate has to be of attendance, but need less investment either on the party's or the candidate's side. Additionally, the remaining listed items require a level of personalization which would be naive to expect from members who did not aspire to $1^{\text {st }}$ tier parliamentary positions.

The existence of the personal campaign team shows a significant connection to the tier of candidacy. $93.9 \%$ of the SMD candidates had personal staff to assist them during the campaign, while only $22.7 \%$ of list candidates did (see Appendix 4.1). Regarding the proportion of staff members hired by the party (campaign organization), candidacy does not seem to be of any significance, in fact, party list candidates appear to hire a larger proportion of their staffs themselves (see Table 4.2). With other words, resources pulled from the party do not vary across the different types of candidacy: parties support SMD and party list candidates to an equal amount. This also highlights the importance of the $1^{\text {st }}$ tier in the electoral competition - which is hardly a new finding -, and the 
parties' willingness to risk the unity of party character in order to gain extra votes from a more personalized campaign on the lower level of the electoral competition.

Issues raised by the MPs as candidates show a great deal of variation in terms of candidacy as well. $78.9 \%$ of nominal level candidates claimed to have raised at least one topic that had an exceptional local significance, but was not mentioned in the party's campaign (see Appendix 4.1). Putting this into context, this proportion was 31 $\%$ in the case of members who were running only on party lists. The issues, however, were no different in terms of specificity: if a list candidate raised a constituency-related issue, it was not less specific than the problems touched upon by their SMD competitors $^{108}$. The case of list candidates mentioning local issues in their campaigns raises an interesting question, namely why they specialize the campaigns even if they are seemingly not interested in gathering the extra information to connect to the local voters. Examining the characteristics of these members two things stand out. First, almost $54 \%$ of them served as local politicians at the time of the elections. This indicates that their efforts to address the district-specific issues may not come from their electoral ambitions, but from their work as mayors or local council members, for instance. It is therefore, probably, that what we see in the national level campaign is the manifestation of the perception of these members of their jobs on the local level. Second, almost $70 \%$ of the MPs who were nominated on party lists only, but still raised issues related to the local level were running for local political positions during the fall of 2010 .

Turning to variables not directly related to the electoral competition, local political positions appear to have a substantial effect on how MPs shape their campaign strategies. According to Table 4.3, members who held local positions at the time of the 2010 campaign were more likely to favour personal campaigns, than those who have no further elected political positions. Also, the usage of personalized campaign tools shows a moderate but significant variation between local politicians and members with no local ties. The variety of methods differs significantly between the two groups as well: most of the listed tools were more likely to be applied if the member held local political office prior to the election. The most prominent differences appear, again, in the cases of holding office hours and making local appearances (see Appendix 4.2). These are the tools that are probably applied in connection with the local position as well, especially,

${ }^{108} \chi^{2}=.954$ 
office hours, which is a must in local politics (Keil and Papp, 2011). The additional cost of carrying out these activities, therefore, is smaller in the case of local politicians, who can easily use this for their advantage. The same applies to the proportion of staff hired by the MPs themselves (Table 4.3): local politicians seem to put extra manpower into their campaigns compared to those who can only rely on the support of the party centre. For them, it is easier to pull local party employees and activists into their personal campaigns on the one hand, and they are able to draw funding from multiple resources on the other. In this sense, local political background creates a measurable advantage in terms of visibility, through constant local presence by holding office hours and attending social gatherings, but on the financial level as well (through the diversity of resources). This is probably why they have personal campaign teams in the first place with a greater chance than members who are not tied to the local level (Appendix 4.2). $87.3 \%$ of local politicians worked with personal staff, while this percentage was $66.3 \%$ among national politicians, all of them being SMD candidates at the same time.

As for agenda, $76.8 \%$ of local politicians mentioned issues related to the constituency, which creates a significant difference as opposed to MPs who are solely national representatives $(57.8 \% \text {, for details see Appendix 4.2 })^{109}$. Due to their presence in the constituency, local politicians are naturally more up-to-date on local problems and issues (Keil and Papp, 2011), substantially decreasing the cost of information gathering during the campaign. In other words, the additional information associated with their jobs as local office holders creates a further advantage in the electoral competition for single member district seats.

TABLE 4.3. The relation of campaign norms, means and organization to local political positions

\begin{tabular}{cccc}
\hline Local background & Campaign norms $^{\mathrm{a}}$ & Campaign means $^{\mathrm{b}}$ & Campaign organization $^{\mathrm{c}}$ \\
\hline National MPs only & $4.86(3.148)$ & $4.3(2.689)$ & $.756(.324)$ \\
Local office holders & $6.11(2.415)$ & $5.38(2.374)$ & $.885(.203)$ \\
\hline Total & $5.6(2.799)$ & $4.94(2.558)$ & $.841(.257)$ \\
\hline F & $10.76^{* * *}$ & $10.37 * * *$ & $9.65^{* * *}$ \\
Eta & .22 & .208 & .238 \\
\hline
\end{tabular}

Entries are mean values; standard deviation in parentheses

${ }^{a}$ Campaign norms are measured by an 11 point scale ( 1 - party campaign, 11 - personal campaign)

${ }^{\mathrm{b}}$ The number of personalized campaign tools.

${ }^{\mathrm{c}}$ The proportion of personally recruited staff members.

$* \mathrm{p}<.1, * * \mathrm{p}<.05, * * * \mathrm{p}<.01$

${ }^{109}$ In terms of the specificity of issues, no significant connection was found to holding local positions $\left(\chi^{2}=.057\right)$ 
The same reasoning is viable in the case of incumbent MPs, who served as single member district representatives between 2006 and 2010. Their information advantage might very well be manifested in the topics they raised in the course of their 2010 campaigns. Data supports this suggestion on the level of the bivariate analysis: incumbents are more likely to raise questions with a specific local focus, than members serving as list MPs before the election or newcomer aspirants ${ }^{110} .85 .4 \%$ (35) of SMD incumbents dealt with these special topics, while this percentage is 65.3 (109) in the case of their competitors. This argument is further strengthened by the results of the very same analysis differentiating between incumbents, those who held SMD positions before 2006 and those who had never served as SMD representatives. In this case, data still support the advantage of incumbents, but emphasizes the importance of previous moments of the representatives' career paths as well: $81.8 \%$ of the former SMD MPs raised special issues during their campaigns. Additionally, $64.5 \%$ (100) of MPs with no SMD careers touched upon local issues not discussed by the party. The difference of the three groups of MPs holds for the whole population (see Appendix 4.3). ${ }^{111}$

Knowledge of the local issues appears in the case of members who held the position before 2006, due to three possible reasons. First, almost $40 \%$ of them held elected local office at the time of the data collection (June 2010) and during the period of the 2010 campaigns. The source of information, therefore, might not be the previous SMD position, but the continued presence in politics on the local level (position explanation). Secondly, previous political experience affects motivations in the present, in this case former SMD positions shape personal vote-seeking incentives (habitual explanation). Thirdly, and most viably, $84 \%$ of MPs with SMD background prior to 2006 ran for the seat again in 2010. Hence, nominal level candidacy might be the most important driving force of raising local issues, which points us back to the election-related motivations of Members of Parliament.

With regards to campaign norms, Table 4.4 presents the results of the bivariate analysis. Incumbents appear to have esteemed personal reputation seeking instead of running a party centred campaign. Oddly, members with previous SMD level legislative experience placed themselves closer to the party centred end of the scale than those who

${ }^{110} \chi^{2}=6.24^{* * *}$, Cramer's V=.173

${ }^{111}$ No significant relationship was found between careers is SMDs and the specificity of issues raised $\left(\chi^{2}=1.202\right)$. 
had never held nominal level mandates. According to the post hoc tests ${ }^{112}$, the difference between the latter two is not notable, as they form a homogeneous subset of the SMD career variable. Consequently, it is not the experience that distinguishes between the MPs, but rather actual political status.

TABLE 4.4. The relation of campaign norms, means and organization to MPs' careers in single

\begin{tabular}{cccc}
\multicolumn{4}{c}{ member districts } \\
\hline SMD career & Campaign norms $^{\mathrm{a}}$ & Campaign means $^{\mathrm{b}}$ & Campaign organization $^{\mathrm{c}}$ \\
\hline None & $5.23(2.779)$ & $4.61(2.604)$ & $.819(.284)$ \\
Incumbent & $7.19(2.358)$ & $6.19(1.976)$ & $.897(.181)$ \\
SMD MP before 2006 & $5.04(2.717)$ & $5.23(2.479)$ & $.888(.102)$ \\
\hline Total & $5.6(2.799)$ & $4.94(2.558)$ & $.841(.257)$ \\
\hline F & $8.92 * * *$ & $7.09 * * *$ & .133 \\
\hline Eta & .28 & .241 &
\end{tabular}

Entries are mean values; standard deviation in parentheses

${ }^{a}$ Campaign norms are measured by an 11 point scale ( 1 - party campaign, 11 - personal campaign)

${ }^{\mathrm{b}}$ The number of personalized campaign tools.

${ }^{\mathrm{c}}$ The proportion of personally recruited staff members.

$* \mathrm{p}<.1, * * \mathrm{p}<.05, * * * \mathrm{p}<.01$

As to the tools applied during the 2010 campaign (see Table 4.4 and Appendix 4.3), nominal level incumbents used significantly more (6.19 on average) personalized campaign techniques than either MPs with former SMD background (5.23) or those without any nominal level parliamentary experience (4.61). Post hoc tests ${ }^{113}$ reveal that the significant relationship between SMD background and campaign means are caused by the sharp contrast between incumbency and having no previous nominal level legislative experience at all ${ }^{114}$. These results highlight the importance of the currently held positions to the habits that originates from the experiences of the past. Office hours and personal websites are the two instances that created the largest difference between the three groups. As suggested earlier in this chapter, office hours are more cost effective in the case of a local politician, either holders of elected local office, or single member district representatives. SMD incumbents, obviously, were tied to the local level through their offices during the 2010 campaign. Therefore the cost of this particular tool of campaigning was substantially lower, than in the case of MPs having to travel to the constituency only for the campaign's sake. As to the usage of personal

\footnotetext{
${ }^{112}$ Tests were conducted under the equal variance assumption (Levene statistic $\left.=1.63\right)$.

${ }^{113}$ Multiple comparison tests (Tamhane's T2, Dunnet's T3 and C) were calculated under the assumption that group variances are not equal (Levene Statistic $=1.63)$.

${ }^{114}$ Mean difference is 1.586 (s.e.=.359)
} 
webpages during the campaign, empirical evidence suggests, that incumbent MPs were more familiar with campaigning on the internet, as they already were regularly updating their homepages with details of their parliamentary and local activities (Ilonszki and Papp, 2012; Oross and Papp, 2010). Hence, the additional cost of campaigning on the internet was substantially lower than in the case of MPs not having websites before the 2010 campaigns.

From an organizational point of view, the advantage of incumbents is evident (Appendix 4.3): $95.1 \%$ of members holding SMD positions at the time of the 2010 elections had personal campaign teams, whereas $75-75 \%$ of MPs from the other two groups had. The relatively high proportion of members having personal staff in the latter groups is explained by the high percentage (90-90\%) of those who were entering the nominal level electoral competition. Furthermore, as ANOVA results displayed in Table 4.4 suggests, there is no evidence that incumbents hire a greater proportion of their staffs themselves compared to the other two groups of MPs. Challengers and incumbents are able to mobilize exactly the same amount of resources if they entered the competition for the seats. Hence, incumbency does not seem to offer any advantages - strictly - on the level of the human resource related campaign financing.

The role of seniority in campaigning is less significant as international theory would suggest. Newcomers do not work harder to differentiate themselves in the eye of the voters. On the contrary, senior members claimed to allocate a greater part of their resources on average into their personal campaigns. Similarly, the number of campaign tools used is higher in the case of senior members; however, this difference was not large enough to produce significant results. In terms of campaign organization, senior members go for a more personalized campaign, as they hire a larger proportion of their staffs themselves than newcomers ${ }^{115}$. Centralized candidate selection leaves no other choice for newcomers to get selected, but to promote their special commitments toward the party. One could argue that junior members are less candidate-centred because of their poor local embeddedness, which leaves them "disposable" and more exposed to the party centre. However, this is not the case, as $65.6 \%$ of junior members come from a solid local background into national politics (Várnagy, 2012). The lack of local embeddedness, therefore, is not the reason why they are less willing (or able) to pursue

\footnotetext{
115 The proportion of members who had personal campaign teams does not differ in the case of newcomers (77.7 \%) and senior members (80.2\%) (Appendix 4.4).
} 
individualistic electoral goals. The answer is probably political loyalty, which is often tested in the first term of the representatives. MPs who had already proven to be loyal to the party in parliament get a larger sweep regarding their actions in their constituencies or campaigning than MPs whose loyalties have not yet been tested ${ }^{116}$. This seems especially true in the case of Fidesz, where seniors are indeed more candidate-centred when it comes to distributing resources. Regarding the other parties in the sample, the opposite appears to be true. Here, junior members were indeed pursuing more personalized campaigns than senior ones. Results displayed by Table 4.5 are most likely the reason of the predominance of Fidesz in the sample (which represents the partisan setup of the parliament rather well). According to descriptive evidence (Mihályffy, 2011 , p. 26), Fidesz candidates were hand-picked by a small group of party leaders ${ }^{117}$, which made candidates want to closely follow partisan appeal, instead of pursuing a greater level of personalization, regardless of whether they were newcomers or more experienced members.

The tendencies regarding the methods of campaigning correspond to the previous findings in this chapter: the dominance of office hours prevails in the case of more experienced members. As to special, constituency related topics, senior members tend to be more responsive to local issues than newcomers, although, as pointed out earlier, a considerable proportion of newcomers came from local politics. Therefore, information advantage cannot be the reason why these differences are observed. ${ }^{118}$

TABLE 4.5. The relation of campaign norms, means and organization to seniority

\begin{tabular}{cccc}
\hline Seniority & Campaign norms & Campaign means & Campaign organization $^{\mathrm{c}}$ \\
\hline Senior member & $6.037(2.928)$ & $5.2(2.59)$ & $.884(.194)$ \\
Newcomer & $5.148(2.597)$ & $4.67(2.509)$ & $.791(.31)$ \\
\hline Total & $5.6(2.799)$ & $4.94(2.558)$ & $.841(.257)$ \\
F & $5.49^{* *}$ & 2.43 & $5.45^{* *}$ \\
Eta & .159 & .102 & .181 \\
\hline
\end{tabular}

Entries are mean values; standard deviation in parentheses

${ }^{a}$ Campaign norms are measured by an 11 point scale (1 - party campaign, 11 - personal campaign)

${ }^{\mathrm{b}}$ The number of personalized campaign tools.

${ }^{\mathrm{c}}$ The proportion of personally recruited staff members.

$* \mathrm{p}<.1, * * \mathrm{p}<.05, * * * \mathrm{p}<.01$

${ }^{116}$ In this sense, senior members of Jobbik and LMP count as newcomers too, as this is their first terms as the representatives of the mentioned parties.

${ }^{117}$ Viktor Orbán, László Kövér, Gábor Kubatov, Mihály Varga (Mihályffy, 2011, p. 26)

${ }^{118}$ There is also no significant relationship between seniority and the specificity of district related issues. 
Consistent with the results concerning the relationship of focus of representation and the perceived ideological distance of MPs to their parties, members ideologically farther from their parties do not esteem personalization higher in either dimension of campaigning than MPs who fully share their parties' views (see Appendix 4.5). This stresses the fact that there is no evidence that personalized campaign behaviour stems from the rejection of the party line.

Last, but not least, party leadership seems not to affect campaign strategies to a substantial extent. The number of personalized campaign tools, campaign organization and agenda is not contingent upon the MPs' positions within their parties. Party leaders pulled off as personalized campaigns as backbench politicians, indicating that individualized strategies do not necessarily defy party interests. Party leaders were willing to advertise themselves, and focus on local issues instead of exclusively focusing on furthering the party's popularity. Backbench members proved to be more active than party leaders in most of the listed techniques of campaigning. Not only in the case of time consuming activities in which MPs cannot be substituted, but also in ones that do not require the MPs presence. The latter indicates that it is not exclusively the different time schedule (party leaders hypothetically being more occupied with party business) of the two groups of MPs, neither their stronger commitment to the party ${ }^{119}$, but their normally higher visibility and their better positions on the closed party lists that enables them to run less personalized campaigns (in exchange for an equal amount of personal vote). The different focus in campaigning shows in the scores of norms: leaders are indeed less concerned about their personal popularity, and allocated their resources more to their parties' campaigns (see Table 4.6).

\footnotetext{
${ }^{119}$ As they actually position themselves farther (.9 on average, std.dev. $=1.358$ ) away from the party on average than backbench representatives $(.7 ; .86)$. The difference in averages is not significant.
} 
TABLE 4.6. The relation of campaign norms, means and organization to national and regional party leadership positions

\begin{tabular}{cccc}
\hline Party leadership & Campaign norms $^{\mathrm{a}}$ & Campaign means $^{\mathrm{b}}$ & Campaign organization $^{\mathrm{c}}$ \\
\hline Not a party leader & $5.9(2.709)$ & $5.12(2.497)$ & $.86(.227)$ \\
Party leader & $5.08(2.89)$ & $4.63(2.647)$ & $.805(.307)$ \\
\hline Total & $5.6(2.799)$ & $4.94(2.558)$ & $.841(.257)$ \\
\hline $\mathrm{F}$ & $4.34^{* *}$ & 1.95 & 1.65 \\
Eta & .142 & .092 & .101 \\
\hline
\end{tabular}

Entries are mean values; standard deviation in parentheses

${ }^{\text {a }}$ Campaign norms are measured by an 11 point scale (1 - party campaign, 11 - personal campaign)

${ }^{\mathrm{b}}$ The number of personalized campaign tools.

${ }^{\mathrm{c}}$ The proportion of personally recruited staff members.

$* \mathrm{p}<.1, * * \mathrm{p}<.05, * * * \mathrm{p}<.01$

\subsection{Explaining campaign personalization}

One of the lessons of the bivariate analysis is that the effects of the different independent variables are hardly separable. Variable overlaps make it necessary to test the relationships in a multivariate setting. On the course of analysis, various models were built. Nevertheless, in the chapter, only the most parsimonious ones are presented and discussed in detail.

\subsubsection{The determinants of campaign norms}

To model the effect of the different independent variables on the relative perceived value of personalization to party campaign, simple OLS (Ordinary Least Squares) models were estimated $^{120}$.

${ }^{120}$ The Stata procedure regress was used to estimate the effects on the dependent variable. Observations are weighted using population weights (pweight) to ensure that data represents the population in terms of mandate type and party affiliation. 
TABLE 4.7. Results of OLS estimation of campaign norms

\begin{tabular}{|c|c|c|c|c|}
\hline & B (s.e.) & B (s.e.) & B (s.e.) & B (s.e.) \\
\hline Candidacy & $3.164(.449)^{* * *}$ & $3.153(.457)^{* * *}$ & $3.01(.456)^{* * *}$ & $2.999(.458)^{* * *}$ \\
\hline Local political positions & $1.077(.513)^{* *}$ & $.996(.548)^{*}$ & $.651(.368)^{*}$ & $.614(.445)$ \\
\hline Local candidacy & & $.123(.509)$ & & $.067(.449)$ \\
\hline Incumbent & $1.023(.499)^{* *}$ & $1.021(.504)^{* *}$ & $.817(.422)^{*}$ & $.816(.425)^{*}$ \\
\hline SMD MP before 2006 & $-.602(.746)$ & $-.619(.738)$ & $-.353(.696)$ & $-.36(.694)$ \\
\hline Newcomer & $-.412(.456)$ & $-.405(.45)$ & $.281(.401)$ & $.282(.402)$ \\
\hline Ideological distance & $.112(.157)$ & $.116(.155)$ & $.097(.133)$ & $.099(.133)$ \\
\hline Party leader & $-.178(.415)$ & $-.182(.411)$ & $-.286(.327)$ & $-.289(.327)$ \\
\hline Jobbik & & & $-.314(.602)$ & $-.297(.625)$ \\
\hline KDNP & & & $-.71(.527)$ & $-.705(.539)$ \\
\hline LMP & & & $-3.673(1.415)^{* * *}$ & $-3.652(1.43)^{* *}$ \\
\hline MSZP & & & $1.564(.435)^{* * *}$ & $1.576(.443)^{* * *}$ \\
\hline Constant & $2.478(.581)^{* * *}$ & $2.456(.592)^{* * *}$ & $2.629(.585)^{* * *}$ & $2.612(.601)^{* * *}$ \\
\hline $\mathrm{N}$ & 206 & 206 & 206 & 206 \\
\hline $\mathrm{F}$ & $19.18 * * *$ & $17.15 * * *$ & $10.08 * * *$ & $9.61 * * *$ \\
\hline Adj. $\mathrm{R}^{2}$ & .322 & .318 & .424 & .421 \\
\hline
\end{tabular}

Entries are coefficients; standard errors in parentheses. Standard errors are robust.

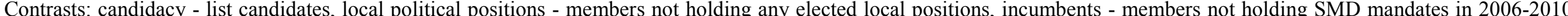
newcomer - members with at least one term experience as national representatives, party leader - backbench MPs, party - Fidesz.

Coefficients represent the change in the value of the dependent variable due to a one unit change in the related independent variables ${ }^{121}$.

$* \mathrm{p}<.1, * * \mathrm{p}<.05, * * * \mathrm{p}<.01$

${ }^{121} Y=\alpha+\sum B_{i} X_{i}+e_{i}$ 
The results of Table 4.7 reveal that electoral interests in the constituencies pose a large effect on how members evaluate the importance of personal to party campaigns. SMD candidates placed themselves - ceteris paribus - 3 points higher on average than list candidates on the scale from 1 to 11 , where higher values represent a higher level of personalization. The value of personalization appears on the nominal tier of the electoral system, regardless of the party centeredness of the electoral rules. Other significant variables set to zero, the average SMD candidate takes 5.6 on the dependent variable measuring campaign norms, from where (s)he is further "pushed" to the personal end of the continuum by career factors like local political background and incumbency. Thus, despite the dominance of the party over the person in the Hungarian electoral system, the original impact of the nominal level elections was not overridden by pure partisan strategy. Candidates and parties still think that personalization is a fairly practicable strategy of voter persuasion. Again, the features of the electoral system that maintain the superiority of the party - and the observation that personalization can occur under such rules - enables us to conclude that party interests are served by a certain level of individualization. Otherwise one could not observe this level of personalization, especially when it comes to distributing resources between personal and party campaigns.

As referred to it earlier, filling in local political positions has a significant positive effect on the value of personal campaigns. Elected local politicians pursue more personalistic goals in their campaigns, even if they are not entering the $1^{\text {st }}$ tier competition. Everything left unchanged, local politicians prefer personal vote-seeking to furthering the party reputation by 1.007 units on average. The positive effect of local political background suggests two things. First, personalization could become a habit to the local politicians. Admittedly, the local level with its closeness to the citizens creates the stance of putting a greater emphasis on the person. The dynamics of representation in local politics has the tendency of shifting the focus to an even lower level, than it is expected based on the national level connection (Keil and Papp, 2011) ${ }^{122}$. Second, the goal of re-election on the local level might very well overwrite the re-election incentives to the national parliament. Members whose primary objective is to be present in local politics may use the parliamentary elections to establish local visibility. This involves

\footnotetext{
${ }^{122}$ Local representatives tend to focus on problems of areas smaller than their constituencies. This is especially true in the case of councilmen elected on party lists.
} 
that the campaign for the national mandate is only an earnest of the competition for local political positions, which takes place during the fall in national election years. Although almost 6 months pass between the two campaigns, a rational strategy could be to begin voter persuasion in advance, to demonstrate the candidate's commitment to the local cause.

Introducing local candidacy into the models, the effect of local positions fade away, at least it is not significant on a $5 \%$ level anymore. Additionally, adding the new variable does not improve the model, on the contrary: both, the value of the F-statistic and the adjusted $\mathrm{R}^{2}$ decreases. Consequently, candidacy at the local elections does not affect norms of campaigning. Based on these developments, the effect of local political background is a consequence of the position held at the time of the 2010 campaign, rather than an election-related phenomenon.

Moving further, nominal level experience too seems to influence how MPs perceive the value of personal campaigning. However, past experience is only important as long as it involves serving as an SMD MP in the foregoing term (2006-2010). Incumbents were more eager to focus their resources to personalized appeal than members with no previous $1^{\text {st }}$ tier experience. Nominal level mandates held before 2006 do not seem to substantially affect campaign norms in a multivariate setting, which undermines the habitual explanations when it comes to norms of campaigning. Additionally, the joint effect of incumbency and previous experience (which are designed to measure SMD experience together) is not significant on a $5 \%$ level $^{123}$.

Regarding seniority, ideological distance from the party and party leadership positions, members tend not to differ as far as the choice between personal and party reputation seeking goes. Fixing the values of significant variables at zero, members position their campaign strategies closer to the party-centred end (2.478 units), and this value remains stable when changing member characteristics with regards to the above factors.

Results of the above models are somewhat altered when party affiliation is controlled for. The dominating effect of candidacy still prevails, however, the impact of local positions and incumbency does not appear as important. Jobbik and KDNP members do not differ from Fidesz in terms of their perception of how important personalization

${ }^{123} \mathrm{~F}=2.91^{*}$. Null hypothesis: the coefficients of incumbency and SMD mandates before 2006 are both zero. 
may be. LMP members performed significantly more party centred campaigns, which is consistent with the findings of Zittel and Gschwend, who found mainstream parties to pursue personalized campaigns with a greater probability than niche parties (especially new ones), that lack the local embeddedness of larger party organizations (Zittel and Gschwend, 2008). Nevertheless, the difference between Fidesz and MSZP members is more challenging. Socialist members focused their resources to personal campaigns: an average MSZP member placed his campaign by 1.5 units toward the personal end than a Fidesz member, ceteris paribus. This result is particularly interesting in the context of the previous findings, namely that direct electoral motivations were found to have the most prominent effect on the norms of campaigning. In the case of MSZP members, these motivations, however, appeared less profoundly on the nominal level, where Fidesz candidates dominated the competition. Due to the absolute majority rule on the $1^{\text {st }}$ tier of the electoral system - and taking the distribution of preferences within the population which clearly disadvantaged MSZP -, it would have been reasonable to push the resources to the PR-level campaign. But this is not what seemed to happen: MSZP focused on individual campaigns on a greater extent than Fidesz did, indicating that the value of personalization was thought to be important, even if there was no real chance of winning in the constituencies. It is important to stress here again that these results do not mirror the true state of resource allocation during the 2010 campaigns. It would be better to perceive campaign norms as how members thought their campaigns were structured. Furthermore, the perception of personalization reveals the effort to somehow cut the party fate adrift from the discredited party label, making personalization a party strategy in the end. Finally, the special features of the electoral system enable nominal votes to be "cashed in" as votes for the party. Therefore, concentrating on the $1^{\text {st }}$ tier campaign is to consider a rational strategy in the case of the Socialists.

The results resemble the findings of Mihályffy (Mihályffy, 2011) and Ughy (Ughy, 2011), who thoroughly documented the campaigns of Fidesz and MSZP. Mihályffy argues that the primary product of the Fidesz campaign was the party itself, which also appeared in their slogan "Csak a Fidesz!" 124 (Mihályffy, 2011, p. 43). The high degree of campaign centralization makes every attempt to personalize a party effort. Additionally, as Ughy points out, the campaign of the Socialists was also utterly

124 „Fidesz only!” 
centralized, however, it was centrally declared that candidates have to run campaigns that intentionally efface the partisan image (Ughy, 2011, pp. 60-61).

\subsubsection{The determinants of campaign means}

Turning to campaign means, first, the number of personalized campaign tools will be explained by the pre-selected independent variables, and then differences in the usage of the various campaign means are revealed. The dependent variable being a count, Poisson models ${ }^{125}$ (Cameron and Trivedi, 1998; Long, 1997) were estimated ${ }^{126}$. According to the results, single member district candidacy is the most influential factor explaining the variance of the dependent variable: SMD candidates used significantly more of the listed personalized campaign tools than party list contestants. There is nothing unexpected here; candidates running for seats on the most personalized level of the Hungarian electoral system evidently chose campaigning methods with a more profound personal focus. In the case of SMD candidates, the rate ratio of the number of personalized campaign tools increases by a factor of almost four ${ }^{127}$.

Local political background has proven to be an important explanatory factor as well. The average number of personalized campaign tools is about 1.1 times higher in the case of members holding local positions ${ }^{128}$. The question whether this effect is due to the future electoral plans at the local level arises again. Local candidacy seems to positively affect the number of personalized campaign tools. Local candidates apply significantly more of the listed methods compared to MPs who had no motivation to fill in multiple offices from October 2010. The effect of local political background, however, remained significant in the $2^{\text {nd }}$ model of Table 4.8 , although it showed a slight decline in magnitude. This result strengthens both the electoral-rational and the position approach: members ambitioning local political careers organize more personalized

\footnotetext{
${ }^{125}$ It has to be noted here, that negative binomial models were estimated as well to test the effect of possible overdispersion within the data, but it has not proven more effective in explaining the number of personalized campaign tools.

${ }^{126}$ The Stata procedure poisson was used to estimate the effects on the dependent variable. Observations are weighted using population weights (pweight) to ensure that data represents the population in terms of mandate type and party affiliation.

${ }^{127}$ Incident rate ratio $(\operatorname{IRR})=3.978$ (s.e. $\left.=.808\right), I R R=3.94(.604), I R R=4.05(.615)$ and $I R R=4.01$ (.614) in the models of Table 4.8 respectively.

${ }^{128} \mathrm{IRR}=1.207$ (s.e.=.068), IRR=1.13 (.05), IRR=1.1 (.05), IRR=1.06 (.037)
} 
campaigns on the one hand, and this effect does not quite capture the influence of currently held local positions on the other. The latter indicated that electoral motivations have to be augmented by explanations that hypothesize the significance of position roles. The slight superiority of the election-related explanations, however, is still maintained by the poor effect of incumbency on campaign means: SMD incumbents use just as many of the personalized campaign tools, than their colleagues.

As to the effect of the party on the dependent variable, candidates of the new parties (Jobbik and LMP) tend to use significantly less of the listed tools than Fidesz members. The major differences between Fidesz (and eventually KDNP and MSZP) and the newcomers showed in office hours ${ }^{129}$, spots in the local TV/radio ${ }^{130}$ and using personalized websites ${ }^{131}$. In the first instance, $61.5 \%$ of Jobbik MPs held office hours compared to the $78.3 \%$ of Fidesz representatives. $57.7 \%$ of Jobbik members appeared in the local electronic media, whereas $69.2 \%$ of Fidesz MPs did, while these proportions were 57.7 and $78.7 \%$ with respect to personal websites. According to the data, LMP was rather passive regarding all of the listed tools, except the attendance of social gatherings, in which case no difference between members of the various parties was found ${ }^{132}$. These results prove that older parties diversified the methods of their personalized campaigning to a greater extent than new ones.

\footnotetext{
${ }^{129} \chi^{2}=36.59^{* * *}, \mathrm{~V}=.416$

${ }^{130} \chi^{2}=23.6^{* * *}, \mathrm{~V}=.334$

${ }^{131} \chi^{2}=15.13^{* * *}, \mathrm{~V}=.269$

${ }^{132} \chi^{2}=3.704$
} 
TABLE 4.8. The results of Poisson models estimating the number of personalized campaign tools used during the 2010 campaign

\begin{tabular}{|c|c|c|c|c|}
\hline & B (s.e.) & $\mathrm{B}$ (s.e.) & B (s.e.) & B (s.e.) \\
\hline Candidacy & $1.381(.153)^{* * *}$ & $1.373(.153)^{* * *}$ & $1.398(.152)^{* * *}$ & $1.389(.153)^{* * *}$ \\
\hline Local political positions & $.188(.057)^{* * *}$ & $.124(.045)^{* * *}$ & $.094(.045)^{* *}$ & $.058(.035)$ \\
\hline Local candidacy & & $.101(.042)^{* *}$ & & $.068(.037)^{*}$ \\
\hline Incumbent & $.076(.04)^{*}$ & $.073(.039)^{*}$ & $.058(.036)$ & $.056(.035)$ \\
\hline SMD MP before 2006 & $.041(.048)$ & $.023(.041)$ & $.04(.045)$ & $.0302(.041)$ \\
\hline Newcomer & $-.028(.053)$ & $-.023(.052)$ & $.051(.046)$ & $.051(.046)$ \\
\hline Ideological distance & $.000(.018)$ & $.004(.017)$ & $.002(.017)$ & $.004(.016)$ \\
\hline Party leader & $.021(.043)$ & $.017(.043)$ & $.000(.0339$ & $-.003(.033)$ \\
\hline Jobbik & & & $-.146(.055)^{* * *}$ & $-.128(.059)^{* *}$ \\
\hline KDNP & & & $-.002(.048)$ & $-.001(.046)$ \\
\hline LMP & & & $-.685(.069)^{* * *}$ & $-.661(.073)^{* * *}$ \\
\hline MSZP & & & $.054(.033)$ & $.064(.035)^{*}$ \\
\hline Constant & $.321(.146)^{* *}$ & $.302(.145)^{* *}$ & $.366(.151)^{* * *}$ & $.349(.149)^{* *}$ \\
\hline $\mathrm{N}$ & 221 & 221 & 221 & 221 \\
\hline Wald $\mathrm{Chi}^{2}$ & $149.18 * * *$ & $171.14 * * *$ & $569.61 * * *$ & $597.03 * * *$ \\
\hline
\end{tabular}

Entries are coefficients; standard errors in parentheses. Standard errors are robust.

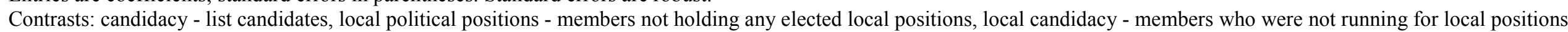
in 2010, incumbents - members not holding SMD mandates in 2006-2010, newcomer - members with at least one term experience as national representatives, party leader -

backbench MPs.

Coefficients represent the change in the value of the log of the dependent variable due to a one unit change in the related independent variables ${ }^{133}$.

$* \mathrm{p}<.1, * * \mathrm{p}<.05, * * * \mathrm{p}<.01$

${ }^{133} \log (Y)=\alpha+\sum B_{i} X_{i}+e_{i}$ 
Additionally, there is a substantial variation in the intensity with which the different factors affect the various methods of campaigning. Table 4.9 represents the results of binary logit ${ }^{134}$ regressions estimating the log-odds of using the different personalized tools in the course of the 2010 campaign. All examined campaign tools are more likely to be used by single member district candidates and local politicians ${ }^{135}$, which is hardly a surprise in the light of the models of Table 4.8. Type of mandate (incumbency in SMDs) affects the likelihood of using posters, placing spots in local radio and TV, as well as operating personal websites positively. Interestingly, previous experience in the constituencies increases the change of distributing posters during campaign, whereas other tools were not used by "veterans" with a greater probability. Naturally, newcomers tend not to have office hours, suggesting that office hours are not held as a part of personalized campaign strategies, but they are the consequences of already held offices. New members are also more likely to use flyers than more experienced representatives. The most intriguing are the findings related to ideological distance, especially that larger distance inspires MPs to start personalized websites. Members who differ from the party line with a somewhat greater deal found themselves a way of trying to influence the public perception on the "togetherness" of themselves and their parties.

Future local level candidacy only affects the likelihood of distributing posters and flyers, positively in both cases ${ }^{136}$. In the case of the latter, it neutralizes the - otherwise slight - effect local political background has on the dependent variable. This suggests the superiority of electoral goals over position roles on the one hand. On the other hand, the insignificance of candidacy on the local level in the case of the remaining campaign techniques confirms that these are interrelated with the currently held local positions of the MPs, indicating that they might not only be perceived as campaign tools but as part of the off-campaign constituency service as well.

${ }^{134}$ The Stata procedure logit was used to estimate the effects on the dependent variable. Observations are weighted using population weights (pweight) to ensure that data represents the population in terms of mandate type and party affiliation.

${ }^{135}$ With the exception of ads in local radio/TV.

${ }^{136}$ Models in which local level candidacy was not found significant were not displayed. Including local candidacy did not substantially change the effects of other factors in the models not presented here. 
TABLE 4.9. Results of the binary logistic regression estimating the log-odds of using various personalized campaign tools

\begin{tabular}{|c|c|c|c|c|c|c|c|c|}
\hline & \multicolumn{2}{|c|}{ Posters } & \multirow{2}{*}{$\begin{array}{c}\begin{array}{c}\text { Ads in local } \\
\text { printed media }\end{array} \\
\text { B (s.e.) }\end{array}$} & \multirow{2}{*}{$\begin{array}{c}\text { Office hours } \\
\text { B (s.e.) }\end{array}$} & \multicolumn{2}{|c|}{ Flyers } & \multirow{2}{*}{$\begin{array}{c}\begin{array}{c}\text { Spots in local } \\
\text { radio/TV }\end{array} \\
\text { B (s.e.) }\end{array}$} & \multirow{2}{*}{$\begin{array}{l}\text { Website } \\
\text { B (s.e.) }\end{array}$} \\
\hline & B (s.e.) & B (s.e.) & & & B (s.e.) & B (s.e.) & & \\
\hline Candidacy & $6.213(1.145)^{* * *}$ & $6.35(1.25)^{* * *}$ & $4.859(.66)^{* * *}$ & $2.096(.448)^{* * *}$ & $6.509(.997)^{* * *}$ & $6.634(1.038)^{* * *}$ & $2.96(.537)^{* * *}$ & $3.627(.581)^{* * *}$ \\
\hline Local political positions & $3.039(1.315)^{* *}$ & $1.938(.999)^{*}$ & $2.015(.641)^{* * *}$ & $2.013(.495)^{* * *}$ & $1.352(.744)^{*}$ & $.043(.686)$ & $.633(.47)$ & $2.028(.552)^{* * *}$ \\
\hline Local candidacy & & $1.717(.675)^{* *}$ & & & & $1.819(.625)^{* * *}$ & & \\
\hline Incumbent & $3.327(1.005)^{* * *}$ & $3.6(.084)^{* * *}$ & $1.245(.843)$ & $1.346(.828)$ & $-.31(1.459)$ & $.2774(1.517)$ & $1.1(.548)^{* *}$ & $2.505(.826)^{* * *}$ \\
\hline SMD MP before 2006 & $2.041(.847)^{* *}$ & $2.067(.92)^{* *}$ & $.414(.842)$ & $-.945(.632)$ & $.707(1.11)$ & $.734(1.155)$ & $.584(.767)$ & $.394(.941)$ \\
\hline Newcomer & $.413(.978)$ & $.571(.925)$ & $-.829(.6)$ & $-1.36(.437)^{* * *}$ & $1.591(.908)^{*}$ & $1.792(.951)^{*}$ & $.104(.484)$ & $-.154(.545)$ \\
\hline Ideological distance & $-.523(.25)^{* *}$ & $-.447(.255)^{*}$ & $-.568(.197)^{* * *}$ & $-.035(.205)$ & $.385(.529)$ & $.491(.551)$ & $.038(.19)$ & $.584(.263)^{* *}$ \\
\hline Party leader & $1.196(.808)$ & $1.164(.761)$ & $.553(.582)$ & $-.212(.459)$ & $-.074(.757)$ & $.004(.789)$ & $-.242(.443)$ & $.031(.478)$ \\
\hline Constant & $-4.848(1.245)^{* * *}$ & $-5.372(1.409)$ & $-3.161(.789)^{* * *}$ & $-.654(.53)$ & $-3.41(1.288)^{* * *}$ & $-3.912(1.503)$ & $-2.359(.603)$ & $-2.883(.853)$ \\
\hline $\mathrm{N}$ & 204 & 204 & 203 & 204 & 204 & 204 & 204 & 204 \\
\hline Wald $\chi^{2}$ & $36.19 * * *$ & $33.3 * * *$ & $26.19 * * *$ & $48.08 * * *$ & $55.97 * * *$ & $51.26^{* * *}$ & $45.82 * * *$ & $49.06 * * *$ \\
\hline Pseudo $\mathrm{R}^{2}$ & .646 & .662 & .508 & .304 & .689 & .703 & .266 & .441 \\
\hline
\end{tabular}

Entries are coefficients; standard errors in parentheses. Standard errors are robust.

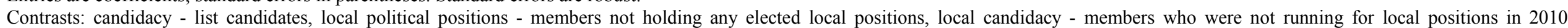
incumbents - members not holding SMD mandates in 2006-2010, newcomer - members with at least one term experience as national representatives, party leader - backbench MPs.

Coefficients represent the change in the value of the log-odds of the dependent variable due to a one unit change in the related independent variables ${ }^{137}$.

${ }^{*} \mathrm{p}<.1, * * \mathrm{p}<.05, * * * \mathrm{p}<.01$

${ }^{137} \log \left(\frac{P_{Y}}{1-P_{Y}}\right)=\alpha+\sum B_{i} X_{i}+e_{i}$ 


\subsubsection{The determinants of campaign organization}

Turning to campaign organization, the dependent variable was transformed in a way that it incorporates both the proportion of staff members hired by the members themselves and not having a personal staff at all. Conveniently, in a multivariate setting it is possible to account for the two different processes under one statistical model. As a part of the dependent variable represents proportions, beta regression seems to be the most appropriate tool to estimate the coefficients (Ferrari and Cribari-Neto, 2004). Additionally, since there is a clump in frequencies at zero, and zeros are the consequences of two different processes ${ }^{138}$, the zero-inflated beta regression is the most reasonable choice (Cook, Kieschnick, and McCullough, 2008). Models were estimated using Maarten L. Buis's zoib procedure in Stata ${ }^{139}$. The zero/one inflated model is built up by three equations: (i) a beta model explaining the proportions in-between the two extremes (0 and 1), (ii) logistic model to estimate the log-odds of the dependent variable to take one, and (iii) a logistic model to estimate the log-odds of the dependent variable to take zero ${ }^{140}$. Due to data characteristics, equations (i) and (iii) were used during the modelling.

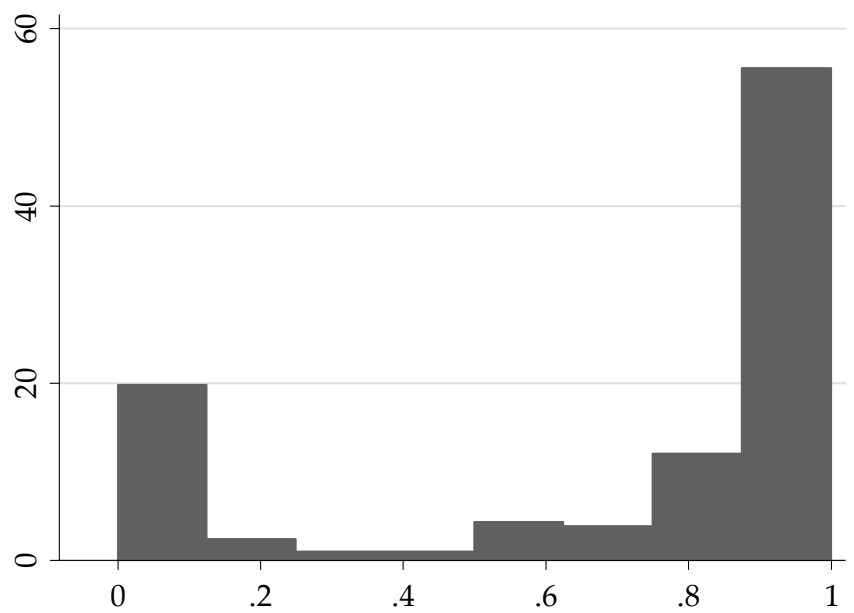

FIGURE 4.3. The distribution of the proportion of staff members hired by the MPs themselves (zeros include not having personal teams at all)

\footnotetext{
${ }^{138}$ Being fully staffed by the party versus not having personal teams at all.

${ }^{139} \mathrm{http} / / /$ econpapers.repec.org/software/bocbocode/s457156.htm

${ }^{140} \mathrm{http}: / /$ maartenbuis.nl/presentations/berlin10.pdf
} 
First columns of each model displayed by Table 4.10 represent the effects of the independent variables on the proportion of staff members hired personally by the MPs. Second columns indicate the effects of the IVs on the log-odds of not having a personal team. Real zeros ${ }^{141}$ are recoded as .0001 , while ones take .9999 , in order to be able to account for them in the beta part of the regression.

Now, taking a closer look at Table 4.10, three groups stand out in terms of the probability of having a team ${ }^{142}$ : SMD candidates, multiple office holders and single member district incumbents have personal staff to dispose of with a greater chance than list candidates, single office holders and members with no previous SMD experience ${ }^{143}$ respectively. These relationships are hardly unexpected, as members of these groups were hypothesized to personalize to a larger extent. Naturally, in order to stand a chance in winning an SMD seat, one has to put special emphasis on the person which is easier to establish with a personal team to work with. This way, personal and party campaigns might be separated more easily. Going further, holding local political positions seems to play an important role in whether an MP gets a personal campaign team. The fact that candidacy was controlled for, is proof that local political background has indeed a strong effect on campaign organization, which strengthens the role of actual positions in explaining campaign strategies. Oddly, however, in none of these instances get representatives less help from their parties. In fact, if sample results are taken into account, in the case of SMD candidates, the parties' role in staffing the personal campaigns becomes more pronounced. This indicated that $1^{\text {st }}$ tier candidates are indeed supported by the parties to a greater extent. List candidates, who still want personal supporting staffs, must pay for this luxury themselves. This suggests that parties recognize the relative value of personal vote on the nominal level, even knowing that it is limited in a sense that the Hungarian voters still vote for parties. The perception of the importance of the local level leads to a measureable personalization of campaigns from an organizational viewpoint in the competition for the SMDs. On the other hand, personalization on party lists is not acceptable, or at least not necessary, which makes

${ }^{141}$ Real zeros display having been staffed exclusively by the party

${ }^{142}$ Technically, Table 4.10 displays the probability of not having a personal campaign team. However, as this is a binary variable, complementer readings are also possible.

${ }^{143}$ Note, that holding a $1^{\text {st }}$ tier mandate before 2006 was also controlled for, therefore, in the multivariate setting, the control group of incumbency in SMDs is not having any previous experience on the nominal level. 
perfect sense under closed party list rules, where voters are not able to modify the ranking of the candidates. Nevertheless, almost $23 \%$ of MPs with no $1^{\text {st }}$ tier ambitions had personal staff, and all these MPs competed under the label of Fidesz-KDNP.

In the case of local political background, however, the higher probability of having a personal team does not go with a higher percentage of staff members to be hired by the party. Again, not valid for the whole population, but sample results suggest that the relationship is even reversed. Local politicians tend to staff their own campaigns in a larger percentage than single office holders. It is fair to assume that local connections enhance the ability to attract additional funding. This also means that SMD candidates filling in elected local positions can boost the amount of resources invested into their personal campaign. Based on the lessons of the previous models, local candidacy was added to the equation, to separate election related motivations and motivations arising from filling in local positions. The proportion of staff members hired by the MP was not affected by the new variable, nor is the likelihood of having to fund the whole staff themselves. 
TABLE 4.10. Results of the zero-inflated beta regression estimating the proportion of staff members hired personally by the MPs

\begin{tabular}{|c|c|c|c|c|c|c|}
\hline & B (s.e.) & B (s.e.) & B (s.e.) & B (s.e.) & B (s.e.) & B (s.e.) \\
\hline & Proportion & $\mathrm{Y}=0$ & Proportion & $\mathrm{Y}=0$ & Proportion & $\mathrm{Y}=0$ \\
\hline Candidacy & $-.45(.329)$ & $-5.92(1.36)^{* * *}$ & $-.452(.325)$ & $-5.917(1.367)^{* * *}$ & $-.391(.302)$ & $-6.92(1.49) * * *$ \\
\hline Current local background & $.211(.186)$ & $-3.954(1.48)^{* * *}$ & $.276(.173)$ & $-3.172(1.41)^{* *}$ & $.072(.174)$ & $-1.483(1.36)$ \\
\hline Local candidacy & & & $-.131(.153)$ & $-1.125(.866)$ & $-.228(.17)$ & $-.653(1.186)$ \\
\hline Incumbent & $.493(.175)^{* * *}$ & $-2.533(1.002)^{* *}$ & $.498(.176)^{* * *}$ & $-2.724(1.033)^{* * *}$ & $.45(.182)^{* *}$ & $-.932(1.349)$ \\
\hline SMD MP before 2006 & $.167(.263)$ & $.079(1.333)$ & $.209(.275)$ & $.295(1.288)$ & $.145(.26)$ & $1.478(1.714)$ \\
\hline Newcomer & $.092(.194)$ & $.51(.848)$ & $.079(.192)$ & $.357(.812)$ & $.196(.247)$ & $-1.075(.905)$ \\
\hline Ideological distance & $.086(.065)$ & $.228(.279)$ & $.083(.065)$ & $.181(.279)$ & $.084(.069)$ & $-.068(.282)$ \\
\hline Party leader & $-.136(.174)$ & $-.609(.764)$ & $-.133(.173)$ & $-.583(.754)$ & $-.125(.175)$ & $.426(.732)$ \\
\hline Jobbik & & & & & $-.838(.321)^{* * *}$ & $2.012(2.131)$ \\
\hline KDNP & & & & & $-.016(.275)$ & $.292(1.367)$ \\
\hline LMP & & & & & a & $18.043(2.702) * * *$ \\
\hline MSZP & & & & & $-.113(.32)$ & $.282(1.382)$ \\
\hline Constant & $1.36(.453)^{* * *}$ & $.206(1.427)^{* * *}$ & $1.417(.473)^{* * *}$ & $4.525(1.48)^{* * *}$ & $1.66(.528)^{* * *}$ & $3.135(1.765)^{*}$ \\
\hline $\mathrm{N}$ & & 199 & & 199 & & \\
\hline Log pseudolikelihood & & 314 & & 15.2 & & \\
\hline
\end{tabular}

Entries are coefficients; standard errors in parentheses. Standard errors are robust.

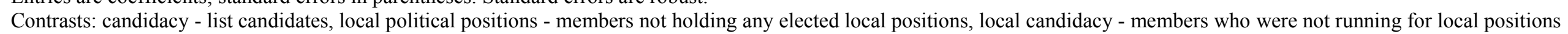

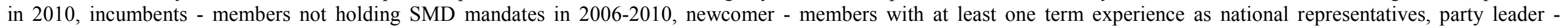
backbench MPs.

Coefficients in the beta regression represent the change in the value of the dependent variable due to a one unit change in the related independent variables.

Coefficients in $Y=1$ and $Y=0$ models represent the change in the value of the log-odds of the dependent variable due to a one unit change in the related independent variables.

${ }^{\text {a }}$ Omitted due to lack of variation.

${ }^{*} \mathrm{p}<.1, * * \mathrm{p}<.05, * * * \mathrm{p}<.01$ 
As expected, SMD incumbents are, ceteris paribus, more likely to have employees to assist them during campaign. Furthermore, the percentage of staff members hired personally by the MPs is also larger than in the case of representatives with no nominal level experience. This time, this connection is significant, which means that the relationship holds for the whole parliament. SMD members invest into their campaign a greater stack of human resources irrespective of the tier they were nominated on. Nevertheless, marginal effects suggest ${ }^{144}$, that everything else held constant, the effect of holding the mandate is greater in the case of $1^{\text {st }}$ level candidates: members who aimed at winning the seat again hired a significantly higher amount of their team members themselves than SMD representative who had no intentions of defending their seats. This indicates that despite candidacy was not found significant, it matters a great deal in shaping the effects of additional factors.

The strong effect of being an SMD member of course does not imply that incumbents have to draw the amount of money sufficient for their campaigns out of their pockets. Financial support might come from the local party budget - which they often control themselves, in addition to the state allowance MPs may spend on hiring support staff. The role of local activists should not be left unaccounted for either. "Hiring" extra manpower does not always involve having to find funding. Volunteers who are not allocated to the MPs by the party centre increase the ability to manoeuvre during campaign independently from the party.

Results of Table 4.10 reveal that Jobbik provided its SMD candidates with the largest stack of human resources in a relative sense. Descriptive evidence suggests that an average Jobbik-candidate receives $42 \%$ of his staff from the party, which is significantly lower than the value of Fidesz's relative contribution to its candidates' campaigns. MSZP candidates had $16 \%$ of their team members coming from the party, while Fidesz and KDNP supported their joint candidates by $11 \%$. The difference between the latter two is not significant in the multivariate setting: regarding the whole population, Fidesz-KDNP and MSZP supports their candidates to an equal degree. However, taking the sample into account, Socialist members receive a somewhat higher percentage of their human resources from the party. This indicates that parties focus a considerable part of their resources into personal campaigns, even if the given candidate

${ }^{144} \mathrm{ME}=.107$ (s.e.=.076), if not an SMD candidate, ME=.202 (s.e.=.086), if nominated in an SMD 
did not have any real chance of being elected - as it was the case in 2010 -, to balance the effect of the unpopularity they had to face in the national political arena, and collect additional votes to their national level vote count.

Previous SMD-level legislative experience does not affect campaign organization. Ideological distance also does not seem to have any influence on campaign organization, which is in synch with previous findings. Therefore, it is fair to assume that habitual factors play a negligible role in setting up one's personal staff during campaigning. Additionally, speaking of the whole parliament, party leaders do not receive a significantly larger part of their human resources from the party centre. More interestingly, they are not more likely to have campaign teams, which indicates that the distribution of resources in general is not dependent upon the status an MP holds within the party. More rational motivations lead the parties to invest into human resources than simple "nobility". ${ }^{145}$

\subsubsection{The determinants of campaign agenda}

Turning to the last aspect of personalized campaign, Table 4.11 shows the results of the binary logistic regressions estimating the logit ${ }^{146}$ of touching upon local issues that were left unattended by the party during the campaign. Again, $1^{\text {st }}$ tier candidates thematized their campaigns according to their electoral goals: they mentioned issues of local concern with a significantly greater probability than members who had no interest in being elected on the nominal level. ${ }^{147}$ It is no surprise that members involved in local politics also used local topics with a greater probability regardless of their status as candidates. Even list candidates with a local political background campaigned with locally relevant issues which were not picked up by the parties. This result sheds light on two things. First, the involvement in local politics shifts the perceived relative importance of local politics to national issues toward the local end. This is true

${ }^{145}$ Nevertheless, looking at the sample, leaders have a slightly larger chance to have personal campaign teams on the one hand, and tend to get greater help from their parties on the other.

${ }^{146}$ The Stata procedure logit was used to estimate the effects on the dependent variable. Observations are weighted using population weights (pweight) to ensure that data represents the population in terms of mandate type and party affiliation.

${ }^{147}$ The probability of SMD candidates mentioning local issues during the campaign was more than 8-9 times larger than in the case of members not running is SMDs. Odds ratios vary between 8.61 and 9.02 . 
regardless of whether the member was an SMD candidate or not. Second, it might indicate that personalized campaign is not necessarily directed to get elected on the national level, but it is rather a part of a campaign in the competition for re-election to the local office. Adding local candidacy to the model enables us to test for the latter. Results seem not to support the importance of future plans on the local level: thematization of the campaign does not follow the MPs interests on the local level. With other words, thematically the two campaigns $\left(1^{\text {st }}\right.$ and $2^{\text {nd }}$ order $)$ do not mingle, which questions the importance of local political candidacy in forming campaign strategies at large. Agenda being the most accurate indicator of district oriented campaigning sheds light on the necessity to separate the two types of campaign. This however, does not diminish the conclusion drawn from the previous models. Factors apart from district focus (agenda) also measure aspects of campaigning. The difference is that whilst agenda measures strictly the lower level focus of the campaigns, the other indicators probably touch upon more extensive phenomena. Personalized campaign tools and personal teams can be used independent of the actual campaign, making them a part of the characteristics of the MPs' work as representatives. These strategies might also look farther than the challenge at hand (being national level elections).

Incumbency and previous nominal level legislative experience do not seem to be of any importance. However, their signs point to the hypothesised direction, indicating that a mechanism that pushes incumbents - in the sample - toward focusing more on the local level is in place. Only, this relation does not hold for the whole population. And finally, candidates of the various parties do not differ in terms whether they campaign with locally relevant issues. 
TABLE 4.11. Results of the binary logistic regression estimating the logit of touching upon local issues

\begin{tabular}{|c|c|c|c|c|}
\hline & B (s.e.) & B (s.e.) & B (s.e.) & B (s.e.) \\
\hline Candidacy & $2.153(.445)^{* * *}$ & $2.157(.448)^{* *}$ & $2.185(.479)^{* * *}$ & $2.2(.48)^{* * *}$ \\
\hline Local political position & $1.259(.455)^{* * *}$ & $1.289(.476)^{* *}$ & $1.015(.46)^{* *}$ & $1.08(.495)^{* *}$ \\
\hline Local candidacy & & $-.0447(.431)$ & & $-.12(.431)$ \\
\hline Incumbent & $.724(.561)$ & $.722(.563)$ & $.65(.558)$ & $.643(.56)$ \\
\hline SMD MP before 2006 & $1.196(1.263)$ & $1.199(1.258)$ & $.97(1.183)$ & $.975(1.177)$ \\
\hline Newcomer & $-.413(.465)$ & $-.417(.464)$ & $-.18(.495)$ & $-.184(.497)$ \\
\hline Ideological distance & $-.111(.152)$ & $-.113(.153)$ & $-.061(.155)$ & $-.065(.158)$ \\
\hline Party leader & $.299(.411)$ & $.302(.41)$ & $-.026(.404)$ & $-.0162(.405)$ \\
\hline Jobbik & & & $.521(.654)$ & $.488(.66)$ \\
\hline KDNP & & & $.833(.972)$ & $.816(.969)$ \\
\hline \multicolumn{5}{|l|}{$\mathrm{LMP}^{\mathrm{a}}$} \\
\hline MSZP & & & $.306(.496)$ & $.281(.499)$ \\
\hline Constant & $-1.48(.619)^{* * *}$ & $-1.47(.635)^{* *}$ & $-1.465(.616)^{* *}$ & $-1.427(.641)^{* *}$ \\
\hline $\mathrm{N}$ & 201 & 201 & 199 & 199 \\
\hline Wald $\mathrm{Chi}^{2}$ & $32.82 * * *$ & $33.41 * * *$ & $30.03 * * *$ & $30.4 * * *$ \\
\hline Pseudo $\mathrm{R}^{2}$ & .199 & .199 & .183 & .183 \\
\hline
\end{tabular}

Entries are coefficients; standard errors in parentheses. Standard errors are robust.

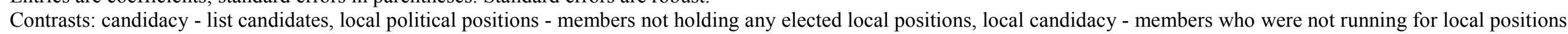

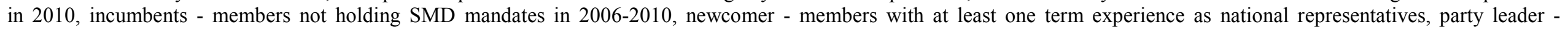
backbench MPs, party - Fidesz.

Coefficients represent the change in the value of the log-odds of the dependent variable due to a one unit change in the related independent variables ${ }^{148}$.

a Variable omitted due to collinearity.

$* \mathrm{p}<.1, * * \mathrm{p}<.05, * * * \mathrm{p}<.01$

${ }^{148} \log \left(\frac{P_{Y}}{1-P_{Y}}\right)=\alpha+\sum B_{i} X_{i}+e_{i}$ 


\subsection{Campaign strategies and the focus of representation}

Last but not least, the relationship of focus of representation and campaign norms raises an interesting issue. The question is whether members with a more solid constituency focus prefer personalization in terms of campaigning. This section establishes the connection between the two aspects of personalization discussed up until this point on a bivariate level. As the two aspects are hypothesized to be affected by the same factors, and the direction of causality is not clear in certain cases, multivariate models will not be built.

The relationship between campaign norms and focus of representation is significant ${ }^{149}$ : members representing their constituencies seem to prefer to run personal campaigns than MPs with different foci. Post hoc tests ${ }^{150}$ reveal that the true threshold lies between representatives with a party focus and constituency oriented members. A stronger connection is detected in the case of the number of personalized campaign tools used. Here, again, district oriented members proved to be running more personalized campaigns as far as campaign methods go. Not only have they shown a significant difference from party-focused $\mathrm{MPs}^{151}$ but also from those who represent all the citizens in the country. ${ }^{152}$ Personalized campaign strategies, in this sense, do not necessarily support the representatives' ambitions to take a stance against their parties, but also their willingness to represent particularistic goals instead of general ones. Most of the personalized campaign tools were particularly used by members with a strong constituency orientation ${ }^{153}$.

\footnotetext{
${ }^{149} \mathrm{Eta}=.265, \mathrm{~F}=5.274 * * *$

${ }^{150}$ Tamhane's T2 was eventually used, but multiple tests lead to the same conclusion. Mean difference took 2.267 (std. err.=.719). Results are significant at the $5 \%$ level.

${ }^{151}$ Mean difference: $1.898(.482)^{* *}$

${ }^{152}$ Mean difference: $1.517(.351)^{* *}$

${ }^{153}$ Posters: $\chi^{2}=19.992 * * *, \mathrm{~V}=.306$; Local ads in printed media: $\chi^{2}=22.781^{* * *}, \mathrm{~V}=.33$; Office hours: $\chi^{2}=16.846^{* * *}, \mathrm{v}=.282$; Social gatherings: $\chi^{2}=3.498, \mathrm{~V}=.128$; Flyers: $\chi^{2}=9.815^{* *}$, $\mathrm{V}=.215$; Ads in local radio/TV: $\chi^{2}=25.5^{* * *}, \mathrm{~V}=.351$; Website: $\chi^{2}=12.167^{* * *}, \mathrm{~V}=.24$.
} 
TABLE 4.12. The relationship between the focus of representation and campaign norms, means and organization

\begin{tabular}{lccccrr}
\hline & \multicolumn{2}{c}{ Norms $^{\mathrm{a}}$} & \multicolumn{2}{c}{ Means $^{\mathrm{b}}$} & \multicolumn{2}{c}{ Organization $^{\mathrm{c}}$} \\
\cline { 2 - 7 } & Mean & Std.dev. & Mean & Std.dev. & Mean & Std.dev. \\
\hline Constituency & 6.255 & 2.379 & 5.93 & 2.014 & .873 & .211 \\
Party & 3.986 & 3.516 & 4.03 & 2.405 & .76 & .39 \\
A specific group in the society & 5.479 & 3.115 & 3.50 & 2.946 & .726 & .3447 \\
All the citizens of the country & 5.363 & 2.758 & 4.41 & 2.692 & .823 & .273 \\
\hline $\mathrm{F}$ & $5.274 * * *$ & $10.011 * * *$ & 1.461 \\
Eta & \multicolumn{2}{c}{.265} & .342 & .164 \\
\hline${ }^{\mathrm{a}}$ Campaign norms are measured by an 11 point scale (1 - party campaign, 11 - personal campaign) \\
${ }^{\mathrm{b}}$ The number of personalized campaign tools. \\
${ }^{\mathrm{c}}$ The proportion of personally recruited staff members. \\
${ }^{*} \mathrm{p}<.1, * * \mathrm{p}<.05, * * * \mathrm{p}<.01$
\end{tabular}

With regards to campaign organization, three different variables were examined in connection with focus of representation. First (Table 4.12), the proportion of staff members hired by the MPs showed no significant relationship with how MPs perceive their roles as representatives. Constituency oriented members in the sample tend to receive less help from the party centre in relative terms ${ }^{154}$, which indicates that the connection points to the hypothesised direction. However, as noted, no substantial difference was found when projecting the results to the whole population. The second and third variable mirrors the logic of the dependent variable that was estimated in the previous section (see Table 4.10). According to the results displayed in Table 4.13, 91 $\%$ of district oriented members has personal campaign teams. Additionally, more than a half of the MPs who did have a support team named their constituencies as the most important unit to represent. It is clear that campaign organization and representational focus have little to do with each other. This is especially true in relation to the degree of party support. If anything, only the existence of a personal team correlates with the way representatives think about their jobs.

\footnotetext{
${ }^{154}$ It is not implied that constituency oriented members receive less help from the party in absolute terms.
} 
TABLE 4.13. The relationship between the focus of representation and campaign organization and organization

\begin{tabular}{|c|c|c|c|c|c|}
\hline & \multicolumn{2}{|c|}{ Organization $(\mathrm{Y}=0)$} & \multicolumn{2}{|c|}{ Agenda } & \\
\hline & $\begin{array}{c}\text { Has no personal } \\
\text { team }\end{array}$ & $\begin{array}{l}\text { Has personal } \\
\text { team }\end{array}$ & $\begin{array}{c}\text { Does not } \\
\text { mention local } \\
\text { issues }\end{array}$ & $\begin{array}{l}\text { Mentions } \\
\text { local issues }\end{array}$ & \\
\hline \multirow{2}{*}{ Constituency } & 9 & 91.0 & 21.9 & 78.1 & $100 \%$ \\
\hline & 17.6 & 51.1 & 32.3 & 52.1 & \\
\hline \multirow{2}{*}{ Party } & 46.7 & 53.3 & 57.7 & 42.3 & $100 \%$ \\
\hline & 27.5 & 9.0 & 23.1 & 7.6 & \\
\hline \multirow{5}{*}{$\begin{array}{l}\text { A specific } \\
\text { group in the } \\
\text { society } \\
\text { All the citizens } \\
\text { of the country }\end{array}$} & 33.3 & 66.7 & 20 & 80 & $100 \%$ \\
\hline & 7.8 & 4.5 & 3.1 & 5.6 & \\
\hline & 27.6 & 72.4 & 35.1 & 64.9 & $100 \%$ \\
\hline & 47.1 & 35.4 & 41.5 & 34.7 & \\
\hline & $100 \%$ & $100 \%$ & $100 \%$ & $100 \%$ & \\
\hline $\begin{array}{c}\chi^{2} \\
\text { Cramer's V }\end{array}$ & \multicolumn{2}{|c|}{$22.756^{* * *}$} & \multicolumn{2}{|c|}{$13.533^{* * *}$} & \\
\hline
\end{tabular}

Entries are percentages.

${ }^{*} \mathrm{p}<.1, * * \mathrm{p}<.05, * * * \mathrm{p}<.01$

The thematization of the campaign, however, is firmly interrelated with how MPs go about representation. $78.1 \%$ of the district oriented touched upon issues with local relevance, and more than $50 \%$ of local problem promoters underline the importance of constituency representation. Nevertheless, this relation might be expected to be more stressful, as intuitively, these two measures should account for the same tendencies. Results suggest, however, that constituency representation is more diverse in a sense that engaging in local issues is just one part of it. This finding is in synch with the conclusion of André and Depauw who argue that the variety of personal vote-seeking activities results in weakly detectable causal mechanisms (André and Depauw, 2013). Therefore, attitudes of representation and the various indicators of constituencyorientation and personalization fall farther away. This setting might be troubling at first sight, since different measures could lead to different conclusions, making results less parsimonious. On the other hand, it draws attention to the fact that personal voteseeking has to be examined from multiple viewpoints, to fully uncover the true relationships between personalization, electoral rules and career factors.

\subsection{Concluding remarks}

This chapter established the connection between member personalization in campaign strategies and several explanatory factors. Independent variables were grouped based on their tendency to support distinct motivational frameworks. Election 
related variables capture the MPs' incentives to get (re)elected: the effects of candidacy on the national and local level measure were interpreted from a goal-rationalistic point of view. Position related variables accounted for the incentives that holding actual political positions exert on campaign personalization. Local office holders, incumbents, newcomers and party leaders have are motivated to emphasize their personal characteristics to differing extent. The common ground of these incentives lies in their status as politicians, either on the local level, or in the party. Last, but not least, habitual motivations were measured by previous nominal level legislative experience and the perceived ideological distant from the parties. Neither is connected to actual positions or direct electoral motivations. In this sense they were perceived to measure the residual effect which variables in the previous two groups were not able to grasp. On the course of the analysis, party affiliation was taken into account, as students of the Hungarian political campaigns revealed several differences between the strategies of the various political groupings (Szabó et al., 2011). With this, I was able to account for the current political situation, without overshadowing general tendencies that are aimed to capture in this dissertation.

Regarding the results, one thing stands out at first: habitual explanations in campaigning do not pull through. With only a few exceptions formerly held nominal mandates and ideological distance do not influence the way in which members organized their campaigns. This is hardly a surprise, as campaign strategies are the most rational aspects from which personalization is approached in the dissertation. The centralization of the campaigns does not allow for individual members to act upon their former experiences.

The evidence presented in this chapter was the strongest in supporting explanations based on the rational calculus of elections. Candidacy on the nominal level was found significant as explanatory variable in every single dimension of personalized campaigning. By this result, it is indicated that the role on the $1^{\text {st }}$ tier does not diminish in fuelling personalization even under such party-centred electoral rules. This means that putting the person into the front row is still a viable strategy for the party to win extra votes. This effect is further strengthened by the special situation, MSZP was in. Pushing the party focus of the campaign into a more personalized direction was the declared strategy of the Socialists, through which they wished to balance the unpopularity of the party label. The effect of candidacy, however, holds regardless of current party strategies, implying that parties that ran party-centred campaigns at large 
also incorporated personalization into their overall approach. As important the effect of candidacy on the national level was in structuring campaigns, as little impact had candidacy at the local elections on the national campaign. Only in the case of campaign organization was limited evidence found that members perhaps look beyond the goal at hand, and start their local campaigns before the national elections. In other cases, local aspirations did not play any role in strategies that enhance visibility.

In terms of position motivations, results present a diverse situation. On the one hand, local political background proved to be a relevant factor explaining the dependent variables. Members holding elected local positions pursued a higher level of personalization than MPs with no current local ties. It is safe to say, that the possibility of mandate accumulation in the Hungarian political system shifts the nature of campaigning into something that would have not emerged under strictly party-oriented electoral rules. Local politics brings the person and the territorial area back to national politics. On the other hand, other position variables supported the attached hypotheses to a varying extent. Incumbency was found significant in several instances, hence, type of mandate influences campaign strategies to a considerable extent. Members serving as district representatives bring their role perceptions into their campaigns, regardless of their status as candidates. These results hold after controlling for party affiliation which indicates that commitment to constituency representation holds even if there is little chance for re-election ${ }^{155}$.

\footnotetext{
${ }^{155}$ One could argue that this is the result of the fact that Fidesz won most of the constituencies in 2010, therefore, former Fidesz district MPs were re-elected to their positions with a greater probability. As the population consists of member elected in 2010, thus Fidesz members dominate the sample, the effect of incumbency could be attributed to these MPs who had a viable chance for re-election on the nominal level. However, these critiques do not hold for several reasons. First, the proportion of SMD incumbents among MSZP members - in the sample - is $44.4 \%$, which is considerably larger than in the percentage of Fidesz-incumbents (2006-2010) within the Fidesz PPG (17.5\%). This means that there is indeed a variation within the group of Socialists as well in terms of the type of mandate they held at the time of the campaign. Effects, therefore, cannot be attributed solely to the characteristics of Fidesz members. Second, the very logic of multivariate analysis implies that the values of the variables controlled for are held constant when evaluating the effects of the factor in question (ceteris paribus). Thus, the effect of incumbency holds under all the circumstances (i.e. regardless of party affiliation) that were accounted for in the equations.
} 
When discussing the effect of variables that measure the effect of currently held positions on campaign personalization, one cannot forget about the possibility that these measures stand for some form of constituency service, rather than campaigning. Based on the extensive analysis presented in this chapter, this seems to be the case in several instances. Holding office hours and attending social gatherings is just the extension of the activities that local politicians and SMD incumbents engage in during off-campaign periods. Therefore, the costs of campaigning for these candidates can be substantially lower than for those who have no connection to the local level.

Last but not least, there is substantial evidence supporting that parties indeed consider personalized strategies useful under certain circumstances. As shown, this motivation is fairly independent of electoral motivations in a sense that candidates not having much chance to win in single member constituencies, invest into their district level campaigns. They do this with the support of their parties. The analysis of campaign norms, means and organization showed how parties balance between focusing their resources to pure party campaigns and allowing individual candidates to personalize. There is, however, not much of "allowing", one could argue. And indeed, previous research has shown (Mihályffy, 2011; Takács, 2011; Ughy, 2011; Zentai, 2011) how centralized campaign strategies were in 2010. Personalization, therefore, had to be part of the overall party strategy, at least in the case of Jobbik and MSZP. Additionally, the fact that agenda was not influenced by party affiliation, which has proven to significantly determine campaign strategies, underlines that this aspect of campaigning is the farthest away from party influence. Thus, campaign agenda is the most suited tool to measure candidate preferences in terms of personalization, without laying ourselves too much to the effect of party affiliation. 


\section{CHAPTER 5 - LOCAL ORIENTATION IN THE HUNGARIAN PARLIAMENT}

There are several ways in which Members of Parliament might express constituency orientation. Activities might be divided according to scenery. First, MPs may engage in constituency service in their districts: they hold office hours, carry out ombudsman-like activities, and deal with problems arising in the area as well as respond to individual petitions. Second, it is possible to represent the interests of the districts, the constituents and the local level in general in parliament. Both, service and allocation responsiveness may be interpreted within the context of the parliamentary work. On the one hand, rollcall behaviour can reflect concerns to issues that are considered important especially for the citizens of a well-defined geographical location. On the other hand, questions submitted to government members also might deal with the specific problems of the people living in the same area. Recognizing that roll-call behaviour is not suitable to measure individual actions, as it is rigorously structured by the PGG-leadership (Ilonszki and Jáger, 2008; Thomassen and Andeweg, 2004), parliamentary behaviour will be investigated through written and oral questions. Tabling questions might also be considered "non-legislative" services, as these procedures do not result either in creating new law, or in modifying existing ones (Russo and Wiberg, 2010).

There is a broadening literature on how members personalize their questioning behaviour. Scholars seek new ways of capturing local representation and the representatives' quest to enhance their personal vote. Martin (2011) argues that there are several advantages of investigating parliamentary questions compared to other methods of measuring personal vote-seeking (Martin, 2011, p. 263). Questioning requires firm resource allocation strategies, by the reason of their substantial direct and opportunity. Therefore, "parliamentary questions provide an indication of the priorities of the legislators" (Martin, 2011, p. 263). Furthermore, despite the variance in the strength of party control, questions are less strictly overseen by the party centre, than roll-call, interpellations or floor speeches for example. Thus, they are more reliable indicators of individual preferences toward personalization, not to mention the fact that questions offer direct, easily accessible measures without sampling bias (Martin, 2011, p. 264).

Traditionally, parliamentary questioning is regarded as a mechanism of ex post government accountability, in a sense that inquiries are addressed to government members enabling legislature to control government actions. However, questions also 
present "micro-functions" that enable representatives to publicize personal achievements as well as express concerns with regards to their constituencies and individual citizens (Bailer, 2011; Wiberg and Koura, 1994). Thus, questioning is a tool of enhancing member visibility, therefore, an attractor of votes at the next elections. As Russo and Wiberg put it, parliamentary questions "often have two dimensions, simultaneously acting as both a way to ask for information and a way to give information" (Russo and Wiberg, 2010, p. 220).

As Martin points out, several studies proxied constituency orientation with the total number of questions asked by the individual MPs. However, as questions may vary in terms of content, this method does not provide us with exact information on the MPs' personal vote earning strategies (Martin, 2011, p. 262). Thus, content analysis is required to differentiate between constituency-oriented questions, and those with policy focus as well as questions touching upon party conflict (Martin, 2011, p. 262). A simple codebook was applied by several researchers investigating parliamentary questioning practices in various countries (Bailer, 2011; Blidook and Kerby, 2011; Dandoy, 2011; Rozenberg, Chopin, Hoeffler, Irondelle, and Joana, 2011; Russo, 2011; Saalfeld, 2011). The very same codebook is applied here, however, as a result of contextual differences, minor changes have to be implemented (see later in this chapter).

There is an ongoing debate on whether written or oral questions are more suitable to measure personal vote-seeking. The choice between these two forms greatly depends on what aspect of questions the researcher considers critical in terms of the research question. On the one hand, Martin and Rozenberg point out that there is a trade-off between written and oral inquiries regarding the publicity of these occasions and the content of inquiry (Rozenberg and Martin, 2011, p. 396). Whereas oral questions receive greater publicity, written questions focus more on local issues and specific policy problems. Thus, students of constituency orientation face a dilemma: analyzing oral questions offers the advantage of controlling for the picture on how voters' may perceive their representatives' work in parliament, while written questions bear greater relevance with regards to constituency-related issues. This study chooses to analyze both types of questions, with the intention to reveal whether there is a meaningful difference in the role of localism between written and oral inquiries.

In this chapter, I explain the variation in constituency orientation of parliamentary questions. First, I briefly review the rules regarding MPs' possibilities to address government members. Then, the research design will be taken a closer look at: after 
presenting Martin's (2011) original ideas, I describe coding instructions to the special case of Hungary. Third, the introduction of the dependent variables will be followed by the bi- and multivariate analysis, which explains the variance in constituency-related questions with variables connected to electoral, position and habitual explanations.

\subsection{Rules of questioning in the Hungarian Parliament}

Four types of questions enable MPs to monitor government actions in the Hungarian Parliament. Interpellation is traditionally thought to be the strongest tool of government control. Its power is given by the fact that in case the questioning MP does not accept the government's answer, a plenary vote might be attached to it. If the plenary session rejects the answer, the case will be assigned to one of the parliamentary committees, and will be further discussed at the next session. Full text has to be submitted four days prior to the session at which the MPs want it to be tabled. Oral presentation is restricted in a sense that it cannot contain extra information compared to the submitted version. Questioning members have three minutes to present the inquiry, which is followed by a four minute answer by the assigned government member. At the end of the cycle, the questioning MP has to make a one-minute statement whether (s)he accepts the government's response. At the beginning of every session, 90 minutes are available to table interpellations and oral questions. In a rank order of their size, every PPG is entitled to at least one inquiry, starting with the opposition. MPs can request written answers, in which case they have to be provided within 30 days.

Ordinary questions (oral or written) must be submitted in writing one day before the plenary session. The main difference between oral and written inquiries is not the form of submission, but whether the MP requests oral or written response. Oral answers are provided at the beginning of the next session, while the addressed departments have 15 days to prepare written ones. Tabled questions are structured in a two-two minutes fashion, which means that both, the questioning MP and the government member have two minutes to plead their cases. Answers will not be evaluated either by the submitting representative or the plenary session.

Last, but not least, direct questions are the most spontaneous tools of ex post control. The title of the inquiry has to be sent to the House Committee one hour prior to the session. Questioning members have two minutes, which is followed by two minutes of response. At this point, the first party has the opportunity to respond in one minute, 
which opens up the floor for the government members for another minute. At each session, 60 minutes are dedicated to direct questions only.

All types of questions can be addressed to individual ministers as well as to the prime minister. Questions covering the joint performance of the government are answered by the latter. Questions related to multiple areas are assigned to members of government by the PM. Furthermore, all inquires and government response (written or oral) are available through the official website of the parliament. Interpellations, oral and direct questions are broadcasted by the public television channels as well as the online broadcasting system of the Hungarian Parliament.

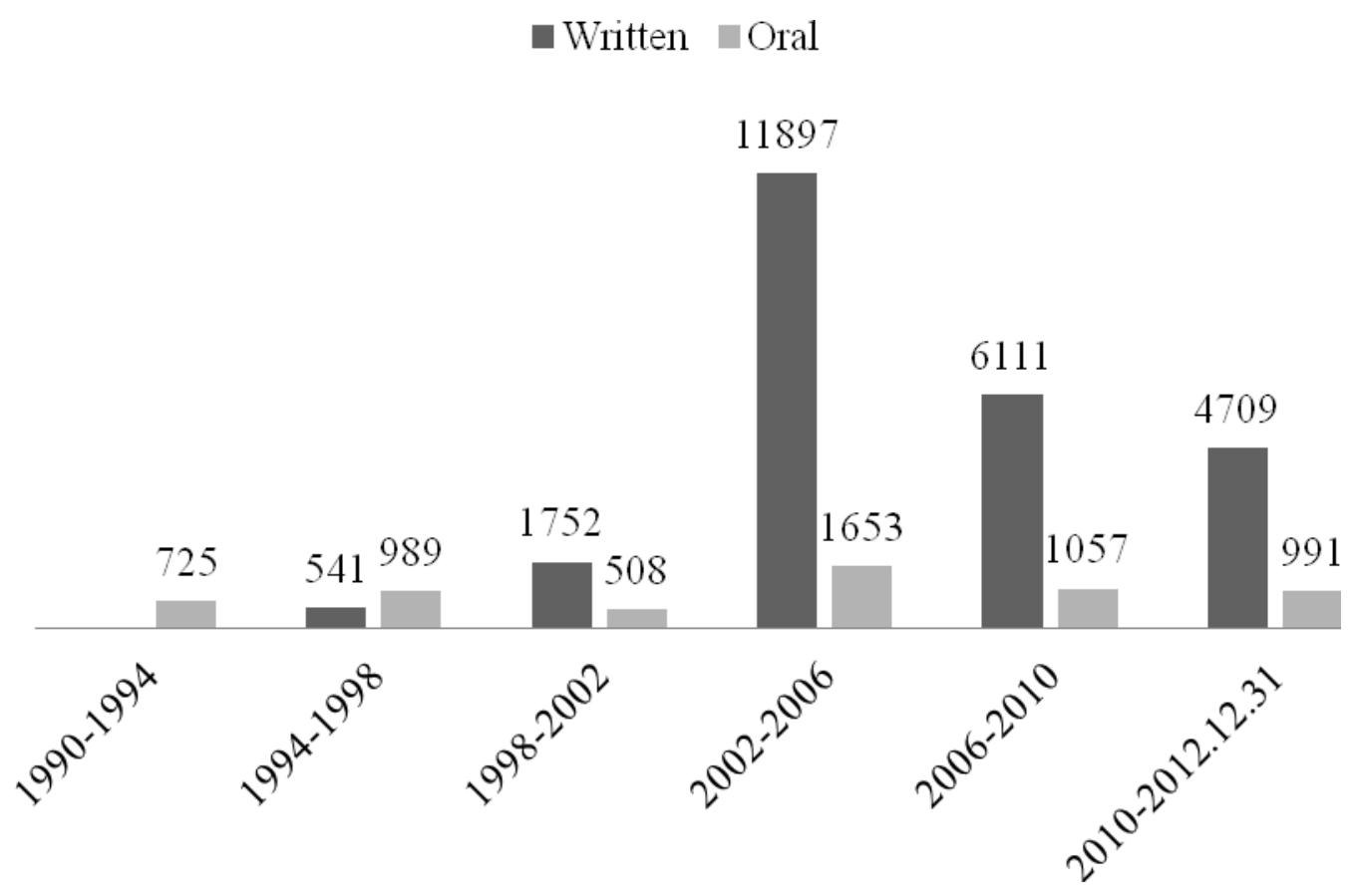

FIGURE 5.1. The number of oral and written questions submitted (Source: www.partlament.hu)

Figure 5.1 shows the absolute number of oral and written questions submitted from 1990 until the end of 2012. Naturally, due to the restricted opportunities of tabling, oral questions lag behind written ones in numbers. As the data suggests, ordinary questions are quite popular tools of inquiry. Even in the "worst" term, 404 questions were sent to the House Committee. The case of written inquiries reflects a particular learning curve. In the first term, members were not able to request written answers to their questions, and it took several terms to recognize the potential in this form of questioning. Between 2002 and 2006, an extreme number of questions were submitted for written response. At 
this time, the opposition discovered questions as the tool of "tiring out" various departmental sections, especially during the Holidays ${ }^{156}$.

As to the distribution of the questions with regards to the government-opposition divide, the majority of inquiries were submitted by the opposition parties within both categories. Nevertheless, according to the rules of the House, every PPG is entitled to present questions at the beginning of the plenary session. Thus, questions delegated by the government parties must appear at the sessions, in case these parties submitted any. Also, they have every motivation to do so, since questioning ministers in public is a powerful way to promote government success. This aspect, however, is less pronounced in the case of inquiries for written response, where the dialog between MPs and ministers is less publicized. This is the consequence of government MPs not using the questioning period as monitoring the government, but to advertise its performance. Since questioning is still regarded as one of the tools to control the government, opposition parties will continue to address ministers regarding issues of their jurisdiction in writing. Therefore, government MPs will claim a larger part from the cake of oral questions (to promote the government), whereas opposition members will overwhelmingly dominate written questions (to continue government control). On average, $5.8 \%$ of the written questions came from government parties from 1994 until 31 December $2012^{157}$. The proportion of oral inquiries submitted by these PPGs is considerably higher, $26.7 \%$ on average ${ }^{158}$.

\subsection{Research design}

As mentioned earlier, the localism codebook of Martin (2011) is applied with modifications that are required to implement the research design in the Hungarian context. In the original design, localism was conditioned by six different factors: mentioning (i) a geographical constituency, (ii) a geographical location within the constituency, (iii) a particular case related to a constituent, (iv) a particular facility

\footnotetext{
${ }^{156}$ In December 2008, Fidesz and KDNP MPs submitted 1300 questions for written response within two days. Department employees worked throughout the Holidays to prepare answers. This was the first - and not the last - time the opposition used questions to other purposes than directly monitoring the government. http://www.origo.hu/itthon/20081220-1300-irasbelikerdes-ket-nap-alatt-a-fidesztol-a-miniszterekhez.html

${ }^{157} \mathrm{http}: / /$ www.parlament.hu/fotitkar/ellenorzes/ir_kerdes.htm

${ }^{158} \mathrm{http}: / /$ www.parlament.hu/fotitkar/ellenorzes/kerdes.htm
} 
within the constituency, (v) a particular business or organization that operated within the constituency, and (vi) an event that takes place in the constituency. If the answer to one of the above is "yes", the given question is coded constituency related (Martin, 2011, p. 264). The unit of analysis is the MP in most of the related research, indicating that we do not intend to explain the variation in the question characteristics, but to capture the differences between Members of Parliament in terms of their questioning behaviour. As the next step, either the number of district related questions is matched with the particular member, or the proportion of localism inquiries within all questions asked by the very MP is assigned to the individual representative. Then, the variance within these two indicators is explained by a number of pre-selected independent variables.

Due to the multi-tier electoral system and dual candidacy, these simple coding rules could not be implemented without losing substantial information. Thus, in our research design at the Centre for Elite Research (CUB), we defined localism as three distinct variables $^{159}$, each measuring a different aspect of constituency-orientation. Due to the almost unmanageable complexity of the problem, we aimed at the simplest possible solution that still enables us to investigate the matter as thoroughly as possible. However, during the process of testing several versions of our codebook, we had to make compromises as well. For example, we had to give up matching single member districts to members on the course of the coding of the three main variables. Nevertheless, at the coding of the second group of variables we tried to reinforce this aspect as well.

As mentioned, questions were coded based on two groups of variables. The first set distinguishes between the three types of localism. First, LOCALISM1 is coded 1 if the member mentions any local issue, where local issues relate to issues that concern a particular geographical area which is smaller than the country; and 0 otherwise. In this sense, the MP's relation to the local level is not of any relevance. Second, LOCALISM2 is related to the county of the MP's election. It takes 1 , if the member mentions his or her county of election, and 0 if not. This way, the constituency orientation of both regional list and SMD members can be measured without having to define separate variables for each type of mandate. Nevertheless, one could argue that the essence of the SMD will not be captured this way, which would certainly be the case. However, there

${ }^{159}$ LOCALISM1, LOCALISM2, LOCALISM3 
are certain advantages to this approach. On the one hand, election and candidacy can be handled jointly. Regional list members stayed within the borders of the county, if they ran in SMDs. Thus, there is a perfect overlap between the constituency of election (either SMD or regional list) and the place of candidacy, not requiring empirical separation. On the other hand, nominal level members mentioning county-related issues will count as local ones, which is a necessity due to the relationship of the SMD- and the county-level. For instance, maintaining hospitals in Hungary is the function of the county. Thus, citizens throughout the area, from various constituencies will visit the same health care institutions, making a county-level issue an issue of the constituency. The same argument can be made with regards to various areas. Naturally, LOCALISM2 is only interpreted in the cases of regional list and SMD members. Analogically, LOCALISM3 is only coded if the member was elected on the $3^{\text {rd }}$ tier of the electoral system, and relates to county-level issues that concern the place of the candidacy on the lower levels. It takes 1 , if the national level MP submitted an inquiry regarding the county of his candidacy either on the regional list or the SMD level, and 0 otherwise. Applying these definitions we can control for the place of election and candidacy at the same time without making the coding too complex. The logic of the three variables is shown by Table 5.1 .

TABLE 5.1. The interrelations between the three localism variables

\begin{tabular}{llll}
\hline & LOCALISM1 & LOCALISM2 & LOCALISM3 \\
\hline \multirow{2}{*}{ SMD member } & 0 & 0 & - \\
& 1 & $0 / 1$ & - \\
\hline \multirow{2}{*}{ Regional list member } & 0 & 0 & - \\
& 1 & $0 / 1$ & - \\
\hline \multirow{2}{*}{ National list member } & 0 & - & 0 \\
& 1 & - & $0 / 1$ \\
\hline
\end{tabular}

After characterizing questions in terms of the first set of variables, a second group of factors are defined in relation to LOCALISM2. These additional variables very much resemble the original codebook of Martin (2011). In all cases, where SMD and regional list members mention issues related to the county of election (LOCALISM2=1), questions are categorized along 7 dimensions. Variables are displayed in Table 5.2. 
TABLE 5.2. Variables describing the nature of the county-related questions

\begin{tabular}{|c|c|}
\hline Variable name & Content \\
\hline CONSTITUENCY & Did the member mention a geographic constituency specifically? \\
\hline LOCATION & $\begin{array}{l}\text { Did the member mention a geographical location that the coder can confirm is } \\
\text { within the geographical constituency of the member? }\end{array}$ \\
\hline CASE & $\begin{array}{l}\text { Did the member mention a constituent or particular case surrounding an } \\
\text { individual, reasonably assumed to be a constituent? }\end{array}$ \\
\hline FACILITY & $\begin{array}{l}\text { Did the member mention a particular building or facility that the coder can } \\
\text { confirm to be located in the geographical constituency of the member? }\end{array}$ \\
\hline ORGANIZATION & $\begin{array}{l}\text { Did the member mention a particular organization that the coder can confirm to } \\
\text { be located in the geographical constituency of the member? }\end{array}$ \\
\hline BUSINESS & $\begin{array}{l}\text { Did the member mention a particular business that the coder can confirm to be } \\
\text { located in the geographical constituency of the member? }\end{array}$ \\
\hline EVENT & $\begin{array}{l}\text { Did the member mention a particular event that specifically taking place in the } \\
\text { geographical constituency of the member? }\end{array}$ \\
\hline
\end{tabular}

On this level of coding, constituencies are specified as SMDs and counties in the cases of $1^{\text {st }}$ and $2^{\text {nd }}$ tier members respectively. Therefore, what we lost at the first stage, we gained at the second, namely constituency-oriented inquiries are now truly connected to the actual districts of the MPs. The aggregated version of these variables gives localism how Martin (2011) defines it. The detailed codebook is represented in Appendix 5.1.

\subsection{Questions in Hungary}

A sum total of 5236 oral and written questions within the period from May $14^{\text {th }} 2010$ to December $31^{\text {st }} 2012$ were coded based on the schema introduced above ${ }^{160}$. In both cases, submitted questions were taken into account regardless of whether they were tabled or not ${ }^{161}$. Within the period under investigation, a sum total of 231 Members of Parliament submitted either oral or written questions to any of the government ministers. $37.7 \%(\mathrm{~N}=87)$ of the MPs were elected on the $1^{\text {st }}$ tier, while this proportion amounts to 35.9 (83) and 26.4 (61) in the cases of regional and national list member respectively. The tendency of MPs with different mandate types submitting questions shows a quite unique picture: while only $49.4 \%$ of nominal level MPs asked questions, $95.3 \%$ of national list members did. This distribution is certainly counterintuitive, as

\footnotetext{
${ }^{160}$ Here I would like to thank Adrienn Tóth and Rudolf Tamás Metz again for their effort to make this dataset as precise as possible.

${ }^{161}$ The exact numbers differ from what was presented by Figure 5.1. The main reason for this discrepancy is that whereas the graph contained withdrawn questions as well, they were excluded from coding.
} 
one could expect $1^{\text {st }}$ tier members to engage into a more active questioning behaviour in parliament provided that we accept that parliamentary inquiries present a great opportunity for constituency service. For the sake of the complete picture: $56.8 \%$ of regional list members submitted either oral or written questions.

Rules allow multiple members to submit questions. Hungarian Members of Parliament took this opportunity in $9 \%$ of the cases: 473 questions were submitted by more than one MP. The highest number of members who teamed up was 7: three written questions were asked by the same group of Fidesz MPs. Additionally, one question was submitted by four members, while the number of questions asked by three amounts to $45 .{ }^{162}$ As to the type of questions, $88.2 \%(\mathrm{~N}=4618)$ requested written answers, while $11.8 \%$ (618) were submitted to oral response.

Due to multiple submission, the description of questions in terms of the mandate type of the submitting MPs is largely hindered ${ }^{163}$. Nevertheless, approximate data points to firm tendencies: while about $54 \%$ of the questions came from regional list MPs, SMD members submitted $8 \%$ of all inquiries, leaving national list members with $38 \%$. It is too early to conclude without having a closer look at the contents, still, these characteristics hint that parliamentary questioning is less of a tool of constituency service and more of government control. Opposition dominance will add to this conclusion later.

Characteristics like the minister to whom the question was addressed or the local attachment of the inquiry (LOCALISM $1^{164}$ ) are meaningful aspects along which questions might be characterized. $20.5 \%(\mathrm{~N}=1071)$ of all the questions under investigation touched upon local issues, where local is perceived in connection with the county. Although the overwhelming majority of the questions concerned national issues, the local aspect of the inquiries cannot be disregarded either. In terms of question type (whether it requested oral or written response) almost no difference was found with regards to localism. $20.1 \%$ (928) of written questions touched upon issues

${ }^{162}$ In the dataset, multiple submissions add to the data aggregated member-wise: questions submitted by three members will appear in all of the three cases.

${ }^{163}$ Individual characteristics are difficult to control for as long as there are questions to which more individuals are attached. The individual-based approach would lead certain questions to multiply, leading us to biased results.

${ }^{164}$ The remaining localism variables (LOCALISM2 and 3) have prerequisites connected to the individual characteristics of the MPs, like the county of election or candidacy. 
related to the county, while this proportion amounts to 23.1 (143) in the case of oral ones.

Moving on, Appendix 5.2 shows the distribution of inquiries with regards to the department they were addressed to. The most questions by far were received by the ministers of the Ministry for National Economy (György Matolcsy) and the Ministry of Development (Tamás Fellegi and Lászlóné Németh). National Resources (Miklós Réthelyi, Zoltán Balogh) and Rural Development (Sándor Fazekas) were the other two departments with major concern. Interestingly, only $2.9 \%$ of the questions are directed to the Prime Minister, Viktor Orbán. No substantial change is detectable when the local background of the questions is taken into account (Figure 5.2).

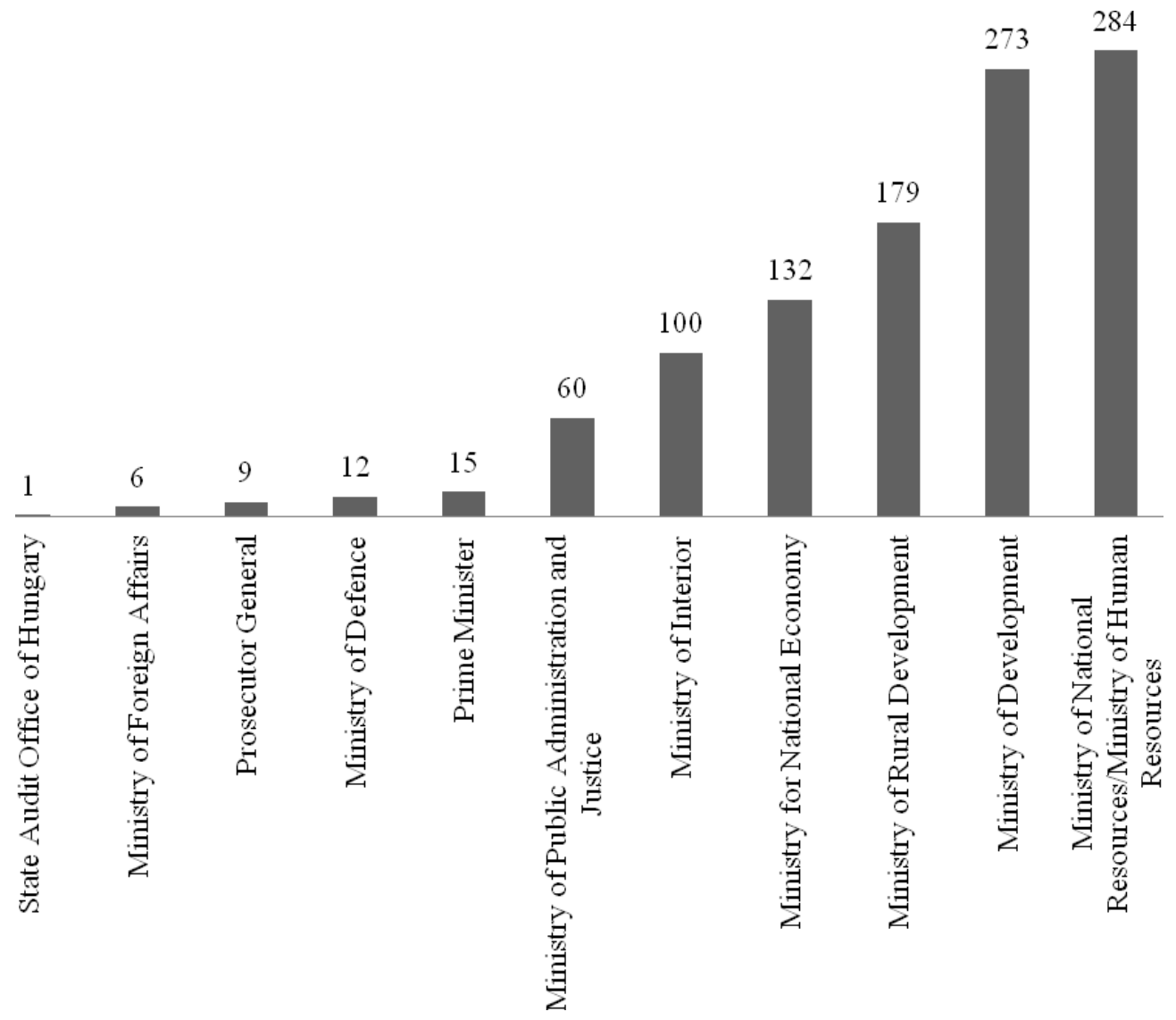

FIGURE 5.2. The distribution of local-oriented questions submitted to different departments and offices

Localism does not discriminate along departments. However, rural issues gained larger importance, which supports the overall impression of the coding: rural issues are one of the main concerns of MPs who submit questions with local orientation. The dominance of issues of national development among local inquiries arises from the 
associative nature of the area. Topics of transportation infrastructure appear to be dominating this segment. The Ministry of Human Resources (formerly known as Ministry of National Resources) unifies areas like health care and social issues, which might explain its overall importance among oral and written questions, both within locally attached and national ones.

In the following, aggregated data is used to characterize the questioning behaviour of the Hungarian Members of Parliament. The question-based dataset was transformed so that it assigns the number of questions to individual members who have submitted inquiries from the beginning of the term until the end of 2012. As mentioned earlier, 231 MPs were submitting at least one inquiry, out of which $37.7 \%$ was elected in single member districts. The partisan characteristics of the questioning MPs show a paradox picture. Although the institution of questioning was designed to enable government control in parliament, $49.8 \%$ (115) of MPs submitting at least one question represent the government (Fidesz-KDNP). Showing the distribution of members according to their PPG affiliations, Appendix 5.3 reveals that government MPs dominate the list of active members. However, considering the unbalanced distribution of mandates in the favour of Fidesz-KDNP, it would be more suitable to measure the proportion of members within different PPGs to submit inquiries ${ }^{165}$.

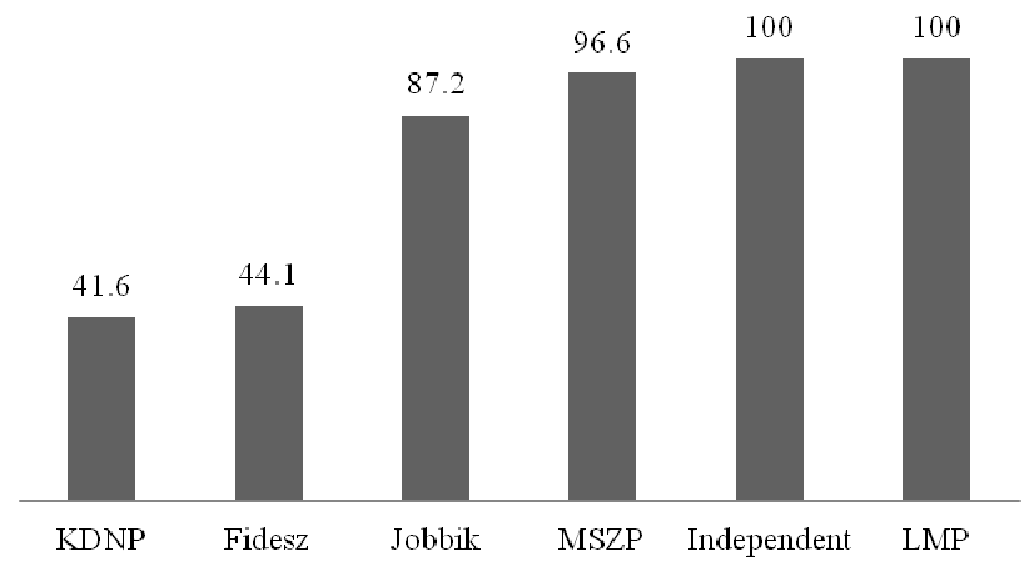

FIGURE 5.3. The proportion of members of the different parties to submit questions

165 The large proportion of Fidesz MPs in parliament leads them to have an equally large percentage among members who submitted at least one inquiry. 
Figure 5.3 shows a completely different - and possibly more reliable - picture. Whereas, Fidesz appeared to be the most active actor if absolute numbers were taken into account, in relative terms, $94.3 \%$ of the opposition members engaged into parliamentary questioning. Only $43.7 \%$ of government MPs participated in this type of activity. As an opposition party, Jobbik concentrated its questions to a relatively small group; still, $87.2 \%$ of its members submitted at least one question. These figures, however, only indicate how concentrated questioning behaviour was regarding the different parties. Although due to multiple submission individual characteristics have to be handled with care, approximate data is worth taking a look at.

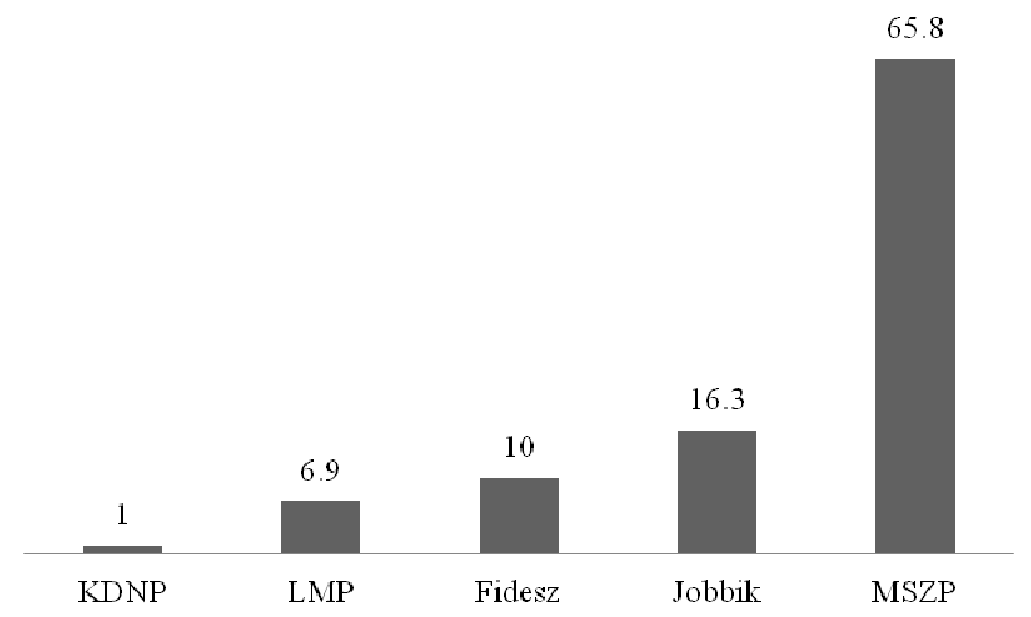

FIGURE 5.4. The (approximate) distribution of questions with regards to party affiliation

The distribution of inquiries reveals (Figure 5.4) that Socialist MPs overwhelmingly dominate parliamentary questioning during the period of concern. LMP lags behind due to its size, while Jobbik manages to take the $2^{\text {nd }}$ place. The relatively small share of the government parties, along with the distribution of questions coming from MPs with various mandate types stresses that questioning is considered a powerful tool for government control by the opposition, and it has a relatively low value for constituency service $^{166}$. This, however, does not imply that constituency orientation does not play any role in the questioning habits of Hungarian Members of Parliament, only that it is not the most important aspect. There is no reason to think that government control and constituency service can only be achieved at the expense of the other. In the following,

\footnotetext{
${ }^{166}$ If constituency service would be the dominant option, one would expect government MPs to be equally active in submitting questions.
} 
localism in questioning behaviour will be investigated from the aspects of the three types of explanations: electoral, position and habitual. First, local orientation of the questions will be taken a closer look at and its relation to mandate type and party affiliations. Then bivariate results are reviewed which is followed by a multivariate presentation of the data.

\subsection{Localism in the Hungarian Parliament}

\subsubsection{Local orientation of the questions in general}

Hereafter, only MPs who submitted at least one question will be taken into account. Thus, various independent variables affect the local connectedness of the questions and not the probability of engaging in this type of activity in general. With other words, IVs will measure whether there are any differences between MPs with regards to the focus of the questions and not whether they had tabled an inquiry. Single member district MPs, for instance, might be less active in questioning, however, if questioning, they might be found more constituency oriented than list members. Thus, the dataset analyzed in this section consists of 231 cases, where cases represent MPs who engaged in parliamentary questioning.

As Figure 5.5 suggests, the distribution of the number of county specific questions is highly skewed, which is hardly unexpected considering the count nature of the variable. $28.6 \%$ (66) of the questioning members raised issues of national concern, while $26.8 \%$ (62) submitted only one inquiry with local focus.

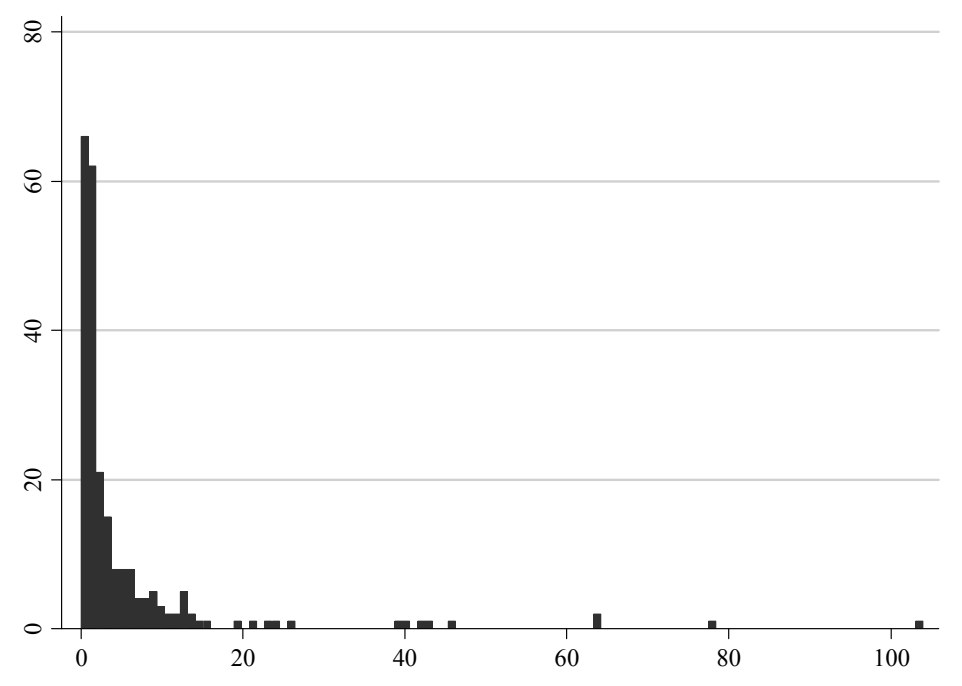

FIGURE 5.5. The number of county specific questions 
As to the connection between mandate type and local issues, a peculiar picture emerges. On average, single member district MPs asked fewer locally relevant questions $(2.78$, std. dev. $=8.87)$ than either regional list $(7.36 ; 13.69)$ or national list $(5.8 ; 13.82)$ members. The most extreme value appears in the case of a national list MP, Attila Mesterházy ${ }^{167}$ of MSZP, who asked 104 questions with special county concern. Additionally, extreme cases appear with large quantity in the case of regional list members. Nándor Gúr (MSZP, 62), Levente Istán Garai (MSZP, 64), Tamás Sós (MSZP, 46), Tamás Harangozó (MSZP, 43), Gábor Ferenczi (Jobbik, 42), Zsolt Németh (Fidesz, 40), Lajos Oláh (MSZP, later on Independent), 39), Zoltán Magyar (Jobbik, 23) and Zoltán Varga (MSZP, 24) all excel from the group of $2^{\text {nd }}$ tier members. Among $1^{\text {st }}$ tier MPs, József Balogh (Fidesz, 78), Sándor Font (Fidesz, 21), Norbert Erdős (Fidesz, 19), Alpár Gyopáros (Fidesz, 11), Szabolcs Czira (Fidesz, 10), Attila Ughy (Fidesz, 10) and János Lázár (Fidesz, 7) submitted a larger amount of locally related inquiries than it is expected based on the group average.

The average number of local issues per party reflects the distribution of questions with regards to party affiliations. MSZP members asked 11.3 county specific questions $($ std. dev.= 19.17), Jobbik had 5.77 (7.87), while the average Fidesz member who engaged in parliamentary questioning, submitted 2.8 (9.1) inquiries with a local focus. To control for the bias of the relatively large differences between the parties in terms of the total number of questions, the number of questions with county orientation relative to the total number of questions is taken into account. This correction draws a completely different picture with regards to both the connection between mandate type versus localism and party versus the number of questions with local concern.

First, SMD MPs perform better in relative terms: an average $1^{\text {st }}$ tier member addresses local issues $52.5 \%$ of the time (std. dev. $=41.8)$. This value is $28.7 \%(31.3)$ and $18.9 \%(26.1)$ in the cases of $2^{\text {nd }}$ and $3^{\text {rd }}$ tier members respectively. Consequently, aside from their moderate activeness SMD members appear to meet the expectations of them being more concerned with local issues. Second, government parties prove to be

\footnotetext{
${ }^{167}$ Concrete names are mentioned in this section, as the data attached to the individual MPs is assessable through the official website of the Hungarian Parliament. In the preceding chapters, however, attitudinal data was reported which falls under the anonymity of the MP-survey. Later on, when questioning data is matched with attitudinal measures, members will not be individually referred to.
} 
more active in furthering local interests, than the opposition. Theoretically, this makes more sense than previous findings. On the one hand, Fidesz and KDNP won the waste majority of the $1^{\text {st }}$ tier seats; therefore based on their mandate background, their local orientation should be more profound. On the other hand, questioning is more of a tool of government control. National issues are often raised by the opposition, thus the relative importance of such issues should be larger in these cases. Having no interests in questioning the government ${ }^{168}$, Fidesz-KDNP members utilize the potential what lies in questioning as constituency service. Out of 100 instances, an average questioning Fidesz member touched upon local issues 47.8 times $($ std. dev. $=42.7)$, while KDNP members did in $44.5 \%$ (34.8) of the cases. Compared to the opposition, these values count as rather high: the same figure in the case of Jobbik, MSZP and LMP only reached $29.2 \%(28.6), 21.7(27)$ and $7.2 \%$ (7.8) respectively.

As to the issue of question type, findings do not seem to support common sense. If the absolute numbers are taken into account, one would think that members tend to bring local issues to parliament through questions requesting written response. The average number of questions with local focus among oral ones is .62 (std. dev. $=1.219$ ) per MP, while 4.59 (11.99) inquiries are addressed to county specific issues as written questions. On the other hand, if we have a look at the questions, approximately $21 \%$ of the written inquiries concern local issues, while $23 \%$ of oral ones do. This suggests that the set-up of the questions in terms of locality does not vary across the different types. The proportion of local questions in the two groups is almost exactly the same, blurring the conclusion on written questions being perceived as more useful in distributing the local message. Moreover, maintaining that oral inquiries are controlled by the PPG to a greater extent, the appearance of local issues on the agenda proves that parties attribute great importance to representing the problems of smaller areas.

The correlation between the number of oral and written questions submitted by a given MP is weak $(r=.159)$. This indicates that members, who send local issues for written response, do not necessarily bring them to the plenary session. This is in accordance with the low level of association between the number of oral and written

\footnotetext{
${ }^{168}$ This is not necessarily true, as in some cases, "self-questioning" might serve the interests of government parties. Parliamentary questioning is a cost effective tool for advertising government success. Nevertheless, data suggests that this aspect does not draw emphasis away from government control and constituency service.
} 
questions $(\mathrm{r}=.263)$. Members who submitted more written questions will not be more active in tabling inquiries. However, it would also be an exaggeration to state that members specialize in either oral or written questioning. $46.7 \%$ (108) of the questioning members participated in both types of questioning. The weak correlation is simply to explain by the fact that while the possible number of written questions is virtually unlimited, the number of questions submitted for oral response has to be restricted due to the time limits. Thus, there are limited opportunities for the members to present their issues in front of the whole assembly. This, however, as pointed out, is not the result of a tendency that discriminates local questions against more general ones, but simply because due to time limits, all issues are restricted.

\subsubsection{Local orientation of the questions with respect to the place of election}

The above analysis applied the variable LOCALISM1, where all issues with local (county) concern were coded as 1 . Now, the place of the election will also be taken into account when deciding whether an issue counts as local. Approximately, 3/4 of the county-related questions had a strong relation to the county of election in the case of SMD and regional list MPs. The relative frequency of questions with local focus is somewhat higher among SMD members: an average MP referred to local issues - where local is understood as the county of election - in $49.22 \%$ of the cases (std. dev. $=42.9$ ), compared to the $22.6 \%(30.4)$ of the $2^{\text {nd }}$ tier MPs. In terms of the differences between the parties, there are no new tendencies to report: Fidesz members are still the most locally oriented, with $44.7 \%$ (43.3) of questions being related to their counties on average. They are followed by KDNP (38.1\%, 39.9), Jobbik (27.6 \%, 29.4), MSZP $(17.7 \%, 22.8)$ and $\operatorname{LMP}(2.2 \%, 5.4)$. Thus, it is safe to say that the connections revealed in relation to the first localism variable (where mentioning any county was enough to be coded as "local") hold in the case of the second one (where the county of election was controlled for).

In the case of $1^{\text {st }}$ tier members, SMD orientation was coded besides countyrelatedness. As outlined earlier, the occurrence of the constituency, a location, a constituent, a facility, an organization, a business or an event were recorded separately. Table 5.3 shows the basic statistics of the number of questions related to these topics. 
TABLE 5.3. Constituency related questions of single member district representatives

\begin{tabular}{lccc}
\hline Mentioned... & Maximum number of questions & Mean & Std. Deviation \\
\hline$\ldots$ the constituency & 65 & 2.218 & 7.424 \\
$\ldots$... a location & 24 & 1.333 & 2.983 \\
$\ldots$... a constituent & 26 & .735 & 3.462 \\
$\ldots$ a facility & 6 & .517 & 1.032 \\
$\ldots$ a business & 18 & .471 & 2.139 \\
$\ldots$ an organization & 2 & .195 & .453 \\
$\ldots$ an event & 1 & .034 & .185 \\
\hline The minimum number of questions is 0 in every category.
\end{tabular}

Among SMD members, the most important thing to mention was the constituency itself. Most of the questions with local ties brought up the single member district. 34.5 $\%$ of the MPs mentioned it once, $10.3 \%$ twice. Constituency issues appeared 65 times in the case of József Balogh of Fidesz, who also breaks the record in all other cases. Apart from the constituency, a certain location within its premises was also a popular subject to raise. $51.7 \%$ of the questioning SMD members submitted at least one inquiry in relation to a given location that the coder could confirm to be a part of the constituency. The third most important factor appears to be the individual case. $12.6 \%$ of the members refer to one single constituent who approached them during office hours. Other aspects, like facilities, organizations, businesses and events seem to hold limited relevance relative to factors mentioned above. These findings indicate that MPs tend to give priority to the collective needs of their constituencies compared to more particularistic interests, like one's business or a certain local organization. In terms of representing a smaller unit within the constituency, casework appears to be the most dominant. In this aspect, members try to fill in ombudsman-like roles to help their constituents in their dealings with the authorities or solve their everyday-life problems.

\subsubsection{Local orientation of the questions with respect to the place of candidacy}

Moving further, not only localism in relation to the place of election can hold theoretical and practical relevance but whether the MPs was nominated on the lower levels of the electoral system. The theory of shadowing hypothesizes that list members act very similar to SMD ones, which - in this context - materializes in raising questions that have a special concern to these areas. In the case of regional list members, this would indicate SMD candidates to submit more locally relevant inquiries than those who were not interested in getting elected on the $1^{\text {st }}$ tier of the electoral system. 
The data seems to support this assumption to various degrees. First, SMD candidates submitted substantially more questions in average: 58.4 inquiries per member were handed in by this group of MPs, while in the other case only 11.28 questions arrived to the central office of the parliament. Second, the average number of questions relating to the county of election was also higher in the case of $1^{\text {st }}$ tier candidates: 8.17 questions compared to .97 . In sum, SMD candidates participated in parliamentary questioning more actively, which lead to a greater number of locally oriented questions in their case. However, when taking the relative occurrence of the inquiries with a county focus into account, the picture gets blurry. The average of the quotient of the number of local questions and the total number of questions is exactly the same in the two groups. 22.5 $\%$ of the questions touched upon local issues in both groups ${ }^{169}$. Consequently, the local dominance of the questions cannot be confirmed, only a higher level of activity in terms of parliamentary questioning among those, who submitted any questions at all.

Moving on, national list members appeared to be exceptionally active in questioning. Even local questions emerged in numerous instances, bringing relevance to the investigation of local aspects in the cases of $3^{\text {rd }}$ tier MPs as well. The picture here is very similar to what was found earlier. SMD candidacy diversifies the group of national list MPs with regards to their overall questioning behaviour: on average they asked 38.8 questions compared to the 26.8 what was observed in the other group. Interestingly, however, $2^{\text {nd }}$ tier candidacy does not structure the number of questions, at least not in a way what could be expected. Regional list candidates submitted fewer questions on average than members not nominated on this level of the competition (34.22 and 38).

As to the number of questions with local relevance, both levels of candidacy appear to affect the way representatives go about furthering the interests of the local level. SMD candidates submitted 2.7 local questions on average, while the others handed in none. Thus, $1^{\text {st }}$ level candidacy appears to be the ultimate structuring factor in the case of national list MPs. Regional candidacy seems to have quite similar effects: $2^{\text {nd }}$ tier candidates are more concerned about issues relating to the counties, however, due to multiple candidacy, this effect is hardly separable from $1^{\text {st }}$ tier nominations.

With regards to the relative number of local issues, both levels of candidacy tend to make a difference. SMD candidates deal with local issues in 10.3 cases out of 100 , as

\footnotetext{
${ }^{169}$ Standard deviation in the group of SMD candidates was 26.3, while in the other group it amounts to 35.5 .
} 
opposed to $3^{\text {rd }}$ tier members with no $1^{\text {st }}$ tier ambitions, who had no county related inquiries. The same difference prevails between regional list candidates and all other MPs. To sum up the findings, lower level candidacy matters when examining the behaviour of national list members in parliament. A rule of thumb here is that the closer one gets to the lowest level of the electoral system, the more county oriented the questioning.

\subsubsection{Parliamentary questioning and independent variables - bivariate relationships}

Up until this point, the complete dataset was used to establish the connections between mandate type, candidacy and the nature of the questions. The investigation was restricted to members who proved to be active in parliamentary questioning. Thus, the previous results only reflect the degree to which mandate type and candidacy differentiated between active members. The next step of the analysis will take us back to the logic of the preceding chapters. To be able to match attitudinal data to the questions dataset, MPs who participated in the 2010 survey will be taken into account ${ }^{170}$.

At this point, I use three dependent variables: (i) the total number of questions submitted, (ii) the number of questions with county focus, and (iii) the quotient of the two. As no substantial difference was found between asking county specific questions and submitting inquiries regarding the place of election, the former approach is used throughout the following analysis. Especially as, not having to split the sample, the number of observations can be held at a higher level ${ }^{171}$.

\footnotetext{
${ }^{170} 87$ MPs of the questioning dataset will be removed from the analysis (by the reason of them not participating in the 2010 survey), and 88 members who participated in the 2010 interviews, but did not submit oral or written questions will be added. Consequently, by bringing the inactive members into the picture, the true effect of the independent variables can be accounted for.

${ }^{171}$ Controlling for local questions with regards to the place of election, national list members would be eliminated from the study, leading to an enormous loss of valuable information.
} 
TABLE 5.4. Questions, question type and type of mandate

\begin{tabular}{|c|c|c|c|c|c|c|c|c|c|}
\hline & \multicolumn{3}{|c|}{ Oral } & \multicolumn{3}{|c|}{ Written } & \multicolumn{3}{|c|}{ Overall } \\
\hline & $\begin{array}{c}\text { Nr. of } \\
\text { questions }\end{array}$ & $\begin{array}{c}\text { Nr. of local } \\
\text { questions }\end{array}$ & $\begin{array}{c}\text { Rel. nr. of local } \\
\text { questions }\end{array}$ & $\begin{array}{c}\text { Nr. of } \\
\text { questions }\end{array}$ & $\begin{array}{c}\text { Nr. of local } \\
\text { questions }\end{array}$ & $\begin{array}{c}\text { Rel. nr. of local } \\
\text { questions }\end{array}$ & $\begin{array}{c}\text { Nr. of } \\
\text { questions }\end{array}$ & $\begin{array}{c}\text { Nr. of local } \\
\text { questions }\end{array}$ & $\begin{array}{c}\text { Rel. nr. of local } \\
\text { questions }\end{array}$ \\
\hline SMD & $.41(.77)$ & $.18(.44)$ & $.12(.29)$ & $1.05(2.8)$ & $.57(1.66)$ & $.17(.35)$ & $1.46(2.88)$ & $.75(1.7)$ & $.25(.39)$ \\
\hline Regional list & 2.3(4.3) & $.62(1.42)$ & $.14(.28)$ & $20(54.3)$ & $4.12(11.04)$ & $.14(.27)$ & $22.3(56.9)$ & $4.75(11.8)$ & $.18(.29)$ \\
\hline National list & $4.9(4.6)$ & $.45(1.36)$ & $.09(.22)$ & $30.6(39.1)$ & $3.35(5.31)$ & $.12(.22)$ & $35.5(39.5)$ & $3.8(5.69)$ & $.12(.21)$ \\
\hline Total & $1.9(3.69)$ & $.39(1.09)$ & $.12(.28)$ & $13.1(38.7)$ & $2.38(7.38)$ & $.15(.3)$ & $15(40.66)$ & $2.77(7.9)$ & $.2(.33)$ \\
\hline $\mathrm{F}$ & $27.02 * * *$ & $4.18 * *$ & .46 & $11.37 * * *$ & $6.211^{* * *}$ & .422 & $13.5 * * *$ & $6.829 * * *$ & 2.272 \\
\hline Eta & .437 & .188 & .064 & .301 & .227 & .061 & .325 & .237 & .139 \\
\hline
\end{tabular}

Entries are mean values; standard deviation in parentheses ${ }^{*} \mathrm{p}<.1, * * \mathrm{p}<.05, * * * \mathrm{p}<.01$

TABLE 5.5. Questions, question type and candidacy

\begin{tabular}{|c|c|c|c|c|c|c|c|c|c|}
\hline & \multicolumn{3}{|c|}{ Oral } & \multicolumn{3}{|c|}{ Written } & \multicolumn{3}{|c|}{ Overall } \\
\hline & $\begin{array}{c}\text { Nr. of } \\
\text { questions }\end{array}$ & $\begin{array}{c}\text { Nr. of local } \\
\text { questions }\end{array}$ & $\begin{array}{l}\text { Rel. nr. of local } \\
\text { questions }\end{array}$ & Nr. of questions & $\begin{array}{l}\text { Nr. of local } \\
\text { questions }\end{array}$ & $\begin{array}{l}\text { Rel. nr. of local } \\
\text { questions }\end{array}$ & $\begin{array}{c}\text { Nr. of } \\
\text { questions }\end{array}$ & $\begin{array}{l}\text { Nr. of local } \\
\text { questions }\end{array}$ & $\begin{array}{l}\text { Rel. nr. of local } \\
\text { questions }\end{array}$ \\
\hline Party list only & $.97(1.98)$ & $.24(.61)$ & $.10(.27)$ & $3.5(8.5)$ & $.44(1.4)$ & $.08(.23)$ & $4.4(10.14)$ & $.67(1.78)$ & $.125(.27)$ \\
\hline SMD & $2.22(4.12)$ & $.45(1.22)$ & $.13(.29)$ & $16.8(44.6)$ & $3.11(8.5)$ & $.18(.32)$ & $19(46.75)$ & $3.56(9.11)$ & $.23(.35)$ \\
\hline Total & $1.88(3.69)$ & $.39(1.09)$ & $.12(.28)$ & $13.15(38.7)$ & $2.38(7.38)$ & $.15(.3)$ & $15(40.66)$ & $2.77(7.9)$ & $.2(.33)$ \\
\hline $\mathrm{F}$ & $5.39 * *$ & 1.76 & .414 & $5.57 * *$ & $6.209 * *$ & $5.089^{* *}$ & $6.068 * *$ & $6.299 * *$ & $4.934 * *$ \\
\hline Eta & .151 & .087 & .042 & .154 & .162 & .147 & .16 & .163 & .145 \\
\hline
\end{tabular}

Entries are mean values; standard deviation in parentheses

$* \mathrm{p}<.1, * * \mathrm{p}<.05, * * * \mathrm{p}<.01$ 
Starting with mandate type, the results point to several interesting facts (see Table 5.4). First of all, list MPs prove to be more active in submitting questions as well as making inquiries that bear local relevance. This difference holds both in the cases of oral and written formulas. Nevertheless, when taking the relative frequency of questions with local focus into account, this tendency fades away immediately. The proportion of locally relevant questions shows no variance between the three groups of MPs. List members are just as likely to submit county-specific questions, as their $1^{\text {st }}$ tier colleagues, when the total number of questions is also controlled for. Putting less emphasis on the sample nature of the data, the county-orientation seems to be stronger in the case of SMD members. The overall proportion of local inquires is undeniably larger within their group than among either regional or national list MPs. Thus, the hypothesized differences appear, only they do not produce significant results.

With regards to district magnitude, bivariate results do not suggest any correlation between district magnitude and questioning behaviour among regional list representatives. Nevertheless, sample results reveal interesting tendencies. First, the number of submissions positively correlates with the number of available seats in the different constituencies. Representatives of larger districts prove to be more active ${ }^{172}$. Second, results point to the opposite direction regarding the number of questions with a county focus. Decreasing magnitude brings an increasing number of local inquiries ${ }^{173}$.

Oddly, the type of candidacy seems to matter a greater deal than type of the mandate (see Table 5.5). Under various question types, members running in SMDs submitted a larger amount of questions. Furthermore, in the case of written inquiries, their dominance in localism prevails. $1^{\text {st }}$ tier candidates appear to be significantly more concerned about local issues than those who did not intend to be elected on the lowest level of the electoral system. The real difference between these two groups of MPs, however, shows in the relative number of local questions. The larger share of questions with a county focus within all submissions indicates that former SMD candidates take local issues seriously. Constituency-orientation appears not only on the attitudinal level, but they seem to act upon it as well. SMD candidates step up as the shadows of single

\footnotetext{
${ }^{172}$ Oral questions: $\mathrm{r}=.017$, Written: $\mathrm{r}=.144$, Overall: $\mathrm{r}=.139$. Results are not significant at $5 \%$.

${ }^{173}$ Oral questions: $r=-.007$, Written: $r=-.142$, Overall: $r=-.134$. Results are not significant at 5 $\%$.
} 
members district representatives, who on the other hand do not differentiate themselves from list members in their actions.

Turning to the effect of local political background on the questioning habits of the Hungarian MPs, one has to keep one particular event in mind. Local elections were held in October 2010. Thus, the effect of local political background might be split into two periods: multiple office-holding between the general elections (April 2010) and the locals (October 2010), and the time after the local elections. As questions were predominantly submitted after the local elections ${ }^{174}$, the variable capturing the second is expected to have a larger effect of the behaviour of the MPs. Nevertheless, the former will also be controlled for, and linked to habitual motivations. Of course, this might be considered a rough simplification, since within a short period, local political background before the local elections received its effect from actual incumbencies, and therefore positions. However, due to the distribution of questions in time, this effect is likely to be second compared to the habitual nature of the variable.

${ }^{174}$ Approximately $12 \%$ of the questions were submitted during the period before the local elections. 
TABLE 5.6a. Questions, question type and local political background (before the local elections in October 2010)

\begin{tabular}{|c|c|c|c|c|c|c|c|c|c|}
\hline & \multicolumn{3}{|c|}{ Oral } & \multicolumn{3}{|c|}{ Written } & \multicolumn{3}{|c|}{ Overall } \\
\hline & $\begin{array}{c}\text { Nr. of } \\
\text { questions }\end{array}$ & $\begin{array}{l}\text { Nr. of local } \\
\text { questions }\end{array}$ & $\begin{array}{c}\text { Rel. nr. of local } \\
\text { questions }\end{array}$ & $\begin{array}{c}\text { Nr. of } \\
\text { questions }\end{array}$ & $\begin{array}{l}\text { Nr. of local } \\
\text { questions }\end{array}$ & $\begin{array}{c}\text { Rel. nr. of local } \\
\text { questions }\end{array}$ & $\begin{array}{c}\text { Nr. of } \\
\text { questions }\end{array}$ & $\begin{array}{l}\text { Nr. of local } \\
\text { questions }\end{array}$ & $\begin{array}{c}\text { Rel. nr. of local } \\
\text { questions }\end{array}$ \\
\hline National MPs only & $2.63(3.86)$ & $.45(1.22)$ & $.11(.27)$ & $20.4(53.8)$ & $2.5(6.25)$ & $.13(.26)$ & $23.1(55.4)$ & $2.95(6.88)$ & $.16(.28)$ \\
\hline Local office holders & $1.36(3.49)$ & $.35(.99)$ & $.12(.29)$ & $8.08(22)$ & $2.29(8.1)$ & $.17(.33)$ & $9.44(24.7)$ & $2.65(8.59)$ & $.23(.36)$ \\
\hline Total & $1.88(3.69)$ & $.39(1.09)$ & $.12(.28)$ & $13.1(38.7)$ & $2.38(7.38)$ & $.15(.3)$ & $15(40.66)$ & $2.77(7.9)$ & $.2(.33)$ \\
\hline $\mathrm{F}$ & $6.808 * * *$ & .493 & .05 & $5.842 * *$ & .042 & .854 & $6.46 * *$ & .083 & $2.93 *$ \\
\hline Eta & .17 & .046 & .015 & .157 & .014 & .061 & .165 & .019 & .112 \\
\hline
\end{tabular}

Entries are mean values; standard deviation in parentheses

${ }^{*} \mathrm{p}<.1, * * \mathrm{p}<.05, * * * \mathrm{p}<.01$

TABLE 5.6b. Questions, question type and local political background (after the local elections in October 2010)

\begin{tabular}{|c|c|c|c|c|c|c|c|c|c|}
\hline & \multicolumn{3}{|c|}{ Oral } & \multicolumn{3}{|c|}{ Written } & \multicolumn{3}{|c|}{ Overall } \\
\hline & $\begin{array}{c}\text { Nr. of } \\
\text { questions }\end{array}$ & $\begin{array}{l}\text { Nr. of local } \\
\text { questions }\end{array}$ & $\begin{array}{l}\text { Rel. nr. of local } \\
\text { questions }\end{array}$ & $\begin{array}{c}\text { Nr. of } \\
\text { questions }\end{array}$ & $\begin{array}{l}\text { Nr. of local } \\
\text { questions }\end{array}$ & $\begin{array}{l}\text { Rel. nr. of local } \\
\text { questions }\end{array}$ & $\begin{array}{c}\text { Nr. of } \\
\text { questions }\end{array}$ & $\begin{array}{l}\text { Nr. of local } \\
\text { questions }\end{array}$ & $\begin{array}{l}\text { Rel. nr. of local } \\
\text { questions }\end{array}$ \\
\hline National MPs only & $2.35(4.24)$ & $.44(1.26)$ & $.10(.25)$ & $16.5(44.5)$ & $2.41(6.27)$ & $.13(.28)$ & $18.8(46.5)$ & $2.86(7.1)$ & $.17(.29)$ \\
\hline Local office holders & $.89(1.79)$ & $.28(.57)$ & $.16(.33)$ & $6.13(20.8)$ & $2.31(9.35)$ & $.19(.34)$ & $7.02(22.2)$ & $2.59(9.5)$ & $.28(.33)$ \\
\hline Total & $1.88(3.69)$ & $.39(1.09)$ & $.12(.28)$ & $13.1(38.7)$ & $2.38(7.38)$ & $.15(.3)$ & $15(40.66)$ & $2.77(7.9)$ & $.2(.33)$ \\
\hline $\mathrm{F}$ & $8.223 * * *$ & 1.144 & 2.276 & 3.664 & .01 & 1.592 & $4.347 * *$ & .058 & $6.043 * *$ \\
\hline Eta & .186 & .07 & .099 & .125 & .007 & .083 & .136 & .016 & .16 \\
\hline
\end{tabular}

Entries are mean values; standard deviation in parentheses

$* \mathrm{p}<.1, * * \mathrm{p}<.05, * * * \mathrm{p}<.01$ 
TABLE 5.7. Questions, question type and careers in single member districts

\begin{tabular}{|c|c|c|c|c|c|c|c|c|c|}
\hline & \multicolumn{3}{|c|}{ Oral } & \multicolumn{3}{|c|}{ Written } & \multicolumn{3}{|c|}{ Overall } \\
\hline & $\begin{array}{c}\text { Nr. of } \\
\text { questions }\end{array}$ & $\begin{array}{c}\text { Nr. of local } \\
\text { questions }\end{array}$ & $\begin{array}{c}\text { Rel. nr. of local } \\
\text { questions }\end{array}$ & Nr. of questions & $\begin{array}{l}\text { Nr. of local } \\
\text { questions }\end{array}$ & $\begin{array}{l}\text { Rel. nr. of local } \\
\text { questions }\end{array}$ & $\begin{array}{c}\text { Nr. of } \\
\text { questions }\end{array}$ & $\begin{array}{c}\text { Nr. of local } \\
\text { questions }\end{array}$ & $\begin{array}{l}\text { Rel. nr. of local } \\
\text { questions }\end{array}$ \\
\hline None & $1.74(3.2)$ & $.32(.97)$ & $.11(.26)$ & $8.54(19.6)$ & $1.81(5.29)$ & $.15(.3)$ & $10.3(21.7)$ & $2.14(5.8)$ & $.19(.33)$ \\
\hline $2006-2010$ & $2.76(5.47)$ & $.65(1.52)$ & $.17(.31)$ & $34.4(77.2)$ & $5.02(13.01)$ & $.16(.31)$ & $37.2(79.9)$ & $5.67(13.7)$ & $.24(.34)$ \\
\hline Before 2006 & $.76(1.49)$ & $.46(.87)$ & $.18(.37)$ & $3.78(10.2)$ & $1.15(3.11)$ & $.11(.28)$ & $4.55(10.8)$ & $1.6(3.66)$ & $.19(.36)$ \\
\hline Total & $1.88(3.69)$ & $.39(1.09)$ & $.12(.28)$ & $13.15(38.7)$ & $2.38(7.38)$ & $.15(.3)$ & $15(40.66)$ & $2.77(7.9)$ & $.2(.33)$ \\
\hline $\mathrm{F}$ & 1.925 & 1.582 & 1.148 & $8.711^{* * *}$ & $3.533 * *$ & .131 & $8.598 * * *$ & $3.687 * *$ & .317 \\
\hline Eta & .129 & .117 & .1 & .266 & .173 & .034 & .264 & .177 & .053 \\
\hline
\end{tabular}

Entries are mean values; standard deviation in parentheses

${ }^{*} \mathrm{p}<.1,{ }^{* *} \mathrm{p}<.05,{ }^{* * *} \mathrm{p}<.01$ 
Taking a look at Table 5.6a, one thing stands out. Members, who were not involved in local politics before the fall of 2010, submitted a significantly larger amount of questions. However, these questions were by no means more constituency-oriented than those submitted by single office holders. Only the overall picture indicates a relatively high difference in the percentages of local inquiry, but this only prevails within the sample. Former local positions do not seem to affect how members manage their questioning. Table 5.6b presents us with a slightly distinct picture. First, the number of questions is still larger in the case of MPs holding national positions only after the local elections in 2010. The distinct schedules might be the reason for this difference: drafting questions takes time, which is a scarcer resource at the hand of local politicians. Managing local business reduces the amount of hours available to traditional parliamentary activities, like questioning. Second, overall results suggest a more localised questioning behaviour on the multiple office-holders' side. The relative number of locally relevant submissions is significantly higher in the case of MPs holding positions on multiple levels of the political system. The difference in the effect of the two types of local background suggests that position motivations are superior to habitual explanations as far as local political experience goes.

Not only current connections to the local level can affect how members behave in parliament, but roles of the past as well. Out of the wide range of possibilities, this dissertation chooses to investigate the relationship between the members' SMD careers and the amount of constituency service they carry out in the legislature. The results presented by Table 5.7 are not conclusive of whether former SMD MPs still hold representing local interests important. On the one hand, 2006-2010 incumbents appear to submit a significantly larger amount of questions - both county-specific and in general - than either those filling in the position before 2006 or those who had never served as $1^{\text {st }}$ tier representatives. On the other hand, however, their questions do not get more local in profile, as the relative number of locally relevant issues does not differ significantly from what is observed in the case of the two other groups of members. On the level of the bivariate analysis, former background discriminates between MPs in terms of their overall activity regarding parliamentary questioning, but does not quite influence how national and local inquiries are split within the whole set of questions. Multivariate results will, however, modify this conclusion (see later in this chapter).

Seniority was only found relevant when explaining the number of questions (see Table 5.8). In the case of written questions, senior members participated more actively 
on average than newcomers. Nevertheless, as to local inquiries, they did not perform better than their younger colleagues. Considering the sample, junior member even demonstrated a slightly more tangible level of constituency focus, but these results can hardly be generalized to the whole population of MPs.

Party leadership seems to create somewhat larger differences, however, still not prominent enough to produce significant results. Taking written requests into account, the local orientation of the questions is stronger in the case of backbench politicians, while the opposite was found in terms of oral inquiries. Anyhow, as to the whole parliament, party leaders are not less concerned about local issues than members with no national level party positions. The different time schedule does not prevent them to raise questions with particular relevance for a well-defined local area. This indicates that certain local issues are picked up by party leaders to be presented at the plenary session irrespective of their personal involvement in the matter.

Ideological distance from the parties performs just as poorly as it did in the previous chapters in explaining MPs' constituency orientation. There are virtually no connections between how far members put themselves from their parties on the left-right scale and either their overall questioning activity or the local orientation of their inquiries. Larger ideological gap does not inspire MPs to work harder for their constituencies, just like it did not influence how they think about representation and structured their campaigns. 
TABLE 5.8. Questions, question type and seniority

\begin{tabular}{|c|c|c|c|c|c|c|c|c|c|}
\hline & \multicolumn{3}{|c|}{ Oral } & \multicolumn{3}{|c|}{ Written } & \multicolumn{3}{|c|}{ Overall } \\
\hline & $\begin{array}{c}\text { Nr. of } \\
\text { questions }\end{array}$ & $\begin{array}{l}\text { Nr. of local } \\
\text { questions }\end{array}$ & $\begin{array}{l}\text { Rel. nr. of local } \\
\text { questions }\end{array}$ & Nr. of questions & $\begin{array}{c}\mathrm{Nr} \text {. of local } \\
\text { questions }\end{array}$ & $\begin{array}{l}\text { Rel. nr. of local } \\
\text { questions }\end{array}$ & $\begin{array}{c}\text { Nr. of } \\
\text { questions }\end{array}$ & $\begin{array}{c}\text { Nr. of local } \\
\text { questions }\end{array}$ & $\begin{array}{l}\text { Rel. nr. of local } \\
\text { questions }\end{array}$ \\
\hline Senior member & $1.63(3.9)$ & $.34(1.02)$ & $.099(.25)$ & $18.7(51.2)$ & $3.1(9.2)$ & $.15(.3)$ & $20.3(53.4)$ & $3.44(9.79)$ & $.19(.33)$ \\
\hline Newcomer & $2.14(3.4)$ & $.44(1.15)$ & $.14(.3)$ & $7.46(17.1)$ & $1.6(4.6)$ & $.15(.3)$ & $9.6(19.4)$ & $2.08(5.3)$ & $.21(.34)$ \\
\hline Total & $1.88(3.69)$ & $.39(1.09)$ & $.12(.28)$ & $13.15(38.7)$ & $2.38(7.38)$ & $.15(.3)$ & $15(40.66)$ & $2.77(7.9)$ & $.2(.33)$ \\
\hline $\mathrm{F}$ & 1.111 & .497 & 1.427 & $4.959 * *$ & 2.298 & .002 & $4.085^{* *}$ & 1.728 & .149 \\
\hline Eta & .069 & .046 & .079 & .145 & .099 & .003 & .132 & .086 & .025 \\
\hline
\end{tabular}

Entries are mean values; standard deviation in parentheses

${ }^{*} \mathrm{p}<.1,{ }^{* *} \mathrm{p}<.05, * * * \mathrm{p}<.01$

TABLE 5.9. Questions, question type and party leadership

\begin{tabular}{|c|c|c|c|c|c|c|c|c|c|}
\hline & \multicolumn{3}{|c|}{ Oral } & \multicolumn{3}{|c|}{ Written } & \multicolumn{3}{|c|}{ Overall } \\
\hline & $\begin{array}{c}\text { Nr. of } \\
\text { questions }\end{array}$ & $\begin{array}{c}\text { Nr. of local } \\
\text { questions }\end{array}$ & $\begin{array}{c}\text { Rel. nr. of local } \\
\text { questions }\end{array}$ & Nr. of questions & $\begin{array}{c}\text { Nr. of local } \\
\text { questions }\end{array}$ & $\begin{array}{c}\text { Rel. nr. of local } \\
\text { questions }\end{array}$ & $\begin{array}{c}\text { Nr. of } \\
\text { questions }\end{array}$ & $\begin{array}{c}\text { Nr. of local } \\
\text { questions }\end{array}$ & $\begin{array}{c}\text { Rel. nr. of local } \\
\text { questions }\end{array}$ \\
\hline Not a party leader & $2.08(4.03)$ & $.35(.97)$ & $.11(.27)$ & $10.6(24.5)$ & $2.36(8.17)$ & $.16(.32)$ & $12.7(27.2)$ & $2.71(8.66)$ & $.21(.34)$ \\
\hline Party leader & $1.54(3.01)$ & $.46(1.27)$ & $.13(.3)$ & $17.4(55.2)$ & $2.4(5.8)$ & $.13(.27)$ & $19(56.8)$ & $2.87(6.47)$ & $.18(.31)$ \\
\hline Total & $1.88(3.69)$ & $.39(1.09)$ & $.12(.28)$ & $13.15(38.7)$ & $2.38(7.38)$ & $.15(.3)$ & $15(40.66)$ & $2.77(7.9)$ & $.2(.33)$ \\
\hline $\mathrm{F}$ & 1.126 & .576 & .411 & 1.66 & .002 & .575 & 1.282 & .02 & .418 \\
\hline Eta & .07 & .05 & .042 & .085 & .003 & .05 & .074 & .009 & .043 \\
\hline
\end{tabular}

Entries are mean values; standard deviation in parentheses

${ }^{*} \mathrm{p}<.1,{ }^{* *} \mathrm{p}<.05, * * * \mathrm{p}<.01$ 


\subsubsection{Explaining parliamentary questioning}

Following the logic of the previous chapters, and because of variable overlaps, this section analyzes the effect of the different independent variables on questioning behaviour in a multivariate setting. (i) The number of questions in general, (ii) the number of locally relevant questions and (iii) their ratio will serve as dependent variables. Models will be built with regards to the whole sample of questions as well as to oral and written inquiries separately.

\subsubsection{Estimating the number of questions}

As a first step, I will present the models explaining the total number of questions and the number of inquiries with a local relevance. The dependent variables embody counts, thus Poission and negative binomial regressions pop into the researcher's mind. By the reason of the possible overdispersion in the data, the overwhelming majority of the literature that aims to explain the number of inquiries sticks with the latter. As for the Hungarian data, across all possible dependent variables, this solution appears to be the most appropriate one, thus in this part of the analysis negative binomial regressions were estimated $^{175}$.

As to the total number of questions, the tendencies uncovered by the bivariate analysis more or less prevail. Taking all types of questions into account, the effect of mandate type provides no surprise: based on the recalculations ${ }^{176}$ of the results of Table 5.10a (first column) regional list members submit 2.6 times ${ }^{177}$ more questions than SMD MPs, while the same ratio amounts to 4.88 in the case of national list $\operatorname{MPs}^{178}$. This difference is very likely to stem from the very distinct schedules of SMD and list members. Having to deal with the constituencies' business, $1^{\text {st }}$ tier members have considerably less time to manage parliamentary activities, except when the two collide. With regards to the number of local questions submitted they outperform both $2^{\text {nd }}$ and

175 The Stata procedure nbreg was used to estimate the effects on the dependent variable. Observations are weighted using population weights (pweight) to ensure that data represents the population in terms of mandate type and party affiliation.

${ }^{176}$ Incidence-rate ratios are reported throughout the text. $I R R=\exp (B)$, where $B$ stands for the regression coefficients, displayed in the tables.

${ }^{177} \mathrm{IRR}=2.6$, s.e. $=.788$

${ }^{178} \mathrm{IRR}=4.88$, s.e. $=2.07$ 
$3^{\text {rd }}$ tier representatives (see the $4^{\text {th }}$ col. of Table 5.10a). Everything else held unchanged, nominal level members submit significantly more locally relevant questions than members of the other groups. Consequently, to some extent, their activism in parliamentary questioning is a part of constituency service. The very same tendencies outline the case of written questions. As far as the number of submitted questions goes, list members appear to be more active relative to constituency MPs (see Table 5.10b, $3^{\text {rd }}$ col.). However, the minute there is something local about the inquiry, $1^{\text {st }}$ tier members regain their strength, and beat out list representatives. The case of oral questions is a slightly different from the above: the effect of mandate type on the number of oral questions maintains its relevance (see Table 5.10a, $5^{\text {th }}$ col.). Nevertheless, type of mandate does not seem to structure the number of local questions (see Table $5.10 \mathrm{~b}, 2^{\text {nd }}$ col.): list members submit just as many locally relevant oral questions as nominal level MPs. Thus, the realm of oral questions is not where SMD members express their concerns toward their constituencies, but this is mainly where government control takes place on the one hand, and where local questions hand-picked by the party leadership appear on the other.

Moving further, the effect of candidacy in SMDs is more consistent under the different dependent variables. On the one hand, shadowing MPs are more active in parliamentary questioning in general: they submitted 7.88 times ${ }^{179}$ more questions than members with no intentions of getting elected in single member districts (based on Table $5.10 \mathrm{a}, 1^{\text {st }}$ col.). This effect prevails when only either oral or written questions are taken into consideration. On the other hand, candidacy is a strong predictor of the number of local questions as well. In all of the three instances (oral, written and overall results) $1^{\text {st }}$ tier nominations have a positive effect on the extent to which members engage in locally driven questioning. Irrespective of question type, SMD candidates are 1.27 times $^{180}$ more active as far as local questions go (Table $5.10 \mathrm{~b}, 3^{\text {rd }}$ col.). The shadowing hypothesis is thus confirmed to bear at least limited relevance in explaining constituency service in parliament.

\footnotetext{
${ }^{179} \mathrm{IRR}=7.88$, s.e. $=2.54$

${ }^{180} \mathrm{IRR}=1.27$, s.e. $=.75$
} 
TABLE 5.10a. The results of the negative binomial models estimating the number of questions submitted between May 2010 and January 2013

\begin{tabular}{|c|c|c|c|c|c|c|}
\hline & \multicolumn{2}{|c|}{ Total nr. of questions } & \multicolumn{2}{|c|}{ Total nr. of questions with a local aspect } & \multicolumn{2}{|c|}{ Total nr. of oral questions } \\
\hline & B(s.e.) & B(s.e.) & B(s.e.) & B(s.e.) & B(s.e.) & B(s.e.) \\
\hline Regional list MP & $.957(.302)^{* * *}$ & $-.16(.274)$ & $.17(.361)$ & $-.84(.368)^{*}$ & $.91(.305)^{* * *}$ & $.29(.331)$ \\
\hline National list MP & $1.58(.424)^{* * *}$ & $-.22(.407)$ & $-.21(.477)$ & $-1.75(.52)^{* * *}$ & $1.4(.447)^{* * *}$ & $.39(.468)$ \\
\hline Candidacy (only losing) & $2.06(.322)^{* * *}$ & $.40(351)$ & $2.39(.401)^{* * *}$ & $.24(.591)$ & $1.36(.31)^{* * *}$ & $.28(.349)$ \\
\hline Local political position (before October 2010) & $-.25(.261)$ & $-.13(.248)$ & $-.02(.301)$ & $.33(.307)$ & $.05(.266)$ & $.31(.295)$ \\
\hline Local political position (after October 2010) & $.021(.261)$ & $.45(.245)$ & $.125(.332)$ & $.41(304)$ & $.03(.25)$ & $.25(.24)$ \\
\hline SMD MP between 2006-2010 & $.73(.309)^{* *}$ & $.36(.305)$ & $.592(.393)$ & $.28(.386)$ & $1.02(.304)^{* * *}$ & $.72(.297)^{* *}$ \\
\hline SMD MP before 2006 & $-.29(.541)$ & $-.18(.486)$ & $-.11(.549)$ & $-.21(.52)$ & $.15(.514)$ & $.17(.493)$ \\
\hline Newcomer & $-.094(.261)$ & $-.08(.245)$ & $-.101(.317)$ & $-.28(.319)$ & $.67(.257)^{* * *}$ & $.49(.282)^{*}$ \\
\hline Ideological distance & $.02(.124)$ & $-.05(.1)$ & $.18(.153)$ & $.13(.138)$ & $-.04(.121)$ & $-.08(.126)$ \\
\hline Party leader & $.18(.222)$ & $-.04(.181)$ & $-.11(.3)$ & $-.19(.228)$ & $-.08(.236)$ & $-.27(.244)$ \\
\hline Jobbik & & $2.95(.424)^{* * *}$ & & $3.75(.662)^{* * *}$ & & $1.97(.526)^{* * *}$ \\
\hline KDNP & & $-.16(.495)$ & & $-1.45(.615)^{*}$ & & $-.62(.684)$ \\
\hline LMP & & $3.01(.394)^{* * * *}$ & & $1.54(.904)$ & & $2.64(.507)^{* * *}$ \\
\hline MSZP & & $3.61(.484)^{* * * *}$ & & $3.47(.768) * * *$ & & $1.95(.497)^{* * *}$ \\
\hline Constant & $.30(.366)$ & $.213(.341)$ & $-.61(.456)$ & $-.66(.467)^{*}$ & $-1.49(.383)^{* * *}$ & $-1.48(.392)^{* * *}$ \\
\hline $\mathrm{N}$ & 221 & 221 & 221 & 221 & 221 & 221 \\
\hline Wald $\mathrm{Chi}^{2}$ & $252.29 * * *$ & $579.66^{* * *}$ & $97.79 * * *$ & $178.61 * * *$ & $146.45^{* * *}$ & $223.89 * * *$ \\
\hline LR-test of alpha $=0^{\mathrm{a}}$ & $2424.42 * * *$ & $1988.20 * * *$ & $519.49 * * *$ & $431.68 * * *$ & $174.42 * * * *$ & $119.74 * * *$ \\
\hline
\end{tabular}

Entries are coefficients; standard errors in parentheses. Standard errors are robust.

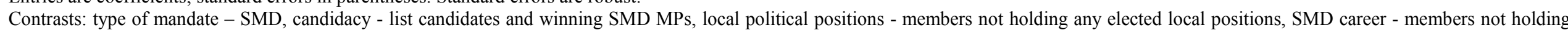

SMD mandates on the course of their careers, newcomer - members with at least one term experience as national representatives, party leader - backbench MPs, party - Fidesz

Coefficients represent the change in the value of the log of the dependent variable due to a one unit change in the related independent variables ${ }^{181}$

${ }^{\text {a }}$ If alpha equals zero, it would be more appropriate to estimate a Poisson regression.

${ }^{*} \mathrm{p}<.1, * * \mathrm{p}<.05, * * * \mathrm{p}<.01$

${ }^{181} \log (Y)=\alpha+\sum B_{i} X_{i}+e_{i}$ 
TABLE 5.10b. The results of the negative binomial models estimating the number of questions submitted between May 2010 and January 2013

\begin{tabular}{|c|c|c|c|c|c|c|}
\hline & \multicolumn{2}{|c|}{$\begin{array}{l}\text { Total nr. of oral questions with a local } \\
\text { aspect }\end{array}$} & \multicolumn{2}{|c|}{ Total nr. of written questions } & \multicolumn{2}{|c|}{$\begin{array}{l}\text { Total nr. of written questions with a local } \\
\text { aspect }\end{array}$} \\
\hline & B(s.e.) & B(s.e.) & B(s.e.) & B(s.e.) & $\mathrm{B}($ s.e. $)$ & B(s.e.) \\
\hline Regional list MP & $.65(.426)$ & $.27(.496)$ & $1.04(.37)^{* * *}$ & $-.39(.36)$ & $.06(.422)$ & $-1.31(.473)^{* * *}$ \\
\hline National list MP & $-.08(.593)$ & $-.56(.667)$ & $1.74(.465)^{* * *}$ & $-.41(.484)$ & $-.09(.529)$ & $-2.08(.628)^{* * *}$ \\
\hline Candidacy (only losing) & $1.47(.449)^{* * *}$ & $-.06(.497)$ & $2.15(.35)^{* * *}$ & $.33(.366)$ & $2.63(.448)^{* * *}$ & $.247(.603)$ \\
\hline Local political position (before October 2010) & $.11(.366)$ & $.79(.434)^{*}$ & $-.332(.3)$ & $-.04(.327)$ & $-.01(.325)$ & $.302(.361)$ \\
\hline Local political position (after October 2010) & $.34(.358)$ & $.48(.361)$ & $-.01(.329)$ & $.44(.321)$ & $.02(.376)$ & $.27(.353)$ \\
\hline SMD MP between 2006-2010 & $1.5(.44)^{* * *}$ & $1.46(.45)^{* * *}$ & $.59(.363)$ & $.25(.397)$ & $.34(.434)$ & $-.15(.463)$ \\
\hline SMD MP before 2006 & $1.06(.707)$ & $1.46(.45)$ & $.24(.675)$ & $-.15(.623)$ & $-.28(.662)$ & $-.49(.59)$ \\
\hline Newcomer & $1.1(.379)^{* * *}$ & $.71(.435)$ & $-.41(.319)$ & $-.47(.312)$ & $-.43(.367)$ & $-.75(.376) * *$ \\
\hline Ideological distance & $.09(.15)$ & $.11(.188)$ & $.004(.163)$ & $-.05(.132)$ & $.13(.182)$ & $-.01(.139)$ \\
\hline Party leader & $.26(.337)$ & $.08(.343)$ & $.25(.272)$ & $-.01(.226)$ & $-.24(.34)$ & $-.27(.261)$ \\
\hline Jobbik & & $2.95(.686)^{* * *}$ & & $3.65(.481)^{* * *}$ & & $4.25(.724)^{* * *}$ \\
\hline KDNP & & $-.95(.894)$ & & $.18(.636)$ & & $-1.74(.848)^{* *}$ \\
\hline LMP & & $1.57(.908)^{*}$ & & $3.53(.457)^{* * *}$ & & $1.74(1.013)^{*}$ \\
\hline MSZP & & $1.55(.732)^{* *}$ & & $4.17(.55)^{* * *}$ & & $4.16(.836)^{* * *}$ \\
\hline Constant & $-3.22(.585)^{* * *}$ & $-3.49(67)^{* * *}$ & $.14(.455)$ & $-.09(.438)$ & $-.63(.499)$ & $-.47(.537)$ \\
\hline $\mathrm{N}$ & 221 & 221 & 221 & 221 & 221 & 221 \\
\hline Wald $\mathrm{Chi}^{2}$ & $37.77 * * *$ & $65.11 * * *$ & $211.33^{* * *}$ & $410.72 * * *$ & $96.65^{* * *}$ & $168.66 * * *$ \\
\hline LR-test of alpha $=0^{\text {a }}$ & $37.88 * * *$ & $29.95^{* * *}$ & $2372.53 * * *$ & $1965.51^{* * *}$ & $519.54 * * *$ & $438.65 * * *$ \\
\hline
\end{tabular}

Entries are coefficients; standard errors in parentheses. Standard errors are robust.

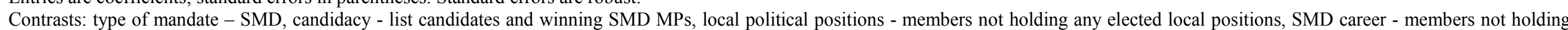

SMD mandates on the course of their careers, newcomer - members with at least one term experience as national representatives, party leader - backbench MPs, party - Fidesz

Coefficients represent the change in the value of the $\log$ of the dependent variable due to a one unit change in the related independent variables ${ }^{182}$

${ }^{a}$ If alpha equals zero, it would be more appropriate to estimate a Poisson regression.

${ }^{*} \mathrm{p}<.1, * * \mathrm{p}<.05, * * * \mathrm{p}<.01$

${ }^{182} \log (Y)=\alpha+\sum B_{i} X_{i}+e_{i}$ 
The biggest surprise was presented, without a doubt, by the effects of local political background. More elaborately, that it had none. Test results suggest no problems of multicollinearity in terms of the two local background variables. Local attachments just do not influence how representatives organize their work in parliament. This finding is quite surprising, as local interests were hypothesized to pose strong incentives on questioning behaviour, by the simple reason of its cost-effectiveness in the lobbying for local interests. Local politicians do not seem to use this tool to represent the interests of their local areas more than single office-holders do. At this point, however, it is too early to state that MPs with local background do not care for their districts. First, based on the results of the preceding chapters, local politicians try to practice personal representation and personalize in their campaign strategies. Second, questioning behaviour is parliament is just one of many possibilities, members follow up on to practice constituency service. The effect of local background on behaviour in parliament might be scattered by the fact that local politicians can carry out constituency service with lower costs in the districts because they have to spend time there and have to offer their services anyway. Thus, rationalizing constituency service may result in a lower effort in parliament to represent local interests.

Nevertheless, members probably do not think of local political background as two separate variables. Former local positions might not only affect the questioning behaviour of the MPs (as it does not) but very well the effect of local background after the local elections. The way members adapt to their new tasks might be influenced by their longer term experience, thus position and habitual motivations might mingle ${ }^{183}$. Following this thought, negative binomial models with an interaction term were run where the effect of one local background variable depends on the value of the other. Across all dependent variables and model specifications, the interaction was found significant in one instance, namely estimating the number of oral questions with a local focus (for the results of this model see Appendix 5.4). Figure 5.6 displays the predictive margins of local positions.

\footnotetext{
${ }^{183}$ This idea might be used in relation to more of the independent variables, and would enable us to look at positions in a more dynamic way. However, at this point, this line of investigation appears to go beyond the scope of this dissertation.
} 


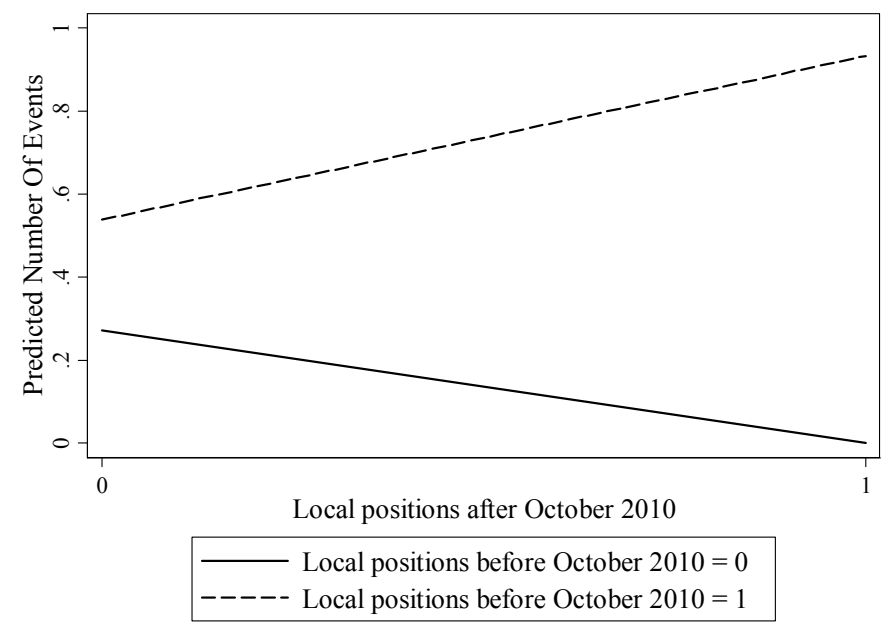

FIGURE 5.6. The predictive margins of the interaction between local political background before and after the local elections

Oddly, with no previous experience, the effect of multiple office-holding after the local elections is negative: elected local officials submit significantly less oral questions with a county focus than members who do not have official local connections. Nevertheless, this effect becomes positive if the MP was holding local positions before the local elections of October. Thus newly obtained local background behaves as hypothesized only when combined with previous experience.

With regards to SMD careers, unusually, holding a nominal level position between 2006 and 2010 seems to make a difference, especially among questions submitted for oral response. Former $1^{\text {st }}$ tier members proved to be more active in terms of questioning in general as well as submitting locally relevant oral questions. The latter is quite unexpected, as the bivariate results did not suggest any effect of this kind. Former SMD MPs submitted 4.31 times $^{184}$ as many oral questions with local relevance than members with no nominal level experience (Table $5.10 \mathrm{~b}, 2^{\text {nd }} \mathrm{col}$ ). This finding seems to be the first strong indication that previous positions matter. Members pick up attitudes that manifest in their questioning behaviour.

The case of newcomers provides us with contradicting evidence. First, they tend to submit a greater amount of oral questions as well as oral questions with a local focus than senior MPs. None of these connections were significant in a bivariate context. Junior Members of Parliament submitted 3.01 times $^{185}$ more constituency-related oral

\footnotetext{
${ }^{184} \mathrm{IRR}=4.31$, s.e. $=1.94$

${ }^{185} \mathrm{IRR}=3.01$, s.e. $=1.44$
} 
questions in average than their more experienced colleagues (Table $5.10 \mathrm{~b}, 1^{\text {st }}$ col.). Second, in the case of written questions, its effect appears to be negative: newcomers tend to submit significantly (32\%) less locally relevant written questions than seniors (Table $5.10 \mathrm{~b}, 6^{\text {th }}$ col.). In the first case, when party affiliations are controlled for, the effect of seniority diminishes, while taking written questions into account, seniority strongly influences local orientation. This difference might settle the contradicting results for the good of newcomers being less active in terms of constituency service in parliament.

The most stable estimator of member behaviour is party affiliation. Lacking longitudinal data, it is always difficult to separate the effects attached to parties. It is not self-evident whether the effects are attributed, for instance, to party size or the government-opposition dichotomy. Therefore, there is a lot of room to speculate. In the case of parliamentary questioning, however, the evidence of Tables 5.10a and 5.10b seem straightforward. Opposition MPs are more active in questioning, both in terms of the total number of questions and questions with local aspects. The connections hold when oral and written inquiries or both are taken into account. Across all models, the largest difference between parties appears in relation to Fidesz and Jobbik. Members of Jobbik submitted about 70 times $^{186}$ more written local questions, and 19 times $^{187}$ as many oral questions with local aspects than Fidesz MPs. MSZP did also outperform Fidesz members in terms of the number of local inquiries ${ }^{188}$. Interestingly, this finding contradicts what was found during the analysis of focus of representation. Representatives of small and new parties appeared to be less sensitive to the local demand, which was attributed to the possibility that constituency is not a part of their sense of being legislators. The reason for this lies in the party's different path: Fidesz and MSZP members aspired for SMD positions right from the beginning, and they had every chance to win the seats. On the contrary, members of new parties (due to their size) do not seem to have this opportunity under the given electoral rules. Thus the mechanisms that socialize MPs to act on behalf of a smaller area might be entirely missing. Without throwing this reasoning out of the window, one must direct attention

\footnotetext{
${ }^{186} \mathrm{IRR}=70.31$, s.e. $=50.9$

${ }^{187} \mathrm{IRR}=19.12$, s.e. $=13.12$

${ }^{188}$ Socialist members submitted $4.72($ s.e. $=3.46)$ and $64.4($ s.e. $=.53 .9)$ times as many oral and written questions as did Fidesz MPs. Values regard questions with local relevance
} 
to the behaviour of Jobbik MPs when it comes to questioning. Local orientation is clearly a part of their work, it just did not yet transformed into attitudes. Based on this logic, Jobbik MPs are expected to become more constituency oriented in the future in terms of whom they think they represent.

Moving further, MPs of LMP proved to be more active in questioning in general, but differences between them and Fidesz members disappear when localism is controlled for. Additionally, in the case of local questions submitted for written response, a gap within the government appears. KDNP MPs are significantly less concerned with local issues regarding written questions than their colleagues from the larger government party.

Controlling for party affiliation, most of the remaining independent factors lose their explanatory powers. There are three exceptions of this rule. First, the effect of mandate type in explaining the number of written questions with a local tone prevails ${ }^{189}$. Second, holding a constituency seat during the previous term has still a positive effect on the number of locally relevant oral questions (Table $5.10 \mathrm{~b}, 2^{\text {nd }}$ col.). Third, newcomers are represented with a smaller number of questions among written ones with local relevance (Table $5.10 \mathrm{~b}, 6^{\text {th }}$ col.). All other effects discussed above are valid only if party effects are not brought into the equation. Despite these results, one should not underestimate the diminishing effects, as they suggest tendencies that might be worth taking into account, when explaining member behaviour.

With regards to the effect of party leadership and ideological distance from the parties, no connection was found between these and questioning behaviour. As to ideological distance, it is hardly a surprise, as it had performed poorly in estimating both attitudes toward representation and campaigning behaviour. Members do not structure their activities based on the perceived differences between them and their parties. Nevertheless, the insignificance of holding party leadership positions is definitely surprising, especially in the case of oral questions. Inquiry submitted to oral response is the opposition's way of controlling the government, and it would be a logical thing to assume that it is done by the party leadership. This, however, does not seem to be the case in Hungary. Party leadership might distribute questioning time between backbench MPs, but not participate in it with a greater intensity. In other words, government control is outsourced to lower ranking representatives.

${ }^{189}$ List members submit less inquiries compared to SMD representatives (Table 5.10b, 6th col.) 
Last but not least, the effect of district magnitude has to be taken a brief look at. Restricting the sample to regional list members only, negative binomial models were estimated using identical dependent variables. In none of the regressions was the log of district magnitude found significant. Its sign, however, is negative in all cases, meaning that the lower the district magnitude, the higher the number of questions members submitted. This finding matches the hypothesis of MPs from smaller constituencies having fewer incentives to free-ride by the reason of the accountability linkage which is clearer in their case. Thus, their level of activity was expected to increase.

\subsubsection{Estimating the relative number of local questions}

Turning to the occurrence of local issues relative to the number of questions, zeroinflated beta regressions seem to be the most appropriate choice to model the dependent variables. The zero part incorporates two different meanings. On the one hand, it involves not submitting any questions at all. On the other hand, no questions with local relevance will also fall into this group (real zeros). Figure 5.7 displays the distribution of the different types of zeros. In the case of oral questions, $72.1 \%$ of the zeros in the variables that stand for the relative number of local questions are the results of the members' not participating in oral questioning at all. The other $27.9 \%$ represents members who submitted questions for oral response, but did not touch upon local issues. The distribution is very similar in the case of written questions $(74.2-25.2 \%)$.

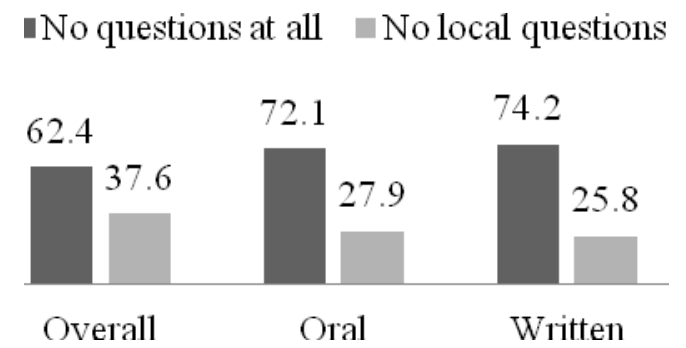

FIGURE 5.7. The distribution of zeros in the case of the relative number of questions with local concern

To empirically separate the various kinds of zeros, real zeros are re-coded to .0001 , so that the zoib procedure can take it into account in the proportion part of its calculations. Furthermore, for the very same reason, ones will also be replaced by .9999 . Hopefully, this "cheat" will lead to more honest results, enabling real zeros and ones to be parts of the beta estimation, thus the part of explaining the proportion of locally 
relevant questions within the whole set of inquiries. Results are presented by Table $5.11^{190}$. Again, first columns in the models represent the beta-parts of the regressions, the second ones stand for the binary logit models estimating the log-odds of asking no questions at all.

${ }^{190}$ Models without the effect of party affiliation are shown in Appendix 5.5. 
TABLE 5.11. Results of the zero-inflated beta regressions estimating the proportion of locally relevant questions

\begin{tabular}{|c|c|c|c|c|c|c|}
\hline & \multicolumn{2}{|l|}{ Overall } & \multicolumn{2}{|l|}{ Oral } & \multicolumn{2}{|l|}{ Written } \\
\hline & B (s.e.) & B (s.e.) & B (s.e.) & B (s.e.) & B (s.e.) & B (s.e.) \\
\hline & Proportion & $\mathrm{Y}=0$ & Proportion & $\mathrm{Y}=0$ & Proportion & $\mathrm{Y}=0$ \\
\hline Regional list MP & $-.554(.338)$ & $.326(.398)$ & $-.138(.415)$ & $-.434(.433)$ & $-.011(.31)$ & $-.434(.432)$ \\
\hline National list MP & $-.96(.433)^{* *}$ & $-.473(1.103)$ & $-.432(.469)$ & $-.345(.768)$ & $-.302(.433)$ & $-.345(.768)$ \\
\hline Candidacy (only losing) & $.046(.259)$ & $-.967(1.161)$ & $-.256(.273)$ & $-.803(.64)$ & $-.059(.372)$ & $-.804(.64)$ \\
\hline Local political position (before October 2010) & $.172(.263)$ & $.214(.452)$ & $.215(.297)$ & $-.211(.422)$ & $.218(.232)$ & $-.211(.422)$ \\
\hline Local political position (after October 2010) & $.403(.327)$ & $-.99(.376)^{* * *}$ & $.607(.345)^{*}$ & $-.621(.378)$ & $.039(.272)$ & $-.621(.378)$ \\
\hline SMD MP between 2006-2010 & $.31(.298)$ & $-.071(.48)$ & $.642(.318)^{* *}$ & $-1.089(.481)^{* *}$ & $.03(.258)$ & $-1.089(.481)^{* *}$ \\
\hline SMD MP before 2006 & $.437(.739)$ & $.586(.707)$ & $.991(.882)$ & $-.612(.704)$ & $.151(.306)$ & $-.6125(.704)$ \\
\hline Newcomer & $-.189(.276)$ & $-.558(.427)$ & $-.178(.332)$ & $-1.194(.463)^{* * *}$ & $.19(.199)$ & $-1.195(.463)^{* * *}$ \\
\hline Ideological distance & $.173(.096)^{*}$ & $.132(.183)$ & $.225(.12)^{*}$ & $-.027(.176)$ & $.039(.09)$ & $-.027(.177)$ \\
\hline Party leader & $-.242(.208)$ & $-.409(.36)$ & $.142(.24)$ & $-.002(.374)$ & $.077(.187)$ & $-.002(.374)$ \\
\hline Jobbik & $.649(.39)^{*}$ & $-2.347(1.51)$ & $.731(.405)^{*}$ & $-1.593(.941)^{*}$ & $.833(.527)$ & $-1.593(.941)^{*}$ \\
\hline KDNP & $-.88(.344) * * *$ & $.859(.559)$ & $-.916(.452)^{* *}$ & $.913(.736)$ & $-.523(.205)^{* *}$ & $.913(.736)$ \\
\hline LMP & $-.061(.494)$ & $-15.1(.99)^{* * *}$ & $.281(.422)$ & $-16.092(.97)^{* * *}$ & $.348(.51)$ & $-15.482(.97)^{* * *}$ \\
\hline MSZP & $-.024(.406)$ & $-2.386(1.498)$ & $-.443(.456)$ & $-1.512(.781)^{*}$ & $.888(.566)$ & $-1.511(.781)^{*}$ \\
\hline Constant & $-.252(.351)$ & $.451(.519)$ & $-.896(.435)^{* *}$ & $2.307(.546)^{* * *}$ & $-1.951(.432)^{* * *}$ & $2.307(.547)^{* * *}$ \\
\hline $\mathrm{N}$ & 221 & & 221 & & 221 & \\
\hline Wald Chi ${ }^{2}$ & $40.71 * * *$ & & $30.39 * * *$ & & $62.13 * * *$ & \\
\hline
\end{tabular}

Entries are coefficients; standard errors in parentheses. Standard errors are robust.

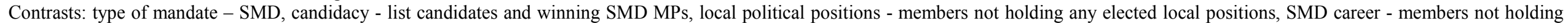
SMD mandates on the course of their careers, newcomer - members with at least one term experience as national representatives, party leader - backbench MPs, party - Fidesz

Coefficients in the beta regression represent the change in the value of the dependent variable due to a one unit change in the related independent variables.

Coefficients in $\mathrm{Y}=1$ and $\mathrm{Y}=0$ models represent the change in the value of the log-odds of the dependent variable due to a one unit change in the related independent variables.

$* \mathrm{p}<.1, * * \mathrm{p}<.05, * * * \mathrm{p}<.01$ 
As to the effect of mandate type, a significant difference emerges between SMD and national list members. $3^{\text {rd }}$ tier members asked a smaller proportion of local questions than constituency representatives when question type is not taken into account. However, speaking of either oral or written questions only, mandate type no longer determines how MPs structure their questioning behaviour. The proportion of questions with a local focus remains unchanged throughout the different types of seats. Nevertheless, if sample results are taken a closer look at, the coefficients of these variables are negative values at every instance and increasing in absolute values heading from SMD members to $3^{\text {rd }}$ tier MPs. This makes the tendency visible, namely that the closer one gets to the $1^{\text {st }}$ level of the electoral system, the higher the percentage of local questions. With regards to the $\mathrm{Y}=0$ part of the regression, mandate type does not seem to make any difference regarding the whole population. Sample findings support previous results: the probability of SMD members to submit any oral or written question is lower than in the case of list members. With other words, list members seem to be more active in parliamentary questioning, and do not lag behind in terms of focusing on a specific local area.

Further attachment to the single member district appears in various ways. First, candidacy at the nominal level was hypothesized to affect member behaviour. Instead, the connection proved to be insignificant when party affiliation was controlled for. Even without the party variable, candidacy only affects the likelihood of not submitting any questions, and not the proportion of locally relevant inquiries, which is a more elaborate estimate of local orientation. Second, careers in SMDs appear to influence the structure of oral questions on the one hand and the likelihood of not participating in either oral or written questioning on the other. Not only have Members of Parliament who served as $1^{\text {st }}$ tier MPs within the period of 2006-2010 submitted with a greater probability than those without any nominal level experience, but in terms of oral questions they were more locally oriented among the given circumstances. Oddly, previous legislative experience, which is perceived as habits within the context of this dissertation, performs better in explaining member behaviour than motivations attached to incumbencies ${ }^{191}$.

\footnotetext{
${ }^{191}$ At this point, one must seriously consider the role of the electoral systems change. While this was not a problem regarding the attitude variables that were collected short after the 2010 elections, data on parliamentary questioning was collected throughout the electoral
} 
This conclusion is further strengthened, when the effects of the local political background variables are examined. Considering the whole population, neither local positions before the local elections nor positions held after that affect the proportion of locally oriented submissions ${ }^{192}$. Nevertheless, the tendencies certainly point to the hypothesized direction. Regarding the sample, local politicians are more focused on local issues in a relative sense than members with no local connections. In the case of oral inquiries, this effect is larger in the group of MPs elected in October 2010, while the opposite holds for written ones. Former local politicians (in office before October 2010) appear to use the platform that is less overseen by the party centre more efficiently. Members in local offices naturally get more space in furthering the local interests on the plenary session. Parties delegate local questions presented by local politicians rather than former local office holders.

A less "rational" reason points to the role of habitual motivations as well. Members serving as local politicians before the local elections in 2010 have held the positions throughout the previous term ${ }^{193}$. This experience must be strong enough to form certain kinds of habits that increase the level of local orientation. Furthermore, former local officials lost their previous offices in which they could carry out constituency-oriented activities. Thus, the only low-cost possibility to continue on furthering local interests is submitting questions that are relevant to the given areas. Local politicians, however, who were elected (or re-elected) in 2010, still have the opportunity to run business "on the spot", making it less desirable to make themselves visible in parliament.

Regarding party affiliations, the real difference appears between the two government parties in terms of the proportion of locally relevant questions. KDNP

term. From the end of 2011 on (and for government MPs probably earlier), changes in the electoral rules are common knowledge. Thus the poor performance of mandate type might be attributed to the fact that SMD members were already confronted with their political fate as $1^{\text {st }}$ tier representatives. Smaller chances of being re-elected lessens the amount of work an MPs puts into the non-legislative activities, and focuses on issues that hold forth a greater benefit.

${ }^{192}$ This is true even if the various types of local positions (mayors, local and regional council members) are handled separately.

${ }^{193}$ Local elections take place during the Fall of the year in which the general elections are held. 
members did not feel the need to express concerns for a lower level, at least not in a degree as Fidesz representatives did. As to the sample, in the case of written inquiries, the divide appears between the government and opposition. MSZP, Jobbik and LMP members submitted significantly more locally oriented written questions as did government parties. In terms of oral inquiries, Jobbik and LMP brought local issues to the plenary sessions with a greater likelihood than Fidesz. Additionally, MSZP MPs seemed to use publicity to control government in national issues rather than local ones.

\subsection{The relation of parliamentary questioning to the focus of representation and campaigning}

In this section, I briefly analyze the interrelations between the various dependent variables from all three empirical chapters: focus of representation, personal campaigning and parliamentary questioning. With regards to the relationship between attitudes toward representation and questioning behaviour, two things stand out. First, there are considerable (and significant ${ }^{194}$ ) differences across the different foci ${ }^{195}$ in terms of the number of questions submitted. Party representatives proved to be the most active in both categories (oral ${ }^{196}$ and written ${ }^{197}$ ), followed by generalists who consider themselves the representatives of the whole citizenry ${ }^{198}$. Constituency representatives submitted an average number of 1.31 oral and 8.28 written inquiries, which indicates that the platform of constituency representation is not likely to be the parliament, at least not more than it is the place for party representation.

Second, the various foci do not induce significant differences either in the number of local questions or their relative frequency within the whole set of questions. In the case of oral questions, advocates of general representation appear to be the most locally oriented: they submitted an average number of .48 locally relevant questions, which amounts to $15 \%$ of all their oral inquiry. An inseparable part of the truth is, however, that constituency representatives took the second place in the imaginary

\footnotetext{
${ }^{194}$ Oral questions: $\mathrm{F}=8.663^{* * *}, \mathrm{Eta}=.321$, Written: $\mathrm{F}=4.948^{* * *}$, Eta $=.248$

${ }^{195}$ (i)Constituency, (ii) the party, (iii) a specific group in the society and (iv) all the citizens of the country.

${ }^{196}$ Mean $=4.88$, s.d. $=4.8$

${ }^{197}$ Mean=37.39, s.d. $=81.5$; eliminating the largest outlier: Mean=20.8, s.d. $=29.5$

${ }^{198}$ Oral questions: Mean=1.5, s.d. $=2.4$, Written: Mean=10.88, s.d. $=29.3$
} 
contest over the greatest number of local questions (.37) as well as their salience $(12 \%)$ among oral questions. The case of written questions is different in a sense that party representatives regained their leading position with 3.47 submissions on average. The relative value of local inquiries is $20 \%$ in the case of members representing the constituencies, which is the highest value across all foci of representation. Thus, one could say that in the most important aspect of parliamentary questioning - from a local representation viewpoint -, constituency oriented members met the hypothesis of them putting a greater emphasis on local issues than MPs with different focus. Furthermore, the fact that party MPs submitted most actively and their local orientation was rather weak proves that party representatives are the vessels of government control in parliament.

Table 5.12 reveals that campaign norms and parliamentary questioning are interrelated in a way that the greater the emphasis on the personal campaign, the higher the number of written questions, the number of local questions of any kind and the relative importance of the local factor in terms of inquiries submitted for written response. The more personal the campaign, the more stressful is the appearance of local issues among questioning topics. The same applies to the number of personalized campaign tools used during the campaign (campaign means). A greater level of personalization in terms of means manifests in a more locally oriented behaviour in parliament. Regarding campaign strategies, the only aspect that has literally no effect on how members behave in parliament is the proportion of personally recruited staff members, which is arguably the weakest estimator of campaign personalization.

TABLE 5.12. The relationships between questioning behaviour, campaign norms, means and organization

\begin{tabular}{llccr}
\hline & & Campaign norms $^{\mathrm{a}}$ & Campaign means $^{\mathrm{b}}$ & Campaign $^{\text {organization }}{ }^{\mathrm{c}}$ \\
\hline \multirow{3}{*}{ Overall } & Nr. of questions & $.281^{* * * *}$ & $.129 * *$ & -.002 \\
& Nr. of local questions & $.238^{* * *}$ & $.133^{* *}$ & -.046 \\
& Rel.nr. of local questions & $.216^{* * *}$ & $.137^{* *}$ & .019 \\
\hline \multirow{3}{*}{ Oral } & Nr. of questions & .049 & .01 & -.03 \\
& Nr. of local questions & $.155^{* *}$ & .034 & -.066 \\
& Rel.nr. of local questions & .123 & .003 & .029 \\
\hline \multirow{2}{*}{ Written } & Nr. of questions & $.29 * * *$ & $.135^{* *}$ & .000 \\
& Nr. of local questions & $.233^{* * *}$ & $.138^{* *}$ & -.04 \\
& Rel.nr. of local questions & $.203 * * *$ & $.141^{* *}$ & -.022 \\
\hline
\end{tabular}

Pearson correlation coefficients

a Campaign norms are measured by an 11 point scale (1 - party campaign, 11 - personal campaign)

${ }^{\mathrm{b}}$ The number of personalized campaign tools.

${ }^{c}$ The proportion of personally recruited staff members.

$* \mathrm{p}<.1, * * \mathrm{p}<.05, * * * \mathrm{p}<.01$ 
In general, it appears that oral questioning is not affected by the level of campaign personalization. This is hardly a surprise, as oral questions can be rarely used as the tool of personal representation, by the oft-cited reason of the limited time available to table the inquiries and the parties' powers in determining the agenda. Only partysupported personalization is allowed to appear in the plenary. With other words, whether one has the opportunity to plead their case, is entirely up to the party and does not serve personal representation goals. Consequently, it can certainly not be structured in synch with campaign behaviour.

As argued at the end of Chapter 4, campaign agenda is the most "honest" measure of personalization among the four aspects of campaigning. This involves agenda not entirely being controlled by the party centre. Based on this, it is again no surprise that there was no connection found between campaign thematization and questioning at the plenary session. The aim of government control does not allow personal preferences to appear in member behaviour. According to the results presented in Table 5.13, members who campaigned with local issues raise slightly more local questions in parliament, but this relationship is far from being generalizable.

TABLE 5.13. The relationship between questioning behaviour and campaign agenda

\begin{tabular}{|c|c|c|c|c|c|c|}
\hline & & $\begin{array}{l}\text { Does not mention local } \\
\text { issues }\end{array}$ & $\begin{array}{l}\text { Mentions } \\
\text { local issues }\end{array}$ & Total & $\mathrm{F}$ & Eta \\
\hline \multirow{3}{*}{ Overall } & Nr. of questions & $10.82(19.1)$ & $18.06(49.3)$ & $15.83(42.49)$ & 1.287 & .079 \\
\hline & Nr. of local questions & $.96(2.63)$ & $3.75(9.67)$ & $2.89(8.27)$ & $5.143 * *$ & .156 \\
\hline & Rel.nr. of questions & $.123(.281)$ & $.252(.358)$ & $.212(.34)$ & $6.517 * *$ & .175 \\
\hline \multirow{3}{*}{ Oral } & Nr. of questions & $2.08(3.51)$ & $1.85(3.89)$ & $1.92(3.77)$ & .162 & .028 \\
\hline & Nr. of local questions & $.178(.422)$ & $.49(1.3)$ & $.395(1.12)$ & $3.518^{*}$ & .13 \\
\hline & Rel.nr. of questions & $.089(.24)$ & $.137(.296)$ & $.122(.28)$ & 1.313 & .08 \\
\hline \multirow{3}{*}{ Written } & Nr. of questions & $8.74(17.4)$ & $16.21(47.2)$ & $13.91(40.56)$ & 1.505 & .085 \\
\hline & Nr. of local questions & $.786(2.52)$ & $3.26(9.028)$ & $2.5(7.72)$ & $4.641 * *$ & .148 \\
\hline & Rel.nr. of questions & $.07(.22)$ & $.203(.343)$ & $.162(.316)$ & $8.137 * * *$ & .195 \\
\hline
\end{tabular}

Entries are mean values; standard deviation in parentheses

${ }^{*} \mathrm{p}<.1, * * \mathrm{p}<.05, * * * \mathrm{p}<.01$

The case of written questions again proves that the primary platform for individually initiated constituency service is submissions requesting written response. MPs concerned about local topics in their campaigns raised more local issues on average on the course of their parliamentary work. But not only is the number of questions affected by the campaign agenda, but the very nature of questioning differs across the various campaign strategies. The relative number of local questions increases from 7 to $20 \%$ if a member campaigned with local issues that were not picked up by the party campaign. 


\subsection{Concluding remarks}

In this chapter, I uncovered the determinants of local orientation in parliament that appears in the non-legislative activities of the MPs. The chapter offers the least abstract approach of this dissertation to constituency orientation, through examining member behaviour instead of attitudes. The measurement is unbiased in a sense that it is not accessed through the MPs' memories, but analyzed using the records of the Hungarian Parliament. Oral and written questions were coded based on a simple codebook which identified locally relevant inquiries. The application of both types of questions enabled us to assess the perceived usefulness of the different tools in representing local interests.

There are several points in which this chapter uncovers interesting tendencies, some of which might seem unexpected. First, absolute measures suggest that although local aspects appear in questioning, it still remains the main tool of government control. Opposition dominance and the relative activity of list MPs reveal that - generally speaking - parliamentary questioning has a relatively low value for constituency service. Nevertheless, it is still not clear to what extent are government control and local representation mutually exclusive. Second, no substantial differences were found between the various question types in terms of the relative occurrence of local issues. Written questions are not more locally oriented than oral ones, which is certainly unexpected in the light of the strict party control over the thematization of the plenary agenda. Data supports that parties attribute great importance to presenting local problems as oral inquiries. Thus local issues appear on agenda encouraged by the party leadership proving that local representation is perceived to serve the interests of the parties without causing any damages to party cohesion and unity.

As to the effects of the different independent variables, mandate type moderately structures the local relevance of issues. The tendencies support the hypothesis of SMD members being more concerned of local problems in their questioning behaviour. However, its effect is limited to the absolute number of questions of local relevance, making this the first instance in which electoral rules did not overwhelmingly influence the dependent variables. It is less the local orientation and more the overall activity in questioning where mandate type truly makes a difference. List members appear to be more active in questioning indicating that the focal point of constituency service lies not in parliament, but probably in the constituency itself. 
This conclusion is supported by the effects of various position related indicators that shed light on some interesting connections.

In the case of written questions, the control of the party centre is minimal compared to oral inquiries. Thus it is expected that factors related to local attachments (SMD mandate and local background) structure member behaviour in a greater extent than they do with oral ones. The fact that they did not, indicate that local inquiries are not powered by the desire to offer local services. Parliamentary questioning is one of the most cost-effective tools of constituency representation. Still, members seem to locate their efforts into different types of services ${ }^{199}$.

The overall picture suggests that candidacy on the lower levels appears to play a more significant role in explaining the local focus of questioning than holding a $1^{\text {st }}$ tier mandate itself. Therefore, parliamentary questions are considered as one of the most important platforms of shadowing. Besides nominal level candidacy, habitual factors in general gain their relevance in parliamentary questioning. Explaining member attitudes they did not appear to make any difference at all, and here we find that they influence behaviour in parliament. This, however, is probably not because habitual factors suddenly became important in structuring local representation. Their effects stem from the fact that members diversify their services. Elected officials (SMD members and multiple office-holders) probably spend more time in their constituencies, towns and villages, thus lessening the emphasis put on questioning. They conduct their services "on the spot", while the cheapest way to carry on with the constituency's business is to submit questions related to the local level for representatives not holding the offices anymore. This strengthens the effect of former positions and candidacy, which might not have appeared if parliamentary questioning had been considered as a primary tool for constituency service.

\footnotetext{
${ }^{199}$ Mapping these „other services” is beyond the scope of this dissertation, but clearly points us to the necessity of future research of the topic.
} 


\section{CONCLUSIONS}

This dissertation aimed to reveal the determinants of constituency orientation and prove that this form of representation can prevail under party-centred electoral rules. Doing all this in a case study fashion, where Hungary served as a least likely case. Based on previous research, Members of Parliament in a country with a particularly high level of incentives to pursue party representation, it is very unlikely that personal representation or constituency orientation appears. However, because of the party-centeredness, if it does, it is either the result of central party strategies encouraging constituency orientation, or permissive party leadership that does not find personalization destructive from the point of view of party cohesion and unity. Nevertheless, these mechanisms were not intended to be laid down in this study. Instead they are indirectly assumed to be the only possible explanations given the level of party control. These assumptions give the basic frame which the topic is placed into.

It is argued that despite the mixed-member fashion of the Hungarian electoral system, it classifies as party-centred to a greater deal as it is accounted for in the scholarly debate on the effects of mixed electoral rules on constituency focus. The effect of the first tier appears. This, however, cannot be the utmost consequence of individual incentives: there is a partisan aspect of the relations that has to be taken into account. Again, how parties vindicate their will is not the main concern of this research. It is more about the investigation of the factors structuring member attitudes and behaviour under these very strict, party-centred circumstances. The causal mechanism is consequently different from what is recognized by the literature that establishes the connection between electoral rules and representative behaviour through individual motivations. However, in the Hungarian setting, individuals have less room to manoeuvre. The fact that they personalize nevertheless, and the nature of the system suggests that personal representation and constituency orientation is related to party strategies.

The dissertation uses several factors to explain member attitudes and behaviour, some of which are drawn from the literature, and some being the results of speculative experimentations on the author's side. The different independent variables were grouped into three categories based on the perceived causal 
mechanisms attached to them: (i) electoral, (ii) position and (iii) habitual motivations. Electoral incentives are closely tied to electoral rules. The effect of position variables are assumed to be present due to incentives that rise in accordance with the positions members hold within their parties, the parliament or local governments. Habitual explanations point back to deeper concerns toward the local level mostly through previous experience in the related positions.

Table 6.1 summarizes the effects of the different independent factors on the various aspects of constituency orientation. Variables that have no role in explaining the extent to which Members of Parliament seek to represent their districts include $1^{\text {st }}$ tier legislative experience before 2006 and perceived ideological distance from the party. These results substantially weaken the importance of habitual motivations the way they are defined throughout this dissertation. Former SMD experience does not appear to make members more focused on their districts: habits of the past will not translate into attitudes or behaviour in the present. Additionally, the driving force behind focusing on the constituency does not feed upon the desire to distance themselves from their parties, or ideological disagreements between parties and their MPs. Parties and representatives are in perfect correspondence in terms of how members perceive their positions on the left-right scale. 
TABLE 6.1. The role of the various independent factors in explaining the different aspects of constituency orientation

\begin{tabular}{|c|c|c|c|c|c|c|c|c|c|c|}
\hline & & \multicolumn{2}{|c|}{$\begin{array}{l}\text { Perceptions of } \\
\text { representation }\end{array}$} & \multicolumn{4}{|c|}{ Campaigning } & \multicolumn{3}{|c|}{ Parliamentary questioning } \\
\hline & & Focus & Style & Norms & Means & Organization & Agenda & $\begin{array}{c}\text { Nr. of } \\
\text { questions }\end{array}$ & $\begin{array}{c}\text { Nr. of local } \\
\text { questions }\end{array}$ & $\begin{array}{l}\text { Proportion of } \\
\text { local questions }\end{array}$ \\
\hline \multirow[t]{2}{*}{ Electoral } & Candidacy & & & ++ & ++ & + & ++ & + & + & \\
\hline & Local candidacy & ++ & & & + & & & & & \\
\hline \multirow[t]{6}{*}{ Position } & Mandate type (2010) & ++ & ++ & M & $M$ & M & M & + & ++ & \\
\hline & Local position & & + & + & ++ & + & ++ & & & \\
\hline & SMD (2006-2010) & MT & $M$ & + & & ++ & & $\mathbb{N}$ & III & \\
\hline & Newcomer & ++ & + & & & & & + & + & \\
\hline & Party leader & ++ & + & & & & & & & \\
\hline & Party & ++ & ++ & ++ & ++ & ++ & ++ & ++ & ++ & ++ \\
\hline \multirow[t]{3}{*}{ Habitual } & SMD (2006-2010) & & & & & & & ++ & + & + \\
\hline & SMD before 2006 & & & & & & & & & \\
\hline & Ideological distance & & & & & & & & & \\
\hline
\end{tabular}

+ The variable has a stable, established effect on the given dependent variable under some of the model specifications.

Blank cells represent variables without any empirical effect on the given dependent variable. In the case of patterned cells the effects of the variables were theoretically not sound. 
Variables with a moderate overall effect on personalization and constituency orientation are local candidacy, party leadership positions and local political positions. First, running for local positions in October 2010 sets focus of representation to the district as opposed to foci like the party, a specific group in the society or all the citizens in the country. Prospective local politicians appear to be concerned for the wellbeing of their closer surroundings. Their focus also manifests in campaign personalization on the level of the usage of personalized campaign tools. Thus, future electoral considerations form the way members think about their jobs as representatives as well as how they structure their campaigns for national office. Second, rather surprisingly, filling in party leadership positions only affects how MPs go about representation, and leaves campaign aspects and parliamentary behaviour unchanged. As far as job perceptions go, party leaders prefer the generalist approach of representation over district orientation. Additionally, taken style of representation into account, they do not identify with the role of the constituency delegate. At the same time, they are not more likely to take a party delegate or trustee position. Thus, representing the party is not the main concern either, and surely, party leaders think bigger than standing out for the interests of a restricted local area. What was, however, even more interesting is the limited role of the party leadership in questioning. As argued in Chapter 5, leaders distribute time between members, but do not take the lead in pleading the party's case. The main difference between the effects of local candidacy and party leadership is that while the former influences dependent variables over two distinct aspects of personalization and constituency orientation, the latter only counts as far as representation attitudes go. Therefore, one could say that the effect of running for local political positions is oddly more substantial in explaining personalization. Third, the role of local positions was not straightforward either. On the one hand, in terms of role perceptions, multiple office holding does not influence constituency orientation. However, in a few instances its effect appeared to be significant. Nevertheless these examples did not verify the hypothesis of local office holders being more constituency-oriented with regards to their ideas of representation. On the other hand, as to campaign strategies, local positions seemed to make a difference. Their campaigns were more person-oriented (norms), they applied significantly more personalized campaign tools (means) and they raised issues that were not touched upon by the party campaign (agenda). What does not appear in their attitudes toward their jobs as national representatives, 
surfaces in campaign strategies. Furthermore, their hypothesized preferences toward their constituencies did not influence actual behaviour. It was concluded that members who had the chance to conduct services on the spot, did not exploit the potential what lies in parliamentary questioning as constituency work. These results suggest that local office holders compartmentalize: their work as local officials does rarely influence how they think and act as national representatives. Due to the effect detected in campaigning, however, the analysis is regarded inconclusive in terms of the decision on the hypothesis.

More stable effects are associated with the remaining factors: seniority, SMD candidacy, mandate type, SMD career, and party ${ }^{200}$. With exception of party affiliation, all the listed variables have prevailing effects in two out of three dimensions of constituency orientation and personalization. Newcomers influence how Members of Parliament think about their roles as representatives on the one hand, and questioning behaviour on the other. Junior MPs prefer the generalist approach of representation instead of promoting the interests of the constituencies. In this sense, new members fit the hypothesis of them being less constituency oriented than more experienced MPs. However, in terms of non-legislative behaviour in parliament, the results were not this clear. Regarding written questions, the hypothesis could be confirmed in some of the model specifications: newcomers tended to submit a smaller quantity of local questions. Nevertheless, with regards to oral questions, an opposing tendency stands out. This result diminishes when party affiliation was controlled for, thus, this contradiction was extenuated as opposed to tendencies pointing to the other direction.

It is hardly a surprise that variables directly connected to the nominal level of the electoral system pose a strong effect on dependents defined in this work. Candidacy on the nominal level naturally affects campaign features. SMD candidates pursued more person-oriented campaigns (norms), applied personalized campaign tools in larger numbers (means), and dealt with issues of local concern (agenda). They even had personal campaign teams with a greater probability (organization); however, no difference was detected between them and list candidates in terms of the party support in setting up their staffs. There was nothing unexpected about these results:

200 Explanatory factors are reported in the order of their significance in explaining personalization. 
electoral motivations outperform other explanations when it comes to campaigning, which is based mostly on rational calculus. More interestingly, candidacy on the $1^{\text {st }}$ tier affects the local aspect of questioning in parliament. Moderate evidence was found in terms of the shadowing hypothesis as far as constituency service goes. SMD candidates might not be more constituency-oriented in attitudes, but they still address local issues in parliament both orally and in written formats. Moving further, the overall effects of mandate type and holding an SMD position between 2006 and 2010 are hardly separable. With regards to campaign strategies, former SMD positions captured the effect of type, whereas in the case of perceptions of roles and parliamentary questioning they accounted for two different processes. As for the effect of mandate type it clearly structures how Members of Parliament think about representation. List members are more party oriented than nominal level MPs, who prefer to represent the wants and needs of their constituencies. This distinction appears with regards to style of representation as well. SMD members are more of constituency delegates, while list MPs would act on behalf of the party. Additionally, $1^{\text {st }}$ tier members are substantially more local-oriented when it comes to submitting written questions. In terms of campaigning, mandate type ${ }^{201}$ had a moderate effect on norms. With regards to organization, SMD members hired a larger proportion of their teams themselves enhancing the personalization aspect of their campaign strategies. After election, previous incumbencies switched from being classified as position related to habitually driven motivations ${ }^{202}$. In this quality, previous nominal level experience did not play any role in explaining member perceptions of their roles. However, it proved to be more useful in determining MPs' behaviour in parliament. Former SMD members were more active in furthering local interests in most of the aspects of questioning. In fact, aside party affiliation, the strongest effect is associated with this variable when seeking for the determinants of the overall local focus of questions, which is argued to be the strongest predictor of local orientation.

Last, but not least at all, the effect of party affiliation overwhelmingly dominated the chapters. Members of virtually every party think and behave different than MPs of the Fidesz. The only exception of this rule is KDNP: Fidesz and its smaller

${ }^{201}$ On Table 6.1, this effect is listed in the row of "SMD (2006-2010)" among position related factors, because during the 2010 campaigns they served as SMD incumbents.

${ }^{202}$ Effects are listed in the row of „SMD (2006-2010)” among habitual explanations. 
companion act as one ${ }^{203}$. The largest differences were established between new parties (Jobbik and LMP) and Fidesz-KDNP. The results regarding LMP were handled with care by the reason of sample bias. However, similar tendencies were followed by Jobbik MPs, which points to general trends in the attitudes and behaviour of new parties. First, as far as focus of representation goes, members of these parties are significantly less constituency oriented than their colleagues in Fidesz-KDNP and MSZP. The fact that MSZP is on the latter side of the relationship suggests that there is indeed a substantial difference between parties having a considerable history in constituency representation and those who were newly formed and had not have the chance to prevail in the SMDs. Thus, party culture might be a decisive factor in terms of how representatives perceive their roles. Parties that have experience in constituency representation will continue to motivate their members to pursue constituency orientation even if they stand only a small chance to actually filling in SMD positions. Consequently, small and new parties that had not been successful in harvesting the single member districts will not show indications of constituency focus. Second, the very same tendencies appear in the campaign behaviour of Jobbik and LMP. The campaigns of these parties are less personalized in terms of norms, means and organization than the campaigns of either Fidesz-KDNP or the Socialists. Third, considerable differences were found between parties in terms of questioning behaviour as well. Oddly, however, the results do not reflect the tendencies uncovered in the cases of role perceptions and campaign behaviour. On the contrary, not only were members of Jobbik and LMP more active in parliamentary questioning, but the number of locally oriented inquiries were larger in their case as well. Nevertheless, as the proportion of local questions is not higher in their case, it would be an overstatement to argue that they are more concerned about local issues than MPs of larger parties. The larger number of local inquiries is the consequence of the role of questions in the representatives' work. They are less of a tool for constituency service than government control, making opposition parties more active relative to their size. As a consequence, other behaviour traits have to be examined to conclude on what MPs do to further the interests of the local areas.

\footnotetext{
${ }^{203}$ However, in the case of the proportion of local questions, Fidesz members appeared to be more locally oriented than KDNP MPs.
} 
Out of the variables used in this dissertation, electoral and position related factors seemed to be the better estimators of role perception, campaign dimensions and nonlegislative behaviour in parliament. In the group of habitual variables, only former SMD background was found important in explaining constituency orientation and personalization. Nevertheless, one has to keep in mind that these conclusions largely depend on the concrete definitions applied throughout the dissertation. How the group of the various factors are established, greatly influences the results attached to the different types of explanations. There are several additional variables that might count as habitual, but were not controlled for on the course of this analysis (i.e. number of years spent in a local position, more detailed election history). Furthermore, the way how IVs are categorized into the three groups of factors is also a manner in dispute. One could rightfully argue that, for instance, candidacy is a rather weak proxy of future electoral intentions, thus it might not be considered as an electoral factor in the case of representational roles (Chapter 3) and behaviour in parliament (Chapter 5). Thus, the conclusions drawn from the analyses are only valid in the context of this very work. Additionally, the same disclaimer could be made in terms of the operationalization of the various variables. Differently operationalized variables could lead to different conclusions. However, throughout the analysis, I aimed at the simplest possible variable coding, so that member characteristics are likely to measure what they were designed to measure. Nevertheless, at some point, different decisions could have been made as well. Also, conclusions were made based on statistical significance, and coefficient signs were rarely taken into account when a variable was not proven significant. Again, one could argue that by the reason of the fact that the sample accounts for a large proportion of the population (64\%), sample results are conclusive to the whole parliament.

To summarize the findings of the different chapters, it appears that Hungarian Members of Parliament are rational actors. Their attitudes and behaviour is mostly structured by electoral calculus and the possibilities (and constraints) their positions offer. Nevertheless, not only electoral rules and positions pose constraints on member behaviour, but the overall party centeredness of the system. Thus, the effects revealed by the analysis are the effects that that have already undergone the thorough monitoring of the party. After this filter, several individual variables remained significant indicating that pursuing constituency orientation and personalization is not something that defies party interests. On the contrary, in certain cases, it is the 
party's strategic interest to encourage district-centred behaviour. For example, in instances where the party vote might be increased through individual behaviour both at the national and the local elections, parties are likely to motivate their members to more constituency-centred actions. Although we have no direct evidence for this, the level of party centeredness in the political system suggests that prevailing personalization are not likely to be the consequence of personal representation, but the extension of the party will. Thus, the two concepts are hardly the two ends of a continuum. Party centeredness does not rule out constituency focus, and district promoters can also be faithful to the party.

Putting aside the party centeredness, the issue of constituency orientation deserves additional thoughts. The fact that the formation of constituency orientation is not random, in other words, it is structured by pre-defined factors, is proof that district focus is a valid concern in Hungary. Thus it is not its level but its structure that leads to the conclusion that constituency orientation is something that prevails even under party-centred electoral rules. In case it would be random, it would require an absolute measure to decide whether the phenomenon is strong enough to be considered relevant. But if its degree changes under different conditions, which conditions have strong hypotheses attached to them, constituency orientation might be considered as the result of established decisions. Especially as they are most commonly tied to electoral or position related motivations. Therefore, the degree of constituency orientation is no longer the issue here, but the factors influencing its occurrence. As long as there are rational decisions behind constituency orientation, it stays a factor that has to be taken into account.

Taking a closer look at the effects of the various independent factors again on constituency orientation and personalization it becomes clear that the majority of variables with strong effects are characteristics connected to electoral rules. The existence of the SMD tier leads the way in explaining why Members of Parliament and parties think that district focus is something to encourage. Thus, the correlation between electoral rules and member attitudes and behaviour is certainly there. The nominal level indeed causes a steady increase in the level of constituency orientation. Strict party control over candidate selection, however, ensures that these effects appear in synch with party interests. Parties recognize that district focus and personalization might be an asset in the quest for maximizing votes. Bringing politics closer to the people is a way to renew. Putting the popular faces into the front lines, 
and showing how concerned members are for their constituencies, might balance the negative associations in connection with parties. This pursuit is in fact not alien to Hungarian politics. In the previous regime, electoral rules were changed to enhance the legitimacy of the whole political system: in 1966, a single national level party list was replaced by single member districts. That time, of course, this did not involve true democratization, as the circle of nominating bodies was extremely restricted until 1970, when legal burdens were lifted only to be replaced by administrative thresholds. However, it is rather an example that Hungarian parties have a history to prefer SMDs and still maintain full control over candidate behaviour.

Although now coming to the end of this study, this research is far from being finished. In fact, these were only the first steps on that road that leads us to better understand the role of the constituency in Hungary. An interesting issue is how the latest changes in the electoral rules might affect constituency orientation. Based on the results of this dissertation, no considerable changes are expected. Nevertheless, by increasing the gap between the different types of mandates, the abolition of the $2^{\text {nd }}$ level between SMDs and the national lists might result in an overall decline in district focus. Changes in the effect of the various explanatory factors through time are also worth analysing. Unfortunately, the data available is restricted especially with regards of how the different terms were operationalized. Future data collection efforts may focus on creating a chain of identically defined variables to enable longitudinal research strategies. Furthermore, additional research might go beyond the single-country nature of this very work and put the subject in a comparative perspective. Investigating constituency orientation in new democracies is one possible direction out of many. Additionally, even if staying in the realm of crosssectional single-country studies, broadening the range of explanatory factors is still a good way to deepen our knowledge on what factors form district focus in Hungary. Last, but not least, this dissertation is restricted in terms of analytical methods applied. Additional quantitative and qualitative strategies would certainly add to the results of this study. Nevertheless, with the boundaries in view, this research had already added a great deal to unravelling constituency orientation in Hungary, where rules of the game should take the focus away from the districts. 


\section{REFERENCES}

André, A. and Depauw, S. (2013) 'District Magnitude and Home Styles of Representation in European Democracies', West European Politics, forthcoming.

Atmor, N., Hazan, R. Y. and Rahat, G. (2011) 'Candidate selection', Josep M. Colomer (ed.) Personal representation. The neglected dimension of electoral systems. Colchester: ECPR Press, pp. 21-36.

Bailer, S. (2011) 'People's Voice or Information Pool? The Role of, and Reasons for, Parliamentary Questions in the Swiss Parliament', The Journal of Legislative Studies, 17(3), 302-14.

Bawn, K. and Thies, M. F. (2003) 'A Comparative Theory of Electoral Incentives Representing the Unorganized Under PR, Plurality and Mixed-Member Electoral Systems', Journal of Theoretical Politics, 15(1), 5-32.

Bengtsson, Å. and Wass, H. (2011) 'The Representative Roles of MPs: A Citizen Perspective', Scandinavian Political Studies, 34(2), 143-67.

Blidook, K. and Kerby, M. (2011) 'Constituency Influence on "Constituency Members": The Adaptability of Roles to Electoral Realities in the Canadian Case', The Journal of Legislative Studies, 17(3), 327-39.

Blomgren, M. and Rozenberg, O. (2011a) Parliamentary Roles in Modern Legislatures. London: Routledge, ECPR.

Blomgren, M. and Rozenberg, O. (2011b) 'Legislative roles and legislative studies.

The neo-institutionalist turning point?', Magnus Blomgren and Olivier Rozenberg (eds.) Parliamentary Roles in Modern Legislatures. London: Routledge, ECPR.

Blomgren, M. and Rozenberg, O. (2011c) 'Introduction', Magnus Blomgren and Olivier Rozenberg (eds.) Parliamentary Roles in Modern Legislatures. London, New York: Routledge, ECPR, pp. 1-7.

Bowler, S. and Farrell, Da. M. (1993) 'Legislator Shirking and Voter Monitoring: Impacts of European Parliament Electoral Systems upon Legislator-Voter Relationships', Journal of Common Market Studies, 31(1), 45-70.

Burke, E. (1854) 'Speech to the Electors of Bristol', The Works of the Right Honourable Edmund Burke. Volume I. London: Henry G. Bohn. 
Cain, B., Ferejohn, J. and Fiorina, M. P. (1987) The personal vote: constituency service and electoral independence. Harvard University Press.

Cameron, A. C. and Trivedi, P. K. (1998) Regression Analysis of Count Data. Cambridge: Cambridge University Press.

Canache, D., Mondak, J. J. and Cabrera, E. (2000) 'Voters and the Personal Vote: A Counterfactual Simulation', Political Research Quarterly, 53(3), 663 -676.

Carey, J. M. and Shugart, M. S. (1995) 'Incentives to Cultivate a Personal Vote: a Rank Ordering of Electoral Formulas', Electoral Studies, 14(4), 417-39.

Carman, C. and Shephard, M. (2007) 'Electoral Poachers? An Assessment of Shadowing Behaviour in the Scottish Parliament', The Journal of Legislative Studies, 13(4), 483-96.

Colomer, J. M. (2011a) 'Introduction: personal and party representation', Josep M. Colomer (ed.) Personal representation. The neglected dimension of electoral systems. Colchester: ECPR Press, pp. 1-20.

Colomer, J. M. (ed.) (2011b) Personal Representation: The Neglected Dimension of Electoral Systems. Colchester: ECPR Press.

Cook, D. O., Kieschnick, R. and McCullough, B. D. (2008) 'Regression analysis of proportions in finance with self selection', Journal of Empirical Finance, 15(5), 860-7.

Cooper, C. A. and Richardson, L. E. (2006) 'Institutions and Representational Roles in American State Legislatures', State Politics \& Policy Quarterly, 6(2), 174 94.

Cox, K. E. and Schoppa, L. J. (2002) 'Interaction Effects in Mixed-Member Electoral Systems', Comparative Political Studies, 35(9), 1027-53.

Crisp, B. F. (2007) 'Incentives in Mixed-Member Electoral Systems', Comparative Political Studies, 40(12), 1460-85.

Curtice, J. and Shively, P. (2000) 'Who represents us best? One member or many?', Presented at the International Political Science Association World Congress, Quebec.

Dalton, R. J., Farrell, D. M. and McAllister, I. (2011) Political Parties and Democratic Linkage. How Parties Organize Democracy. Oxford: Oxford University Press.

Dandoy, R. (2011) 'Parliamentary Questions in Belgium: Testing for Party Discipline', The Journal of Legislative Studies, 17(3), 315-26. 
Dewogheraele, J., Berton, R. M. and Navarro, J. (2008) 'Cumul de Mandats' in Contemporary French Politics. An Empirical Study of the XIIe legislature of the Assemblée Nationale [online]. . Retrieved from http://halshs.archivesouvertes.fr/docs/00/12/79/06/PDF/_Cumul_des_Mandats_in_Contemporary_ French_Politics.pdf

Enyedi, Zs. (2006) 'The Survival of the Fittest: Party System Concentration in Hungary', Susanne Jungerstan-Mulders (ed.) Post-Communist EU Member States: Parties and Party Systems. Aldershot: Ashgate, pp. 177-202.

Enyedi, Zs. (2007) 'Stability in the Shadow of Chaos. The Hungarian Party System in 2006', Vit Housek and Roman Chytilek (eds.) Parliamentary Elections and Party Landscape in the Visegrad Group Countries. Brno: Masaryk University, pp. 116-34.

Esaiasson, P. (2000) 'How Members of Parliament Define their Taks', P. Esaiasson and K. Heidar (eds.) Beyond Westminster and Congress: The Nordic Experience. Cleaveland: Ohio State University Press.

Eulau, H. and Karps, P. D. (1977) 'The Puzzle of Representation: Specifying Components of Responsiveness', Legislative Studies Quarterly, 2(3), 233-54.

Eulau, H., Wahlke, J. C., Buchanan, W. and Ferguson, L. C. (1959) 'The Role of the Representative: Some Empirical Observations on the Theory of Edmund Burke', The American Political Science Review, 53(3), 742-56.

Fearon, J. (1999) 'Electoral Accountability and the Control of Politicians: Selecting Good Types versus Sanctioning Poor Performance', Adam Przeworski, Susan C. Stokes and Bernard Manin (eds.) Democracy, Accountability, and Representation. New York: Cambridge University Press.

Fenno, R. F. (1978) Home Style: House Members in Their Districts. Glenview, IL: Longman.

Ferrara, F. and Herron, E. S. (2005) 'Going It Alone? Strategic Entry under Mixed Electoral Rules', American Journal of Political Science, 49(1), 16-31.

Ferrari, S. and Cribari-Neto, F. (2004) 'Beta Regression for Modelling Rates and Proportions', Journal of Applied Statistics, 31(7), 799-815.

Fiorina, M. P. (1977) 'The Case of the Vanishing Marginals: The Bureaucracy Did It', The American Political Science Review, 71(1), 177-81. 
Gaines, B. J. (1998) 'The Impersonal Vote? Constituency Service and Incumbency Advantage in British Elections, 1950-92', Legislative Studies Quarterly, 23(2), 167-95.

Gallagher, M. (1988) 'Conclusion', Michael Gallagher and Michael Marsh (eds.) Candidate Selection in Comparative Perspective. The Secret Garden of Politics. London: Sage Publications, pp. 236-83.

Gallagher, M. and Holliday, I. (2003) 'Electoral Systems, Representational Roles and Legislator Behaviour: Evidence from Hong Kong', New Zealand Journal of Asian Studies, 5(1), 107-20.

Heitshusen, V., Young, G. and Wood, D. M. (2005) 'Electoral Context and MP Constituency Focus in Australia, Canada, Ireland, New Zealand, and the United Kingdom', American Journal of Political Science, 49(1), 32-45.

Herrera, R. and Yawn, M. (1999) 'The Emergence of the Personal Vote', The Journal of Politics, 61(1), 136-50.

Herron, E. S. (2002) 'Electoral Influences on Legislative Behavior in Mixed-Member Systems: Evidence from Ukraine's Verkhovna Rada', Legislative Studies Quarterly, 27(3), 361-82.

Herron, E. S. and Nishikawa, M. (2001) 'Contamination effects and the number of parties in mixed-superposition electoral systems', Electoral Studies, 20(1), $63-86$.

Ilonszki, G. (2000) 'Belated Professionalization of Parliamentary Elites. Hungary: 1848-1999', Heinrich Best and Maurizio Cotta (eds.) Parliamentary Representatives in Europe 1848-2000. Legislative Recruitment and Careers in Eleven European Democracies. Oxford: Oxford University Press, pp. 196225.

Ilonszki, G. and Jáger, K. (2008) 'Erős kormány - gyenge parlament? A törvényhozási kapacitás as törvényhozási teljesítmény politikai szociológiai összefüggései’, Századvég, 2008(4), 119-42.

Ilonszki, G. and Kurtán, S. (2008) 'Munka, foglalkozás, hivatás - a képviselõi professzionalizáció több szempontú elemzése', Gabriella Ilonszki (ed.) Amatõr és hivatásos politikusok. Képviselõk Magyarországon II. Budapest: Új Mandátum, pp. 17-42.

Ilonszki, G. and Kurtán, S. (2011) 'Látszat és valóság. A 2010-ben megválasztott parlamenti képviselök arculata', Zsolt Enyedi, Andrea Szabó and Róbert 
Tardos (eds.) Új képlet. A 2010-es választások Magyarországon. Budapest: DKMKA, pp. 95-112.

Ilonszki, G. and Papp, Zs. (2012) 'The Paradoxes of Parliament-Citizen Connections in Hungary: A Window on the Political System', Journal of Legislative Studies, 18(3-4), 334-50.

Ingall, R. E. and Crisp, B. F. (2001) 'Determinants of Home Style: The Many Incentives for Going Home in Colombia', Legislative Studies Quarterly, 26(3), 487-512.

Ishiyama, J. (2000) 'Candidate Recruitment, Party Organisation and the Communist Successor Parties: The Cases of the MSzP, the KPRF and the LDDP', Europe-Asia Studies, 52(5), 875-96.

Jun, H.-W. and Hix, S. (2010) 'Electoral systems, political career paths and legislative behavior: evidence from South Korea's mixed-member system', Japanese Journal of Political Science, 11(2), 153-71.

Karlsen, R. and Skogerbø, E. (2013) 'Candidate campaigning in parliamentary systems Individualized vs. localized campaigning', Party Politics.

Karvonen, L. (2004) 'Preferential Voting: Incidence and Effects', International Political Science Review, 25(2), 203-26.

Keil, A. and Papp, Zs. (2011) 'Forma és tartalom: a helyi képviselők és választóik kapcsolata Biatorbágy, Cegléd és Vác példáján', Pro Publico Bono, 2011(1), $147-61$.

Klingemann, H.-D. and Wessels, B. (2001) 'The Political Consequence of Germany's Mixed-Member System: Personalization at the Grass Roots?', Matthew S. Shugart and Martin P. Wattenberg (eds.) Mixed-Member Electoral Systems. The Best of Both Worlds? Oxford: Oxford University Press.

Krauss, E., Nemoto, K. and Pekkanen, R. (2011) 'Reverse Contamination: Burning and Building Bridges in Mixed-Member Systems', Comparative Political Studies, (45), 747-773.

Kumbhat, M. C. and Marcian, Y. M. (1976) 'Constituent Orientation Among Malaysian State Legislators', Legislative Studies Quarterly, 1(3), 389-404.

Lancaster, T. D. (1986) 'Electoral Structures and Pork Barrel Politics', International Political Science Review, 7(1), 67-81. 
Lancaster, T. D. and Patterson, W. D. (1990) 'Comparative Pork Barrel Politics', Comparative Political Studies, 22(4), 458-77.

Leston-Bandeira, C. (2012) 'Studying the Relationship between Parliament and Citizens', The Journal of Legislative Studies, 18(3-4), 265-74.

Loewenberg, G. and Kim, C. L. (1978) 'Comparing the Representativeness of Parliaments', Legislative Studies Quarterly, 3(1), 27-49.

Long, J. (John) S. (1997) Regression Models for Categorical and Limited Dependent Variables. SAGE Publications, Inc.

Lundberg, T. C. (2006) 'Second-Class Representatives? Mixed-Member Proportional Representation in Britain', Parliamentary Affairs, 59(1), 60-77.

Mair, P. (2005) 'Democracy beyond Parties' [online], University of California. Retrieved from http://cadmus.eui.eu/bitstream/handle/1814/3291/viewcontent.pdf?sequence= 1

Mansbridge, J. (2003) 'Rethinking Representation', American Political Science Review, 97(04), 515-28.

Mansbridge, J. (2009) 'A “Selection Model” of Political Representation', Journal of Political Philosophy, 17(4), 369-98.

Marjai, E. (2012) Candidate selection patterns in the 2010 Hungarian parliamentary elections. MA-thesis, Central European University, Budapest.

Marsh, M. (2007) 'Candidates or Parties? Objects of Electoral Choice in Ireland', Party Politics, 13(4), 500-27.

Martin, S. (2011) 'Parliamentary Questions, the Behaviour of Legislators, and the Function of Legislatures: An Introduction', The Journal of Legislative Studies, 17(3), 259-70.

Massicotte, L. (2011) 'Mixed Systems', Josep M. Colomer (ed.) Personal representation. The neglected dimension of electoral systems. Colchester: ECPR Press, pp. 99-119.

Mayhew, D. R. (1974) Congress: The Electoral Connection, Second Edition. Yale University Press.

Mihályffy, Zs. (2011) 'Kampány óvatosan - A Fidesz 2010. évi országgyülési választási kampánya', Gabriella Szabó, Zsuzsanna Mihályffy and Balázs Kiss (eds.) Kritikus kampány. A 2010-es országgyülési választási kampány elemzése. Budapest: L'Harmattan, pp. 24-47. 
Miller, W. E. and Stokes, D. E. (1963) 'Constituency Influence in Congress', The American Political Science Review, 57(1), 45.

Mitchell, P. (2000) 'Voters and their representatives: Electoral institutions and delegation in parliamentary democracies', European Journal of Political Research, 37(3), 335-51.

Mondak, J. J. (1995) 'Competence, Integrity, and the Electoral Success of Congressional Incumbents', The Journal of Politics, 57(4), 1043-69.

Mondak, J. J. and Huckfeldt, R. (2006) 'The accessibility and utility of candidate character in electoral decision making', Electoral Studies, 25(1), 20-34.

Montgomery, K. A. (1999) 'Electoral Effects on Party Behavior and Development', Party Politics, 5(4), 507-23.

Morgenstern, S. (2004) Patterns of Legislative Politics: Roll-Call Voting in Latin America and the United States. Cambridge: Cambridge University Press.

Morgenstern, S. and Swindle, S. M. (2005) 'Are Politics Local?', Comparative Political Studies, 38(2), 143-70.

Morlang, D. (1999) Socialists building capitalism: the Hungarian Socialist party and economic policy making. Duke University.

Navarro, J. (2009) Multiple-Office Holders in France and in Germany: An Elite within the Elite? Jena: SFB 580 Mitteilungen.

Norris, P. (2000) 'The Twilight of Westminster? Electoral Reform and its Consequences', Political Studies, 49(5), 877-900.

Norris, P. (2004) Electoral Engineering: Voting Rules and Political Behavior. Cambridge: Cambridge University Press.

Norris, P., Vallance, E. and Lovenduski, J. (1992) 'Do Candidates Make a Difference? Gender, Race, Ideology and Incumbency', Parliamentary Affairs, 45(4), 496-517.

Norton, P. (2002) 'Introduction: Linking Parliaments and Citizens', Philip Norton (ed.) Parliaments and Citizens in Western Europe. London: Frank Cass, pp. $1-18$.

Norton, P. and Wood, D. (1990) 'Constituency Service by Members of Parliament: Does It Contribute to a Personal Vote?', Parliamentary Affairs, 43(2), 196208. 
Oross, D. and Papp, Z. (2010) 'Internet webpage campaign in the 2010 Hungarian general elections', Presented at the 3rd ECPR Graduate Conference, Dublin, Ireland, 30 September.

Papp, Zs. (2011) 'Constituency Focus in the Hungarian MPs' Perceptions of Representation', DISC Working Paper Series, No. 21.

Pekkanen, R., Nyblade, B. and Krauss, E. S. (2006) 'Electoral Incentives in MixedMember Systems: Party, Posts, and Zombie Politicians in Japan', American Political Science Review, 100(02), 183-93.

Pitkin, H. F. (1967) The Concept of Representation. Berkley/Los Angeles/London: University of California Press.

Putnam, R. d. (1976) The Comparative Studies of Political Elites. Englewood Cliffs, NJ: Prentice-Hall.

Riera, P. (2011) 'Closed party list', Josep M. Colomer (ed.) Personal representation. The neglected dimension of electoral systems. Colchester: ECPR Press, pp. $55-80$.

Rohlfing, I. (2012) Case Studies and Causal Inference: An Integrative Framework. Palgrave Macmillan.

Rozenberg, O., Chopin, O., Hoeffler, C., Irondelle, B. and Joana, J. (2011) 'Not Only a Battleground: Parliamentary Oral Questions Concerning Defence Policies in Four Western Democracies', The Journal of Legislative Studies, 17(3), $340-53$.

Rozenberg, O. and Martin, S. (2011) 'Questioning Parliamentary Questions', The Journal of Legislative Studies, 17(3), 394-404.

Russo, F. (2011) 'The Constituency as a Focus of Representation: Studying the Italian Case through the Analysis of Parliamentary Questions', The Journal of Legislative Studies, 17(3), 290-301.

Russo, F. and Wiberg, M. (2010) 'Parliamentary Questioning in 17 European Parliaments: Some Steps towards Comparison', The Journal of Legislative Studies, 16(2), 215-32.

Saalfeld, T. (2011) 'Parliamentary Questions as Instruments of Substantive Representation: Visible Minorities in the UK House of Commons, 2005-10', The Journal of Legislative Studies, 17(3), 271-89. 
Saalfeld, T. and Müller, W. C. (1997) 'Roles in Legislative Studies: A Thoretical Introduction', W.C. Müller and Thomas Saalfeld (eds) Members of Parliament in Western Europe. Roles and Behaviour. London: Frank Cass.

Schlesinger, J. A. (1991) Political Parties and the Winning of Office. Ann Arbor: University of Michigan Press.

Scholl, E. L. (1986) 'The Electoral System and Constituency-Oriented Activity in the European Parliament', International Studies Quarterly, 30(3), 315-32.

Searing, D. (1994) Westminster's World: Understanding political roles. Cambridge: Harvard University Press.

Searing, D. (2011) 'Foreword', Magnus Blomgren and Olivier Rozenberg (eds.) Parliamentary Roles in Modern Legislatures. London, New York: Routledge, ECPR, p. xxi-xxviii.

Seddon, J., Gaviria, A., Panizza, U. and Stein, E. (2002) Political Particularism Around the World (Working Paper No. 463). Inter-American Development Bank.

Shugart, M. S. (2001) "Extreme” Electoral Systems and the Appeal of the MixedMember Alternative', Matthew S. Shugart and Martin P. Wattenberg (eds.) Mixed-Member Electoral Systems. The Best of Both Worlds? Oxford: Oxford University Press.

Shugart, M. S., Valdini, M. E. and Suominen, K. (2005) 'Looking for Locals: Voter Information Demands and Personal Vote-Earning Attributes of Legislators under Proportional Representation', American Journal of Political Science, 49(2), 437-49.

Shugart, M. S. and Wattenberg, M. P. (2001) 'Introduction: The Electoral Reform of the Twenty-First Century?', Matthew S. Shugart and Martin P. Wattenberg (eds.) Mixed-Member Electoral Systems. The Best of Both Worlds? Oxford: Oxford University Press.

Sieberer, U. (2010) 'Behavioral consequences of mixed electoral systems: Deviating voting behavior of district and list MPs in the German Bundestag', Electoral Studies, 29(3), 484-96.

Soroka, S., Penner, E. and Blidook, K. (2009) 'Constituency Influence in Parliament', Canadian Journal of Political Science, 42(03), 563-91.

Strøm, K. (1997) 'Rules, Reasons and Routines: Legislative Roles in Parliamentary Democracies', W.C. Müller and Thomas Saalfeld (eds) Members of 
Parliament in Western Europe. Roles and Behaviour. London: Frank Cass, pp. $155-74$.

Swindle, S. M. (2002) 'The Supply and Demand of the Personal Vote Theoretical Considerations and Empirical Implications of Collective Electoral Incentives', Party Politics, 8(3), 279-300.

Szabó, G., Mihályffy, Zs. and Kiss, B. (2011) Kritikus kampány. A 2010-es országgyülési választási kampány elemzése. Budapest: L’Harmattan.

Takács, M. (2011) ‘A lehetőségek határai - Az LMP 2010-es országgyülési választási kampánya', Gabriella Szabó, Zsuzsanna Mihályffy and Balázs Kiss (eds.) Kritikus kampány. A 2010-es országgyülési választási kampány elemzése. Budapest: L'Harmattan.

Tavits, M. (2010) 'Effect of Local Ties On Electoral Success and Parliamentary Behaviour The Case of Estonia', Party Politics, 16(2), 215-35.

Thames, F. C. (2005) 'A House Divided Party Strength and the Mandate Divide in Hungary, Russia, and Ukraine', Comparative Political Studies, 38(3), 282303.

Thomassen, J. and Andeweg, R. B. (2004) 'Beyond collective representation: individual members of parliament and interest representation in the Netherlands', The Journal of Legislative Studies, 10(4), 47-69.

Ughy, M. (2011) 'MSZP - A muszáj-kampány', Gabriella Szabó, Zsuzsanna Mihályffy and Balázs Kiss (eds.) Kritikus kampány. A 2010-es országgyülési választási kampány elemzése. Budapest: L’Harmattan, pp. 48-68.

Várnagy, R. (2012) Polgármester vagy képviselö? A mandátumhalmozás jelensége a Magyar Országgyülésben. Doctoral Dissertation, Corvinus University of Budapest.

Wahlke, J. C. (1971) 'Policy Demands and System Support: The Role of the Represented', British Journal of Political Science, 1(03), 271-90.

Wahlke, J. C., Eulau, H., Buchanan, W. and Ferguson, L. C. (1962) The Legislative System. Explorations in Legislative Behavior. New York: Wiley.

Ward, L. J. (1998) 'Second-Class MPs? New-Zealand's Adaptation to MixedMember Parliamentary Representation', Political Science, 1998(1), 127.

Wessels, B. (2007) 'Political Representation and Democracy', Robert J. Dalton and Hans-Dieter Klingemann (eds.) The Oxford Handbook of Political Behavior. Oxford: Oxford University Press. 
Wiberg, M. and Koura, A. (1994) 'The Logic of Parliamentary Questions', Matti Wiberg (ed.) Parliamentary Control in Nordic Countries. Helsinki: Finnish Political Science Association, pp. 19-43.

Zentai, L. (2011) 'Utolsó, előre fuss! A Jobbik hajrája 2010-ben', Gabriella Szabó, Zsuzsanna Mihályffy and Balázs Kiss (eds.) Kritikus kampány. A 2010-es országgyülési választási kampány elemzése. Budapest: L’Harmattan.

Zittel, T. (2012) 'Legislators and their representational roles: strategic choices or habits of the heart?', Magnus Blomgren and Olivier Rozenberg (eds.) Parliamentary Roles in Modern Legislatures. London: Routledge, ECPR, pp. $101-21$.

Zittel, T. and Gschwend, T. (2008) 'Individualised Constituency Campaigns in Mixed-Member Electoral Systems: Candidates in the 2005 German Elections', West European Politics, 31(5), 978-1003. 


\section{APPENDIX}

\section{Appendix to Chapter 1}

APPENDIX 1.1. The hierarchy of the different measures of member personalization in terms of abstraction

Attitudes toward representation
Focus of representation
Sytle of representation
Campaign strategies
Campaign nonns
Campaign agenda
Campaign means and organization
Parliamentary questions




\section{Appendix to Chapter 2}

\section{APPENDIX 2.1 Questions from the questionnaire of the Hungarian Election Study MP survey discussed by the empirical chapters}

$10 .^{204}$ Kik döntöttek az Ön jelöléséröl?

$$
\begin{aligned}
& 1 \text { - pártom tagjai } \\
& 2 \text { - a párt küldöttgyülése } \\
& 3 \text { - a pártvezetés } \\
& 4 \text { - egyéb }
\end{aligned}
$$

11. Milyen szinten döntöttek az Ön jelöléséről?

1 - választókerületi szinten

2 - megyei szinten

3 - országos szinten

15. A kampány során használta-e az alábbi eszközöket?

\begin{tabular}{|l|c|c|}
\cline { 3 - 3 } \multicolumn{1}{l|}{} & Igen & nem \\
\hline a. Személyes plakátok & 1 & 2 \\
\hline b. Személyes hirdetés a helyi sajtóban & 1 & 2 \\
\hline c. Fogadóóra & 1 & 2 \\
\hline d. Társadalmi események & 1 & 2 \\
\hline e. Személyes szórólap & 1 & 2 \\
\hline f. Személyes hirdetés a helyi rádióban, TV-ben & 1 & 2 \\
\hline g. Saját honlap & 1 & 2 \\
\hline
\end{tabular}

16. Ön személyesen mennyire tartja fontosnak ezeket az eszközöket?

\begin{tabular}{|l|c|c|c|c|}
\cline { 2 - 5 } \multicolumn{1}{l|}{} & $\begin{array}{c}\text { Egyáltalán nem } \\
\text { fontos }\end{array}$ & $\begin{array}{c}\text { Inkább nem } \\
\text { fontos }\end{array}$ & Inkább fontos & Nagyon fontos \\
\hline a. Személyes plakátok & 1 & 2 & 3 & 4 \\
\hline b. Személyes hirdetés a helyi sajtóban & 1 & 2 & 3 & 4 \\
\hline d. $\quad$ Társadalmi események & 1 & 2 & 3 & 4 \\
\hline e. Személyes szórólap & 1 & 2 & 3 & 4 \\
\hline f. $\quad$ Személyes hirdetés a helyi rádióban, & 1 & 2 & 3 & 4 \\
\hline g. & 1 & 2 & 3 & 4 \\
\hline
\end{tabular}

\footnotetext{
${ }^{204}$ Original question numbers.
} 
17. Volt-e olyan eszköz a fentiek közül, melyet az Ön személyes kampánycsapata hozott létre, és nem a kampányközpont?

Több választ is megjelölhet!

0 - egyik sem

1 - Személyes plakátok

2 - Személyes hirdetés a helyi sajtóban

3 - Fogadóóra

4 - Társadalmi események

5 - Személyes szórólap

6 - Személyes hirdetés a helyi rádióban, TV-ben

7 - Saját honlap

18. Mi volt kampánya elsődleges célja? Hová helyezné el a célt az alábbi 0-10 fokú skálán, ahol 10 jelentése "a lehető legtöbb figyelmet kelteni jelölésemre vonatkozóan“ és a 0 jelentése ,a lehető legtöbb figyelmet kelteni pártom iránt" ?

$\begin{array}{lllllllllll}10 & 09 & 08 & 07 & 06 & 05 & 04 & 03 & 02 & 01 & 00\end{array}$

Lehetö legtöbb

Figyelmet kelteni

Saját jelölésemre

vonatkozóan

19. Kampánya során foglalkozott-e választókerületére vonatkozó olyan kérdésekkel, amelyeket sem megyei, sem országos szinten nem vetett fel a pártja?

1 - Igen

$2-$ nem

20. Melyek voltak ezek közül a legfontosabbak?

22. Volt-e önálló kapmány-csapata?

1 - Igen

$2-$ nem

23. Hány föből állt a kampánycsapat?

főből

24. Közülük hányan segítették Önt hivatalosan a párt megbízásából?

fö

31. Sokan használják a baloldal és a jobboldal kifejezést a politikai álláspontok jellemzésére. Ön hol helyezné el saját magát egy 10-es skálán, ahol a '0' jelenti a "baloldali" beállítottságot, és a '10' jelöli a "jobboldali" beállítottságot?

$\begin{array}{lllllllllll}10 & 09 & 08 & 07 & 06 & 05 & 04 & 03 & 02 & 01 & 00\end{array}$

Baloldali

(20)

8

?

10

\begin{abstract}
08
\end{abstract}
07

06

\begin{abstract}
05
\end{abstract}
04

03

02

01

00

Jobboldali 
38. Különböző vélemények vannak arról, hogy a parlament választott képviselöi kiket képviseljenek elsősorban. Ön parlamenti munkájában kiket képvisel elsősorban? Kérjük jelölje meg azt, amelyet a legfontosabbnak tekint!

1 - Választókerületén belül a saját szavazóit

2 - Választókerületét

3 - Pártja választóit

4 - Egy bizonyos társadalmi csoportot

5 - Az ország valamennyi állampolgárát

39. Az Ön véleménye szerint, hogyan kellene viselkednie a képviselőnek akkor, ha a választóinak akarata és a pártálláspont eltér egymástól?

1 - a frakció álláspontja szerint kellene szavaznia

2 - választóinak álláspontja szerint kellene szavaznia

40. És mit kellene tennie, ha saját álláspontja és a választóinak akarata eltér egymástól?

1 - saját álláspontja szerint kellene szavaznia

2 - választóinak álláspontja szerint kellene szavaznia

41. És ha saját álláspontja és a pártálláspont tér el egymástól?

1 - saját álláspontja szerint kellene szavaznia

2 - a frakció álláspontja szerint kellene szavaznia

APPENDIX 2.2. The coding of the independent variables of the dissertation

\begin{tabular}{|c|c|c|}
\hline Variable & Values & Meaning \\
\hline \multirow[t]{3}{*}{ Mandate type } & 1 & Single member district MP \\
\hline & 2 & Regional list MP \\
\hline & 3 & National list MP \\
\hline $\begin{array}{l}\text { Log of district } \\
\text { magnitude }\end{array}$ & & $\begin{array}{l}\text { The natural base logarithm of the total number of seats available } \\
\text { of the district in which the MP was elected }(\mathrm{SMD}=1 \text {, regional } \\
\text { list }=4-28 \text {, national list }=58 \text { ) }\end{array}$ \\
\hline \multirow[t]{2}{*}{ Candidacy } & 0 & The MP was not an SMD candidate \\
\hline & 1 & The MP was an SMD candidate \\
\hline \multirow[t]{2}{*}{ Candidacy (only losing) } & 0 & The MP was not an SMD candidate or the MP won the SMD seat \\
\hline & 1 & The MP was an SMD candidate but got elected from a party list \\
\hline \multirow[t]{2}{*}{ Local candidacy } & 0 & The MP was not a candidate at the local elections in 2010. \\
\hline & 1 & The MP was a candidate at the local elections in 2010. \\
\hline \multirow{2}{*}{$\begin{array}{l}\text { Local political } \\
\text { background (before } \\
\text { Oct. 2010) }\end{array}$} & 0 & $\begin{array}{l}\text { The MP did not hold multiple offices between May and October } \\
2010 \text {. }\end{array}$ \\
\hline & 1 & The MP held multiple offices between May and October 2010. \\
\hline \multirow{2}{*}{$\begin{array}{l}\text { Local political } \\
\text { background (after Oct. } \\
\text { 2010) }\end{array}$} & 0 & The MP did not hold multiple offices after October 2010. \\
\hline & 1 & The MP held multiple offices after October 2010. \\
\hline \multirow[t]{3}{*}{ SMD career } & 1 & None \\
\hline & 2 & The MP served in an SMD between 2006 and 2010. \\
\hline & 3 & The MP serves in an SMD before 2006. \\
\hline \multirow[t]{2}{*}{ Newcomer } & 0 & Senior members \\
\hline & 1 & The MP serves his/her first term. \\
\hline \multicolumn{2}{|l|}{ Ideological distance } & $\begin{array}{l}\text { The absolute value of the perceived distance between the MP and } \\
\text { his/her party on the left-right scale. }\end{array}$ \\
\hline \multirow[t]{2}{*}{ Party leader } & 0 & Backbench \\
\hline & 1 & National party leader \\
\hline \multirow[t]{5}{*}{ Party } & 1 & Fidesz \\
\hline & 2 & Jobbik \\
\hline & 3 & KDNP \\
\hline & 4 & LMP \\
\hline & 5 & MSZP \\
\hline
\end{tabular}




\section{Appendix to Chapter 3}

APPENDIX 3.1. The continuity of candidacy on the nominal level, 1990-2006

\begin{tabular}{|c|c|c|c|c|c|c|}
\hline & & \multicolumn{5}{|c|}{ Candidacy } \\
\hline \multirow{6}{*}{ Candidacy } & & 1990 & 1994 & 1998 & 2002 & 2006 \\
\hline & 1994 & 84.1 & & \multirow{5}{*}{86.2} & \multirow{5}{*}{82.5} & \\
\hline & 1998 & & 87.5 & & & \\
\hline & 2002 & & & & & \\
\hline & 2006 & & & & & \\
\hline & 2010 & & & & & 86.1 \\
\hline
\end{tabular}

Source: Hungarian Representatives Dataset

Entries are percentages. Values represent the proportion of representatives running on the nominal level at the election marked by columns nominated at the next elections (the election marked by the rows). Retiring members are not taken into account.

APPENDIX 3.2. Focus of representation and candidacy on the nominal level in 2010 (list members only)

\begin{tabular}{ccccc}
\hline & Constituency & Party & $\begin{array}{c}\text { A given group in the } \\
\text { society }\end{array}$ & $\begin{array}{c}\text { All the citizens in the } \\
\text { country }\end{array}$ \\
\hline $\begin{array}{c}\text { Not an SMD } \\
\text { candidate }\end{array}$ & $23.4(15)$ & $18.8(12)$ & $7.8(5)$ & $50(32)$ \\
SMD candidate & $24.2(15)$ & $24.2(15)$ & $8.1(5)$ & $43.5(27)$ \\
\hline $\begin{array}{c}\chi^{2} \\
\text { Cramer's V }\end{array}$ & & & .725 & \\
\hline
\end{tabular}

Entries are percentages; case numbers in parentheses.

The original question was formulated as follows: "Who do you represent in your work as a Member of

Parliament?'

$* \mathrm{p}<.1, * * \mathrm{p}<.05, * * * \mathrm{p}<.01$

APPENDIX 3.3 The effect of the log of district magnitude on the probabilities of an MP focusing of different alternatives
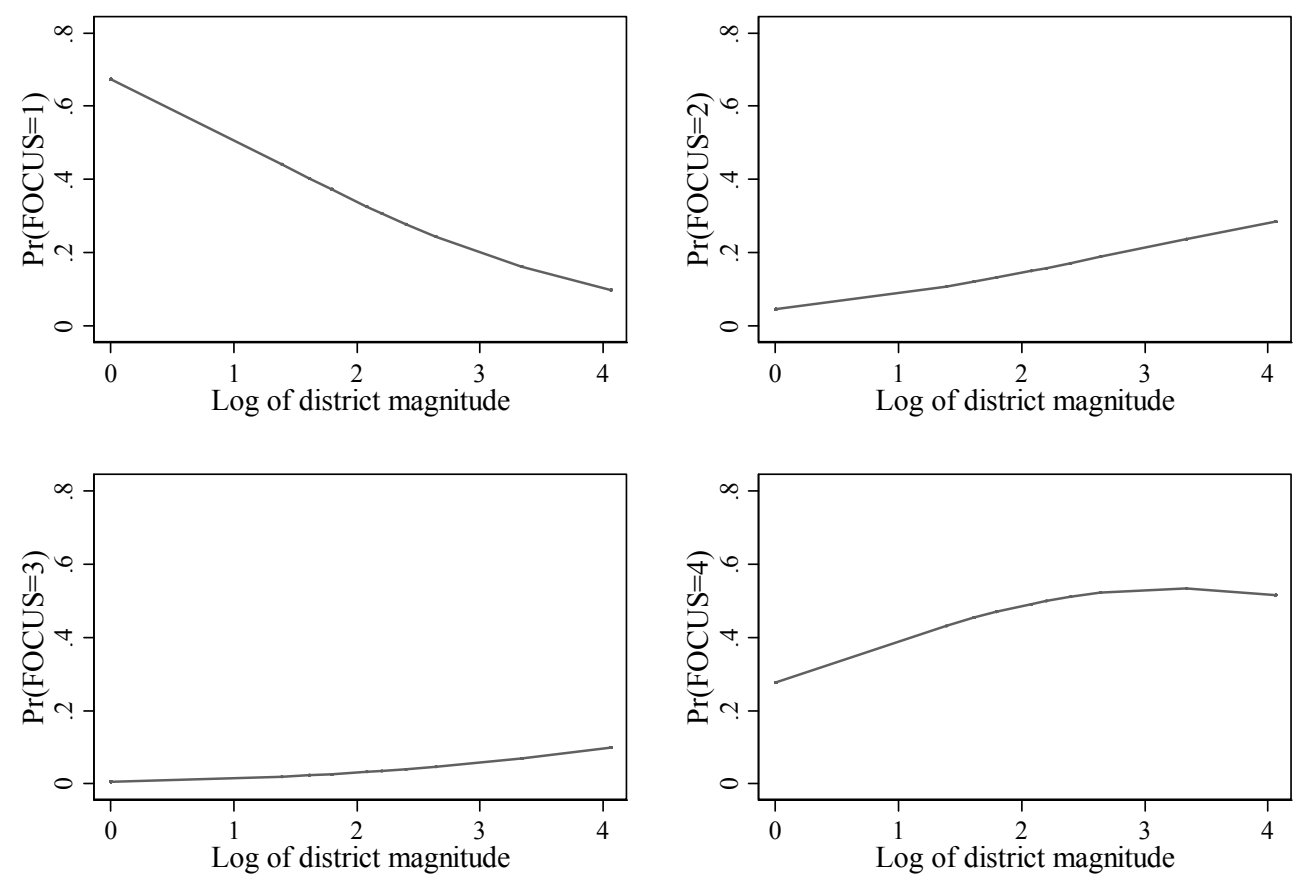

1=Constituency; $2=$ Party; $3=$ A specific group in the society; $4=$ All the citizens in the country 
APPENDIX 3.4. Style of representation and seniority

\begin{tabular}{ccccccc}
\hline & $\begin{array}{c}\text { Senior } \\
\text { member }\end{array}$ & Newcomer & $\begin{array}{c}\text { Senior } \\
\text { member }\end{array}$ & Newcomer & $\begin{array}{c}\text { Senior } \\
\text { member }\end{array}$ & Newcomer \\
\hline the voters & $49(48)$ & $61.4(62)$ & $61.8(63)$ & $61(64)$ & & \\
the party & $51(50)$ & $38.6(39)$ & & & $64.4(65)$ & $60(60)$ \\
him/herself & & & $38.2(39)$ & $39(41)$ & $35.6(36)$ & $40(40)$ \\
\hline $\begin{array}{c}\chi^{2} \\
\text { Cramer's V }\end{array}$ & $3.097^{*}$ & .014 & .008 & .045 \\
\hline
\end{tabular}

Entries are percentages; case numbers in parentheses.

The original question was formulated as follows: "How should a Member of Parliament vote in parliament if...

(1) the voters in his/her constituency have one opinion and his/her party takes a different position?

(2) his/her own opinion on an issue does not correspond with the opinion of the voters in his/her constituency?

(3) his/her own opinion on an issue does not correspond with the opinion of the voters in his/her party's position?"

${ }^{*} \mathrm{p}<.1, * * \mathrm{p}<.05, * * * \mathrm{p}<.01$

APPENDIX 3.5. Style of representation and party leadership

\begin{tabular}{ccccccc}
\hline & Backbench & Party leader & Backbench & $\begin{array}{c}\text { Party } \\
\text { leader }\end{array}$ & Backbench & $\begin{array}{c}\text { Party } \\
\text { leader }\end{array}$ \\
\hline the voters & $55(71)$ & $55.1(38)$ & $66.2(86)$ & $53.9(41)$ & & \\
the party & $45(58)$ & $44.9(31)$ & & & $64.8(83)$ & $56.9(41)$ \\
him/herself & & & $33.8(44)$ & $46.1(35)$ & $35.2(45)$ & $43.1(31)$ \\
\hline $\begin{array}{c}\chi^{2} \\
\text { Cramer's V }\end{array}$ & .000 & $3.023^{*}$ & 1.22 \\
\hline
\end{tabular}

Entries are percentages; case numbers in parentheses.

The original question was formulated as follows: "How should a Member of Parliament vote in parliament if...

(1) the voters in his/her constituency have one opinion and his/her party takes a different position?

(2) his/her own opinion on an issue does not correspond with the opinion of the voters in his/her constituency?

(3) his/her own opinion on an issue does not correspond with the opinion of the voters in his/her party's position?"

$* \mathrm{p}<.1, * * \mathrm{p}<.05, * * * \mathrm{p}<.01$ 


\section{APPENDIX 3.6. Results of the binary logistic regressions estimating the log-odds of voting} according to the voters' views in a voters vs. MP conflict

\begin{tabular}{|c|c|c|c|}
\hline & B (s.e.) & B (s.e.) & B (s.e.) \\
\hline Regional list MP & $-.431(.425)$ & $-.438(.426)$ & $-.389(.441)$ \\
\hline National list MP & $-1.082(.638)^{*}$ & $-1.096(.635)^{*}$ & $-.906(.71)$ \\
\hline Candidacy (only losing) & $.002(.502)$ & $.004(.503)$ & $-.336(.729)$ \\
\hline Local political position & $.594(.361)$ & $.631(.436)$ & $.64(.458)$ \\
\hline Local candidacy & & $-.059(.409)$ & $-.117(.413)$ \\
\hline SMD MP between 2006-2010 & $-.643(.486)$ & $-.644(.485)$ & $-.626(.514)$ \\
\hline SMD MP before 2006 & $-.239(.683)$ & $-.234(8.684)$ & $-.327(.679)$ \\
\hline Newcomer & $-.272(.407)$ & $-.273(.408)$ & $-.277(.445)$ \\
\hline Ideological distance & $.045(.145)$ & $.043(.147)$ & $.074(.149)$ \\
\hline Party leader & $-.571(.339)$ & $-.568(.341)^{*}$ & $-.605(.341)^{*}$ \\
\hline Jobbik & & & $.774(.904)$ \\
\hline KDNP & & & $-.426(.64)$ \\
\hline LMP & & & $-15.813(1.036)^{* * *}$ \\
\hline MSZP & & & $.041(.884)$ \\
\hline Constant & $.951(.525)^{*}$ & $.969(.534)^{*}$ & $1.057(.56)^{*}$ \\
\hline $\mathrm{N}$ & 199 & 199 & 199 \\
\hline Wald $\chi^{2}$ & $16.6^{*}$ & $17.37 *$ & $510.06 * * *$ \\
\hline Pseudo $\mathrm{R}^{2}$ & .076 & .07 & .128 \\
\hline
\end{tabular}

Entries are coefficients; standard errors in parentheses. Standard errors are robust.

Contrasts: type of mandate - SMD, candidacy - list candidates and winning SMD MPs, local political positions members not holding any elected local positions, local candidacy - members who were not running for local positions in 2010, SMD career - members not holding SMD mandates in 2006-2010, newcomer - members with at least one term experience as national representatives, party leader - backbench MPs, party - Fidesz

Coefficients represent the change in the value of the log-odds of choosing the voters' opinion in case it is conflicted with the position of the MP himself, due to a one unit change in the related independent variables. ${ }^{205}$ ${ }^{*} \mathrm{p}<.1, * * \mathrm{p}<.05, * * * \mathrm{p}<.01$

$$
{ }^{205} \log \left(\frac{P_{X}}{1-P_{X}}\right)=\alpha+\sum B_{i} X_{i}+e_{i}
$$




\section{APPENDIX 3.7. Results of the binary logistic regressions estimating the log-odds of voting} according to the MP's views in an MP vs. party conflict

\begin{tabular}{llll}
\hline & $\mathrm{B}($ s.e. $)$ & $\mathrm{B}($ s.e. $)$ & $\mathrm{B}(\mathrm{s.e.})$ \\
\hline Regional list MP & $-.473(.448)$ & $-.544(.453)$ & $-.739(.47) 8$ \\
National list MP & $-.677(.615)$ & $-.811(.617)$ & $-1.367(.698)^{* *}$ \\
Candidacy (only losing) & $.846(.505)^{*}$ & $.851(.496)^{*}$ & $.61(.727)$ \\
Local political position & $-.604(.363)^{*}$ & $-.256(.436)$ & $-.153(.49)$ \\
Local candidacy & & $-.572(.432)$ & $-.448(.43)$ \\
SMD MP between 2006-2010 & $.082(.507)$ & $.097(.501)$ & $-.005(.539)$ \\
SMD MP before 2006 & $-.544(.829)$ & $-.483(.82)$ & $-.476(.766)$ \\
Newcomer & $.298(.405)$ & $.306(.396)$ & $.175(.455)$ \\
Ideological distance & $.044(.152)$ & $.026(.151)$ & $.007(.156)$ \\
Party leader & $.232(.343)$ & $.259(.34)$ & $.115(.358)$ \\
Jobbik & & & $.589(.915)$ \\
KDNP & & & $1.364(.725)^{*}$ \\
LMP & & & $.77 .045(1.089)^{* * *}$ \\
MSZP & & $-.161(.515)$ & $-.3786(.836)$ \\
Constant & $-.329(.496)$ & 193 & 193 \\
\hline $\mathrm{N}$ & 193 & 8.88 & $463.9 * * *$ \\
Wald $\chi^{2}$ & 7.66 & .046 & .128 \\
Pseudo R & .039 & & \\
\hline
\end{tabular}

Entries are coefficients; standard errors in parentheses. Standard errors are robust.

Contrasts: type of mandate - SMD, candidacy - list candidates and winning SMD MPs, local political positions members not holding any elected local positions, local candidacy - members who were not running for local positions in 2010, SMD career - members not holding SMD mandates in 2006-2010, newcomer - members with at least one term experience as national representatives, party leader - backbench MPs, party - Fidesz

Coefficients represent the change in the value of the log-odds of choosing his/her own opinion in case it is conflicted with the position of the party, due to a one unit change in the related independent variables. ${ }^{206}$

${ }^{*} \mathrm{p}<.1, * * \mathrm{p}<.05, * * * \mathrm{p}<.01$

$$
{ }^{206} \log \left(\frac{P_{X}}{1-P_{X}}\right)=\alpha+\sum B_{i} X_{i}+e_{i}
$$


APPENDIX 3.8. The effect of the log of district magnitude on the probabilities of an MP being a party delegate, a delegate of the constituents or a trustee (regional list members only)
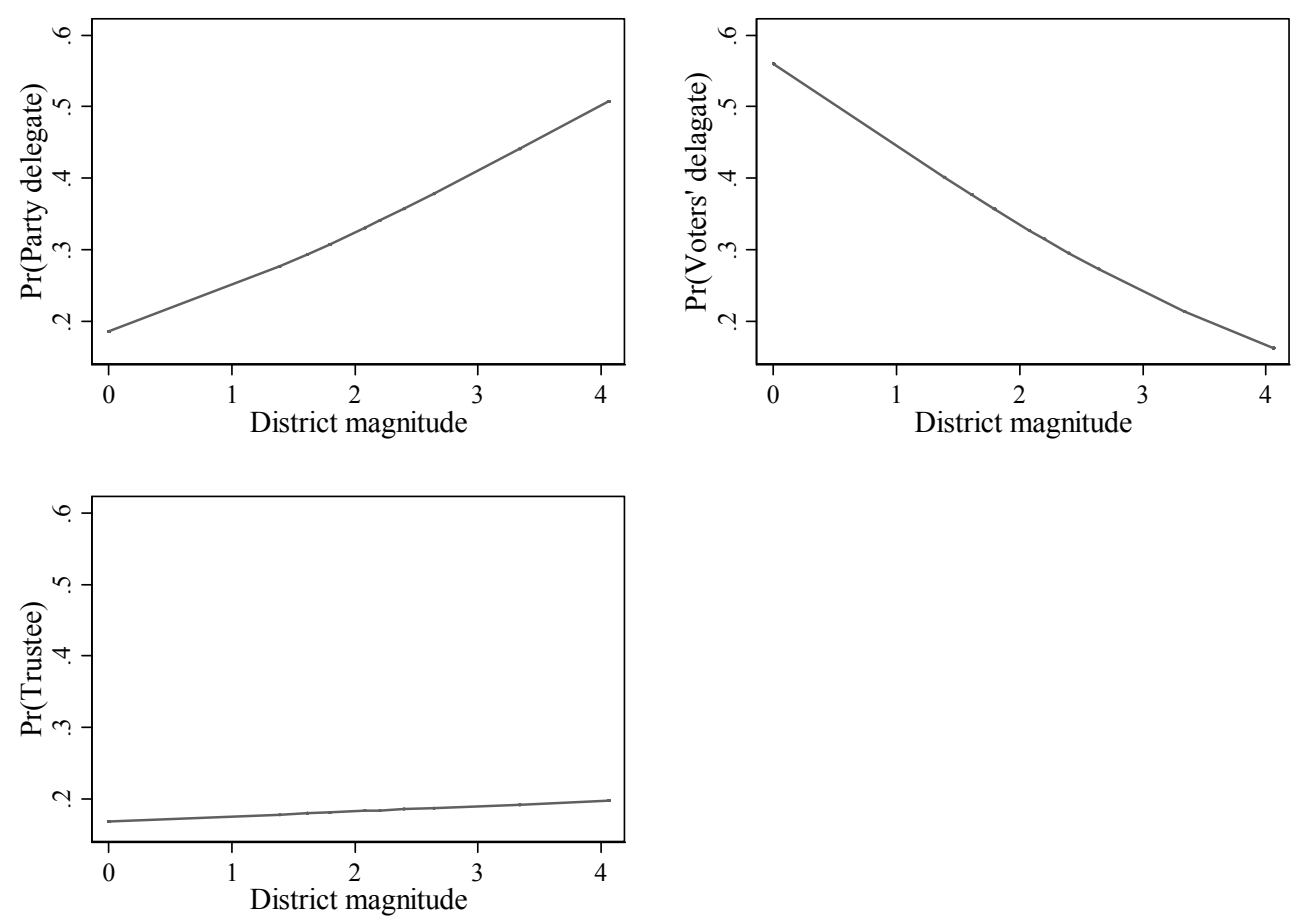


\section{Appendix to Chapter 4}

\begin{tabular}{|c|c|c|c|c|c|}
\hline & & $\begin{array}{c}\text { Party list } \\
\text { candidate } \\
\text { only }\end{array}$ & $\begin{array}{c}\text { SMD } \\
\text { candidate }\end{array}$ & $\chi^{2}$ & $\begin{array}{c}\text { Cramer's } \\
\text { V }\end{array}$ \\
\hline \multirow{7}{*}{ Campaign means ${ }^{\mathrm{a}}$} & Posters & $13(6)$ & $94.6(157)$ & $134.7 * * *$ & .797 \\
\hline & Ads in local printed media & $8.9(4)$ & $87.3(145)$ & $105 * * *$ & .706 \\
\hline & Office hours & $41.3(19)$ & $83.1(138)$ & $32.8 * * *$ & .393 \\
\hline & Public appearances & $85.1(940)$ & $100(166)$ & $25.5^{* * *}$ & .346 \\
\hline & Flyers & $22.2(10)$ & $98.8(165)$ & $144.3 * * *$ & .825 \\
\hline & Ads in local radio/TV & $13.3(6)$ & 77.7 (129) & $63.7 * * *$ & .549 \\
\hline & Website & $23.9(11)$ & $90.4(150)$ & $87.05 * * *$ & .641 \\
\hline Campaign agenda $^{b}$ & Raising local issues & $31(13)$ & $78.9(131)$ & $36.12 * * *$ & .417 \\
\hline $\begin{array}{c}\text { Campaign } \\
\text { organization }^{\mathrm{c}}\end{array}$ & Having personal team & $22.7(10)$ & $93.9(155)$ & $105.98 * * *$ & .712 \\
\hline
\end{tabular}

Entries are percentages, case numbers in parentheses. The number of party list and SMD candidates respectively represent $100 \%$.

a The type of personalized tool used.

$\mathrm{b}$ Issues with local concern mentioned.

$\mathrm{c}$ Having a personal team to assist the MP during the campaign.

${ }^{*} \mathrm{p}<.1, * * \mathrm{p}<.05, * * * \mathrm{p}<.01$

APPENDIX 4.2. The relationship between campaign means, agendas, and multiple office holding

\begin{tabular}{|c|c|c|c|c|c|}
\hline & & $\begin{array}{l}\text { National } \\
\text { MPs only }\end{array}$ & $\begin{array}{c}\text { Local } \\
\text { office- } \\
\text { holders }\end{array}$ & $\chi^{2}$ & $\begin{array}{c}\text { Cramer's } \\
\text { V }\end{array}$ \\
\hline \multirow{7}{*}{ Campaign means ${ }^{\mathrm{a}}$} & Posters & $66.7(58)$ & $84(105)$ & $8.67 * * *$ & .202 \\
\hline & Ads in local printed media & $57.5(50)$ & $80.5(99)$ & $13.09 * * *$ & .25 \\
\hline & Office hours & $57.5(50)$ & $85.6(107)$ & $21.12 * * *$ & .316 \\
\hline & Public appearances & $92(81)$ & $100(125)$ & $10.28 * * *$ & .22 \\
\hline & Flyers & $76.1(67)$ & $87.1(108)$ & $4.29 * *$ & .142 \\
\hline & Ads in local radio/TV & $55.7(49)$ & $69.4(86)$ & $4.16^{* *}$ & .14 \\
\hline & Website & $64(55)$ & $84.1(106)$ & $11.36^{* * *}$ & .232 \\
\hline Campaign agenda $^{\mathrm{b}}$ & Raising local issues & $57.8(48)$ & $76.8(96)$ & $8.42 * * *$ & .201 \\
\hline $\begin{array}{c}\text { Campaign } \\
\text { organization }^{\mathrm{c}}\end{array}$ & Having personal team & $66.3(55)$ & $87.3(110)$ & $13.32 * * *$ & .252 \\
\hline
\end{tabular}

Entries are percentages, case numbers in parentheses. The number of local office holders and national MPs only respectively represent $100 \%$.

a The type of personalized tool used.

b Issues with local concern mentioned.

c Having a personal team to assist the MP during the campaign.

${ }^{*} \mathrm{p}<.1, * * \mathrm{p}<.05, * * * \mathrm{p}<.01$ 
APPENDIX 4.3. The relationship between campaign means, agendas, and MPs' careers in single member districts

\begin{tabular}{|c|c|c|c|c|c|c|}
\hline & & & & SMD & & \\
\hline & & None & Incumbent & $\begin{array}{c}\text { MP } \\
\text { before } \\
2006\end{array}$ & $\chi^{2}$ & $\begin{array}{c}\text { Cramer's } \\
\text { V }\end{array}$ \\
\hline \multirow{7}{*}{$\begin{array}{l}\text { Campaign } \\
\text { means }^{\mathrm{a}}\end{array}$} & Posters & $\begin{array}{l}72.3 \\
(115)\end{array}$ & $95.1(39)$ & $81.8(9)$ & $9.77 * * *$ & .215 \\
\hline & Ads in local printed media & $\begin{array}{l}65.6 \\
(103)\end{array}$ & $90.5(38)$ & $75(9)$ & $10.07 * * *$ & .218 \\
\hline & Office hours & $\begin{array}{c}69.8 \\
(111)\end{array}$ & $95.1(39)$ & $58.3(7)$ & $12.5 * * *$ & .243 \\
\hline & Public appearances & $\begin{array}{l}96.9 \\
(155)\end{array}$ & $97.6(40)$ & $91.7(11)$ & 1.07 & .071 \\
\hline & Flyers & $\begin{array}{c}79.7 \\
(126)\end{array}$ & $92.7(38)$ & $81.8(9)$ & 3.75 & .134 \\
\hline & Ads in local radio/TV & $57.9(92)$ & $85.4(35)$ & $66.7(8)$ & $10.71 * * *$ & .225 \\
\hline & Website & $\begin{array}{c}71.3 \\
(114) \\
\end{array}$ & $97.5(39)$ & $75(9)$ & $12.25 * * *$ & .24 \\
\hline $\begin{array}{c}\text { Campaign } \\
\text { agenda }^{b}\end{array}$ & Raising local issues & $\begin{array}{c}64.5 \\
(100) \\
\end{array}$ & $85.4(35)$ & $81.8(9)$ & $7.48 * *$ & .19 \\
\hline $\begin{array}{c}\text { Campaign } \\
\text { organization }^{c}\end{array}$ & Having personal team & 75 (117) & $95.1(39)$ & $75(9)$ & $8.029 * *$ & .196 \\
\hline
\end{tabular}

Entries are percentages, case numbers in parentheses. The number of incumbents, former SMD representatives and none of the above respectively represent $100 \%$.

a The type of personalized tool used.

b Issues with local concern mentioned.

c Having a personal team to assist the MP during the campaign.

$* \mathrm{p}<.1, * * \mathrm{p}<.05, * * * \mathrm{p}<.01$

APPENDIX 4.4. The relationship between campaign means, agendas, and seniority

\begin{tabular}{|c|c|c|c|c|c|}
\hline & & $\begin{array}{c}\text { Senior } \\
\text { member }\end{array}$ & Newcomer & $\chi^{2}$ & $\begin{array}{c}\text { Cramer's } \\
\text { V }\end{array}$ \\
\hline \multirow{7}{*}{ Campaign means ${ }^{\mathrm{a}}$} & Posters & $78(85)$ & $76.5(78)$ & .07 & .018 \\
\hline & Ads in local printed media & $76.1(83)$ & $65.7(67)$ & $2.8^{*}$ & .115 \\
\hline & Office hours & $82.6(90)$ & $65(67)$ & $8.46 * * *$ & .2 \\
\hline & Public appearances & $95.5(105)$ & $98(100)$ & 1.1 & .072 \\
\hline & Flyers & $79.8(87)$ & $84.5(87)$ & .78 & .061 \\
\hline & Ads in local radio/TV & $67(73)$ & $60.2(62)$ & 1.05 & .07 \\
\hline & Website & $80.6(87)$ & $71.2(74)$ & 2.56 & .11 \\
\hline Campaign agenda $^{\mathrm{b}}$ & Raising local issues & $75.5(80)$ & $62.7(64)$ & $3.95 * *$ & .138 \\
\hline Campaign organization $^{\mathrm{c}}$ & Having personal team & $80.2(85)$ & $77.7(80)$ & .199 & .031 \\
\hline
\end{tabular}

Entries are percentages, case numbers in parentheses. The number of senior members and newcomers respectively represent $100 \%$.

a The type of personalized tool used.

$\mathrm{b}$ Issues with local concern mentioned.

c Having a personal team to assist the MP during the campaign.

$* \mathrm{p}<.1, * * \mathrm{p}<.05, * * * \mathrm{p}<.01$ 
APPENDIX 4.5. The relationship between campaign norms, means, agendas, organization and MPs' ideological distance from their parties

\begin{tabular}{|c|c|c|c|c|c|c|}
\hline & & & $\begin{array}{c}\text { Mean of the } \\
\text { ideological } \\
\text { distance (std.dev.) }\end{array}$ & $\mathrm{F}$ & Eta & $\begin{array}{c}\text { Pearson } \\
\text { r }\end{array}$ \\
\hline Campaign norms & $\begin{array}{c}\text { Scale: } 1 \text { - party campaign, } 11 \text { - } \\
\text { personal campaign }\end{array}$ & & & & & .057 \\
\hline \multirow{9}{*}{ Campaign means } & $\begin{array}{c}\text { Usage of personalised } \\
\text { campaign tools }\end{array}$ & & & & & \\
\hline & Posters & $\begin{array}{l}\text { No } \\
\text { Yes }\end{array}$ & $\begin{array}{l}.932(1.04) \\
.802(1.11)\end{array}$ & .517 & .051 & \\
\hline & Ads in local printed media & $\begin{array}{l}\text { No } \\
\text { Yes }\end{array}$ & $\begin{array}{l}1.005(1.104) \\
.767(1.088)\end{array}$ & 1.99 & .099 & \\
\hline & Office hours & $\begin{array}{l}\text { No } \\
\text { Yes }\end{array}$ & $\begin{array}{l}.791(.957) \\
.847(1.142)\end{array}$ & 1.1 & .022 & \\
\hline & Public appearances & $\begin{array}{l}\text { No } \\
\text { Yes }\end{array}$ & $\begin{array}{l}1.254(1.504) \\
.819(1.079)\end{array}$ & .95 & .068 & \\
\hline & Flyers & $\begin{array}{l}\text { No } \\
\text { Yes }\end{array}$ & $\begin{array}{l}.804(.911) \\
.839(1.33)\end{array}$ & .03 & .012 & \\
\hline & Ads in local radio/TV & $\begin{array}{l}\text { No } \\
\text { Yes }\end{array}$ & $\begin{array}{l}.804(.869) \\
.851(1.21)\end{array}$ & .08 & .021 & \\
\hline & Website & $\begin{array}{l}\text { No } \\
\text { Yes }\end{array}$ & $\begin{array}{l}.598(.814) \\
.896(1.16)\end{array}$ & $2.82 *$ & .117 & \\
\hline & $\begin{array}{c}\text { Nr. of personalised campaign } \\
\text { tools used }\end{array}$ & & & & & .072 \\
\hline Campaign agendas & Raising local issues & $\begin{array}{l}\text { No } \\
\text { Yes }\end{array}$ & $\begin{array}{l}.797(.77) \\
.81(1.15)\end{array}$ & .007 & .006 & \\
\hline \multirow{2}{*}{$\begin{array}{l}\text { Campaign } \\
\text { organization }\end{array}$} & $\begin{array}{c}\text { The proportion of staff } \\
\text { members hired directly by the } \\
\text { MP }\end{array}$ & & & & & .058 \\
\hline & Having personal team & $\begin{array}{l}\text { No } \\
\text { Yes }\end{array}$ & $\begin{array}{l}.817(1.11) \\
.871(1.02) \\
\end{array}$ & .081 & .02 & \\
\hline
\end{tabular}

Entries are means, standard deviations in parentheses.

$* \mathrm{p}<.1, * *_{\mathrm{p}}<.05, * * *_{\mathrm{p}}<.01$ 
APPENDIX 4.6. The relationship between campaign means, agendas, and national and regional party leadership positions

\begin{tabular}{|c|c|c|c|c|c|}
\hline & & $\begin{array}{c}\text { Not a party } \\
\text { leader }\end{array}$ & $\begin{array}{l}\text { Party } \\
\text { leader }\end{array}$ & $\chi^{2}$ & Cramer's V \\
\hline \multirow{7}{*}{ Campaign means $^{\mathrm{a}}$} & Posters & $79.1(106)$ & $74.4(58)$ & .63 & .055 \\
\hline & Ads in local printed media & $73.5(97)$ & $66.7(52)$ & 1.1 & .073 \\
\hline & Office hours & $78.4(105)$ & $66.7(52)$ & $3.5 *$ & .129 \\
\hline & Public appearances & 97 (130) & $96.2(75)$ & .11 & .023 \\
\hline & Flyers & $86.6(116)$ & $75.6(59)$ & $4.1 *$ & .139 \\
\hline & Ads in local radio/TV & $67.9(91)$ & $56.4(44)$ & $2.8 *$ & .115 \\
\hline & Website & $79.9(107)$ & $69.2(54)$ & $3.04 *$ & .12 \\
\hline Campaign agenda $^{b}$ & Raising local issues & $70.1(94)$ & $67.6(50)$ & .15 & .027 \\
\hline $\begin{array}{c}\text { Campaign } \\
\text { organization }^{\mathrm{c}}\end{array}$ & Having personal team & $81.8(108)$ & $74(57)$ & 1.777 & .092 \\
\hline
\end{tabular}

Entries are percentages, case numbers in parentheses. The number of backbenchers and party leaders respectively represent $100 \%$.

a The type of personalized tool used.

b Issues with local concern mentioned.

c Having a personal team to assist the MP during the campaign.

$* \mathrm{p}<.1, * * \mathrm{p}<.05, * * * \mathrm{p}<.01$ 


\section{Appendix to Chapter 5}

\section{APPENDIX 5.1. The codebook on oral and written questions}

Note: only the most important variables are listed here. Additional factors like the assigned minister and department were coded as well.

LOCALISM1 Did the member mention ANY local issue? (issues that concern a particular geographical area which is smaller than the country)

$$
\begin{aligned}
& 0=\text { no } \\
& 1=\text { yes }
\end{aligned}
$$

LOCALISM2 If yes (LOCALISM=1), was it related to the COUNTY of his/her election?

$0=$ no

$1=$ yes

Note: only for regional list and SMD MPs

LOCALISM3 If yes (LOCALISM=1), was it related to the COUNTY of his/her candidacy?

$0=$ no

$1=$ yes

Note: only for national list MPs

\section{Variables related to LOCALISM2}

CONSTITUENCY Did the member mention a geographic constituency specifically?

$0=$ no

$1=$ yes

Note: SMD for SMD members, county for regional list members. Towns count as SMDs.

e.g. SMD member mentions SMD or town $\rightarrow 1$

regional list member mentions county $\rightarrow 1$

regional list member mentions SMD or town $\rightarrow 0 \rightarrow$ LOCATION $=1$

LOCATION Did the member mention a geographical location that the coder can confirm is within the geographical constituency of the member?

$0=$ no

$1=$ yes

Note: SMD for SMD members, county for regional list members. Towns count as SMDs.

e.g. SMD member mentions a location within his/her SMD or town $\rightarrow 1$

regional list member mentions a location (including SMD or town) within his/her county of election $\rightarrow 1$

CASE Did the member mention a constituent or particular case surrounding an individual, reasonably assumed to be a constituent?

$$
0=\text { no }
$$$$
1=\mathrm{yes}
$$

FACILITY Did the member mention a particular building or facility that the coder can confirm to be located in the geographical constituency of the member?

$0=$ no

$1=$ yes 
Note: SMD for SMD members, county for regional list members. Towns count as SMDs.

e.g. SMD member mentions a facility within his/her SMD or town $\rightarrow 1$ regional list member mentions a facility (including SMD or town) within his/her county of election $\rightarrow 1$

ORGANIZATION Did the member mention a particular organization that the coder can confirm to be located in the geographical constituency of the member?

$0=$ no

$1=$ yes

Note: SMD for SMD members, county for regional list members. Towns count as SMDs.

e.g. SMD member mentions a organization within his/her SMD or town $\rightarrow 1$ regional list member mentions a organization (including SMD or town) within his/her county of election $\rightarrow 1$

BUSINESS Did the member mention a particular business that the coder can confirm to be located in the geographical constituency of the member?

$0=$ no

$1=$ yes

Note: SMD for SMD members, county for regional list members. Towns count as SMDs.

e.g. SMD member mentions a business within his/her SMD or town $\rightarrow 1$

regional list member mentions a business (including SMD or town) within his/her county of election $\rightarrow 1$

EVENT Did the member mention a particular event that specifically taking place in the geographical constituency of the member?

$0=$ no

$1=$ yes

Note: SMD for SMD members, county for regional list members. Towns count as SMDs.

e.g. SMD member mentions a event within his/her SMD or town $\rightarrow 1$

regional list member mentions a event (including SMD or town) within his/her county of election $\rightarrow 1$ 
APPENDIX 5.2. The distribution of questions submitted to different departments and offices

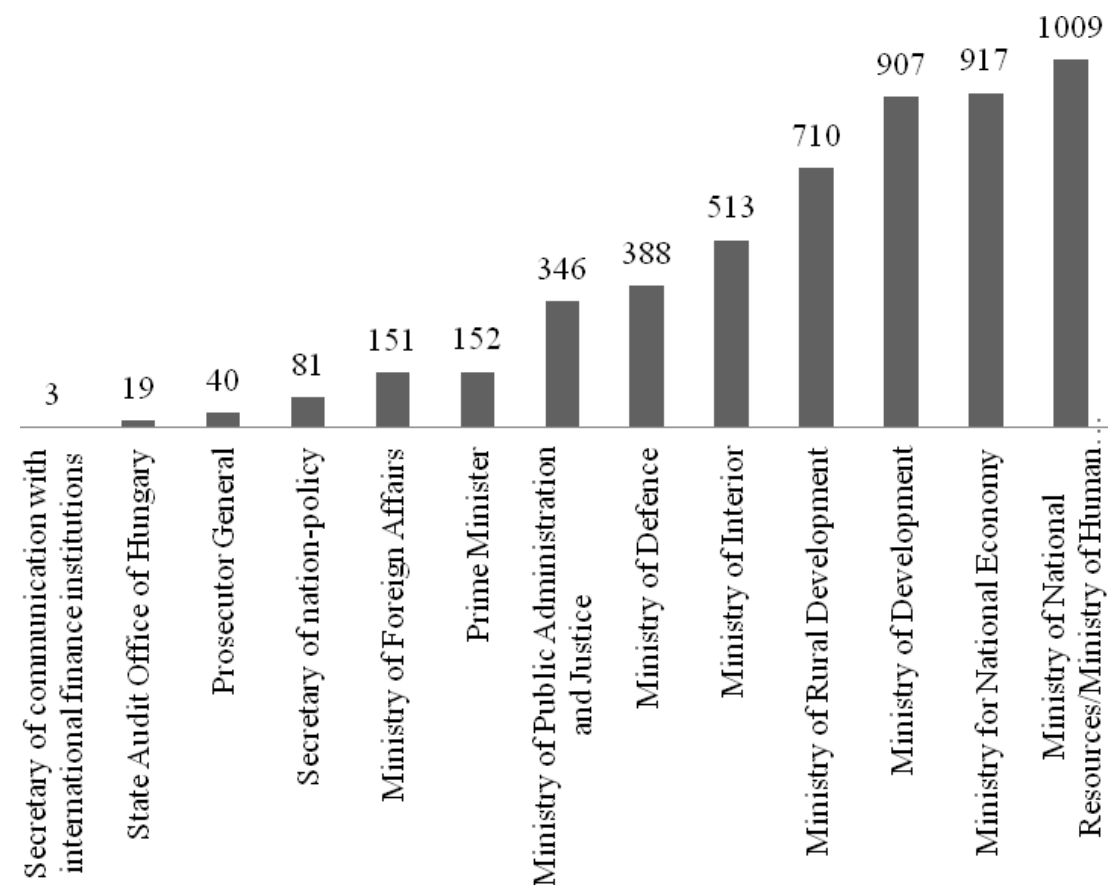

APPENDIX 5.3. The distribution of questioning MPs in terms of PPG membership

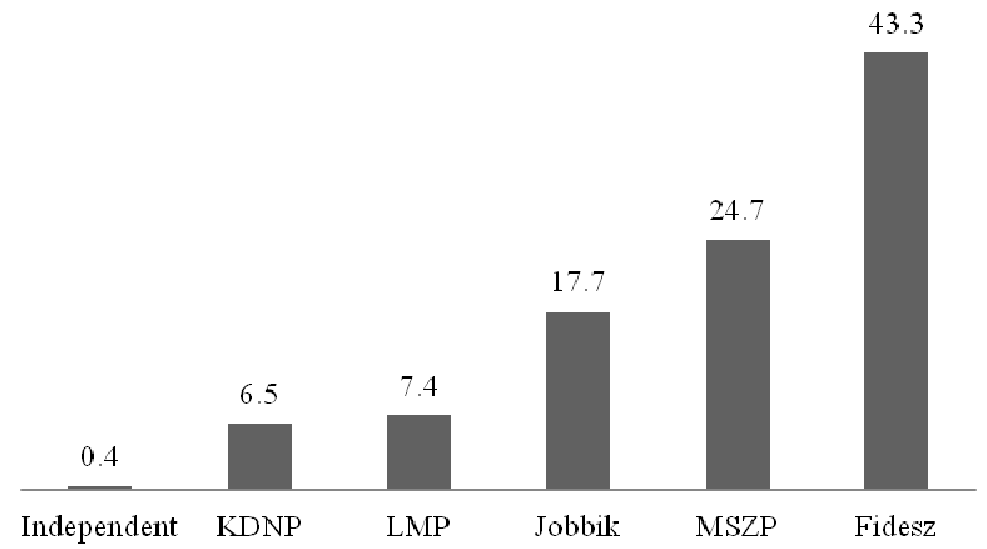


APPENDIX 5.4. The result of the negative binomial model estimating the number of questions with a local focus submitted between May 2010 and January 2013

\begin{tabular}{ll}
\hline & $\mathrm{B}($ s.e. $)$ \\
\hline Regional list MP & $.228(.5)$ \\
National list MP & $-.615(.669)$ \\
Candidacy (only losing) & $-.046(.498)$ \\
Local political position (before October 2010) & $.685(.463)$ \\
Local political position (after October 2010) & $-16.422(.503)^{* * *}$ \\
Interaction of local positions (before * after October 2010) & $\mathbf{1 6 . 9 7 1 ( . 5 9 ) * * *}$ \\
SMD MP between 2006-2010 & $1.451(.451)^{* * *}$ \\
SMD MP before 2006 & $.871(.848)$ \\
Newcomer & $.714(.431)^{*}$ \\
Ideological distance & $.103(.187)$ \\
Party leader & $.048(.346)$ \\
Jobbik & $2.91(.681)^{* * *}$ \\
KDNP & $-.93(.894)$ \\
LMP & $1.536(.913)^{*}$ \\
MSZP & $1.566(.733)^{* *}$ \\
Constant & $-3.39(.678)^{* * *}$ \\
\hline N & 221 \\
Wald Chi & \\
LR-test of alpha=0 & $44.46 * * *$ \\
\hline
\end{tabular}

Entries are coefficients; standard errors in parentheses. Standard errors are robust.

Contrasts: type of mandate - SMD, candidacy - list candidates and winning SMD MPs, local political positions - members not holding any elected local positions, SMD career - members not holding SMD mandates in 2006-2010, newcomer - members with at least one term experience as national representatives, party leader - backbench MPs, party - Fidesz

Coefficients represent the change in the value of the $\log$ of the dependent variable due to a one unit change in the related independent variables ${ }^{207}$.

$* \mathrm{p}<.1, * * \mathrm{p}<.05, * * * \mathrm{p}<.01$

$$
{ }^{207} \log (Y)=\alpha+\sum B_{i} X_{i}+e_{i}
$$


APPENDIX 5.5. Results of the zero-inflated beta regressions estimating the proportion of locally relevant questions

\begin{tabular}{|c|c|c|c|c|c|c|}
\hline & \multicolumn{2}{|c|}{ Overall } & \multicolumn{2}{|c|}{ Oral } & \multicolumn{2}{|c|}{ Written } \\
\hline & B (s.e.) & B (s.e.) & B (s.e.) & B (s.e.) & B (s.e.) & B (s.e.) \\
\hline & Proportion & $\mathrm{Y}=0$ & Proportion & $\mathrm{Y}=0$ & Proportion & $\mathrm{Y}=0$ \\
\hline Regional list MP & $-.48(.304)$ & $.151(.384)$ & $-.245(.383)$ & $-.649(.41)$ & $.202(.272)$ & $-.649(.41)$ \\
\hline National list MP & $-.919(.343)^{* * *}$ & $-1.767(.913)^{*}$ & $-.499(.431)$ & $-1.086(.664)$ & $-.047(.373)$ & $-1.086(.664)$ \\
\hline Candidacy (only losing) & $.228(.25)$ & $-2.663(.75) * * *$ & $-.096(.283)$ & $-1.848(.498)^{* * *}$ & $.458(.295)$ & $-1.848(.498)^{* * *}$ \\
\hline Local political position (before October 2010) & $.11(.255)$ & $.353(.415)$ & $-.083(.299)$ & $.062(.398)$ & $.248(.249)$ & $.062(.398)$ \\
\hline Local political position (after October 2010) & $.226(.291)$ & $-.903(.377)^{* *}$ & $.522(.331)$ & $-.514(.38)$ & $.133(.24)$ & $-.514(.38)$ \\
\hline SMD MP between 2006-2010 & $.258(.275)$ & $-.386(.485)$ & $.415(.32)$ & $-1.303(.49)^{* * *}$ & $.171(.232)$ & $-1.303(.49)^{* * *}$ \\
\hline SMD MP before 2006 & $.648(.702)$ & $.515(.687)$ & $1.164(.837)$ & $-.607(.681)$ & $.167(.312)$ & $-.607(.681)$ \\
\hline Newcomer & $-.101(.228)$ & $-.763(.401)^{*}$ & $.087(.262)$ & $-1.417(.426)^{* * *}$ & $.065(.188)$ & $-1.417(.426)^{* * *}$ \\
\hline Ideological distance & $.131(.1)$ & $.079(.148)$ & $.098(.102)$ & $-.073(.157)$ & $.011(.085)$ & $-.073(.157)$ \\
\hline Party leader & $-.27(.209)$ & $-.547(.353)$ & $.066(.244)$ & $-.106(.352)$ & $.165(.174)$ & $-.106(.352)$ \\
\hline Constant & $-.216(.336)$ & $.644(.528)$ & $-.673(.436)$ & $2.354(.539)^{* * *}$ & $-1.881(.433)^{* * *}$ & $-.106(.352)^{* * *}$ \\
\hline $\mathrm{N}$ & \multicolumn{2}{|c|}{221} & \multicolumn{2}{|c|}{221} & \multicolumn{2}{|c|}{221} \\
\hline Wald $\mathrm{Chi}^{2}$ & \multicolumn{2}{|c|}{$23.86^{* * *}$} & \multicolumn{2}{|c|}{$17.98 * * *$} & \multicolumn{2}{|c|}{9.52} \\
\hline
\end{tabular}

Entries are coefficients; standard errors in parentheses. Standard errors are robust.

Contrasts: type of mandate - SMD, candidacy - list candidates and winning SMD MPs, local political positions - members not holding any elected local positions, SMD career - members not holding SMD mandates in 2006-2010, newcomer - members with at least one term experience as national representatives, party leader - backbench MPs, party - Fidesz

Coefficients in the beta regression represent the change in the value of the dependent variable due to a one unit change in the related independent variables.

Coefficients in $\mathrm{Y}=1$ and $\mathrm{Y}=0$ models represent the change in the value of the log-odds of the dependent variable due to a one unit change in the related independent variables. $*_{\mathrm{p}}<.1, * * \mathrm{p}<.05, * * * \mathrm{p}<.01$ 
